\title{
Design and Construction of a Scaled Whirl Tower Facility
}

By

\section{John Alexander Pickard}

\author{
A thesis submitted to \\ The Faculty of Graduate Studies and Research \\ in partial fulfilment of \\ the degree requirements of \\ M.A.Sc. in Aerospace Engineering \\ Ottawa-Carleton Institute for \\ Mechanical and Aerospace Engineering
}

Department of Mechanical and Aerospace Engineering

Carleton University

Ottawa, Ontario, Canada

August, 2010

Copyright $(9$

2010 - John Alexander Pickard 
Library and Archives

Canada

Published Heritage Branch

395 Wellington Street Ottawa ON K1A ON4

Canada
Bibliothèque et

Archives Canada

Direction du

Patrimoine de l'édition

395 , rue Wellington

Ottawa ON K1A ON4

Canada
Your file Votre référence

ISBN: 978-0-494-71569-7

Our file Notre référence

ISBN: 978-0-494-71569-7
NOTICE:

The author has granted a nonexclusive license allowing Library and Archives Canada to reproduce, publish, archive, preserve, conserve, communicate to the public by telecommunication or on the Internet, loan, distribute and sell theses worldwide, for commercial or noncommercial purposes, in microform, paper, electronic and/or any other formats.

The author retains copyright ownership and moral rights in this thesis. Neither the thesis nor substantial extracts from it may be printed or otherwise reproduced without the author's permission.
AVIS:

L'auteur a accordé une licence non exclusive permettant à la Bibliothèque et Archives Canada de reproduire, publier, archiver, sauvegarder, conserver, transmettre au public par télécommunication ou par l'Internet, prêter, distribuer et vendre des thèses partout dans le monde, à des fins commerciales ou autres, sur support microforme, papier, électronique et/ou autres formats.

L'auteur conserve la propriété du droit d'auteur et des droits moraux qui protège cette thèse. Ni la thèse ni des extraits substantiels de celle-ci ne doivent être imprimés ou autrement reproduits sans son autorisation.
In compliance with the Canadian Privacy Act some supporting forms may have been removed from this thesis.

While these forms may be included in the document page count, their removal does not represent any loss of content from the thesis.
Conformément à la loi canadienne sur la protection de la vie privée, quelques formulaires secondaires ont été enlevés de cette thèse.

Bien que ces formulaires aient inclus dans la pagination, il n'y aura aucun contenu manquant. 


\section{Abstract}

Experimental development of helicopter rotors requires centrifugal testing before entry into a wind tunnel or flight test campaign. This centrifugal testing is performed on test rigs called whirl towers. These facilities are very rare, in fact there were none available in Canada at the time of writing this thesis, but they are very valuable experimental research tools.

This thesis describes the design and construction of a whirl tower facility for the centrifugal testing of scaled helicopter rotors with actively controlled systems for reducing vibration. First, the trade-offs between the desired capabilities for the facility to be designed are reviewed, leading to the identification of a set of design requirements. Following this, various concepts for the drive system, frame, data acquisition, and safety infrastructure are proposed. From these, a final design is assembled, whose main advantage is its flexibility and robustness for developmental research. The whirl tower is capable of testing single or multi-bladed rotors (up to four blades), with blades between 1.0 and 1.6 m radius, up to 1,800 RPM frequency with no 'dead zones'. The whirl tower is equipped with a $60 \mathrm{HP}, 575 \mathrm{~V}$, AC motor, with flexible coupling and direct drive to the scaled rotor hub. The facility also features a digital telemetry system, slip rings for power and signal transmission for active control, interchangeable rotor heads with variable root distance, and a containment wall for protection from possible rotor blade 
failures. The manufacturing and construction of the facility, as well as its installation at the National Research Council in Ottawa, is described in detail. 
Dedicated to all the members of my family who have helped shape my life and give me the direction I have today. 


\section{Acknowledgements}

Thank you to my supervisor, Daniel Feszty, for providing such an interesting project, as well as the opportunity to expand and diversify my skills in so many new directions.

Thank you to my colleague, Steve Vamosi. Without his help this facility could never have been constructed.

Thank you to Kevin Sangster and Alex Proctor for their gentle tutelage in the art of machining.

Thank you to Norman Ball and NRC Canada, whose partnership gave this project the opportunity to succeed.

Thank you to all the helpful vendors and fabricators, whose excellent service and assistance deserve explicit mentioning:

- Science and Technology Center, Carleton University

- The Adams Company

- Waco Composites

- Schleifring

- Joliet Technologies

- RLD Industries 


\section{Table of Contents}

$\begin{array}{ll}\text { Abstract } & \text { i }\end{array}$

Acknowledgements $\quad$ iv

Table of Contents $\quad$ v

List of Tables $\quad$ viii

$\begin{array}{ll}\text { List of Figures } & \text { ix }\end{array}$

Nomenclature $\quad$ xii

$\begin{array}{ll}\text { Chapter 1: Introduction } & 1\end{array}$

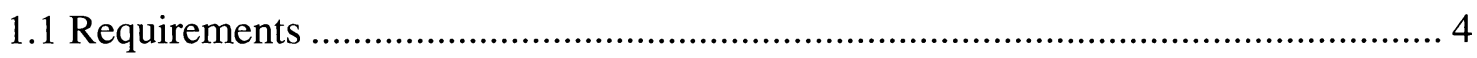

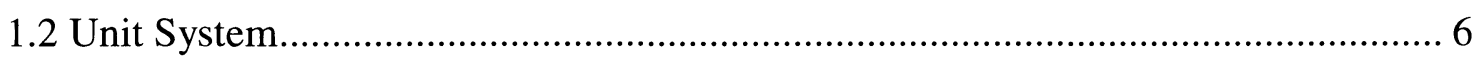

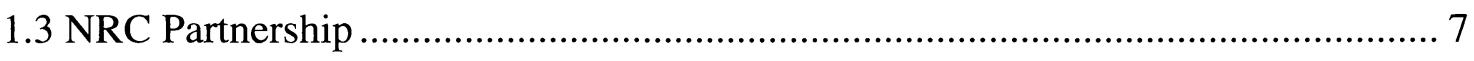

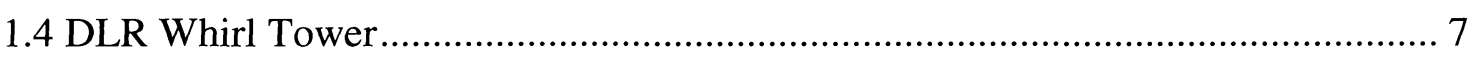

$\begin{array}{ll}\text { Chapter 2: Drive System } & 9\end{array}$

2.1 Scaling Parameter Considerations .............................................................. 9

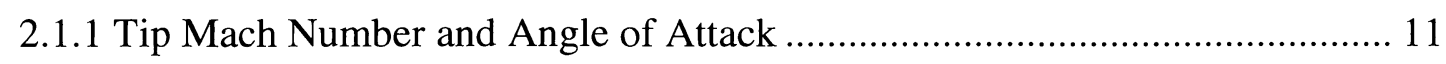

2.1.2 Calculation of Drive System Requirements............................................. 20

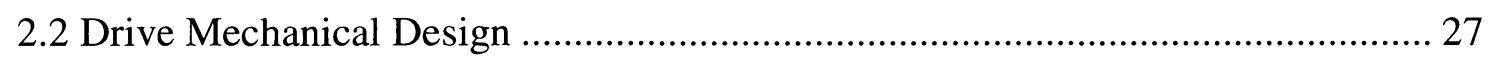

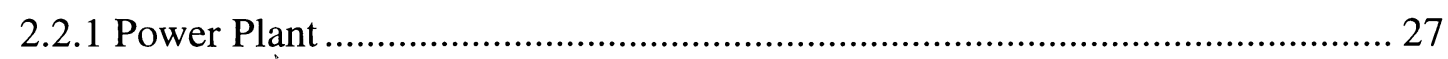

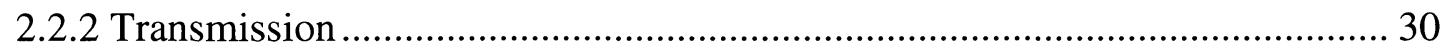

2.3 Drive System Design Changes due to NRC Partnership ................................... 34

$\begin{array}{ll}\text { Chapter 3: Mechanical Design } & 35\end{array}$

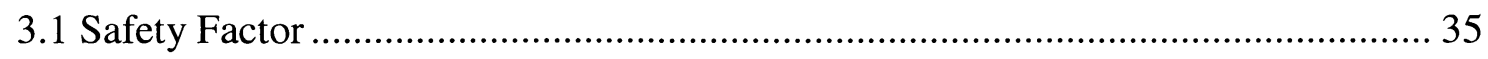

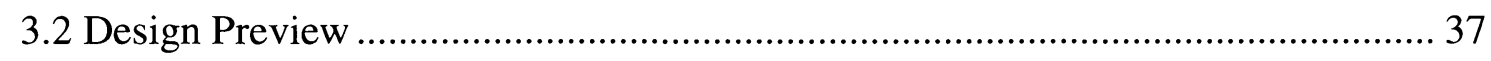




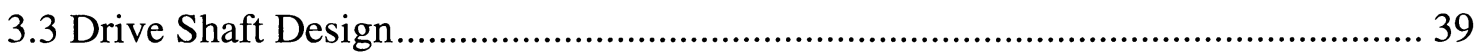

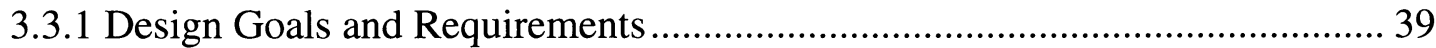

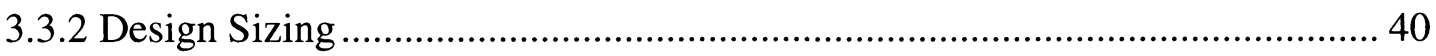

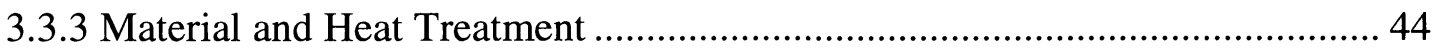

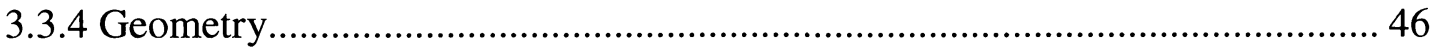

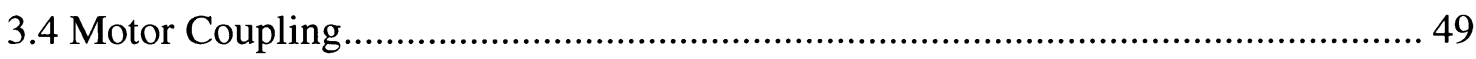

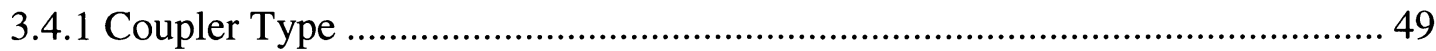

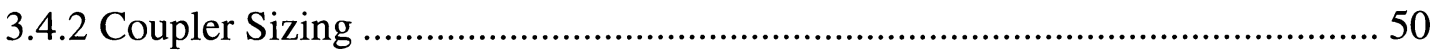

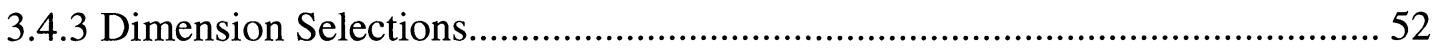

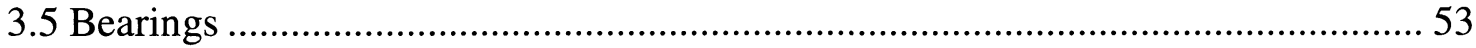

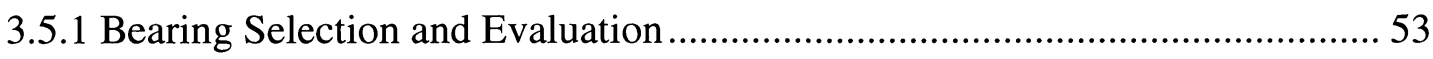

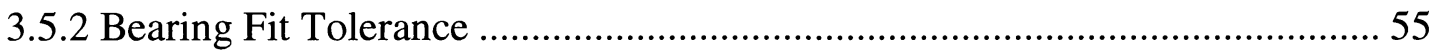

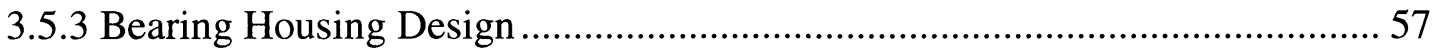

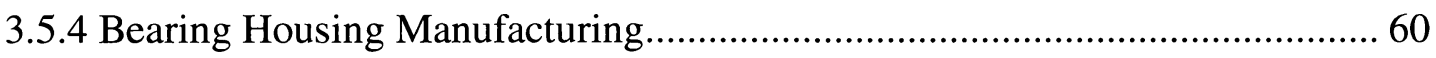

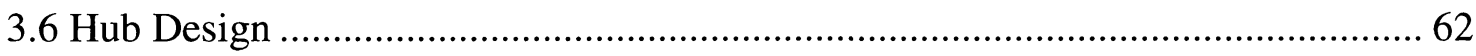

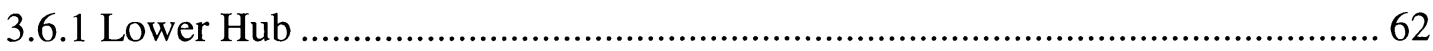

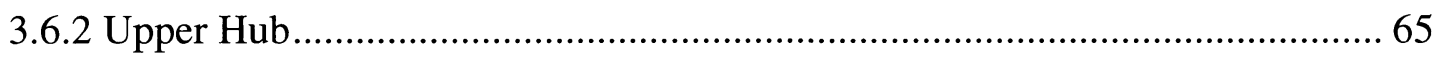

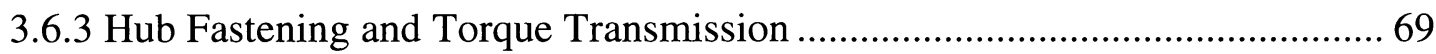

3.7 Blade Attachment Mechanism.......................................................................... 72

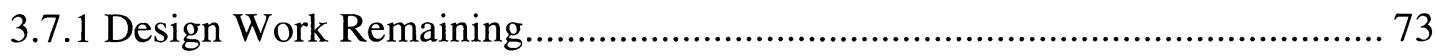

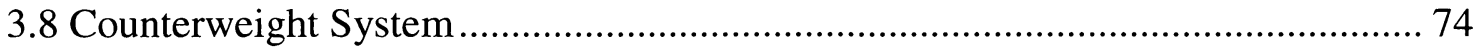

$\begin{array}{lr}\text { Chapter 4: Frame Design } & 80\end{array}$

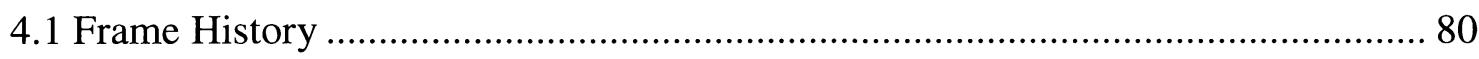

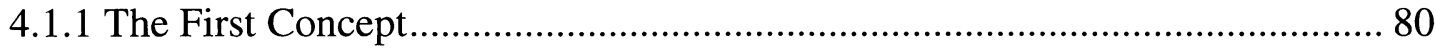

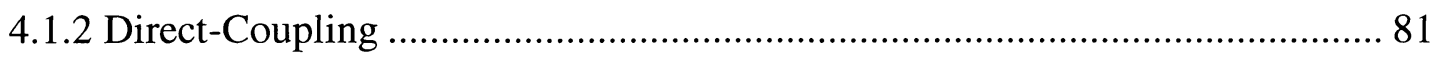

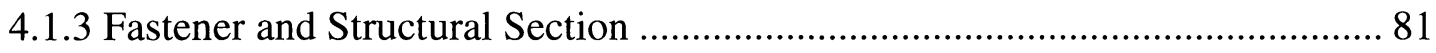

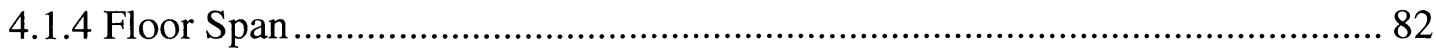

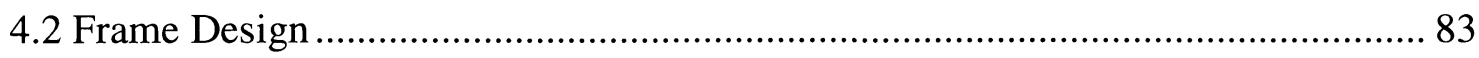

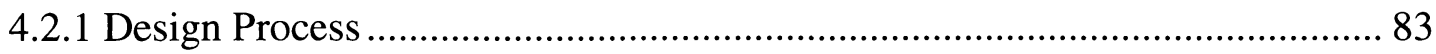


4.2.2 Frame Description.......................................................................... 84

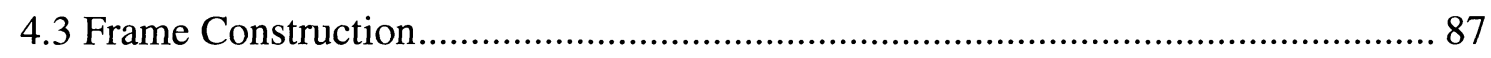

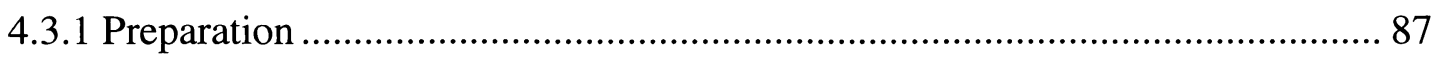

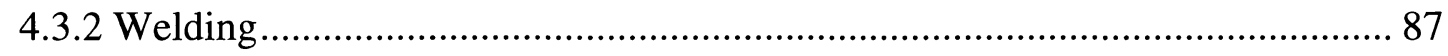

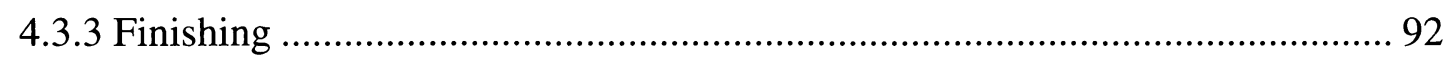

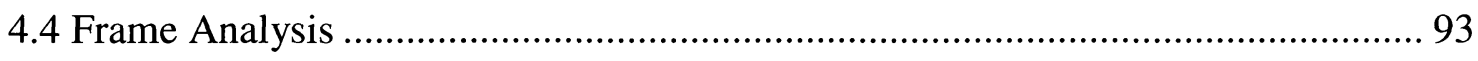

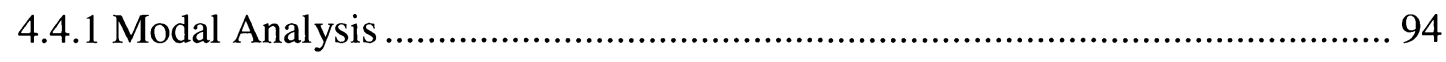

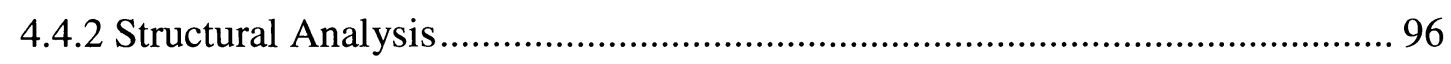

$\begin{array}{ll}\text { Chapter 5: Signal Interfaces } & 101\end{array}$

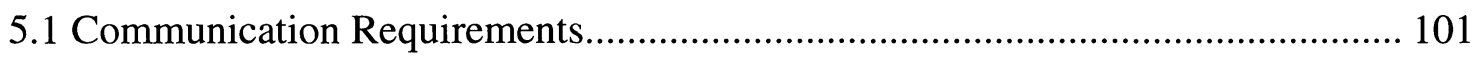

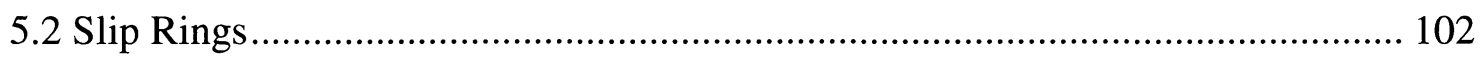

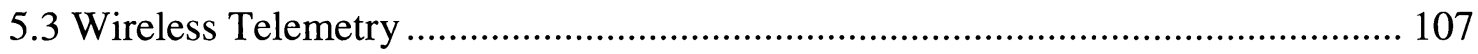

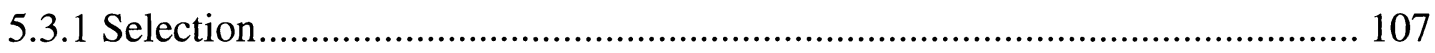

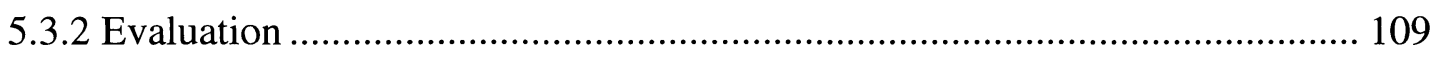

$\begin{array}{ll}\text { Chapter 6: Safety Systems and Considerations } & 118\end{array}$

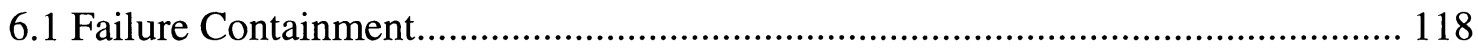

6.1.1 Containment Sizing......................................................................... 118

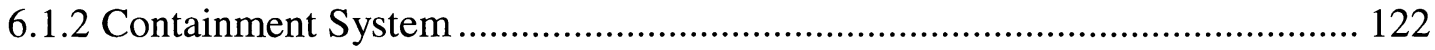

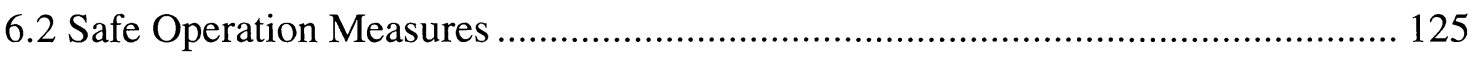

$\begin{array}{ll}\text { Chapter 7: Facility Infrastructure } & 127\end{array}$

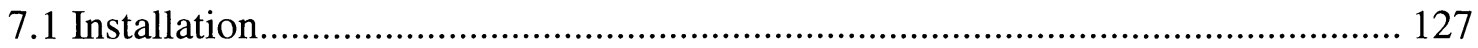

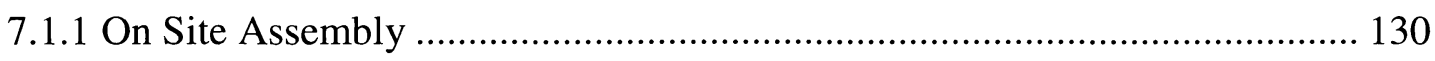

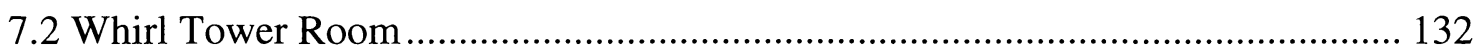

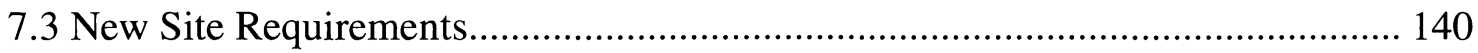

$\begin{array}{lr}\text { Chapter 8: Conclusion } & 142\end{array}$

$\begin{array}{ll}\text { References } & 145\end{array}$

$\begin{array}{ll}\text { Appendix A } & 151\end{array}$ 


\section{List of Tables}

Table 2.1: Comparison of tip pitch angle at which drag-divergence occurs for blades with NACA 0015 and NACA 0009 airfoils................................................................ 19

Table 2.2: Effect of $M_{T \iota p}$ and $\alpha_{T \iota p}$ on Rotor Power, Torque, and Thrust.................... 24

Table 2.3: Power requirement for varying rotor configurations $(\mathrm{kW})$........................ 25

Table 2.4: Torque requirement for varying rotor configurations $(\mathrm{N} \cdot \mathrm{m})$...................... 25

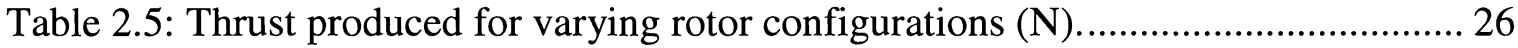

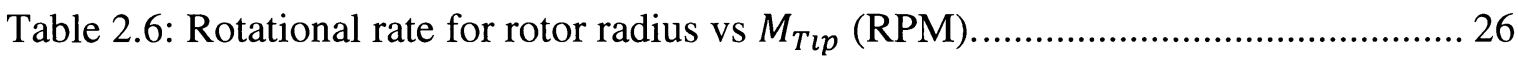

Table 2.7: WEG W21 high-efficiency general-purpose motors, 575V [20]................. 28

Table 2.8: Transmission weighted selection summary............................................. 32

Table 2.9: NRC owned WEG motor capabilities [20]............................................. 34

Table 3.1: Sure-Flex material properties [30]................................................... 51

Table 3.2: AuroraBearing AM-7 bearing dimensions (inches) [43], see Figure 3.15..... 73

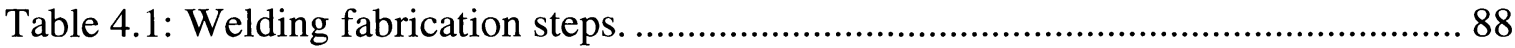

Table 4.2: Grid dependence results............................................................................ 94

Table 5.1: Instrumentation channels. ................................................................. 102

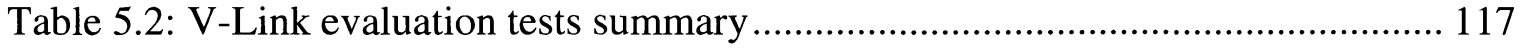

Table 6.1: Energy for various blade components ................................................... 119

Table 6.2: Bullet resistance for Armorcore protection levels 1 to 8 [53].................... 122

Table 6.3: Physical properties for Armorcore protection levels 1 to 8 [54]................. 123

Table 6.4: Armorcore protection levels 1 to 8 bullet resistance description [55]......... 123

Table A.1: Pertinent section of belt pitch selection table [60].................................. 152

Table A.2: Parts for Transmission System. ........................................................ 155 


\section{List of Figures}

Figure 1.1: Active sub-systems in the SHARCS rotor system [1] ................................ 2

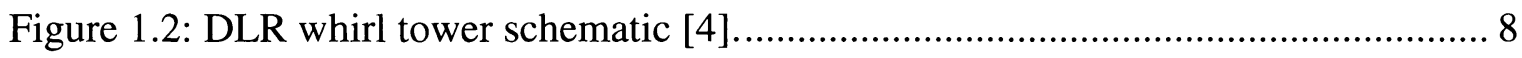

Figure 2.1: Effect of forward flight on rotor blade relative airspeed [10] ...................... 12

Figure 2.2: Shock formation on progressively higher Mach number airfoils [13]........... 13

Figure 2.3: Section Lift Coefficient vs Mach number for the NACA 0015 Airfoil [11].. 14

Figure 2.4: Section Drag Coefficient vs Mach number for the NACA 0015 Airfoil [11].15

Figure 2.5: Effect of $M_{\text {Tip }}$ and $c_{l}$ on profile-drag torque correction factor [12].............. 16

Figure 2.6: Effect of $M_{\text {Tip }}$ and $\alpha_{\text {Tip }}$ on profile-drag torque correction factor [12]......... 17

Figure 2.7: Rotor drag divergence onset for NACA 0015 [12] ....................................... 18

Figure 2.8: Rotor drag divergence onset for NACA 0009 [14] ....................................... 19

Figure 2.9: Top view of the SHARCS blade with main dimensions [1] ......................... 21

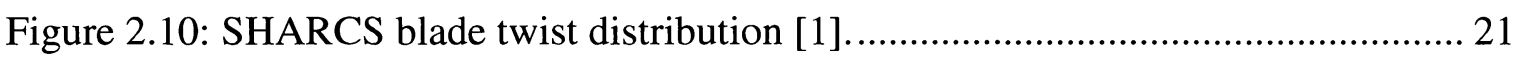

Figure 2.11: Drag polar for various Reynolds numbers for NACA 0015 [16] [17] [18]. 23

Figure 3.1: Mechanical design preview.................................................................... 38

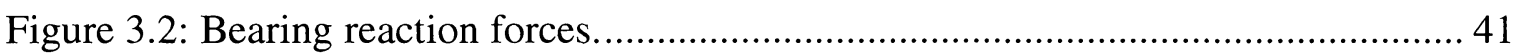

Figure 3.3: Oscillation about equilibrium position........................................................... 43

Figure 3.4: Whirl tower drive shaft geometry. …………......................................... 47

Figure 3.5: Whirl tower drive shaft with dimensions and tolerances. ............................. 48

Figure 3.6: Various models from the TB Woods Sure-Flex series [29] ........................... 50

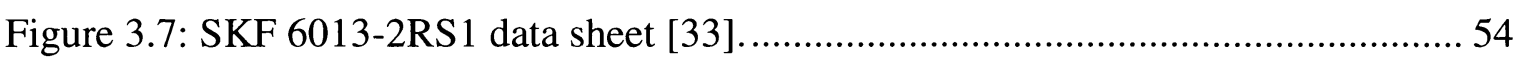

Figure 3.8: Upper bearing housing with drive shaft removed from tower. ...................... 56

Figure 3.9: Forces in a preloaded bolt system [35]....................................................... 58

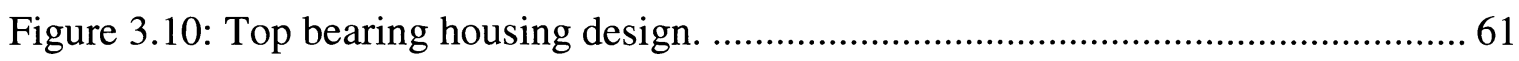

Figure 3.11: Lower hub design, manufactured part dimensions in inches. ....................... 64 


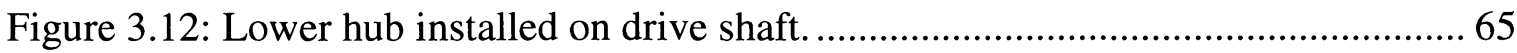

Figure 3.13: Upper hub design, manufactured part dimensions in inches.................... 66

Figure 3.14: External key design with finished dimensions...................................... 70

Figure 3.15: External key installed in position between the two hubs. .......................... 71

Figure 3.16: AuroraBearing AM series rod end [43] .......................................... 73

Figure 3.17: Counterweight mechanism exploded view............................................ 76

Figure 3.18: Counterweight locking mechanism cross-section view. ........................ 77

Figure 3.19: Counterweight mechanism installed on rotor hub.................................. 79

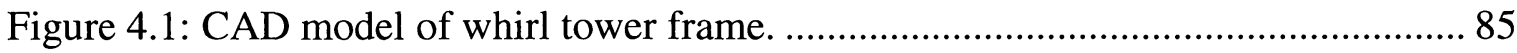

Figure 4.2: CAD model of whirl tower frame, reverse side. ..................................... 86

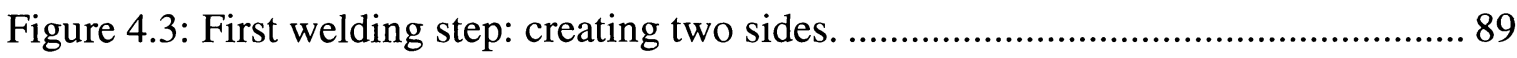

Figure 4.4: Second welding step: creating motor mount.......................................... 89

Figure 4.5: Third welding step: complete frame box......................................... 90

Figure 4.6: Fourth Welding Step: add diagonals, gussets, and crust tube. ..................... 90

Figure 4.7: Fifth Welding Step: locate then weld the bearing housings and posts.......... 91

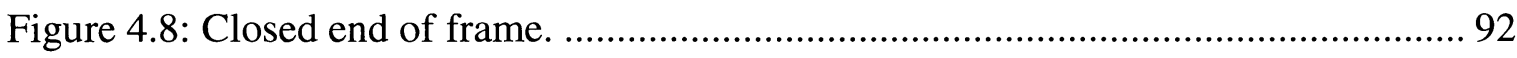

Figure 4.9: First mode of the whirl tower, warmer colours indicate displacement. ........ 95

Figure 4.10: Safety factor of frame's base beam near the anchoring location. ...............97

Figure 4.11: Mesh refinement in the vicinity of the predicted failure locations..............98

Figure 4.12: Stress concentration in the seams between the frame beam members........ 99

Figure 5.1: Schleifring Series K Type S sample photo [48]..................................... 105

Figure 5.2: Schleifring Series K Type SIB sample photo [48] ................................. 106

Figure 5.3: V-Link Node and base station............................................................ 109

Figure 5.4: Strain from 22 grams placed on $1 / 2$ inch solid aluminum square beam. ...... 113

Figure 5.5: V-Link transmission test. .............................................................. 114

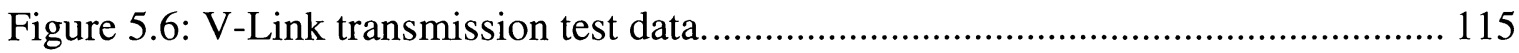

Figure 5.7: V-Link transmission data derivative showing discrepancy....................... 117

Figure 6.1: 3 SHARCS blade titanium skeleton [1] .............................................. 120

Figure 6.2: 3 Live fire test - 0.44 Magnum on Level 3 [56] .................................. 124 
Figure 7.1: M22 trench cross section, dimensions in inches, all concrete...................... 128

Figure 7.2: Aligning the two shafts using parallels. .................................................... 131

Figure 7.3: Assembled and installed whirl tower. ......................................................... 132

Figure 7.4: 3D CAD model of the test room framing................................................ 134

Figure 7.5: Framing jig with frame being fabricated..................................................... 135

Figure 7.6: Debris created from drilling ArmorCore panels......................................... 135

Figure 7.7: Completed pair of safety walls standing together. ....................................... 136

Figure 7.8: Top and bottom joint for wall frame. ..................................................... 136

Figure 7.9: Layout of planned whirl tower room............................................................ 137

Figure 7.10: Seam stud preparation. …………………….......................................... 138

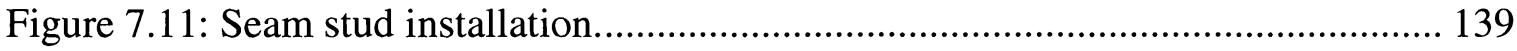

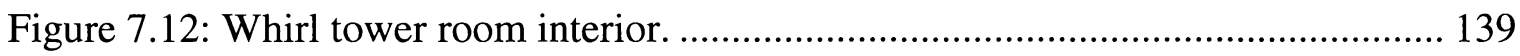

Figure 7.13: Whirl tower room exterior...................................................................... 140

Figure A.1: Dynamic Balancing Requirements [60] ................................................ 154 


\section{Nomenclature}

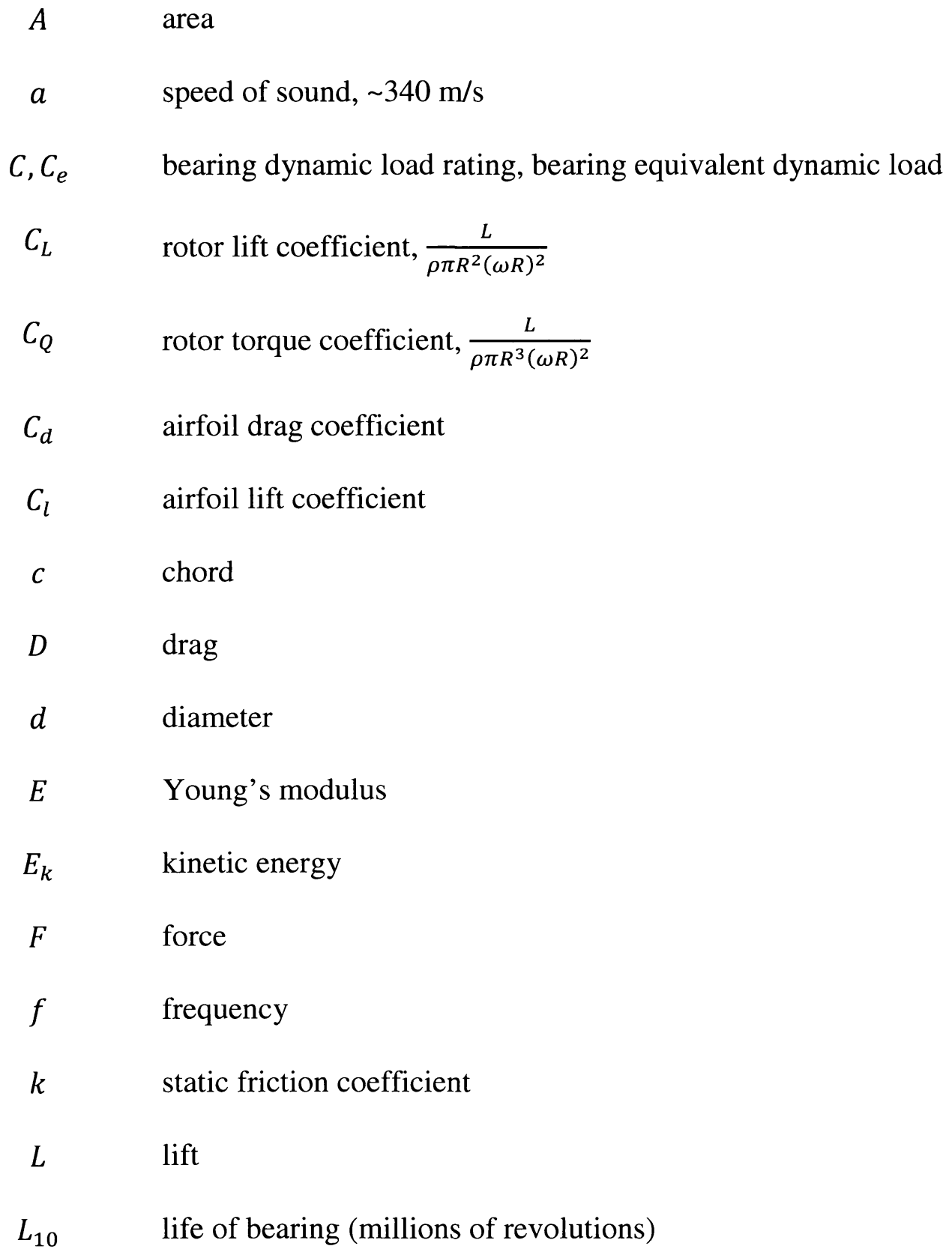


$L_{e} \quad$ Thread engagement length

$M, M_{T l p} \quad$ mach number, tip mach number

$m \quad$ mass

$N_{b} \quad$ number of blades in a rotor

$P \quad$ power

Q torque

$R, r \quad$ radius of blade, radial position on blade

Re Reynolds number, $R e=\frac{\rho v L}{\mu}$, where $\mathrm{L}$ is length

$T \quad$ thrust

U air velocity, electric potential

$V, v \quad$ velocity

$y \quad$ local blade radial position

$\alpha, \alpha_{\text {Tıp }} \quad$ angle of attack (angle with respect to air), tip angle of attack

strain

$\theta \quad$ blade pitch (angle with respect to rotor plane)

$\mu \quad$ dynamic viscosity

$\rho \quad$ mass density of air

$\sigma \quad$ rotor solidity, $\sigma=\frac{N_{b} c}{\pi R}$

$\phi \quad$ inflow angle, $\phi=\tan ^{-1}\left(\frac{V_{c}+v_{l}}{\omega y}\right)$

$\omega \quad$ angular velocity 


\section{Chapter 1: Introduction}

The Rotorcraft Research Group at Carleton University is in the process of developing multiple systems for rotary wing aircraft that are designed to reduce aerodynamic induced vibration and noise. All systems being considered are rotor-based, i.e. they are located on the main rotor blades or the rotor hub itself. The following systems are currently being developed (See Figure 1.1) [1]:

- An Active Pitch Link (APL) which dampens vibrations being transmitted from the rotor blade into the aircraft control mechanisms.

- Actively Controlled Flap (ACF), a mechanism located on the trailing edge of the rotor blades. This is designed for purposes of both generating vibration in testing environments, and to experiment with aero-elastic control of rotors to reduce vibration and noise.

- Actively Controlled Tip (ACT), a deflection mechanism to control the location and characteristics of the tip vortices generated by the blades. 


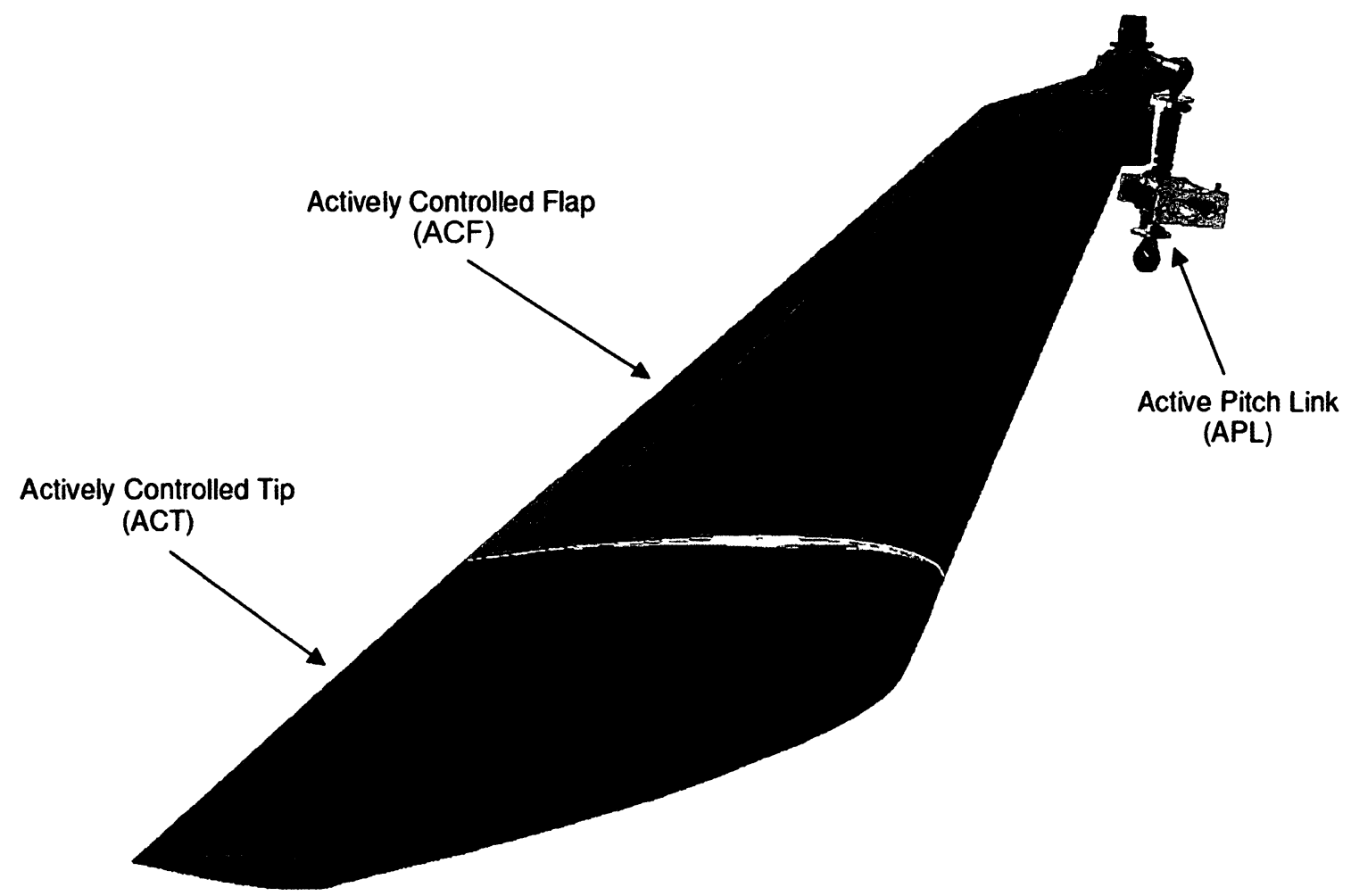

Figure 1.1: Active sub-systems in the SHARCS rotor system [1].

Computational feasibility studies of the above systems have been successfully completed [2]. The ultimate goal is to demonstrate these systems experimentally in wind tunnel or through flight tests. Such campaign must be preceded with careful static and centrifugal tests. In fact, the latter one is usually a prerequisite of entering wind tunnel or flight testing and must verify the performance and functionality of these systems under high inertial loads. It also helps to verify the safety of the design and operation of these systems before installing them in a wind tunnel facility or on a test aircraft. A test facility designed to test helicopter rotors for those purposes, i.e. under centrifugal loads, is called a "whirl tower". 
There are two types of whirl tower facilities: full-scale and scaled ones. Full-scale whirl towers are typically owned by helicopter manufacturers and some of the larger aerospace research centers, such as NASA Langley [3]. They serve primarily for testing full-scale rotor blades and rotor hubs prior to their installation on prototype or production helicopters.

Scaled whirl towers, on the other hand, are typically used for research and development purposes only, mostly as a prerequisite for wind-tunnel testing of scaled rotors. These are preferred by researchers because they are usually cheaper than fullscale rotors. Novel rotor-based technologies, such as various concepts of passive or active control systems, are typically verified on scaled rotors first before proceeding to more expensive full-scale demonstrations.

Scaled or full-scale whirl towers are quite rare. For example, there are none in Canada despite two major helicopter manufacturers (Bell Helicoper Textron and Eurocopter Canada) being present in the country. There is only one scaled whirl tower facility known in Europe, and about 8-10 in the United States. The Rotorcraft Research Group at Carleton University used to rent the rotor test facilities of other institutes in the past, namely that of the German Aerospace Center (DLR) in Braunschweig, Germany. With some minor concessions, such as the radial distance of blade attachment (DLR uses a full-sized rotor hub), the facility was able to provide the capabilities required for testing some early system designs. However, the group experienced considerable cost and organizational challenges in using this facility and was only able to spend a brief period of time there. 
After the test sessions at DLR, it became clear that the availability of a local, in-house test facility would greatly decrease the cycle time to go from design to test and back to redesign.

The objective of the work described in this thesis, was therefore to design and construct a scaled whirl tower facility in Ottawa, for the testing of rotor-based actively controlled systems. The thesis addresses not only the design and construction of the actual test rig, but also the corresponding safety, telemetry, infrastructure and support systems to provide the above testing capability.

\subsection{Requirements}

The capability requirements for the whirl tower facility were largely driven by a rotor concept called SHARCS: Smart Hybrid Active Rotor Control System [1], which has been pursued by the Carleton Rotorcraft Research Group for the past seven years. It encompasses Active Pitch Link (APL), Actively Controlled Flap (ACF), and Actively Controlled Tip (ACT) systems simultaneously [1]. Beyond meeting the specific requirements of the SHARCS rotor, the facility was desired to be flexible enough to test a range of rotor designs such that the facility will be useable for future work by the Rotorcraft Research Group in general, as well as other potential external clients.

The full range of mandatory operational capability was not given for this test facility, but targets were given with the understanding that the operational capabilities would be investigated and bounds, which fell within reasonable design and cost limitations, would be pursued. The desirable targets included: 
- capability for rotors between $1 \mathrm{~m}$ and $2 \mathrm{~m}$ in radius with typical (as yet unestablished) rotational speeds

- a scaled, articulated ( i.e. 3 degrees of freedom: pitch, flap, lead-lag) rotor hub that meets the SHARCS rotor requirements

- that the test stand should be capable of receiving different rotor hubs and rotor configurations

- a hub and dynamic balancing system for testing single rotor blades

- data acquisition channels from sensors

- power transmission to active systems in the rotating frame

- safety for operators consisting of containment of the apparatus through failures, and

- reasonable survivability of the whirl tower for failures resulting in large rotor imbalance.

Starting with these goals and requirements, it was understood that as the design progressed, limitations would be created, which may transform the operating bounds for the facility into other characteristics. For example, the final limitations may not be on rotor dimensions, but rather the torque of the powerplant, the centripetal force of the rotor blade, or the kinetic energy of the rotor blade for containment. Each of these eventual boundaries will be clearly defined such that any interested operators can fully understand the limitations of the facility. 


\subsection{Unit System}

The SHARCS rotor uses the metric unit system exclusively for all of its design. Additionally, the Rotorcraft Research Group has been using metric values for all the produced work to date. This places a strong influence on this facility and thesis to use the metric system as well. However, the physical procurement and manufacturing was found to be primarily in the imperial system. Many design aspects are easily convertible, for example the power plant and transmission. Other physical design points were naturally in one unit system and not as convenient to convert, for example using 3 inch steel square tube, $4 \times 8 \mathrm{ft}$ wall sections, and even the selection of bolts and threads. Many times metric alternatives were not available, and if they were, it certainly was not cost effective to procure new tooling (such as broaches, end mills, taps, etc.).

Due to the conflicting preferences on unit system choice, both unit systems will be used in tandem. This thesis will use the metric system to describe all dimensions and values relating to the rotor and rotor performance. The thesis will preferentially use the imperial unit system to describe all other aspects of the facility design, with the exception of some sourced components that were natively metric (and also resulted in a mixed unit system drive shaft). In situations where comparisons are being made between the two regions or systems, then both values will be shown. 


\subsection{NRC Partnership}

During the design process of this facility, a partnership was made with the Institute for Aerospace Research (IAR) of the National Research Council Canada, (NRC). This partnership made a new operating location available and included the loan of some equipment for the facility. It also created additional supervisors or parties to satisfy in the design process and created new concerns to be addressed. For the most part it was not an interruption to the design process, but for certain design decisions, some changes were required for various reasons, for example to accommodate loaned equipment. In sections affected by this partnership, both the original design choice as well as the reason for design change will be included.

\subsection{DLR Whirl Tower}

When starting the project to build our own whirl tower, DLR kindly provided the thesis describing the design and construction of their facility [4]. This infrastructure was already well known to some members of the research group who had traveled there to use it, but having the thesis on hand provided an understanding of the design choices made. The document is entirely in German, so it was mostly used for its figures and some values for key comparison points. Many of the design choices in the DLR whirl tower were not maintained in this facility. It was felt that many design improvements could be made to help the Rotorcraft Research Group achieve their objectives as best as possible.

In brief, the DLR whirl tower uses a $30 \mathrm{~kW}$ electric motor and a synchronous belt system to drive the rotor shaft. It is only sized for single bladed operation and uses a 
counterweight system to dynamically balance the blade. The drive shaft is supported by a single bearing unit on a steel frame made of angle or ' $L$ '-sections. The rotor hub is a retired full-scale BO-105 rotor hub. A poured concrete block is used as the base of the system. A schematic drawing of the DLR whirl tower facility can be seen in Figure 1.2.

As will be seen in the following chapters, the facility described in this thesis supersedes most of the capabilities of the DLR whirl tower and therefore pushes the state-of-the-art in rotorcraft centrifugal testing to a new level.

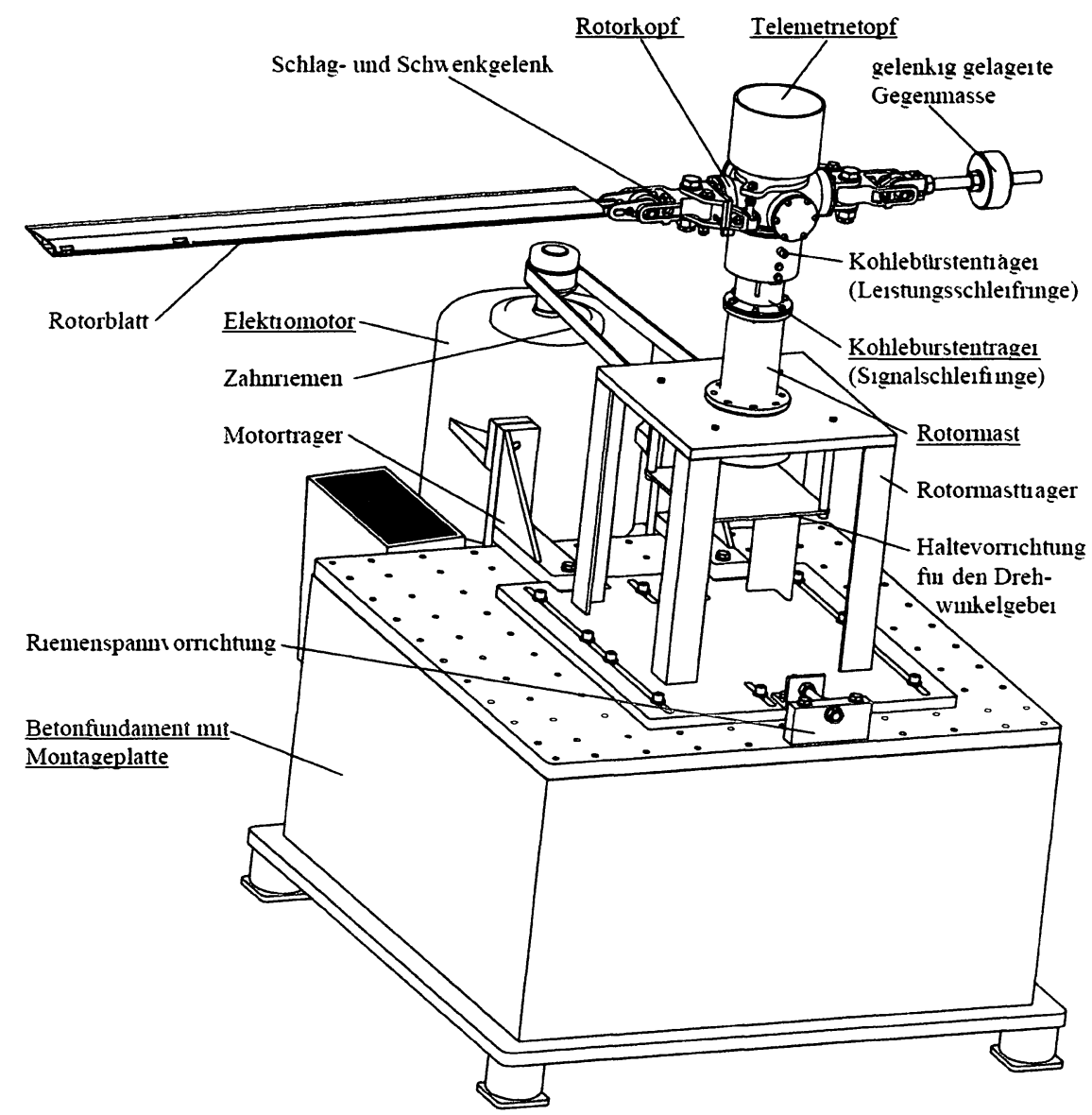

Figure 1.2: DLR whirl tower schematic [4]. 


\section{Chapter 2: Drive System}

\subsection{Scaling Parameter Considerations}

The selection of a system powerplant is dependent on the expected power, torque, and rotation rate required for the system. Because the facility is intended for scaled rotors, first the method by which helicopter rotors are scaled must be understood.

The geometric scale factor for rotors is the rotor radius; i.e. a rotor with a $1 / 4$ scaling factor has $1 / 4$ the radius. Typically this geometric factor also applies to the rotor blade chord, which as a result preserves similarity in rotor solidity $\sigma$, which is the ratio of blade area to the total rotor disk area [5].

$$
\sigma=\frac{\text { blade area }}{\text { disk area }}=\frac{N_{b} c R}{\pi R^{2}}=\frac{N_{b} c}{\pi R}
$$

For scaled rotors a key parameter to preserve is the tip Mach number [1][6] [7] [8]. Helicopter rotors typically operate at a constant tip speed of $M_{\text {Tip }}=0.6$, which at a forward flight speed of $M=0.2$ yields a resultant tip speed of $M=0.8$ on the advancing blade. This produces important compressibility (i.e. transonic) effects generating noise and vibration. Thus, matching the tip Mach number preserves compressibility effects; however, it violates Reynolds number similarity which is the typical similarity parameter 
for scaled aerodynamic testing. This is because the blade chord has been scaled by the geometric scale factor, and so it is not possible to maintain the blade's Reynolds number profile (i.e. the variation of $R e$ along the blade radius), even if the tip Mach number were allowed to change. In order to preserve Reynolds number similarity the tip Mach number should be increased by the reciprocal of the geometric scaling factor, which for helicopter rotors of $M_{T i p}=0.6$ would mean supersonic tip speed for the scaled version $(4 \times 0.6=$ Mach 2.4). This would be more detrimental to aerodynamic similarity than sacrificing Reynolds number, and would additionally put extreme stress into the rotor blade and hub. A possible solution to this problem could be to operate the rotor in a different aerodynamic medium, for example in refrigerants $\mathrm{R}-12$ or R-134a, which would allow for lowering the tip speed while maintaining the full-scale rotor's tip Mach number and retaining Reynolds number similarity better [8]. However, due to complications in infrastructure design, this thesis will not investigate the use of alternative media.

The consequence of not having Reynolds number similarity has been investigated by Singleton et al. [8]. The results indicate that the rotor torque coefficient, $C_{Q}$, increases for tests matching the tip Mach number and rotor lift coefficient $C_{L}$, but operate at a lower Reynolds number than the reference rotor. Despite this, the research done on rotor scaling technique by the NASA Langley Research Center [8] has yielded the following conclusion: "It is known that it is not possible to simultaneously match all key full-scale aerodynamic parameters. The best course of action for testing model-scale rotors is to match the tip Mach number and test at as high a Reynolds number as is 
feasible". It is therefore reasonable to assume that rotors operated at this test facility will operate at similar tip Mach numbers to full-scale rotors.

\subsubsection{Tip Mach Number and Angle of Attack}

In order to size the drive system (motor) of the whirl tower, the worst-case scenario rotor that can be installed on the test rig needs to be determined. The worst-case scenario rotor will be defined by the combination of $M_{t i p}$ and $\alpha_{\text {Tip }}$, which requires the most torque and power to drive the rotor. The present section will examine in detail the relationship between $M_{\text {tip }}$ and $\alpha_{\text {Tip }}$ to determine the worst-case candidates for those values that will be experienced. Three values will then be used as inputs to calculate the required rotor torque and power.

The tip Mach number range, over which helicopter rotors operate, has an upper limit of approximately 0.64 . This limitation is due to an effect called drag divergence, which can happen on the advancing blade in forward flight (see Figure 2.1), or on all the blades when high collective is used in hover. This results in power divergence of rotors, which occurs when the relationship between the rotational speed and rotor thrust begins to break down and small increases in lift begin to require exponentially more power [9]. This drag divergence effect is strongly associated with the blade airfoil angle of attack, and therefore the rotor collective and thrust produced. The relationship between tip Mach number and rotor collective for typical operating range will be investigated in tandem. 


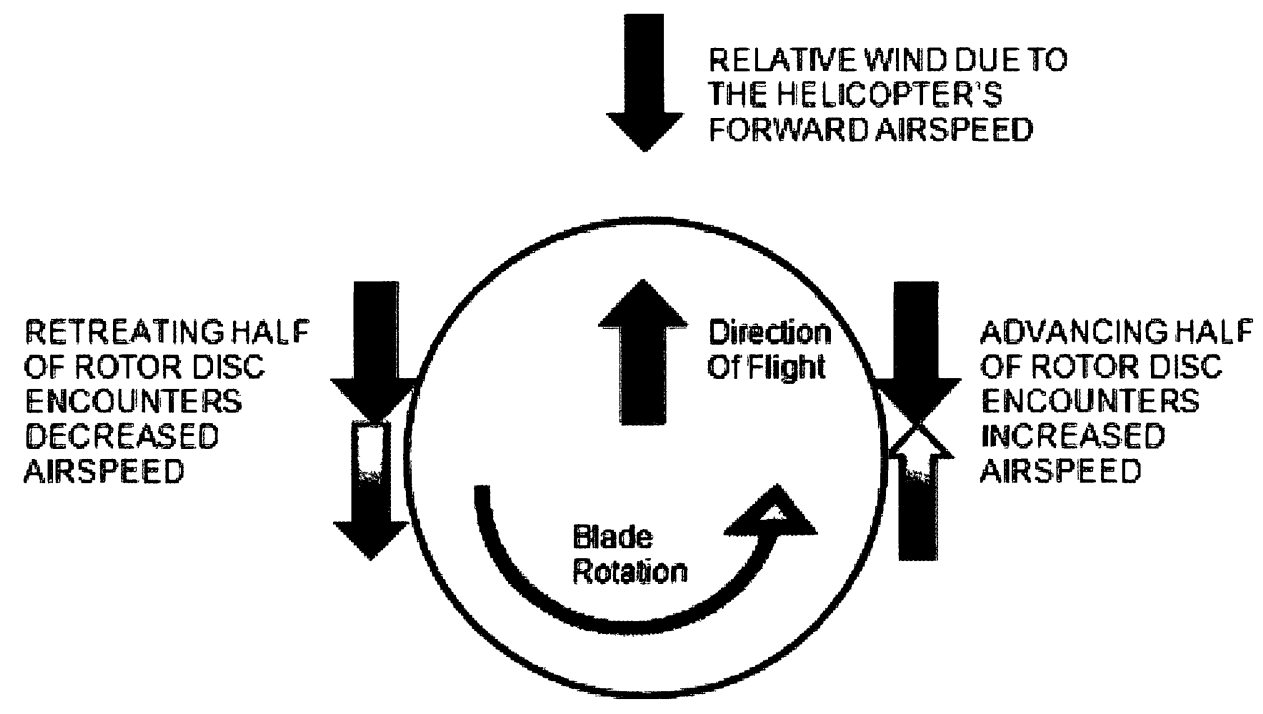

Figure 2.1: Effect of forward flight on rotor blade relative airspeed [10].

The limits of typical flight are given by the blade airfoil drag divergence characteristics. Drag divergence occurs when the drag on an airfoil begins to increase rapidly with small increases to its Mach number or pitch. This occurs when shocks form on the upper surface of the blade and flow separation occurs [11][12]. Figure 2.2 shows how progressively high Mach numbers can cause a shock to form and lead to flow separation. The point at which this happens is highly dependent on the airfoil angle of attack and Mach number, and thus limits the rotor blade to either shallow angles of attack or lower tip Mach speeds. Figures 2.3 and 2.4 show how the lift and drag coefficients of the NACA 0015 airfoil are affected by flow separation in 2D airfoil testing. Note the rapid rise of $C_{d}$ with the increase of Mach number, this is the point of drag divergence. 


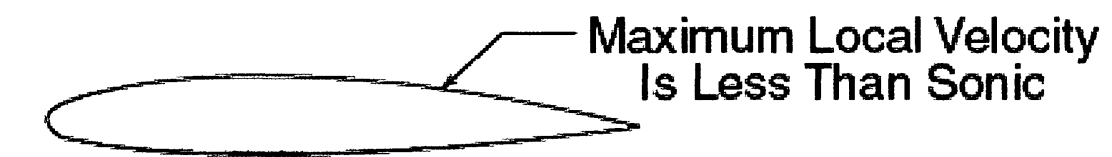

$M=.72$ (Critical Mach Number)
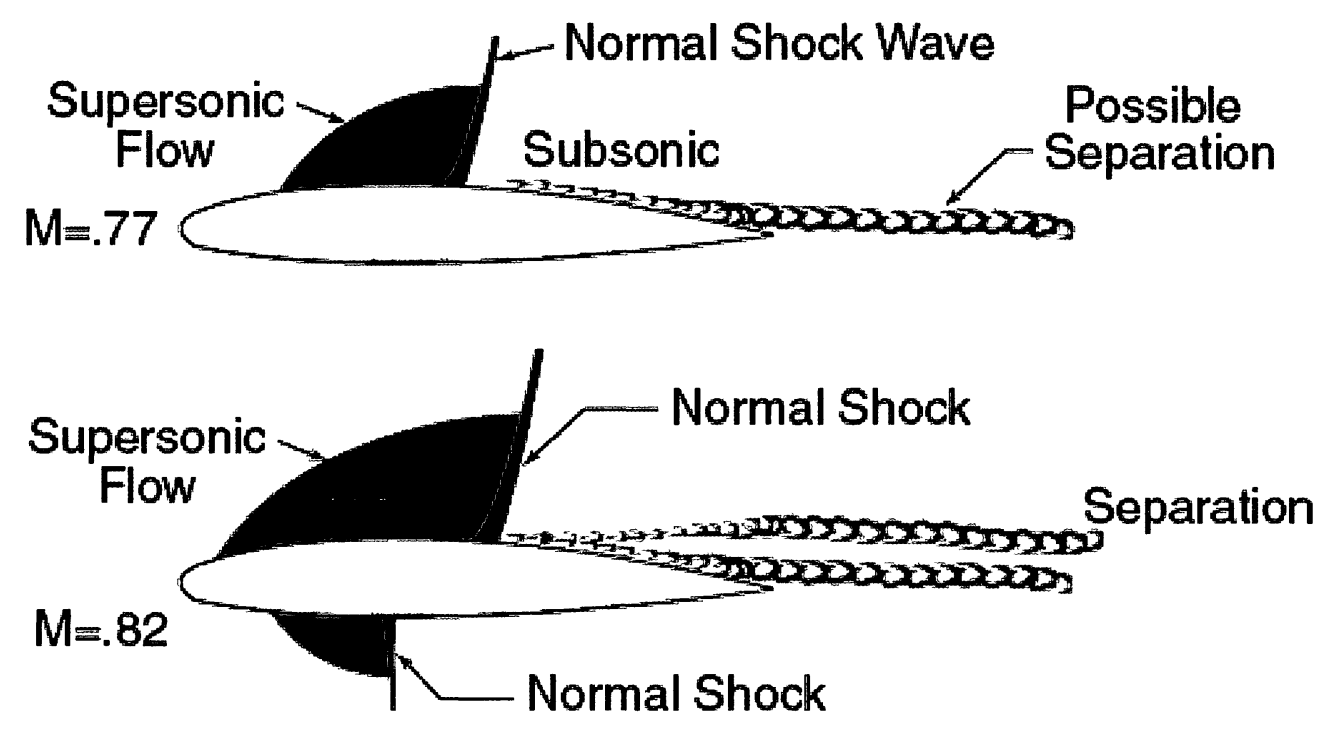

Figure 2.2: Shock formation on progressively higher Mach number airfoils [13]. 


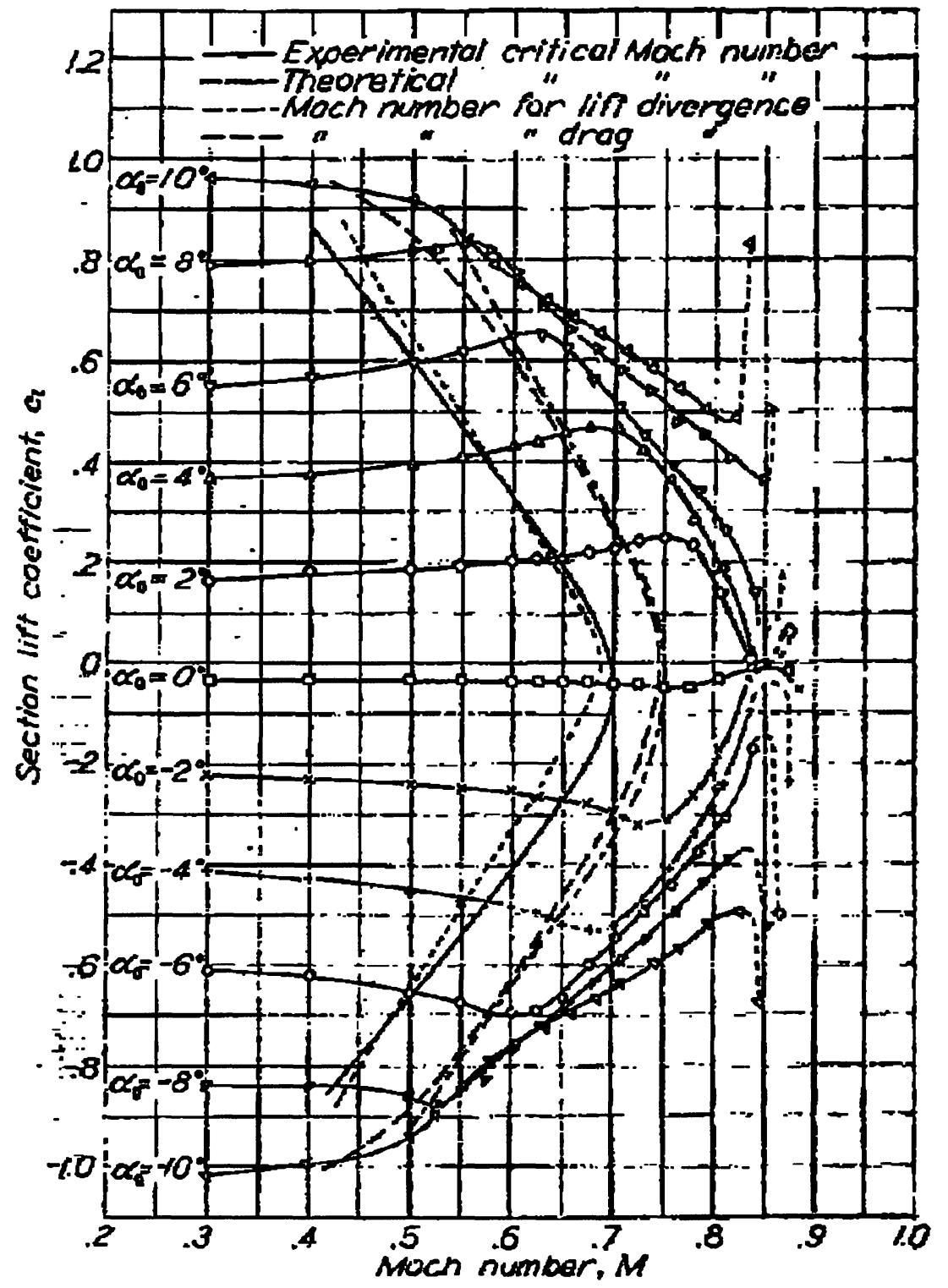

Figure 2.3: Section Lift Coefficient vs Mach number for the NACA 0015 Airfoil [11]. 


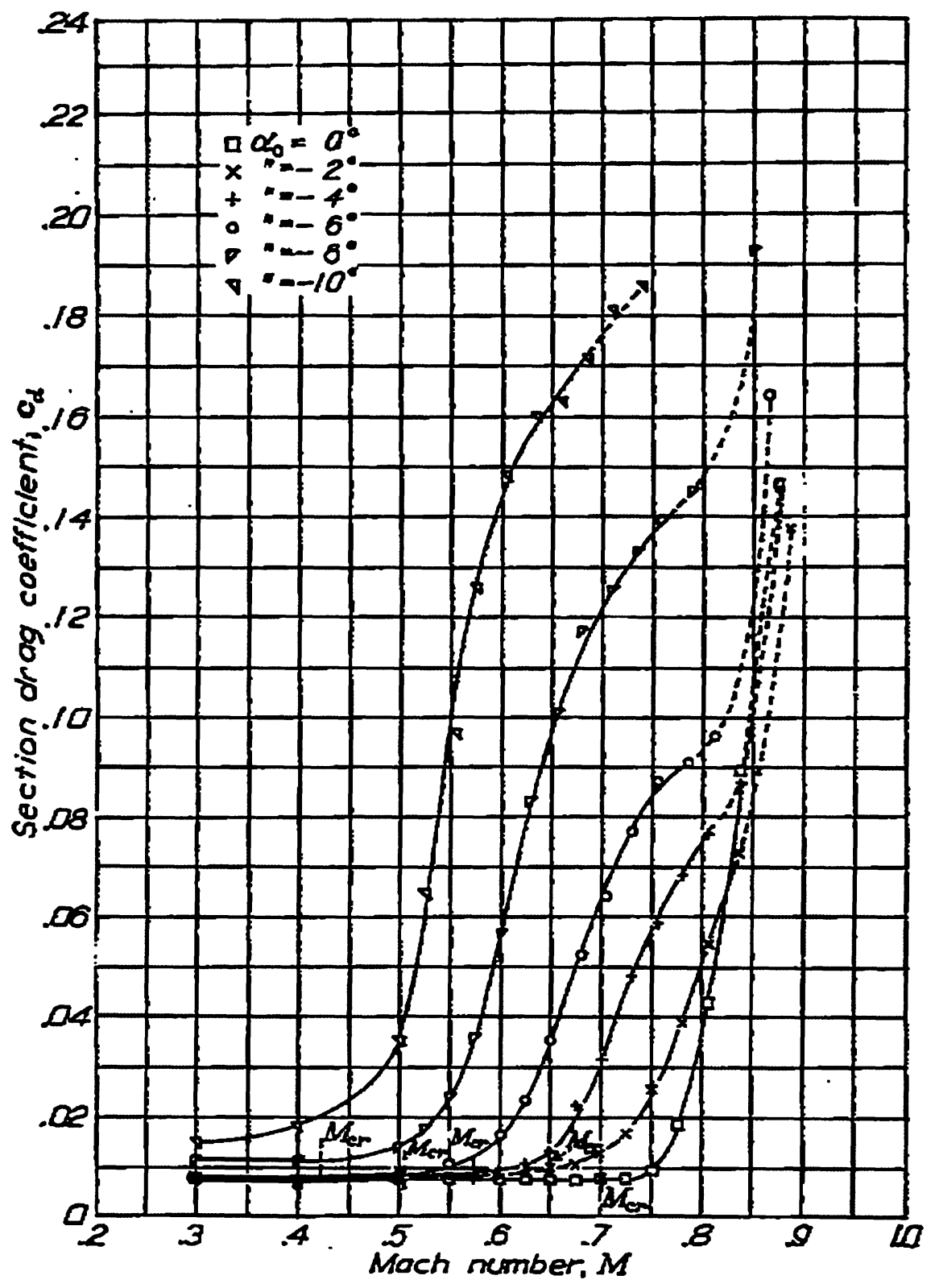

Figure 2.4: Section Drag Coefficient vs Mach number for the NACA 0015 Airfoil [11].

The figures also show how shock induced flow separation has an equally detrimental effect on an airfoils lift and drag coefficient, making operation within this regime undesirable. The flow separation not only causes a decrease in lift, but a 
substantial increase in drag. As can be seen in both figures, the point of separation is dependent on both the Mach number and the airfoil angle of attack $\alpha$ (separation occurs at approximately the hashed lines in the first figure, and is labeled as $M_{C r}$ in the second figure). Operation at higher Mach numbers requires the use of a lower angle of attack to avoid flow separation.

Figures 2.5 and 2.6 below show how flow separation specifically affects a helicopter rotor's performance (i.e. experimental results including 3D effects as well). The rotor tested uses a blade with NACA 0015 airfoil and linear twist. The point where each line in the figure begins to diverge from the vertical axis value of 1 is where drag divergence begins. The vertical axis is the coefficient describing this divergence.

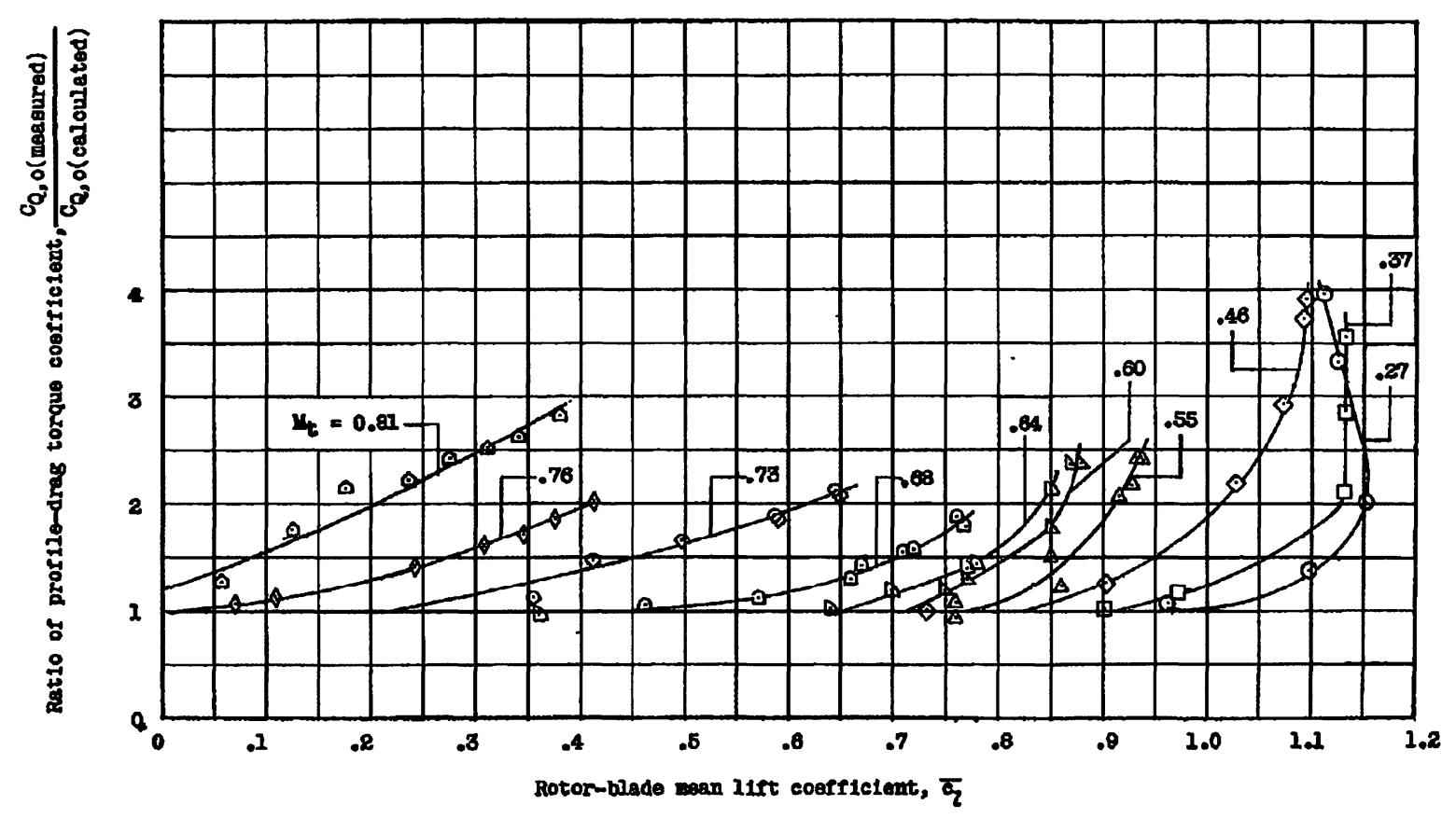

Figure 2.5: Effect of $M_{T i p}$ and $\overline{c_{l}}$ on profile-drag torque correction factor [12]. 


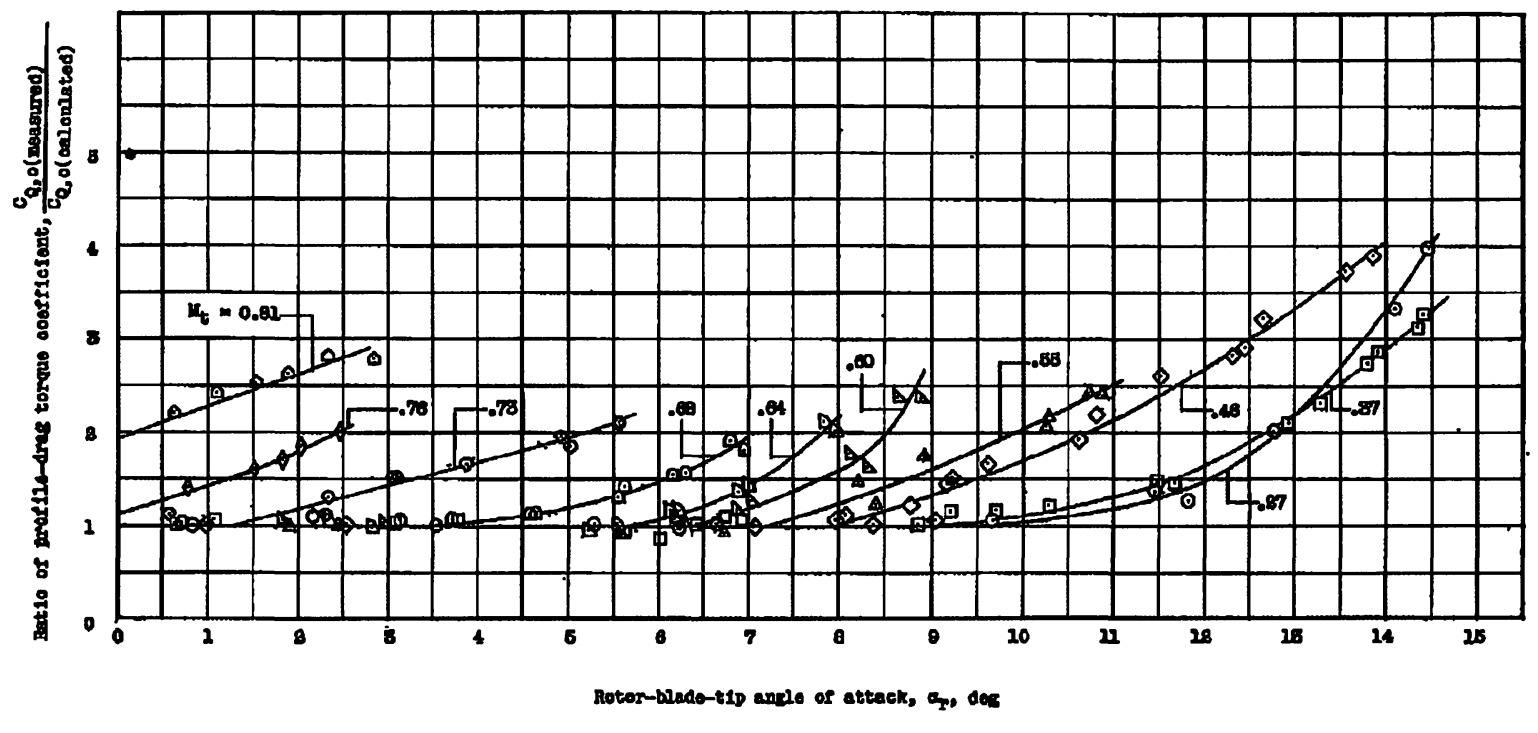

Figure 2.6: Effect of $M_{\text {Tip }}$ and $\alpha_{\text {Tip }}$ on profile-drag torque correction factor [12].

The $M_{T \iota p}$ vs. $\alpha_{T \imath p}$ boundary for experimentally determined drag divergence of both NACA 0015 and NACA 0009 is shown in Figures 2.7 and 2.8, with comparison point values given in Table 2.1. The thicker NACA 0015 airfoil performs more favourably with regard to drag divergence; it achieves a higher tip Mach number for given angle of attack before drag divergence is experienced, thus allowing more thrust from the rotor. This is the airfoil used for the SHARCS blade too, and thus makes the SHARCS blade profile a good candidate for representation of rotors that will reach the limits of the whirl tower's capabilities. 


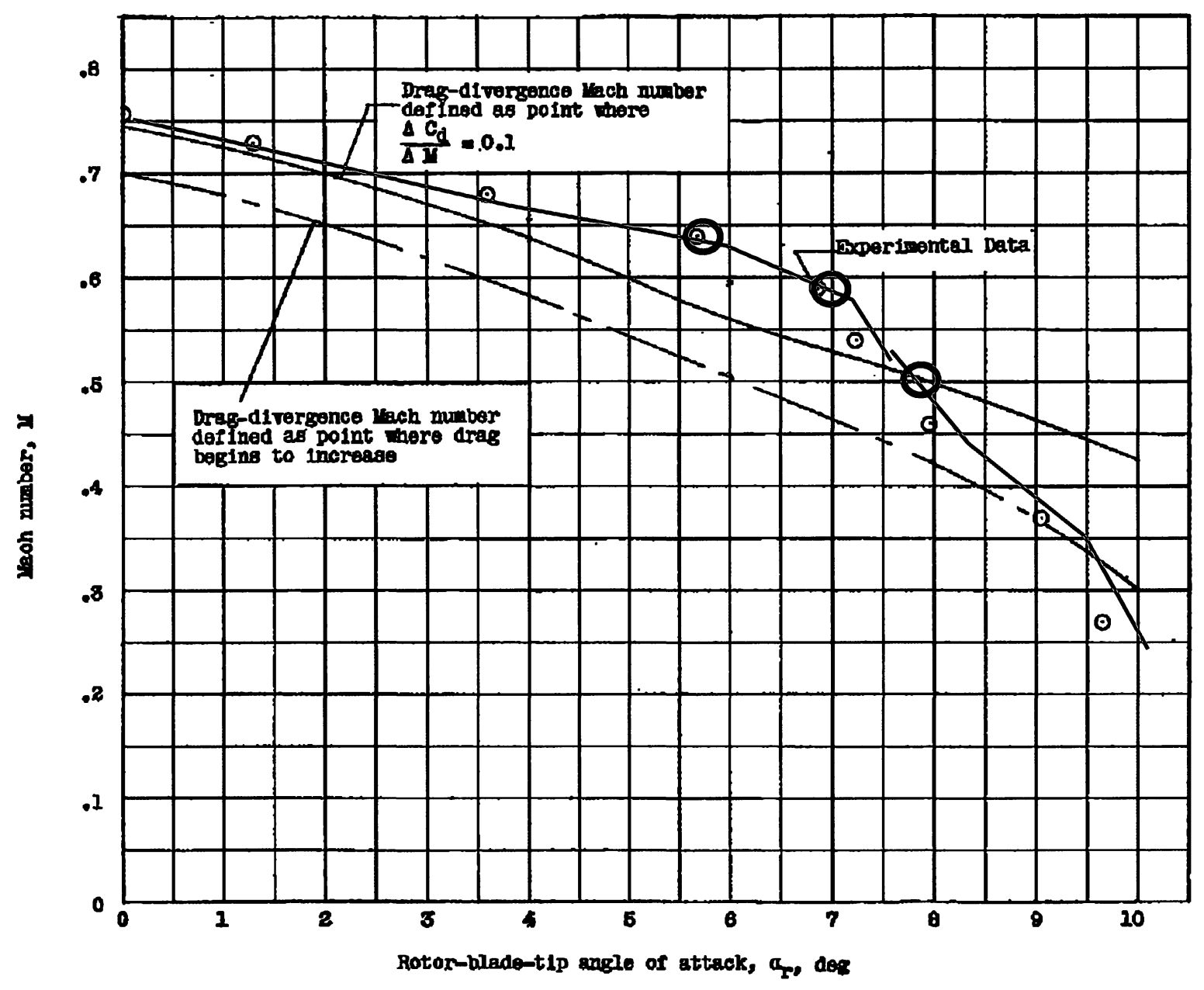

Figure 2.7: Rotor drag divergence onset for NACA 0015 [12]. 


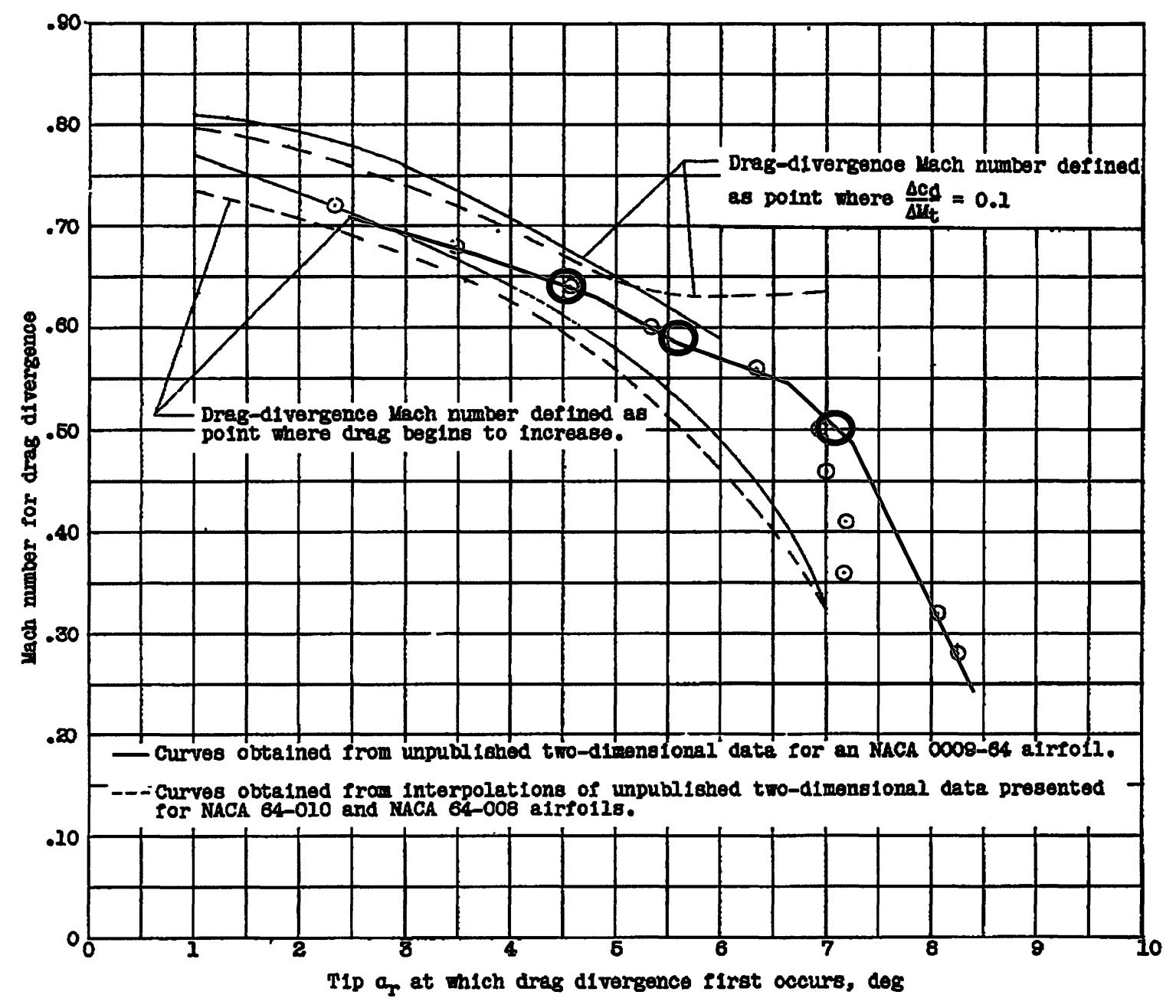

Figure 2.8: Rotor drag divergence onset for NACA 0009 [14].

Table 2.1: Comparison of tip pitch angle at which drag-divergence occurs for blades with NACA 0015 and NACA 0009 airfoils.

\begin{tabular}{|c|c|c|c|}
\hline Airfoil & $M_{\text {Tip }}=0.65$ & $M_{\text {Tip }}=0.60$ & $\mathrm{M}_{\text {Tip }}=\mathbf{0 . 5 2}$ \\
\hline NACA 0015 & $\alpha_{T l p}=5.5^{\circ}$ & $\alpha_{T \iota p}=6.75^{\circ}$ & $\alpha_{T \iota p}=7.5^{\circ}$ \\
\hline NACA 0009 & $\alpha_{T \iota p}=4.3^{\circ}$ & $\alpha_{T \iota p}=5.3^{\circ}$ & $\alpha_{T \iota p}=6.75^{\circ}$ \\
\hline
\end{tabular}

Data based on Figures 2.7 and 2.8 
From the table above, the test points of $M_{\text {tip }}=0.65$ and 0.60 are chosen as candidates for maximum rotor torque and power. Above this range, $\alpha_{\text {Tip }}$ decreases too rapidly resulting in the rotor requiring high power but producing less lift due to limitation in the maximum $\overline{c_{l}}$ achievable before drag divergence. These values match well with the $M_{\text {Tip }}$ values of production rotors, such as the BO-105 with a value of 0.64 [6]. The test point of 0.52 is chosen to allow comparison of the SHARCS rotor.

The conclusion of this analysis is that a rotor with the NACA 0015 airfoil, operating at $M_{t i p}=0.65$ and $\alpha_{\text {Tip }}=5.5^{\circ}$, or at $M_{t i p}=0.60$ and $\alpha_{\text {Tip }}=6.75^{\circ}$, is likely to approximate the most strenuous rotor configuration for a given rotor size. The test values of $M_{\text {tip }}=0.52$ and $\alpha_{\text {Tip }}=7.5^{\circ}$ are interesting due to their pertinence to the SHARCS rotor.

\subsubsection{Calculation of Drive System Requirements}

Using the tip Mach numbers and angles of attack determined above, a hypothetical rotor can be defined, which uses the SHARCS blade profile (consisting of a NACA 0015 airfoil) with 4 rotor blades. This rotor resembles a 1:4 scale BO-105 rotor and is shown in Figure 2.9. The SHARCS blade has the following design characteristics [1]:

- Root cut-out: $126 \mathrm{~mm}$

- Chord length: $80 \mathrm{~mm}$

- Blade radius: 1,096 mm

- Airfoil: NACA 0015

- Rotational speed: 1,555 RPM ( $\left.\mathrm{M}_{\mathrm{Tip}}=0.52\right)$

- Linear twist distribution with $5.5^{\circ}$ absolute twist (See Figure 2.10) 


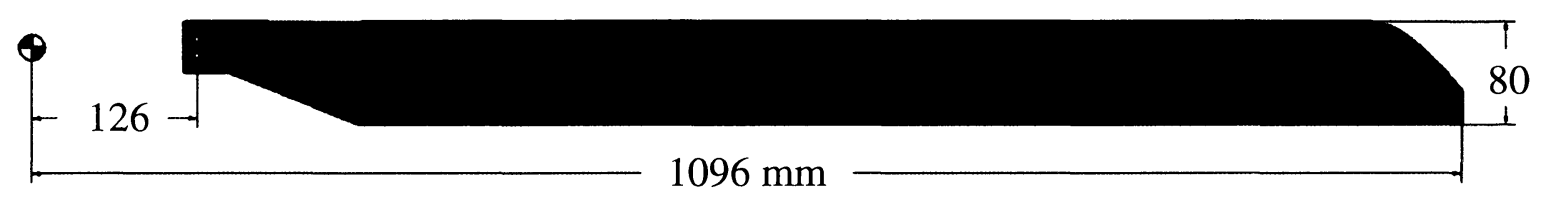

Figure 2.9: Top view of the SHARCS blade with main dimensions [1].

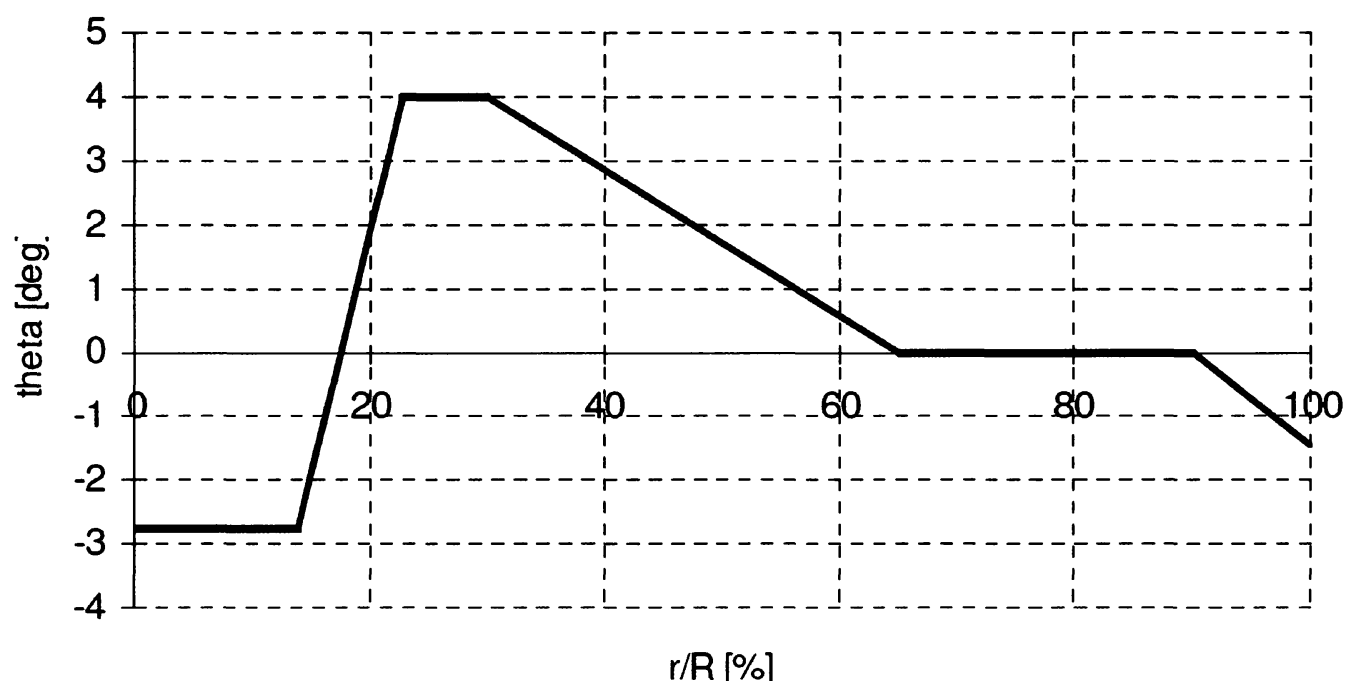

Figure 2.10: SHARCS blade twist distribution [1].

To determine the torque and power requirements of the drive systems, the above rotor configuration was analyzed for the worst-case scenario by Blade Element Momentum Theory (BEMT). This consists of discretizing the rotor blades into thin strips at varying radial position and then integrating the calculated loads along the rotor blade and summing for the number of blades. Momentum theory, which accounts for the local induced velocity effects of flow through the rotor, is added to this to form the Blade Element Momentum Theory. The process for this analysis is described by J. Seddon and Simon Newman [15]. The radial increments taken are $1 \%$ increments of the blade radius, and the rotor is assumed to be in hover in an open environment, which is a necessity to 
follow the given technique. The method involves the following series of iterative calculations.

The inflow angle is the angle between the flow direction and the plane of rotation, given by:

$$
\phi=\tan ^{-1}\left(\frac{V_{c}+v_{l}}{\omega y}\right)
$$

Where the climb velocity $V_{c}$, is zero and the inflow velocity, $v_{l}$, is as of yet undetermined. From this angle the blade angle of attack is:

$$
\alpha=\theta-\phi
$$

For each blade section, the net flow velocity and the elementary lift and drag are found, and then the forces are resolved into the thrust and torque direction.

$$
\begin{gathered}
U=\sqrt{\left(V_{c}+v_{l}\right)^{2}+(\omega y)^{2}} \\
d L=\frac{1}{2} \rho U^{2} c d y C_{l} \quad d D=\frac{1}{2} \rho U^{2} c d y C_{d} \\
d T=d L \cos (\phi)-d D \sin (\phi) \quad d Q=(d L \sin (\phi)+d D \cos (\phi)) y
\end{gathered}
$$

The values of $C_{l}$ and $C_{d}$ are obtained from Sandia Labs 2D airfoil data [16] [17], originally sourced from Ref. [18]. The data covers a range of Reynolds numbers from $3.6 \times 10^{5}$ to $1.0 \times 10^{7}$, but the values used are for $R e=1.0 \times 10^{6}$ as this most closely matches the SHARCS blade tip Reynolds number of $9.5 \times 10^{5}$. 


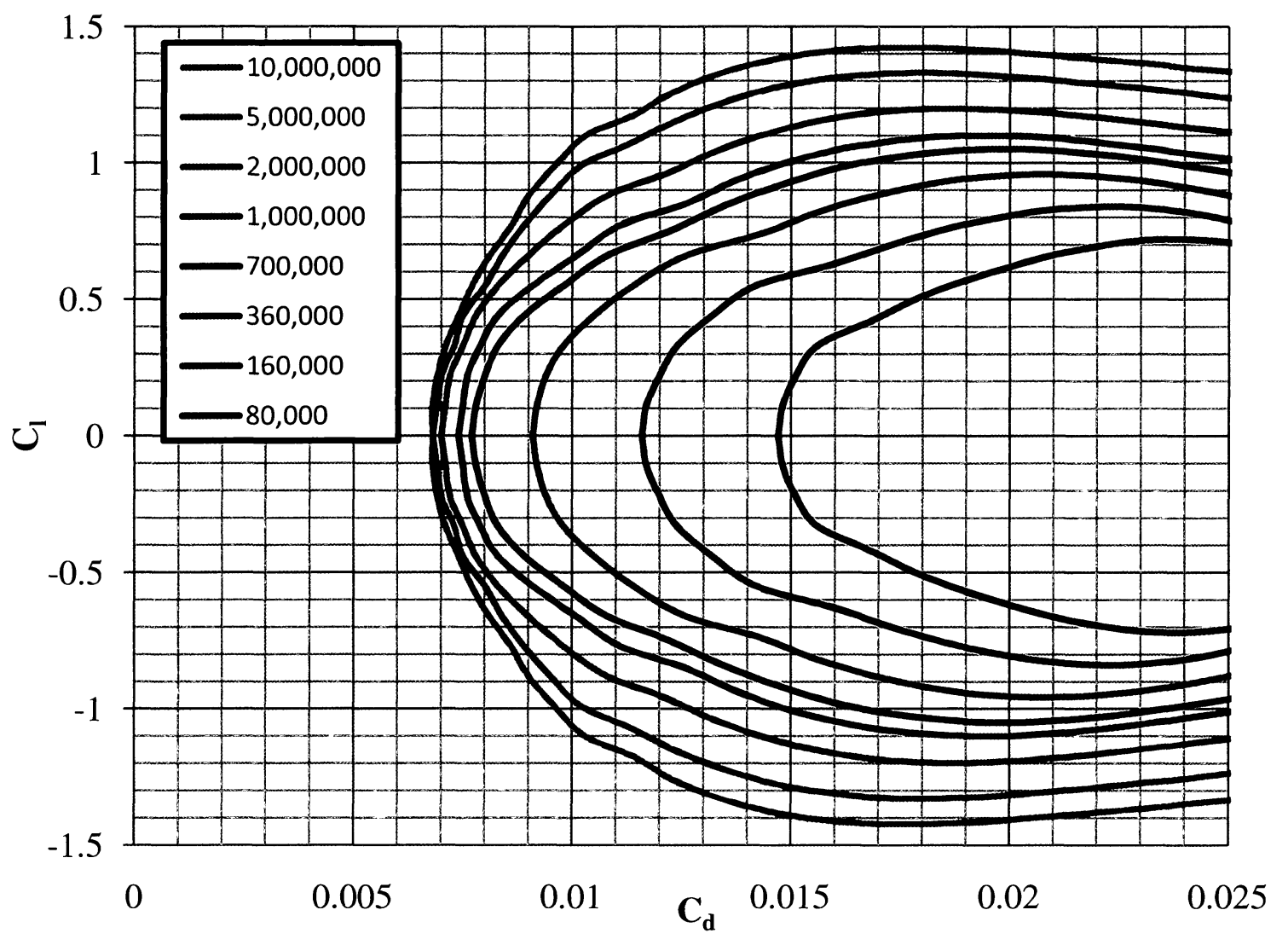

Figure 2.11: Drag polar for various Reynolds numbers for NACA 0015 [16] [17] [18].

The total thrust of the rotor can be obtained as:

$$
T=N_{B} \int_{0}^{R} d T
$$

Where the result of this calculation is used to determine the rotor inflow velocity:

$$
T=2 \rho A v_{l}^{2} \quad v_{l}=\sqrt{\frac{T}{2 \rho A}}
$$


This rotor inflow velocity is then back-substituted into the inflow angle equation (eq. 2.1) and the process is iterated until converged. Once converged, the rotor torque and power are found with:

$$
Q=N_{B} \int_{0}^{R} d Q \quad P=\omega Q
$$

Using the critical design points found in Section 2.1.1, the above analysis is carried out for a rotor of $1.096 \mathrm{~m}$ radius, the same as the SHARCS rotor, and the results are shown in Table 2.2.

Table 2.2: Effect of $M_{\text {Tip }}$ and $\alpha_{\text {Tip }}$ on Rotor Power, Torque, and Thrust.

\begin{tabular}{|c|c|c|c|}
\hline Rotor Characteristics & $\begin{array}{c}\text { Power } \\
(\mathbf{k W})\end{array}$ & $\begin{array}{c}\text { Torque } \\
(\mathbf{N} \cdot \boldsymbol{m})\end{array}$ & $\begin{array}{c}\text { Thrust } \\
(\mathbf{N})\end{array}$ \\
\hline$M_{t \iota p}=0.52, \alpha_{T \iota p}=7.5^{\circ}$ & 32.7 & 203 & 1,930 \\
\hline$M_{t \iota p}=0.60, \alpha_{T \iota p}=6.75^{\circ}$ & 44.2 & 237 & 2,350 \\
\hline$M_{t \iota p}=0.65, \alpha_{T \iota p}=5.5^{\circ}$ & 43.7 & 217 & 2,306 \\
\hline
\end{tabular}

The table indicates that the maximum input power and torque, as well as output thrust, occur for rotors operating around $M_{t \iota p}=0.60$ and $\alpha_{T \iota p}=6.75^{\circ}$. Note that this conclusion is independent of the rotor diameter. The values for rotors of varying diameter and number of blades are shown in Tables 2.3 to 2.6. 
Table 2.3: Power requirement for varying rotor configurations (kW).

\begin{tabular}{|c|c|c|c|}
\hline R x Nb & $M_{\text {tip }}=\mathbf{0 . 5 2}$ & $M_{\text {tip }}=\mathbf{0 . 6 0}$ & $M_{\text {tip }}=\mathbf{0 . 6 5}$ \\
& $\boldsymbol{\alpha}_{\text {Tip }}=\mathbf{7 . 5}^{\circ}$ & $\boldsymbol{\alpha}_{\text {Tip }}=\mathbf{6 . 7 5}^{\circ}$ & $\boldsymbol{\alpha}_{\text {Tip }}=\mathbf{5 . 5}^{\circ}$ \\
\hline $1.096 \mathrm{~m} \mathrm{\times} \mathrm{4}$ & 32.7 & 44.2 & 43.7 \\
\hline $1.6 \mathrm{~m} \mathrm{x2}$ & 26.7 & 36.3 & 36.3 \\
\hline $1.3 \mathrm{~m} \mathrm{x} \mathrm{4}$ & 46.0 & 62.2 & 61.4 \\
\hline $2.0 \mathrm{~m} \mathrm{\times} \mathrm{2}$ & 41.8 & 56.8 & 56.8 \\
\hline $1.6 \mathrm{~m} \mathrm{x} \mathrm{4}$ & 69.7 & 94.2 & 93.0 \\
\hline $2.0 \mathrm{~m} \mathrm{x} \mathrm{4}$ & 109 & 147 & 145 \\
\hline
\end{tabular}

Table 2.4: Torque requirement for varying rotor configurations $(N \cdot m)$.

\begin{tabular}{|c|c|c|c|}
\hline $\mathbf{R} \times \mathbf{N b}$ & $\begin{aligned} M_{t i p} & =0.52 \\
\alpha_{\text {Tip }} & =7.5^{\circ}\end{aligned}$ & $\begin{array}{l}M_{\text {tip }}=0.60 \\
\alpha_{\text {Tip }}=6.75^{\circ}\end{array}$ & $\begin{aligned} M_{\text {tip }} & =0.65 \\
\alpha_{\text {Tip }} & =5^{\circ} 5^{\circ}\end{aligned}$ \\
\hline $1.096 \mathrm{~m} \mathrm{x} 4$ & 203 & 237 & 217 \\
\hline $1.6 \mathrm{~m} \mathrm{x} 2$ & 242 & 285 & 263 \\
\hline $1.3 \mathrm{~m} \mathrm{x} 4$ & 338 & 396 & 361 \\
\hline $2.0 \mathrm{~m} \times 2$ & 473 & 557 & 514 \\
\hline $1.6 \mathrm{~m} \mathrm{x} 4$ & 631 & 739 & 674 \\
\hline $2.0 \mathrm{~m} \mathrm{x} 4$ & 1,230 & 1,440 & 1,320 \\
\hline
\end{tabular}

The values in Tables 2.3 and 2.4 are only to overcome the rotor's aerodynamic forces. Additional power and torque will be required to accommodate the mechanical losses in the system. 
Table 2.5: Thrust produced for varying rotor configurations (N).

\begin{tabular}{|c|c|c|c|}
\hline $\mathrm{R} \times \mathrm{Nb}$ & $\begin{aligned} M_{\text {tip }} & =0.52 \\
\alpha_{\text {Tip }} & =7.5^{\circ}\end{aligned}$ & $\begin{array}{l}M_{\text {tip }}=0.60 \\
\alpha_{\text {Tip }}=6.75^{\circ}\end{array}$ & $\begin{aligned} M_{\text {tip }} & =0.65 \\
\alpha_{\text {Tip }} & =5.5^{\circ}\end{aligned}$ \\
\hline $1.096 \mathrm{~m} \mathrm{x} 4$ & 1,930 & 2,350 & 2,310 \\
\hline $1.6 \mathrm{~m} \mathrm{x} 2$ & 2,130 & 2,600 & 2,570 \\
\hline $1.3 \mathrm{~m} \mathrm{x} 4$ & 2,720 & 3,310 & 3,240 \\
\hline $2.0 \mathrm{~m} \mathrm{x} 2$ & 3,320 & 4,060 & 4,010 \\
\hline $1.6 \mathrm{~m} \mathrm{x} 4$ & 4,110 & 5,010 & 4,910 \\
\hline $2.0 \mathrm{~m} \mathrm{x} 4$ & 6,430 & 7,830 & 7,680 \\
\hline
\end{tabular}

Table 2.6: Rotational rate for rotor radius vs $M_{\text {Tip }}$ (RPM).

\begin{tabular}{|c|c|c|c|}
\hline Rotor Radius & $\boldsymbol{M}_{\text {tip }}=\mathbf{0 . 5 2}$ & $\boldsymbol{M}_{\text {tip }}=\mathbf{0 . 6 0}$ & $\boldsymbol{M}_{\text {tip }}=\mathbf{0 . 6 5}$ \\
\hline $1.096 \mathrm{~m}$ & 1,540 & 1,780 & 1,930 \\
\hline $1.3 \mathrm{~m}$ & 1,300 & 1,500 & 1,620 \\
\hline $1.6 \mathrm{~m}$ & 1,060 & 1,220 & 1,320 \\
\hline $2.0 \mathrm{~m}$ & 840 & 970 & 1,060 \\
\hline
\end{tabular}

As noted earlier, the rotors operating at $M_{T \imath p}=0.60$ and $\alpha_{T \imath p}=6.75^{\circ}$ require the most power and torque regardless of size. The rotors are sorted by their increasing torque requirement, as seen in Table 2.4. This is because torque is later determined to be the limiting drive system factor and therefore more appropriate to have $1.6 \mathrm{~m} \times 2$ blades appear before $1.3 \mathrm{~m} \mathrm{x} 4$ blades, as the larger 2-bladed rotor requires less torque. 


\subsection{Drive Mechanical Design}

\subsubsection{Power Plant}

Early in the design process, it was specified that due to the uncertainty of available ventilation in the operating environment, the system's power plant should be electric. For this application it was decided to use a synchronous AC motor. This is due to synchronous AC motors having higher efficiency, more compact size, speed independence from load (simpler control) and less maintenance (brushless) in comparison to a similar DC motor. Synchronous AC drives must be selected with a set number of poles, which define their native operating speed on local $60 \mathrm{~Hz}$ power. As seen in Table 2.6 , the majority of target rotors operate at $1,800 \mathrm{RPM}$ or less, resulting in the selection of a 4 pole motor with 1,800 RPM speed. The motor was additionally known to be 3 phase $575 \mathrm{~V}$, as this is the local industrial power standard.

In order to allow precise speed control, as well as operation of rotors at speeds other than 1,800 RPM without a transmission of perfect ratio, the use of a variable frequency transformer (VFT) was also selected. The VFT is an AC-DC-AC transformer that allows for variable control of output frequency and voltage. Because a synchronous $\mathrm{AC}$ motor has its speed directly proportional to the $\mathrm{AC}$ power frequency, this allows for precise control of the motor speed. The VFT does not change the limits of motor torque, and thus the motor's maximum power changes proportional to motor speed. Caution should be taken when operating near full torque and at reduced speed with a totally enclosed fan-cooled (TEFC) motor, the type selected for this facility. This is due to TEFC motors having an integrated, directly driven fan for cooling. It does not produce 
sufficient airflow for cooling when operating at high torque and low speed, and the motor must therefore be thermally monitored to check for overheating [19].

Selection of the specific motor first involved speaking to an array of suppliers and finding a brand or series to simplify the selection process. WEG brand drives were widely available and well priced; they have a lot of very similar series of motor, with very minor differences in performance, so the W21 High-Efficiency General-Purpose series was used as a comparison point. The motors come in standard frame sizes, which are basically the dimensions of the iron casting used to create the motor housing. Some frame sizes are used for more than one motor specification, but due to the frame dictating size and most of the weight, the use of a motor of less than maximum capacity for the frame is not recommended. The largest motors for each frame size that are in the range of the power plant's requirements are shown in Table 2.7 below.

Table 2.7: WEG W21 high-efficiency general-purpose motors, 575V [20].

\begin{tabular}{|c|c|c|c|c|}
\hline Frame & $\begin{array}{c}\text { Speed } \\
(\mathbf{R P M})\end{array}$ & $\begin{array}{c}\text { Power } \\
(\mathbf{H P} / \mathbf{k W})\end{array}$ & $\begin{array}{c}\text { Torque } \\
(\mathbf{f t} \cdot \boldsymbol{l b} / \boldsymbol{N} \cdot \boldsymbol{m})\end{array}$ & $\begin{array}{c}\text { Mass } \\
(\mathbf{l b})\end{array}$ \\
\hline $365 \mathrm{~T}$ & 1,775 & $75 / 55$ & $218 / 295$ & 900 \\
\hline $405 \mathrm{~T}$ & 1,775 & $100 / 75$ & $298 / 404$ & 1,118 \\
\hline $444 \mathrm{~T}$ & 1,780 & $150 / 110$ & $436 / 591$ & 1,665 \\
\hline $447 \mathrm{~T}$ & 1,780 & $250 / 185$ & $732 / 992$ & 2,315 \\
\hline
\end{tabular}

The $75 \mathrm{HP}$ motor produces sufficient torque to directly drive 4 bladed rotors approximately the size of the SHARCS rotor, with an upper limit of approximately $1.2 \mathrm{~m}$ 
radius depending on specific rotor design. It also produces sufficient torque to power 2 bladed rotors of up to $1.6 \mathrm{~m}$ radius directly (see Table 2.4 ). The $100 \mathrm{HP}$ motor increases capability for 4 bladed rotors up to $1.3 \mathrm{~m}$, and pushes 2 bladed rotors closer to $2 \mathrm{~m}$, but not fully. At $150 \mathrm{HP}$, a directly coupled motor can power a 4 bladed $1.5 \mathrm{~m}$ rotor, or a 2 bladed $2 \mathrm{~m}$ rotor. The low speed and high torque for a 4 bladed $2 \mathrm{~m}$ rotor places it in a very unrealistic range. A motor capable of driving 4 bladed rotors of the given design, and also operating at 1,800 RPM for smaller rotors, would be a $400 \mathrm{HP}$ 3,200 pound design, which is outside of the desired size and cost for this project. The design problem is that as rotors get larger, they require more torque but less RPM. The 400 HP motor would have sufficient torque, but would have twice the power required because it is designed to operate at twice the speed. This suggests that direct driving a 1,800 RPM motor and slowing it down is not the ideal solution, but instead a 1,800 RPM motor with a transmission system should be used.

The motor selection, based on the usage of a transmission, was discussed with the Rotorcraft Research Group. After collecting quotes, looking at motor sizes, and looking at the capability of each selection, the recommendation was made to use a $100 \mathrm{HP}$ drive system. This selection provided capability for 4 bladed rotors up to $1.6 \mathrm{~m}$ radius, and 2 bladed rotors up to $2 \mathrm{~m}$ radius, with enough headroom for transmission losses and imperfect transmission ratio. It also allows operation of 4 bladed rotors up to $1.3 \mathrm{~m}$ radius with no transmission ratio. This recommendation was accepted by the research group and the motor size was set. 
Selection of a corresponding VFT for the motor is also required. This involves defining the load as either constant torque or variable torque. Constant torque is normally assumed; it describes loads where the torque does not vary with speed, such as a hoist. A larger VFT is required as the motor is run over its rated torque when accelerating and thus puts a substantial electrical current load on the VFT. Variable torque loads, such as fans, have torque that increase proportionally or exponentially with speed, just like this whirl tower. The classification of only variable torque loads means much less stress during startup, and allows for a smaller, less expensive VFT. The corresponding unit for $100 \mathrm{HP}$ variable torque load is the WEG CFW-090079THDBZ [21].

\subsubsection{Transmission}

The selection of a transmission type was directed by considerations such as cost, maintenance, durability, ease of installation, adjustment capability (switching drive ratio), smoothness of transmission and size. The types of systems under consideration are geared, V-belt, and synchronous belt, with direct-coupling included as a reference. Before making a decision on which one to use, their advantages and disadvantages will be described below.

Geared systems have the advantage of precise drive ratios. The rotor speed can be directly determined from the output frequency of the VFT, which makes setting a precise operating speed simple. They also have the advantage of not requiring pretension, which pulls the shafts together and causes additional wear to bearings in the 
system (there is still asymmetric transmission loading on bearings). Lastly they are the most durable of transmission systems, not having any rubber belt component. The disadvantages of gears are the need for precise alignment between the drive shafts, large initial cost, and highest maintenance of all the systems. They require regular lubrication to prevent gear wear and failure.

V-belt systems are friction based belts which are very forgiving in operation, and still maintain high efficiency. Precise alignment between shafts is not needed and the two shafts are isolated from vibration or jamming. The belt can slip if one shaft is interrupted, which can help to protect the motor, although this is not of major concern with a helicopter rotor. The belt is also very low maintenance requiring no lubrication, although the high tension it requires can wear out bearings. The belt also provides for smoother power transmission than gear systems.

Synchronous belts are toothed belts that provide much higher levels of power transmission than V-belts. They still provide the smooth transmission and the low maintenance advantages of $\mathrm{V}$-belts, but also provide the precise control of gears due to their toothed design. They require pre-tensioning resulting in higher bearing wear.

Direct-coupling consists of lining the shafts up axially and using a rigid or semirigid connector between them. No transmission ratio is possible, but it provides precise control of the drive system with the motor, and has the least vibration of any option. It does have some difficulty in precisely aligning the shafts, but otherwise it is very simple, easy, and low maintenance. 
A weighted selection process for the transmission systems is shown in Table 2.8 below. Each of the selection criteria has been weighted in importance and for each criterion the systems are ranked of a scale of 0 to 3 . The weighted totals are shown at the bottom; they indicate which system is the best choice to fulfill the selection criteria. Direct coupling transmission is included for comparison sake.

Table 2.8: Transmission weighted selection summary.

\begin{tabular}{|c|c|c|c|c|}
\hline Type (weight) & Gears & V-Belt & Synchronous Belt & Direct Coupling \\
\hline Cost (1) & 1 & 2 & 2 & 3 \\
\hline Maintenance (1) & 1 & 2 & 2 & 3 \\
\hline Durability (1) & 3 & 1 & 2 & 3 \\
\hline Ease (1) & 1 & 2 & 3 & 2 \\
\hline Adjustability (3) & 2 & 3 & 3 & 3 \\
\hline Smoothness (2) & 1 & 3 & 1 & 3 \\
\hline Size (2) & 2 & 0 & $\mathbf{2 6}$ & $\mathbf{2 3}$ \\
\hline Weighted Total & $\mathbf{1 8}$ & $\mathbf{2 2}$ & & \\
\hline
\end{tabular}

The top scoring transmission system by ranking of the weighted criteria is the synchronous belt system. It combines the best qualities of the geared and friction based belt systems. The second highest scoring system is the direct coupling. It received a nearly perfect score except for its complete lack of transmission ratio adjustability. If not for the need for transmission ratios then it would be the clear choice. The selection of a synchronous belt system is further confirmed as a suitable choice by its usage in the DLR whirl tower system. 
However, a belted transmission system appears to be extremely difficult to implement smoothly, which might be a problem for a test rig designed to study vibration. The problem is that although one side of the belt is under high tension while transmitting power, the opposite side becomes slack and tends to flap. This flapping can occur at unpredictable frequencies and is extremely difficult to control as the belt pre-tensioning would have to exceed the full load transmission tension to prevent the slack from occurring. This puts considerable stress on the entire drive system. The flapping is very detrimental to vibrations measurements being performed, especially since it is unpredictable in nature, and should be avoided if possible. After discussing these discoveries with the project supervisors, it was verified that all of the foreseeable drive system requirements for the next year or more can be met by a $100 \mathrm{HP}$ direct drive system. As such it was decided to postpone the usage of the synchronous belt system, even though it had already been selected, sized, designed and even quoted. After operating the whirl tower for the current project goals in a direct drive configuration, it can be re-evaluated if a transmission system is needed for a future upgrade. As such the synchronous belt selection methodology is still included in appendix A as a reference.

The sizing and selection of the direct-coupling system is included in Chapter 3: Mechanical Design, specifically Section 3.4. 


\subsection{Drive System Design Changes due to NRC Partnership}

The drive system design at the time of establishing the NRC partnership consisted of the following design choices and components:

The motor is a 3 phase 575 volt AC drive. It has a native speed of $1,800 \mathrm{RPM}$ on 60 $\mathrm{Hz}$ lines with a power rating of $100 \mathrm{HP}(75 \mathrm{~kW})$. The model selected is a WEG W21 High-Efficiency General-Purpose edition and would be used with a CFW-09 series VFT sized for variable torque loads only. Based on Table 2.4 , it is capable of operating 4 bladed $1.3 \mathrm{~m}$ radius rotors, or 2 bladed $1.6 \mathrm{~m}$ radius rotors in a direct drive configuration.

With the NRC partnership came an offer to borrow a drive system they had available. It consisted of a 575V WEG W21 Premium-Efficiency Severe-Duty motor of 1,800 RPM and $60 \mathrm{HP}$ in size. It is the same $365 \mathrm{~T}$ frame size as the $75 \mathrm{HP}$ edition. The motor comes with a VFT sized for constant torque applications (oversized, but not detrimental except to price). The capabilities of this drive system are listed below in Table 2.11. This drive is capable of powering 4 bladed rotors only up to the SHARCS rotor size (although with headroom for SHARCS since the rotor is slower) and 2 bladed rotors up to approximately $1.5 \mathrm{~m}$ radius. Since this would meet the needs of the research group for the next year, and it has an attractive cost, it was decided to scale back the design to utilize this drive system.

Table 2.9: NRC owned WEG motor capabilities [20].

\begin{tabular}{|c|c|c|c|c|}
\hline Frame & $\begin{array}{c}\text { Speed } \\
(\mathbf{R P M})\end{array}$ & $\begin{array}{c}\text { Power } \\
(\mathbf{H P} / \mathbf{k W})\end{array}$ & $\begin{array}{c}\text { Torque } \\
(\mathbf{f t} \cdot \mathbf{l b} / \mathbf{N} \cdot \boldsymbol{m})\end{array}$ & $\begin{array}{c}\text { Mass } \\
(\mathbf{l b})\end{array}$ \\
\hline $365 \mathrm{~T}$ & 1775 & $60 / 45$ & $179 / 243$ & 853 \\
\hline
\end{tabular}




\section{Chapter 3: Mechanical Design}

Before proceeding to describe the design methodology of the whirl tower's mechanical systems, it should be noted that the design process for these systems was highly iterative. Some of the design estimates made were refined many times before settling on a suitable configuration and freezing it. The design process will be described in a linear fashion, although it is not necessarily the order in which each design component was frozen.

\subsection{Safety Factor}

Establishing the safety factor for usage in the design process was one of the first steps to be performed when sizing components. The factors that went into consideration when choosing the values were:

- certainty of loads

- certainty of strength

- required service life

- $\quad$ service wear, and

- consequences of failure. 
The load certainty for the designs made is considered very high. The SHARCS rotor is well characterized, as will be any future rotors allowed to operate. All rotors using this facility must be characterized before operation, especially with regard to their blades' centripetal force.

The certainty of strength for the mechanical design is targeted to be high as well. The failure modes for the whirl tower are rather simple, so analysing the strength with regard to each failure will be performed.

The required service life of the facility is expected to be low. Tests will be performed within a few minutes to collect data, and the duty cycle is expected to be very low. Full 'loading' of the tower is considered to occur during operations while in a failed state, which will only last a few seconds before shut down and deceleration begins.

The wear on the tower is expected to be very low; no corrosive factors plus very infrequent movement means it is unlikely to wear the paint off, let alone damage the structure.

Finally, the consequences of failure are reconstruction of the failed elements, without risk to any persons. This is due to the plan for a multi-layer containment system. A failure would undoubtedly begin with destruction of the rotor, which in itself would take weeks to replace. Since the tower can be re-fabricated on a similar timescale and will not be needed in the interim, damage to the tower is only a monetary loss, although it is still planned to be unlikely. Due to these assessments, the minimum safety factor selected for design is 2.0 . 


\subsection{Design Preview}

This section describes the proposed concept of the mechanical drive system design. Figure 3.1 shows a cross-sectional view of the drive system with major components labelled.

The drive shaft has multiple shoulders for bearings and hub seating. It also has a through bore and cross-hole for wiring from the slip rings, which are located between the two bearings. The coupler between the drive shaft and motor is an elastomeric design to alleviate the loads caused by misalignment of the shafts during installation. There are two bearing units to counteract the bending moments caused by a rotor blade failure, and also to fully constrain the drive shaft axially. The top bearing housing is removable, and will subsequently allow disassembly and maintenance of the rest of the drive system. The rotor hub system consists of an upper and lower hub section, which are fastened together to provide a fully constrained connection to the shaft. The lower hub also contains a skirt for attaching an armature to connect the bottom of the Active Pitch Link to. This replaces the function of a swashplate, which is not required to be implemented in a whirl tower (but is necessary for wind tunnel tests). The rotor hub is articulated, i.e. allows 3 degrees of freedom movement of the blade at the root. A counterweight system is also provided when operating with single blades only. Note that these last two mechanisms do not appear in Figure 3.1.

All of the above systems are described in detail in Sections 3.3 to 3.8. 


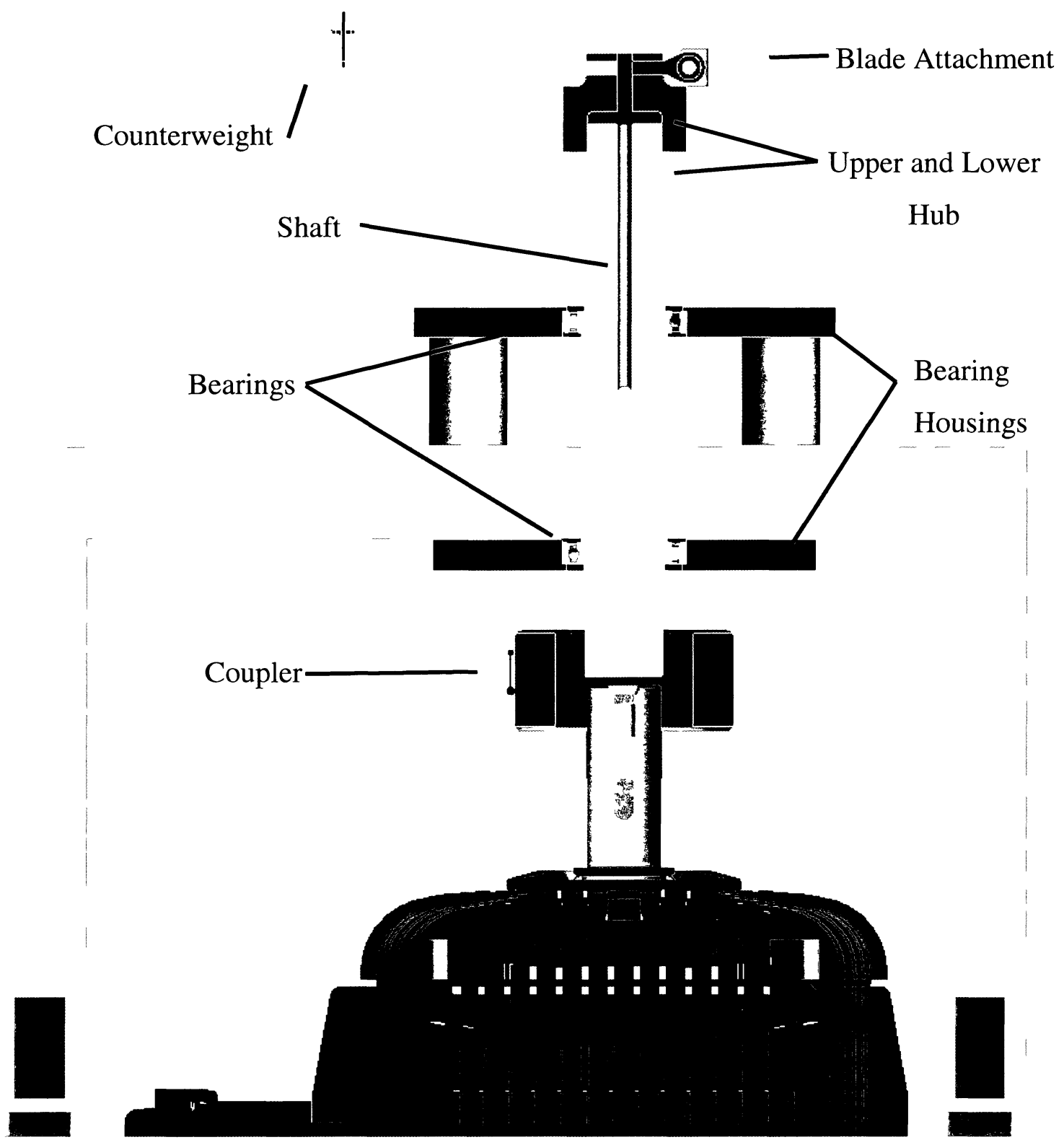

Figure 3.1: Mechanical design preview. 


\subsection{Drive Shaft Design}

\subsubsection{Design Goals and Requirements}

Before designing the main drive shaft, a concept is outlined of what the design should look like and be capable of. The goal for the structural design of the whirl tower is to survive a rotor blade failure with as little damage as possible. Blade failures are expected to occur and rebuilding the whirl tower every time this happens would be unacceptable. To survive these failures, the shaft should be supported by two bearings with sufficient spacing to support the bending moment loads. A single bearing, even if it were double rowed, could not take the high moment and would either transfer the load into the motor or fail, potentially causing other damage. The moment that the shaft will experience is proportional to the centripetal force on the rotor blade, and the distance between the final bearing and the rotor plane. Since the maximum centripetal force should be left as high as possible, the rotor plane height should be minimized as much as possible.

Underneath the rotor, it is necessary to leave room to install the pitch link, specifically the Active Pitch Link under development by the Rotorcraft Research Group. The use of a swashplate allowing the collective of cyclic change of the blade pitch angle was not deemed necessary by the group, so it will not be included. Instead, a simple corotating attachment point will be used for the other end of the link. It is possible to install the rotor upside down or put the pitch link pointing up, but these options were dismissed in preference of keeping the rotor configuration as classical as possible. As a result, the only mechanism below the rotor plane is the pitch link and its attachment point. The 
ideal position for the slip rings would be between the top bearing and the rotor, so that the wiring could travel along the outside of the shaft to the rotor plane, but this would increase the shaft extension past the last bearing a significant amount therefore requiring a stronger shaft. Instead, the slip rings will be installed between the two shaft bearings and wiring will be run though a cross hole up a bore in the shaft. The shaft will need to be axially confined using shoulders and cannot exceed the bore size of the slip rings used. The rotor hub needs to be removable and replaceable, but must be fully constrained and attached sufficiently to also survive blade failures. Finally, the system should be capable of disassembly for maintenance.

\subsubsection{Design Sizing}

The first step for the shaft was to establish some basic estimates of dimension. The shaft extension past the top bearing is dictated by the requirements for the Active Pitch Link (APL). The link has a nominal length of $126 \mathrm{~mm}$ eye-to-eye distance between the top and bottom rod ends. However, the next generation APL, currently under development, is expected to exceed this dimension and is predicted to be around 150 to $180 \mathrm{~mm}$. This put the necessary lateral bending moment arm for the shaft at approximately $200 \mathrm{~mm}$. It was estimated that the rotor distance to the top bearing would be roughly equal to the separation between bearings. This creates the following approximate reaction forces, assuming the bearings are simple supports: 


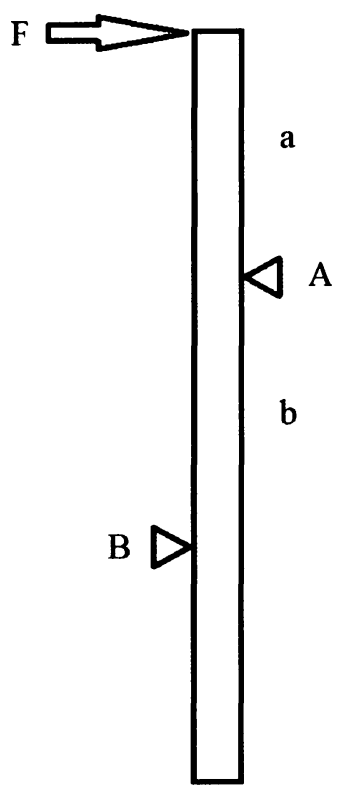

If $a=b$ then

$$
\left|F_{B}\right|=|F|
$$

and,

$$
\left|F_{A}\right|=2 \cdot|F|
$$

Figure 3.2: Bearing reaction forces.

The SHARCS design report predicts the rotor centripetal force to be $9,689 \mathrm{~N}$, but this does not include the blade attachment mechanism. A conservative estimate was made that the mechanism would be less than 500 grams at a mean radial distance of $10 \mathrm{~cm}$. This results in an additional 1,300 $\mathrm{N}$ of load if it were to fail, giving a total force of approximately $11,000 \mathrm{~N}$. The vector sum of two adjacent blade failures, which would be the worst case scenario for the SHARCS rotor, is 15,500 N $(11,000 \mathrm{~N} * \sqrt{2})$. The equation for centripetal force is:

$$
F_{C}=\frac{m \cdot v^{2}}{r}
$$


The limitation in strength will be the resistance to bending moment in the shaft. Bending stress is equal to:

$$
\sigma=\frac{M \cdot y}{I} \cdot c_{1} \cdot c_{2}
$$

Where:

$M$ - bending moment: $M=F_{c} \cdot h$

$y$ - distance from shaft neutral axis: $y=r$

$I-$ second moment of area: $I=\frac{\pi R^{4}}{4}$

$c_{1}$ - bending moment factor due to reaction force in lower bearing: $c_{1}=2$

$c_{2}$ - load factor due to vibratory motion about the equilibrium bending position: $c_{2}=2$

A bore of approximately $1 / 2$ inch is necessary through the shaft for wiring, and this void must be subtracted from the second moment of area. The maximum bending moment will occur at the top bearing, and due to the reaction force of the lower bearing it will be equal to twice the moment created by the unbalanced rotor, thus $c_{1}=2$. The maximum stress expected will be up to twice the value calculated from static analysis, because the steel used for the shaft will be elastic and the bending of the shaft will be an oscillatory mass-spring system (see Figure 3.2). This is not due to rotation of the rotor, since it is in the same rotating frame of reference as the shaft, but due to the unbalanced force being applied while the shaft is not in bending equilibrium, and therefore causing it to oscillate about the equilibrium point and stress as depicted in Figure 3.3. This results in coefficient $c_{2}=2$. 


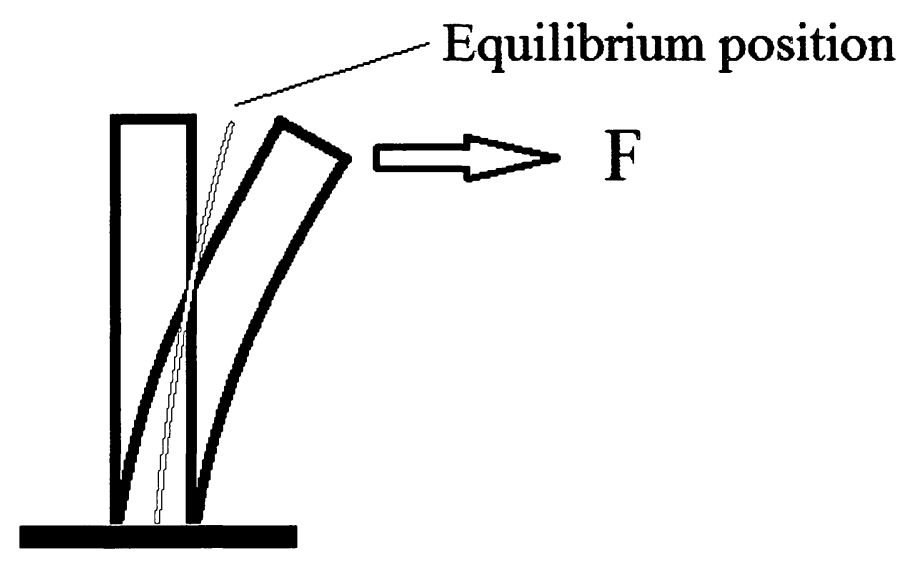

Figure 3.3: Oscillation about equilibrium position.

Therefore the maximum stress in the shaft is equal to:

$$
\begin{gathered}
\sigma=\frac{M \cdot y}{I} \cdot c_{1} \cdot c_{2} \\
=\frac{\left(F_{c} \cdot h\right) \cdot r}{\left(\frac{\pi}{4}\left(r_{o}^{4}-r_{i}^{4}\right)\right)} \cdot 2 \cdot 2 \\
=\frac{15500 N \cdot 200 \mathrm{~mm} \cdot r}{\frac{\pi}{4}\left[r^{4}-(0.25 \text { inch })^{4}\right]} \cdot 2 \cdot 2
\end{gathered}
$$

Since later research identified a limitation of 2 inch diameter $(r=1$ in.) for easy slip ring selection, stress calculations for this diameter are performed. The result is a maximum stress of $140 \mathrm{ksi}(967 \mathrm{MPa})$, without yet considering safety factor. This indicates that a larger shaft diameter will be needed, and as a result forced substantial effort to be expended locating slip rings. Eventually suitable $70 \mathrm{~mm}$ slip rings were located, and thus this could be defined as the maximum shaft diameter. By this time, a 
shouldered bearing installation had also been selected, and the bearing manufacturer offered units at $70 \mathrm{~mm}, 69.85 \mathrm{~mm}$ (2.75 in.), and $65 \mathrm{~mm}$. Since the $69.85 \mathrm{~mm}$ bearing would have had too small a shoulder and was not the appropriate size other than bore, the $65 \mathrm{~mm}$ units were selected. This resulted in a maximum stress value of $66.8 \mathrm{ksi}$ (461 $\mathrm{MPa}$ ) being calculated with $\mathrm{r}=32.5 \mathrm{~mm}$. This was deemed to be achievable, including required safety factor, by utilizing high-strength low alloy steel.

\subsubsection{Material and Heat Treatment}

Due to the need for high-strength alloy, high precision manufacturing, and heat treatment for the shaft, it was realized early on that this part would be contracted out for manufacturing. Locating a manufacturer willing to produce a single part proved difficult, but eventually a company specializing in custom gearing and shafting, The Adams Company, was located in Iowa. Discussions with The Adams Company about their capabilities and pricing proved favourable, so the design process continued with their capabilities in mind. The Adams Company recommended a material selection of 9310 Steel due to their experience with it and its favourable pricing. This material was thus evaluated for its suitability for the application.

9310 Steel is a high-strength low alloy steel of the Nickel-Chromium-Molybdenum family. It contains on average $3.25 \% \mathrm{Ni}, 1.2 \% \mathrm{Cr}, 0.55 \% \mathrm{Mn}$ and very low carbon at only $0.1 \% \mathrm{C}$ [22]. It is described as "a high-quality, high hardenability, high toughness, case-hardening steel. It was specifically designed to be a case-hardening steel for use in applications which require the high surface strength achieved by case-hardening, 
combined with very high core toughness resulting from the low-carbon, hence low hardness core. It is intended for use in extreme applications, where high contact stress is combined with high shock and impact loading." [23] It is frequently used in premium quality gears, and has also been used in production helicopter shafting, such as the RotorWay Exec series [23].

9310 Steel in the non-case-hardened, non-carburized condition has an ultimate tensile strength (UTS) of approximately $160 \mathrm{ksi}(1.10 \mathrm{GPa})$. This condition is typically not used as it is not considered appropriate for high-strength, high-fatigue applications [23]. Instead, it is usually case-hardened by carburizing and then tempering. In this condition, it has a Rockwell-C hardness of approximately 60 , corresponding to a surface tensile strength of approximately $320 \mathrm{ksi}(2.2 \mathrm{GPa})$, and is suitable for these high-strength and fatigue applications [23][24][25]. The UTS of the final part is a composite value based on geometry and case-hardening depth, but using the non-carburized condition strength as a minimum provides greater margin of safety in the value. Values given for casehardened and tempered condition are a UTS of greater than $170 \mathrm{ksi}(1.17 \mathrm{GPa})$. It also retains a percent elongation at failure of approximately $15-18 \%$, an excellent value considering the steel's strength [26].

The Adams Company provided a quote for manufacturing with 9310 Steel, including case-hardening to a depth of 0.030 to 0.040 in. and a Rockwell C hardness of 58-62 followed by heat treatment. The quote required purchasing of two shafts to guarantee delivery of one successful part as it was a one-time manufacturing job. The manufacturing process and price were favourable, so the quote was accepted and the final 
design prepared. In the end only one shaft was received as the second unit was cut to have its strength and hardness tested by the heat treatment company in order to verify that the material properties obtained are as specified.

\subsubsection{Geometry}

The final geometry of the shaft was dictated by component selections for other parts of the drive system and design requirements for testing. The descriptions detailing these values and their determination will be found in the component's corresponding section, although some basic determinations are provided below.

The pitch link requires a spacing of approximately $200 \mathrm{~mm}$ from rotor plane to bearing, and due to the predicted rotor hub height and bearing thickness, the shaft extension past the top bearing shoulder was chosen as $170 \mathrm{~mm}$. The same distance was assigned to the distance between bearing shoulders for bearing spacing. The lower shaft extension for coupling to the motor was dictated by the coupler selection. The design of the coupling interfaces, both to the motor and the rotor hub, are determined from those component's interface requirements, and will be found in later sections.

It should be noted that it was not possible to design the drive shaft to be 'natively' in one unit system. The slip rings and bearings required that metric shaft diameters be used in those locations, and the preference was to use metric for shaft lengths as well due to the pitch link being the driving factor. The motor and rotor coupling were both natively in imperial units. The motor was in imperial so the coupler to interface with it had to use that system too. The shaft manufacturer desired the rotor interface, consisting of a 
keyway and thread, to be in imperial for tooling reasons; this was consistent with the tooling requirements for the Carleton University Mechanical \& Aerospace machine shop for manufacturing the hub. As a result, the drive shaft is presented in both unit systems, with tolerances given in inches as requested by The Adams Company. The drive shaft geometry and dimensions are shown in Figures 3.4 and 3.5.
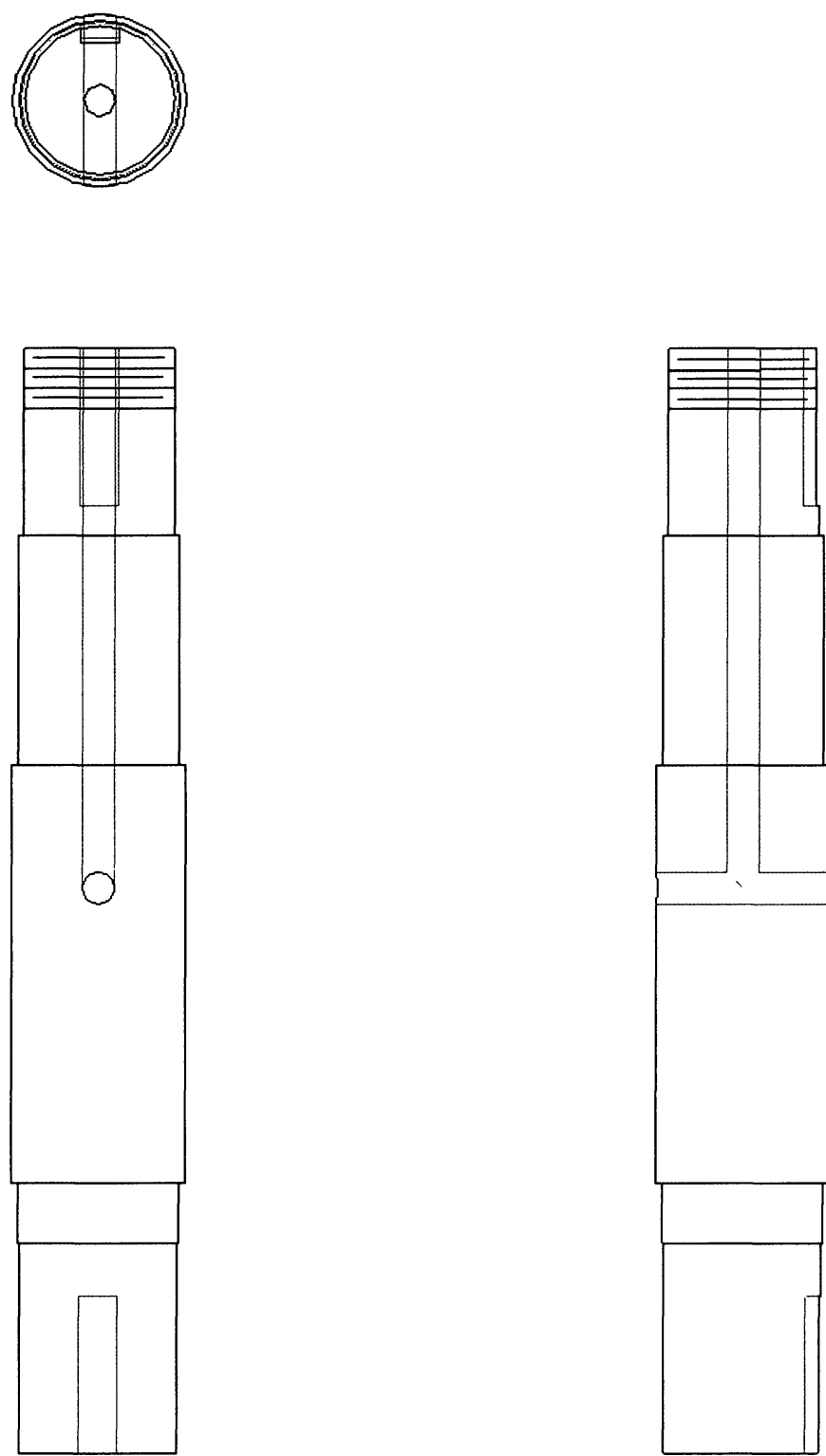

Figure 3.4: Whirl tower drive shaft geometry. 


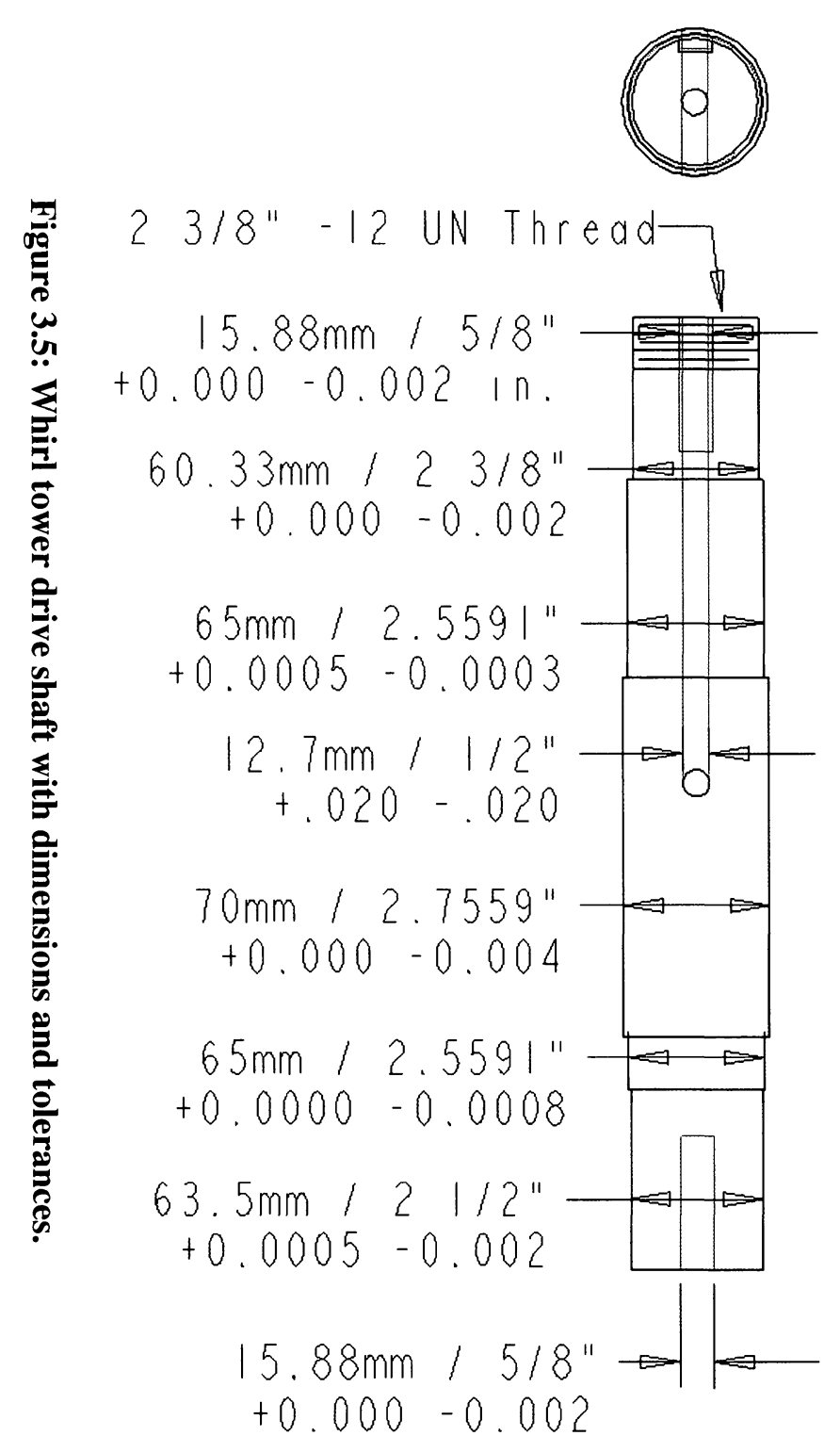

All Vertical Tolerances are +/-0 050"

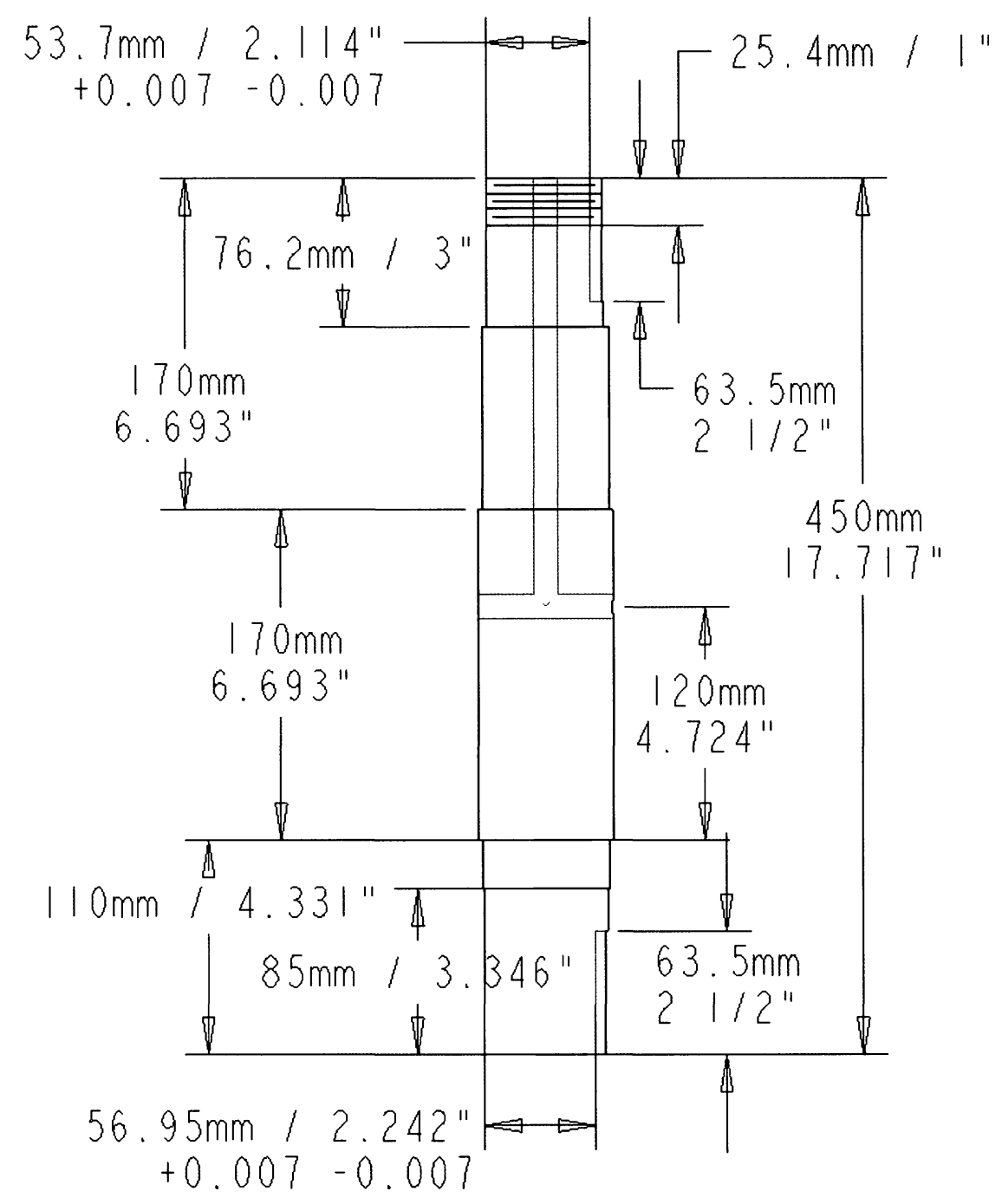




\subsection{Motor Coupling}

\subsubsection{Coupler Type}

For direct coupling between the motor and the drive shaft, a coupler type selection was needed. The first type investigated was the simple sleeve coupling. It consists of a steel round which is bored out to the diameters of the shaft and motor, and then broached with a keyway to transmit torque. This coupler type is very strong, inexpensive, and simple; it could even be made at the Carleton University Mechanical \& Aerospace machine shop rather than purchasing it. After having tentatively selected the coupling type, its description was included in various design presentations and concerns were raised of the ability to align the two shafts with the precisions necessary for using this design. If a misalignment between shafts was present on installation, then it would cause fatigue loading, as the shafts would be bent into alignment and then rotated during operation. The likelihood of a shaft or coupling failure is very low, but the reaction forces from this bending would cause very high bearing wear and premature failure [27].

To reduce the precision necessary when aligning shafts, and alleviate the risk of premature shaft and bearing fatigue, the use of an elastomeric coupling is often selected. These couplings use steel flanges, which are keyed and attached to each of the shafts. In between the two flanges, an elastomeric sleeve is installed to transmit torque while allowing slight misalignments [28]. The series to be eventually selected was the T.B. 
Woods Sure-Flex, which uses a splined elastomeric insert. Various models from the series can be seen in Figure 3.6.

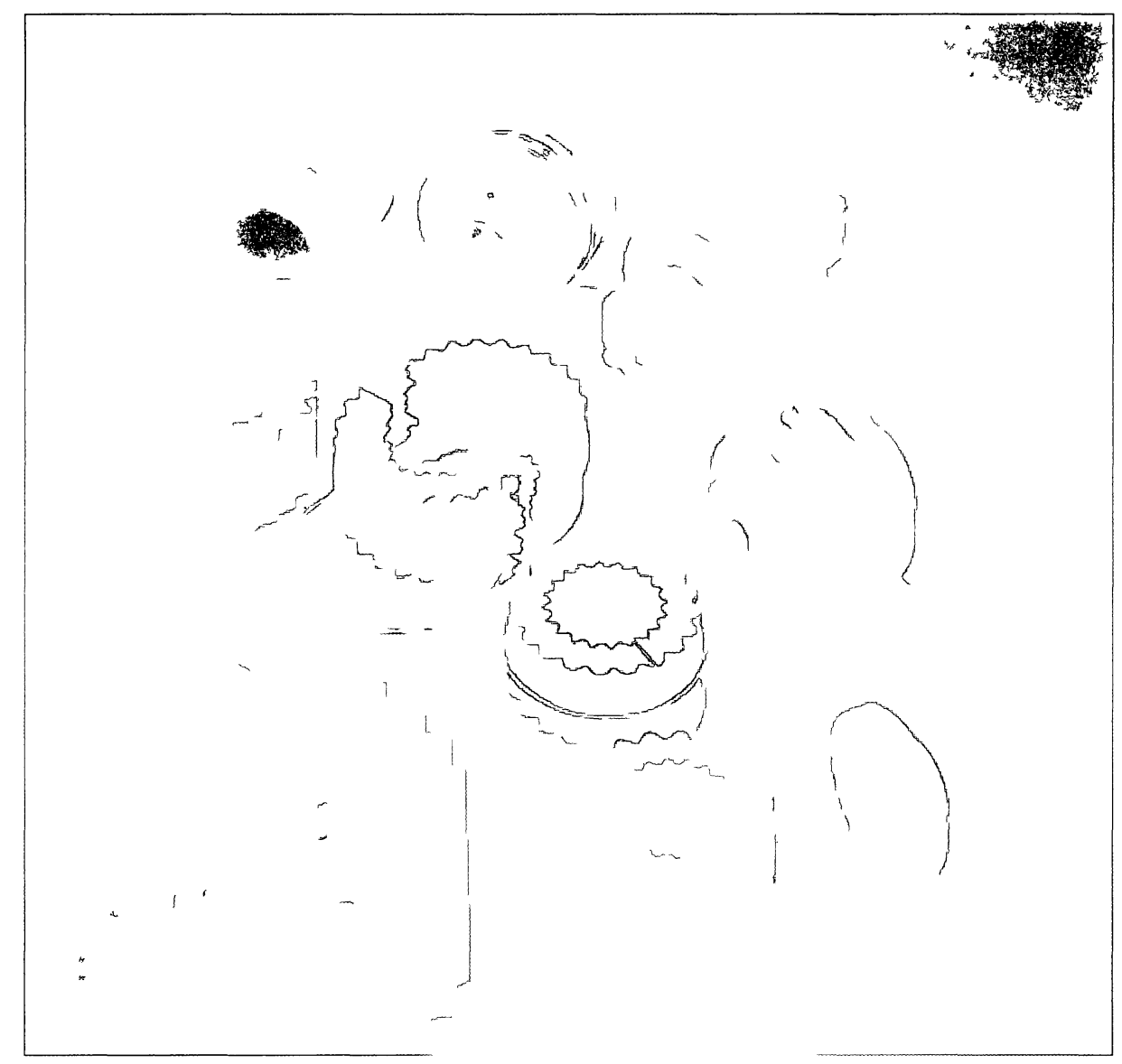

Fingure 3.6: Varrious modells firom the THB Woods Sunre-Fllex series [29]。

\subsubsection{Counpler Sizing}

Sure-Flex couplers come with a choice of four avanlable sleeve materials. The materials available are $\mathbb{E P D M}$ rubber, Neoprene, $\mathbb{H} y t r e l$, and Urethane. Each offers different advantages and characteristics which are presented in Table 3.1. 
Table 3.1: Sure-Flex material properties [30].

\begin{tabular}{|l|c|c|c|c|}
\hline & EPDM & Neoprene & Hytrel & Urethane \\
\hline Typical Use & $\begin{array}{c}\text { General } \\
\text { Purpose }\end{array}$ & $\begin{array}{c}\text { Oil-Resistant } \\
\text { Non-Flame }\end{array}$ & $\begin{array}{c}\text { General } \\
\text { Purpose }\end{array}$ & Stiffness \\
\hline Relative Torque Rating & $1 \mathrm{X}$ & $1 \mathrm{X}$ & $4 \mathrm{X}$ & $4 \mathrm{X}$ \\
\hline Angular Wind-Up & $15^{\circ}$ & $15^{\circ}$ & $7^{\circ}$ & $3^{\circ}$ \\
\hline Misalignment & $1^{\circ}$ & $1^{\circ}$ & $1 / 4^{\circ}$ & $1 / 4^{\circ}$ \\
\hline Maximum Temp (F) & $275^{\circ}$ & $200^{\circ}$ & $250^{\circ}$ & $200^{\circ}$ \\
\hline Minimum Temp (F) & $-30^{\circ}$ & $0^{\circ}$ & $-65^{\circ}$ & $-80^{\circ}$ \\
\hline
\end{tabular}

Not every sleeve material is available at each coupler size. To fit the $23 / 8$ in. shaft of the motor, a minimum of a size 9 coupler is needed due to required bore size on the flanges [30]. For size 9 only EPDM, Neoprene, and Hytrel are available. At 1,750 RPM, a size 9 EPDM or Neoprene coupler is only rated for $50 \mathrm{HP}$, which is less than the motor before even considering the suggested service factor for an AC motor driven fan of 1.25. The Hytrel sleeve has four times the rated capacity at $200 \mathrm{HP}$, and provides less wind-up in the coupler, but does not allow as much flexibility in alignment quality [30].

The choice for coupler model was refined down to a choice of a size 10 EPDM or a size 9 Hytrel. The EPDM unit allows 0.025 in. parallel alignment error, a power rating of $80 \mathrm{HP}$ at $1,750 \mathrm{RPM}$, and a full torque win-up of $15^{\circ}$. The size 9 Hytrel unit is capable of only 0.017 in. in alignment error. However, it has a $2.5 \mathrm{X}$ higher torque capability, and only $7^{\circ}$ wind-up at full torque, resulting in less than $20 \%$ of the wind up at same capacity compared to the EPDM unit [30]. The deciding factors for final selection ended up being the reduced wind-up and smaller size of the Hytrel unit, so it was selected for usage. 


\subsubsection{Dimension Selections}

The keyway to be used on the drive shaft is the same width as the keyway in the motor, $5 / 8$ in. This is the standard key width for this shaft diameter and typically is used with a key thickness of $7 / 16$ in. [31] A combination of standard tables and Sure-Flex documentation was used to determine the keyway depth and tolerances (see Figure 3.4) [30] [31]. The Sure-Flex flange is $213 / 32$ in. deep [30], thus the shaft keyway is defined to be $2 \frac{1}{2}$ in. long. Additional space after the keyway is left before transitioning the shaft to $65 \mathrm{~mm}$ diameter, because it is known that the keyway will be end-milled and thus the additional space will be needed. The recommend tolerance for the shaft diameter can be found in the coupler specifications [30]. However, as the shaft had not yet been ordered, the flange for attachment to the shaft was sent to The Adams Company prior to shaft manufacturing. It was requested that the shaft be a very tight clearance fit of less than 0.001 in. for minimal slop.

The shear stress in a key transmitting torque is given by:

$$
\sigma=\frac{Q}{r} \cdot \frac{1}{A}
$$

which for a torque of $Q=179 \mathrm{ft} \cdot \mathrm{lb}$, a shaft diameter of $2 \cdot r=23 / 8$ in. diameter, and a key of 5/8 in. by 2 in. dimension gives a shear stress of $1.5 \mathrm{ksi}(10 \mathrm{MPa})$. This is an order of magnitude less than what mild steel is capable of, so any key of practical length will suffice. The key does not need to be sized to shear so as to protect the motor from an equipment jam. 


\subsection{Bearings}

\subsubsection{Bearing Selection and Evaluation}

The bearings selected for the drive shaft required a bore of $65 \mathrm{~mm}$. This was a geometric constraint, as it is the next bore size down from the maximum shaft diameter needed of $70 \mathrm{~mm}$. The bearing type selected was single row deep groove ball bearings. They are designed for high radial loads with high rotational speed. They are the default choice for bearing applications and are excellent for applications with minimal bending moment and low axial thrust compared to radial load rating. This falls in line with the expected loads from the whirl tower.

Bearings are not rated for their maximum capacity, but are instead given a dynamic load rating which is their equivalent dynamic load capacity for a 1 million rotation life span [32]. Since the maximum rotor imbalance is expected to be approximately $15.5 \mathrm{kN}$, and the top bearing is predicted to experience twice that radial load, the selected bearing is the SKF $6013-2 \mathrm{RS} 1$. It is a sealed grease bearing (low maintenance for lubrication) with a dynamic load rating of $31.9 \mathrm{kN}$, giving it a predicted rotational life of 1 million revolutions while under failed rotor conditions (over 10 hours at 1,550 RPM). The unit has an external diameter of $100 \mathrm{~mm}$ and a thickness of $18 \mathrm{~mm}$ [33]. The product data sheet is shown in Figure 3.7. The equation for predicted life span at loads other than the dynamic load rating is [32]:

$$
L_{10}=\left(\frac{C}{C_{e}}\right)^{3}
$$


Where $C$ is the dynamic load rating, $C_{e}$ is the dynamic equivalent load, and $L_{10}$ is the life in millions of revolutions. This means that if the bearing were to operate at constant dynamic equivalent load of twice its capacity, it would still provide a life span of 125,000 revolutions. There is a more comprehensive version of the life-rating equation available that accounts for factors such as lubrication type, contamination, temperature, and other factors, but the basic life-rating method is sufficient to indicate that the bearings will be able to survive multiple rotor failures without damage.

\section{Deep groove ball bearings, single row, seal on both sides}

\begin{tabular}{|c|c|c|c|c|c|c|c|c|c|}
\hline Princi & al din & tons & $\begin{array}{l}\text { Basic loa } \\
\text { dynamic } \\
\text { C }\end{array}$ & $\begin{array}{l}\text { statuc } \\
\mathrm{C}_{0}\end{array}$ & $\begin{array}{l}\text { Fatigue } \\
\text { load } \\
\text { limit } \\
P_{u}\end{array}$ & $\begin{array}{l}\text { Speed ratings } \\
\text { Reference } \\
\text { speed }\end{array}$ & $\begin{array}{l}\text { Liming } \\
\text { speed }\end{array}$ & Mass & - SKF Explorer bearing \\
\hline $\mathrm{mm}$ & & & $\overline{k N}$ & & $\overline{k N}$ & stmun & & kg & - \\
\hline 65 & 100 & 18 & 31,9 & 25 & 106 & - & 4000 & 0,44 & $6013-2 R S 1 *$ \\
\hline
\end{tabular}
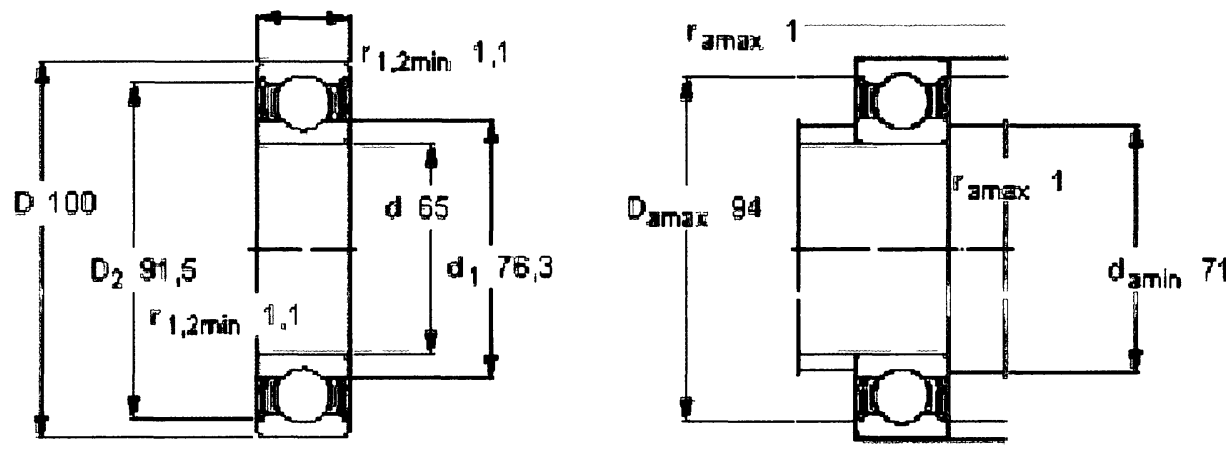

\section{Calculation factors} $k, 0,025$ $f_{0} 16$

Figure 3.7: SKF 6013-2RS1 data sheet [33].

Besides the load from rotor imbalance, there are axıal loads from rotor generated thrust. As seen in Table 2.5, the maximum thrust expected when operating with a $60 \mathrm{HP}$ 
motor is $2.5 \mathrm{kN}$. This value needs to be translated into an equivalent dynamic load by the equation [32]:

$$
C_{e}=X \cdot F_{r}+Y \cdot F_{a}
$$

Where $F_{r}$ and $F_{a}$ are the radial and axial loads, and $X$ and $Y$ are coefficients. For operation with negligible imbalance and $2.5 \mathrm{kN}$ thrust, the coefficients are $X=0.56$ and $Y=1.41$, resulting in an equivalent dynamic load of $3.5 \mathrm{kN}$. By using the bearing life equation, the units should have a life span of 750 million revolutions of normal operation, which is expected to be longer than the operational life of the facility.

\subsubsection{Bearing Fit Tolerance}

The bearings purchased are not enclosed within a bearing housing. Units were available in standard housings, but they did not fit with the desired usage on the whirl tower. Instead, custom bearing housings were constructed out of 1 inch thick steel plate. The top bearing housing is removable from the tower to allow maintenance of the bearings, drive shaft, slip rings, motor coupler etc. By having the bottom bearing use a very tight clearance fit onto the drive shaft, but having the top bearing use an interference fit, it will be possible to disassemble the whirl tower by removing the top bearing housing with the drive shaft, slip rings, wiring, and rotor all included (see Figure 3.8).

The top bearing is expected to experience twice the maximum load of the bottom bearing during rotor failures, and due to the load being dynamic with respect with the bearing housing (due to the loads rotation), it will be necessary to press fit the top bearing onto both the shaft and the bearing housing to maximize its life. The bottom bearing will 
experience half the maximum load and will only be press fit into the housing, which is the suggested method due to the load being dynamic with respect to the housing [33].

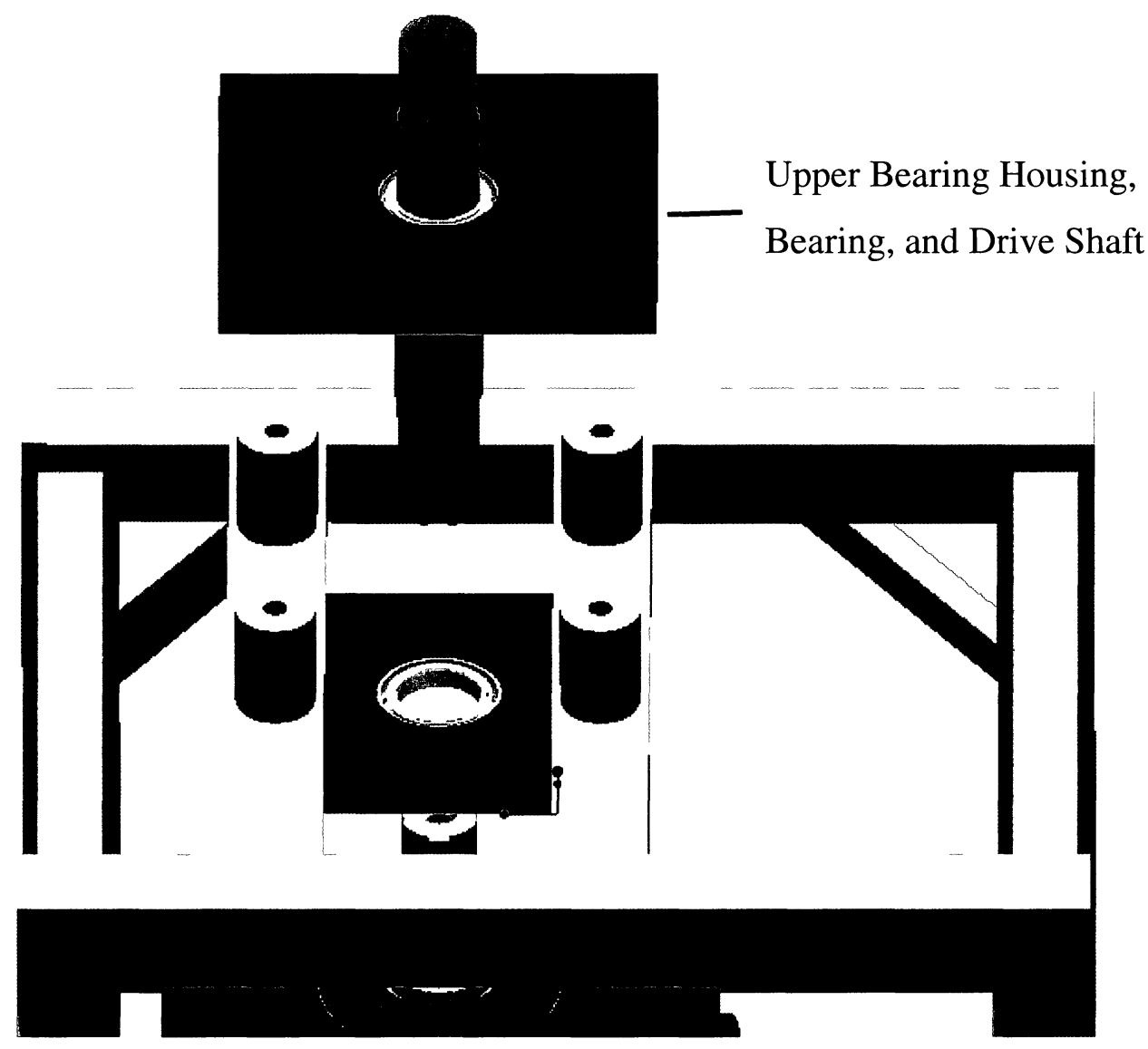

Figure 3.8: Upper bearing housing with drive shaft removed from tower.

The top bearing is a light interference fit and the bottom bearing is a light clearance fit. Both bearings will use a moderate interference fit on the housing. The shaft tolerance for the top bearing is +12 to $-7 \mu \mathrm{m}(+0.0005$ to -0.0003 in.). The shaft tolerance for the bottom bearing is +0 to $-19 \mu \mathrm{m}(+0.0000$ to $-0.0008 \mathrm{in}$.). The housing tolerance for both bearings is -10 to $-45 \mu \mathrm{m}(-0.0004$ to -0.0018 in.) [33]. In preference 
to obtaining the tightest clearance fit possible for the bottom bearing, the bearing was sent to the shaft manufacturer before fabrication so that it could be precisely measured and the shaft ground to size. The fit received was impressive, with a clearance on the order of 0.0001 in. with no perceivable slop between the parts.

\subsubsection{Bearing Housing Design}

As stated earlier, a 1 in. steel plate is the basis for the bearing housings. The bearings are $18 \mathrm{~mm}(0.71 \mathrm{in}$.$) thick and require a shoulder in the housing to constrain the bearing$ from 'popping out' due to axial loads. The shoulder used is approximately $3 \mathrm{~mm}(0.1 \mathrm{in}$. in size both axially and radially. It is located on the opposite side of the bearing from the shoulder on the shaft so as to fully constrain it. The bottom bearing housing is approximately 12 in. $x 10$ in. and the top 13 in. $x 12$ in. The difference is due to the difference in mounting where the top housing requires bolting and the bottom housing requires welding.

The top bearing housing needs to be removable and thus is bolted to the tower using 4 bolts. The bolts selected are Grade $8,3 / 4$ in. -16 thread. Grade 8 bolts have a rated UTS of $150 \mathrm{ksi}(1.03 \mathrm{GPa})$ [34]. The bolt has a tensile area of $0.351 \mathrm{in}^{2}$, resulting in an ultimate tensile strength of $52,600 \mathrm{lbf}(234 \mathrm{kN})$. This was chosen to be well in excess of the rotor imbalance force so that the bolt could be pre-loaded to a sufficient clamping force that the shear due to bearing forces could be transmitted through clamp friction, rather than shear through the bolt area [35]. 
The practice of pre-loading bolts serves multiple purposes. If a bolt is pre-loaded to a higher tension than the maximum tension pulling the parts it clamps apart, then the bolt will not experience any fatigue. The bolt will always stay loaded to its pre-load value and only the clamping force between the parts will change. This clamping force also serves to transmit shear between the parts through friction if the bolt is in a clearance hole [35]. The shear force that can be transmitted through friction by using bolt pre-load is (see Figure 3.9):

$$
F_{s}=F_{c} \cdot k \text { where } \quad F_{c}=F_{p}-F_{t}
$$

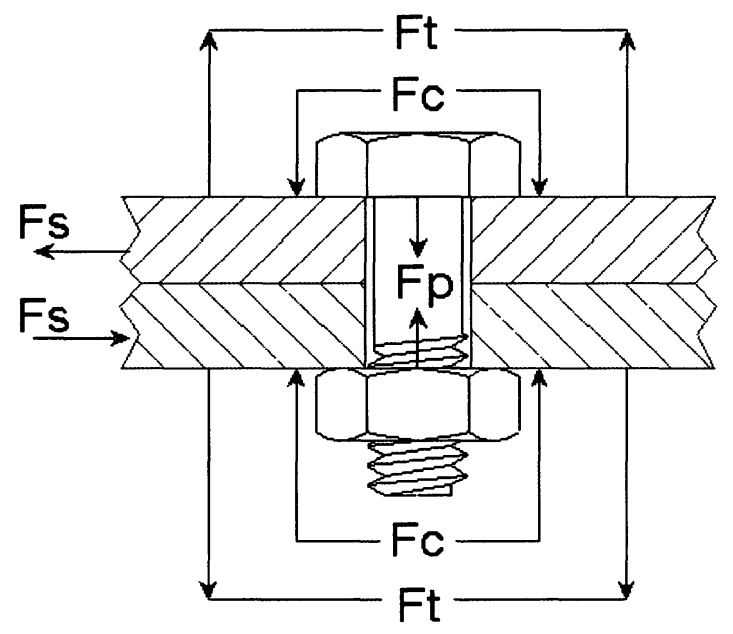

$\mathrm{Fp}=$ Preload Force

$\mathrm{FC}=$ Clamping Force

$\mathrm{Fs}=$ Shear Force

$\mathrm{Ft}=$ Tension Force

Figure 3.9: Forces in a preloaded bolt system [35].

For steel-on-steel interfaces, the static friction coefficient, $k$, is approximately 0.7

[36]. The bolt pre-load is a function of the bolts tightening torque through the equation:

$$
T=F_{p}\left(\frac{\text { Pitch }}{2 \pi}+\frac{D_{b} \mu_{k}}{2 \cos \theta}+\frac{D_{n} \mu k}{2}\right)
$$


The above equation incorporates values such as thread pitch, thread angle, bolt head size, and nut head size [37]. This equation is rarely used because common bolt tightening techniques, such as a torque wrench, do not provide an accuracy better than $+/-$ $25 \%$, thus allowing the use of a simplified equation:

$$
T=k \cdot F_{p} \cdot d
$$

where for lubricated bolts $k$ is approximately 0.15 [37]. The suggested pre-load for most bolts in $75 \%$ of capacity. For 3/4-16 oil-lubricated bolts this is a torque of approximately $320 \mathrm{ft} \cdot \mathrm{lb}$ [38]. The torque wrench available is limited to $200 \mathrm{ft} \cdot 1 \mathrm{~b}$, which with the $+/-$ $25 \%$ error in torque wrench tightening will provide a high pre-load without risking bolt overload. At $200 \mathrm{ft} \cdot \mathrm{lb}$, the simplified bolt torque equation predicts a pre-load of 12,000 pound force $(53 \mathrm{kN})$. Since this value is per bolt, and with an expected friction coefficient of 0.7 , this will be sufficient to prevent movement of the top bearing housing relative to the frame.

With the predicted tension in the bolt known, it is necessary to verify the strength of the threaded connection being used. The limit of a threaded connection is the shear strength of the threads of the weakest material. The equation for shear area of threaded connections is [39]:

$$
A_{s}=L_{e} * 0.5 \pi(D-0.64952 \cdot \text { pitch })
$$

where $L_{e}$ is the thread engagement length, which for this application is approximately 2 inches. The resulting shear area is $2.23 \mathrm{in}^{2}$. The shear yield strength of 1020 steel is approximately $58 \%$ of its tensile yield strength of $48 \mathrm{ksi}$ (330 MPa) [31]. This gives a value of $28 \mathrm{ksi}(192 \mathrm{MPa}$ ), which when multiplied by the shear area gives a 
capacity of $62,000 \mathrm{lbf}(276 \mathrm{kN})$. This is greater than the capacity of the bolt, which confirms the thread strength. This verification was performed as grade 8 bolts usually come with grade 8 nuts of sufficient strength. In the planned application, the bolt is threaded into mild steel of much lower strength and thus the calculations were performed.

\subsubsection{Bearing Housing Manufacturing}

Both bearing housings were manufactured at the Carleton University Mechanical \& Aerospace machine shop. A partial sheet of mild steel was purchased locally and cut to dimension using a horizontal band saw. The housings were manufactured entirely in a lathe. They were loaded into a 4 jaw chuck and faced by removing approximately 0.020 in. on the side they would be mounted to the tower. This was done to ensure the bearing cavities would be perfectly square to the mounting face for proper bearing alignment. Progressively larger drills were used to create a bore hole that could eventually fit a boring bar. The boring bar was used to machine the housing to the necessary internal dimensions and tolerance. The housings were then flipped and the steel scale removed on the other side. The housing that required bolt holes was drilled with $25 / 32$ in. holes on an end mill for accurate hole placement. Figure 3.10 depicts the design of the top bearing housing. 

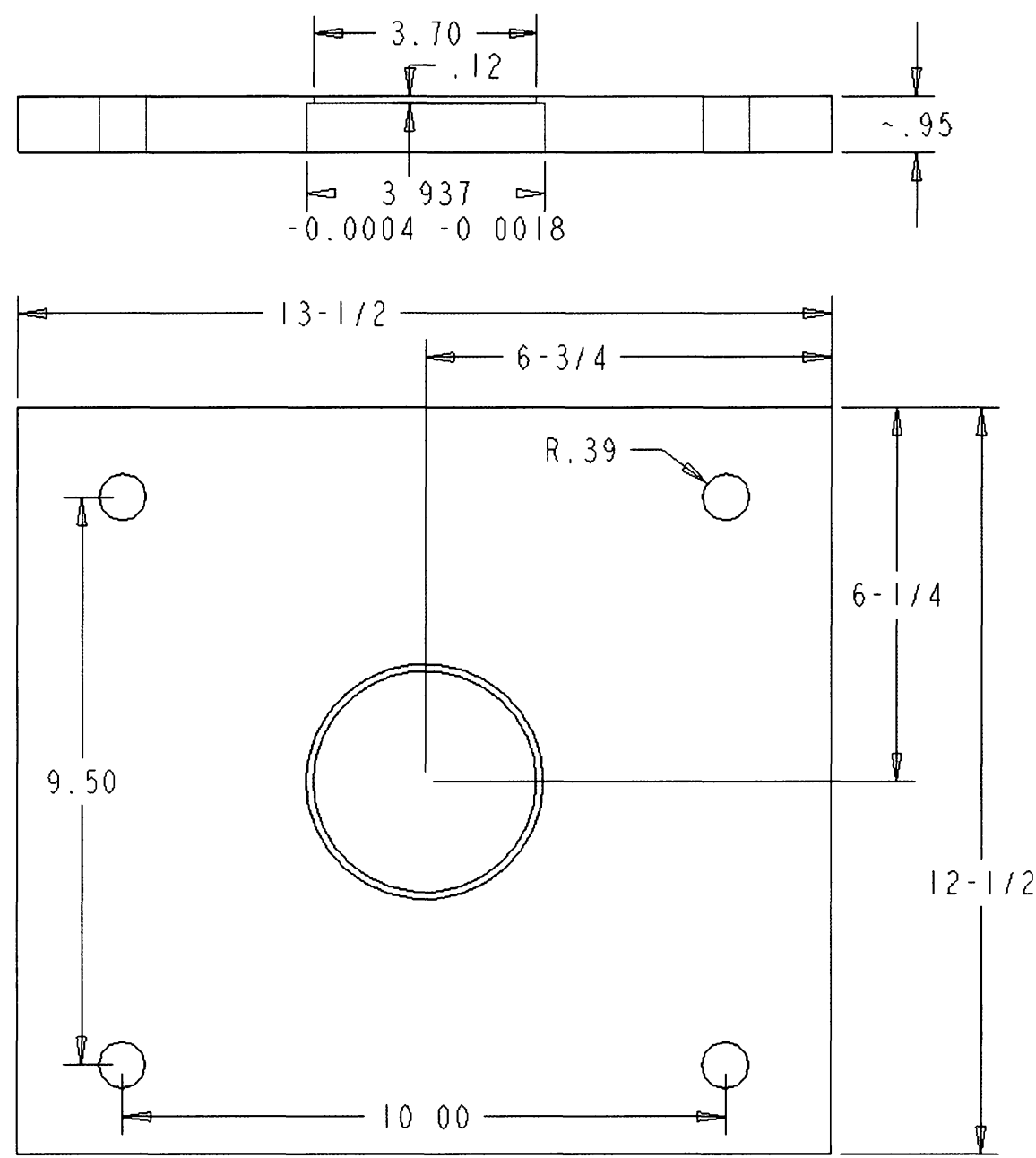

Figure 3.10: Top bearing housing design.

Once completed, the bearings were pressed into the housing using an arbour press. When pressing bearings, it is necessary to load the side of the bearing rings that is being fit. For example, press on the outside bearing ring when pressing into a housing, and the inside ring when pressing on a shaft. This is done to prevent loading through the bearing races and subsequent damage to the bearing. For this purpose, custom parts were made from shop scrap. Also created were two aluminum plugs, one the same outer 
dimension of the bearings and one the inner race dimension. When used with an armature and threaded rod, these plugs can be used to push bearings in or out of their housings when on site. The larger plug can also be installed in place of a bearing and thus protect the bearing housing when the frame is sent out for sand blasting and paint.

\subsection{Hub Design}

The hub's attachment to the shaft required a lot of consideration. Many options were available, but one with low slop and excellent strength was needed. It would not be possible to alter or even drill the shaft once received so it was necessary to design a connection that could be entirely accommodated when manufacturing the hub. This meant interfaces such as shear pins through the shaft were not possible as they would not be perfectly tight unless the entire hole, including through the shaft, was drilled at the same time.

The goal for the hub was to have it both axially and rotationally constrained. The final design as developed consisted of two independent hub pieces, one constrained in each axis, which were to be fastened together.

\subsubsection{Lower Hub}

The lower hub is the rotationally constrained component. It transfers torque from the drive shaft into the upper hub, which drives the blades. This torque transfer is achieved through a keyway of the same design as the one used on the drive shaft's other end (5/8 in. key, same tolerances). This keyway is broached through the entire lower hub by using a keyway broach. The hub also has a shoulder on it, which sits on a shoulder on 
the shaft. This shoulder transitions from the bearing diameter of $65 \mathrm{~mm}$ to the next lowest imperial diameter, which could be used for threads on the shaft, $23 / 8 \mathrm{in}$. This shoulder has a step size of $4.7 \mathrm{~mm}$ (0.18 in.), which will be used to squeeze the lower hub when the upper hub is torque down on it.

The hub is manufactured from a 4 in. solid round of free machining 12L14 steel. This steel contains finely dispersed lead to make it easier to machine, resulting in a machinability rating of $190 \%$ compared to 1112 steel [40]. It has a yield strength of 60 ksi (415 MPa) and an ultimate strength of $78 \mathrm{ksi}$ (540 MPa) [40][41]. By using a 4 in. round the hub has ample wall thickness to transmit the required torque. Also included on the lower hub is a skirt, which covers the exposed drive shaft above the top bearing. This is not for shaft protection, but to provide a drillable surface to mount attachment points for the pitch link. It would not be possible to make these attachments directly to the shaft as the shaft is case-hardened, and the alterations would severely weaken the shaft.

The lower hub was manufactured in the Carleton University Mechanical \& Aerospace machine shop. Using a lathe, all the outer surfaces were resurfaced to square and balance the hub. The bore was first drilled and then a boring bar used to enlarge it to final size. The outer diameter was then reduced to create the skirt on the bottom. A brass plug was created to match the bore diameter, and then this plug was end milled with a slot for the width of the broaching tool. The plug was used to align the broach when creating the keyway using the arbour press. The broaching was successful, but in the future when another hub is required, then a hydraulic press is recommended, as two 
grown men were hanging off the arbour press handle to get the tool to cut through the part.

The lower hub, including its interface to the upper hub which will be explained in the following section, is shown below in Figure 3.11. The lower hub installed on the drive shaft and awaiting the upper hub is shown in Figure 3.12.
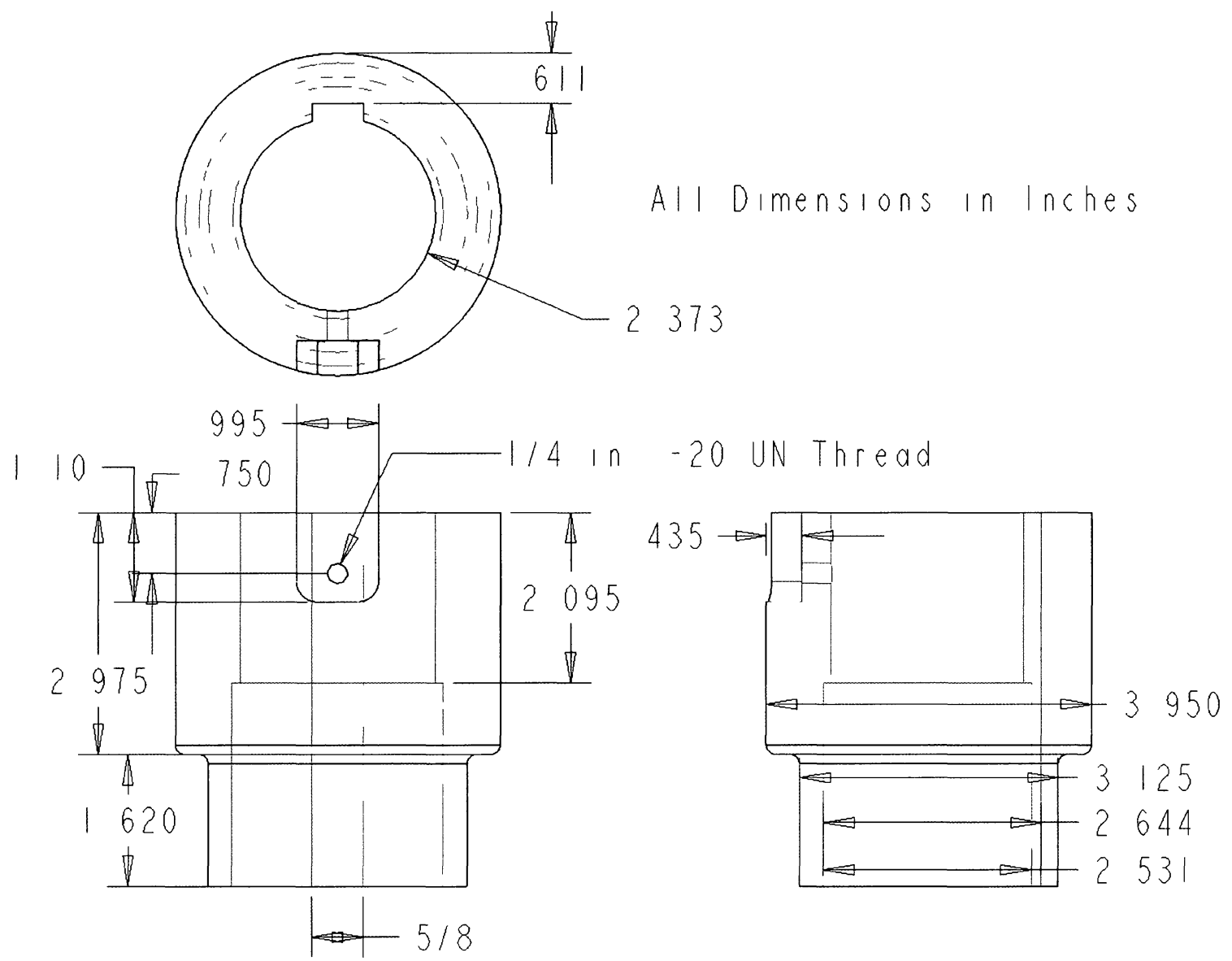

Figure 3.11: Lower hub design, manufactured part dimensions in inches. 


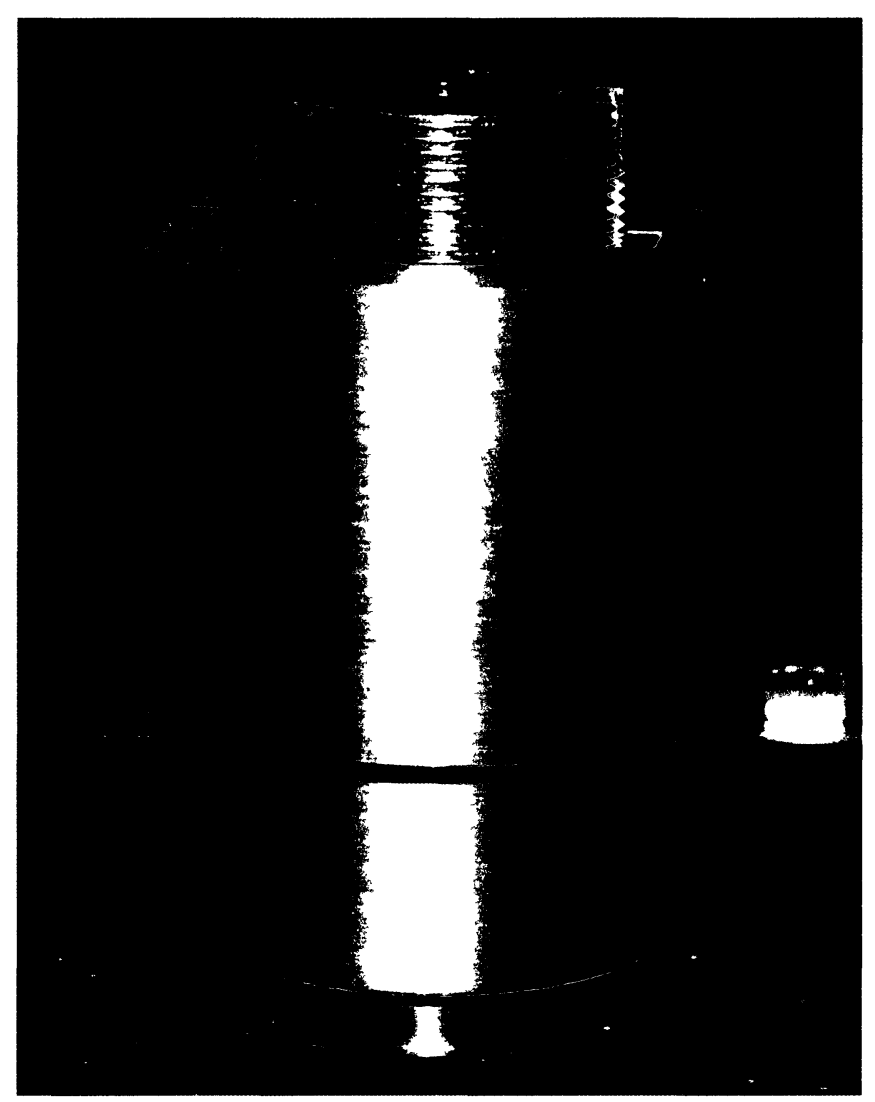

Figure 3.12: Lower hub installed on drive shaft.

\subsubsection{Upper Hub}

The upper hub is the axially constrained part of the interface. This is done with a $23 / 8-12$ thread machined into the end of the shaft, effectively making the upper hub a giant cap-nut. The upper hub is hand-torqued onto the shaft until it presses against the lower hub. The lower hub is resting on a shoulder on the shaft to resist the load as the upper hub is tightened. Once the two shafts are fastened together, the upper hub will take all the bending moment and axial load through its threaded connection, while the lower hub will transfer the torque between the upper hub and the shaft so that the upper 
hub cannot unthread when loads reverse. The upper hub has a $1 / 2 \mathrm{in}$. bore to run wiring from the shaft bore out the top and into the telemetry dome installed on top of the hub. The basic geometry of the upper hub was manufactured entirely by lathing, similar to the lower hub. The inner thread was created using a Computer Numerical Control (CNC) lathe as the specified thread required stopping at a specific depth with consistency. The hub uses threaded cross holes to attach what will eventually be the blade attachment mechanisms. These were end-milled and tapped by hand. The upper hub, including its interface to the lower hub and blade attachment mechanisms, each of which will be explained later, is shown below in Figure 3.13.

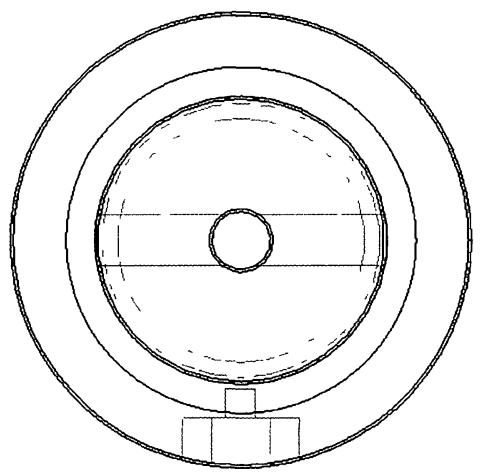

Al| Dimensions in Inches
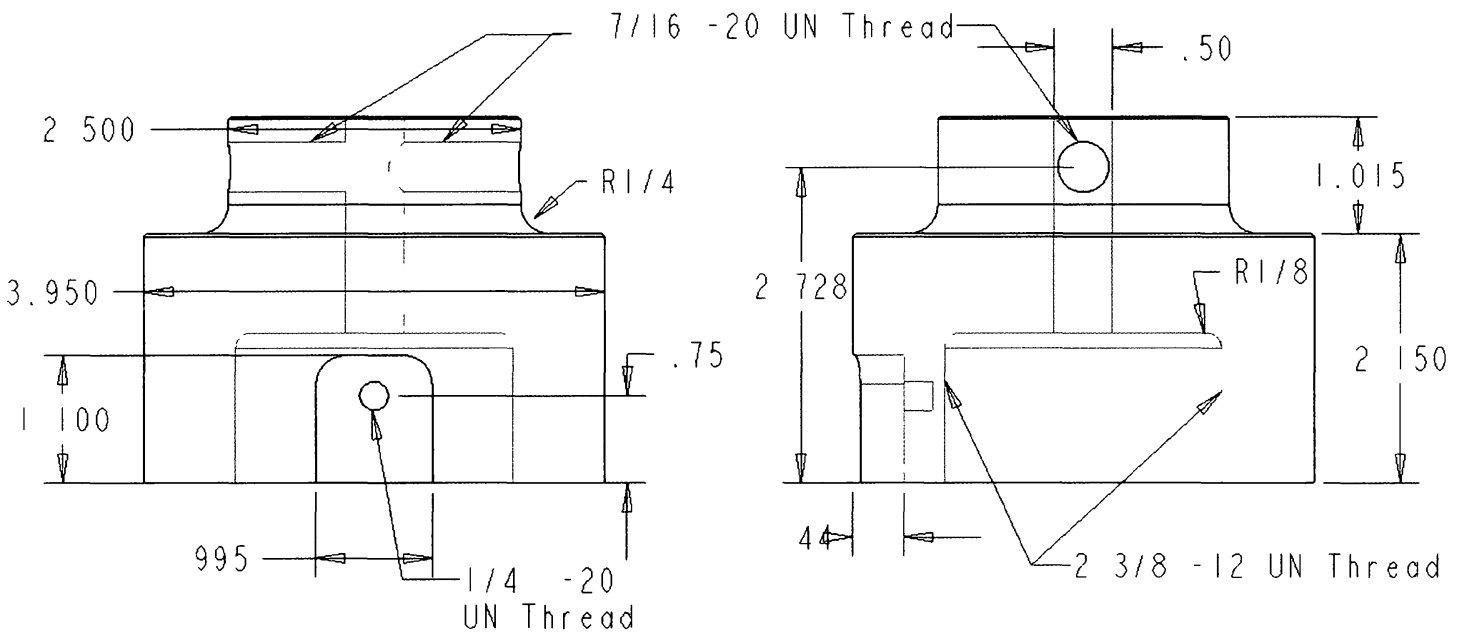

Figure 3.13: Upper hub design, manufactured part dimensions in inches. 
The primary strength concern with the upper hub is its ability to withstand the moment produced by a rotor imbalance. There are two potential load paths, one through the lower hub and into the shoulder on the shaft. This load path is only compressive though, so it will be ignored in preference of depending on the other load path, the threads with the shaft. The approach taken is to derive the equivalent second moment of area consisting of the shear area through the threads, using the fundamental equation:

$$
I_{y}=\int_{A} z^{2} d A
$$

The principal difference is that instead of $d A$ being a tensile area, it is rather the shear area though the threads, given by $0.5 \cdot L_{e} \cdot r d \theta$. The solution is as follows.

$$
\begin{gathered}
I_{y}=\int_{0}^{2 \pi}(r \cdot \sin (\theta))^{2} \cdot\left(0.5 \cdot L_{e} \cdot r\right) d \theta \\
I_{y}=\frac{1}{2} \mathrm{r}^{3} L_{e} \int_{0}^{2 \pi} \sin ^{2} \theta d \theta \\
I_{y}=\left.\frac{1}{2} \mathrm{r}^{3} L_{e}\left(\frac{1}{2}\left(\theta-\frac{\sin (2 \theta)}{2}\right)\right)\right|_{0} ^{2 \pi} \\
I_{y}=\frac{1}{4} \mathrm{r}^{3} L_{e} *((2 \pi)-(0)) \\
I_{y}=\frac{1}{2} \mathrm{r}^{3} L_{e} \pi
\end{gathered}
$$

$r$ can be found from the bolt thread engagement equations:

$$
\begin{gathered}
r=0.5(D-0.64952 \cdot \text { pitch }) \\
r=1.16 \text { inches }
\end{gathered}
$$


The thread engagement length is assumed to be 11 of the 12 threads on the shaft, giving:

$$
\begin{aligned}
L_{e} & =0.917 \text { inches } \\
\therefore I_{y} & =2.25 \text { inches }^{4}
\end{aligned}
$$

This value is then used in the equation:

$$
\sigma=\frac{M \cdot y}{I}
$$

in which $r$ can be used as a substitute to approximate $y$, but the more accurate value is:

$$
y=\sqrt{r^{2}+\left(\frac{L_{e}}{2}\right)^{2}}
$$

This solves for the vector distance from the center of plane at the midpoint of the thread engagement to the farthest thread. The result is 1.25 in., only $8 \%$ higher than the approximation of $y=r$. The moment $M$ is the product of $15,500 \mathrm{~N}$ (3480 lbf) and the moment arm from the lowest thread to the rotor plane of 2.728 in. (see Figure 3.12 ).

Final value of maximum shear stress calculated is $5.28 \mathrm{ksi}(36.4 \mathrm{MPa})$. The predicted shear strength of $12 \mathrm{~L} 14$ steel is $58 \%$ of its yield strength of $60 \mathrm{ksi}$, a value of $34.8 \mathrm{ksi}(240 \mathrm{MPa})$. This means that the safety factor for the rotor connection is 6.6. This indicates that the hub connection will not be the limiting factor in maximum allowable rotor imbalance, as the bending strength of the drive shaft is weaker than the hub connection. 


\subsubsection{Hub Fastening and Torque Transmission}

Many attachment mechanisms were investigated to attach the upper and lower hubs together and transmit torque between them. The first possibility was a pair of bolting flanges, but it was realized these would interfere with the location of the pitch links. This was considered avoidable by using lobed flanges, which had space for pitch links to pass, but this later was realized to potentially cause damage to the hub during installation. The flanges would need to be welded to each hub, since starting with an 8 inch diameter steel round and machining it down to size is impractical. This weld would heat the parts substantially, causing warping, and would damage any machining done to them, such as threads. Welding the flanges on before machining could not be done, as then there would be no way to ensure alignment of the flanges. Complicated methods of getting around this were considered, but instead a much cleaner-looking concept was pursued. Eventually a system using an external key and key slot was developed to transmit the torque.

The key slots can already be seen in Figures 3.10 and 3.12. They were created by assembling the entire rotor hub onto the drive shaft, and then loading the whole assembly into an end mill. The end mill was used to plunge cut a slot of 1 inch width, 2.2 inch length, and approximately 7/16 inch depth into the outside of the two hubs. After producing the slot, a piece of medium carbon steel was fabricated into a precise and snug fitting key. The key needed to be secured into the key slot since rotational force and the torque transmitted could force or pinch the key out and thus let the upper hub unthread from the shaft. To do this, 1/4 in. bolts were put through countersunk clearance holes in 
the key and threaded into holes in the base material of the two hub halves. The clearance holes in the key were tapped with $3 / 8$ in. threads so that to remove the key the $1 / 4$ in. bolts are removed and 3/8 in. ones are threaded in to push on the bottom of the key slot and push the key out. The finished key was installed in the completed hub with cap screws and the whole assembly then loaded into a lathe. The surface of both hubs, the key, and the cap screws was machined down to provide a single smooth, continuous surface with no discontinuities, resulting in a very elegant design. The final dimension of the external key can be seen in Figure 3.14, and the key installed in the key slot can be seen in Figure 3.15.

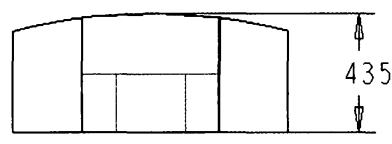

All Dimension in Inches

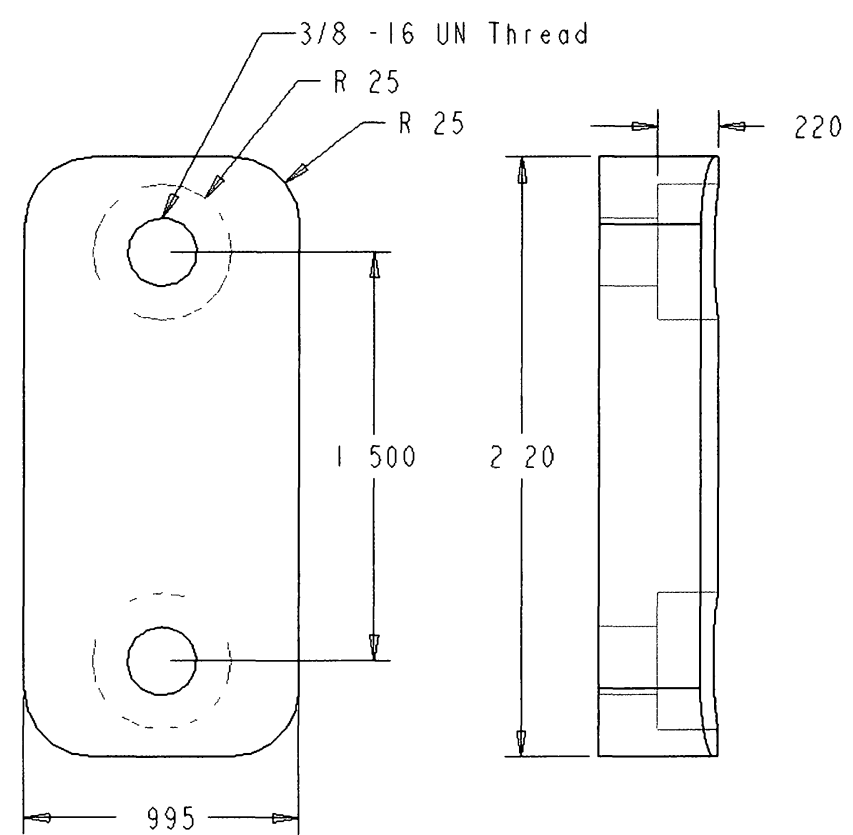

Figure 3.14: External key design with finished dimensions. 


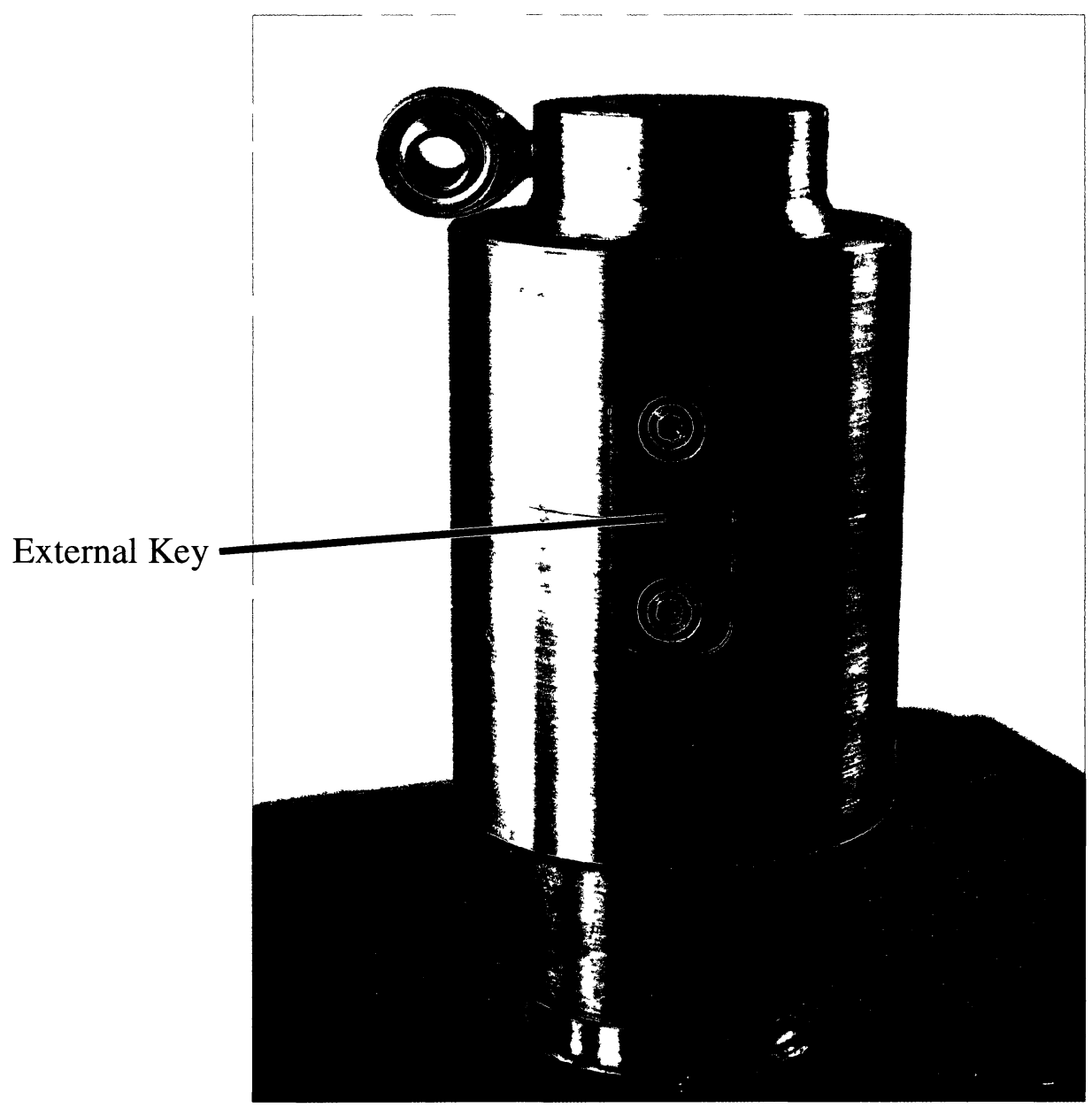

Figure 3.15: External key installed in position between the two hubs.

The key has a shear area of $0.412 \mathrm{in}^{2}$ and a mean radial distance of $1.758 \mathrm{in}$. This means that to transmit a full load torque of $179 \mathrm{ft} \cdot \mathrm{lb}$, the key will experience a shear stress of $3.0 \mathrm{ksi}(20 \mathrm{MPa})$. This is less than $10 \%$ of the shear strength of the steel used and will provide ample torque transmission between the two hub halves. 


\subsection{Blade Attachment Mechanism}

The rotor blades require a fully articulated attachment to the rotor hub. The motions required are blade flapping, lead-lag, and pitch. There are various methods to achieve these motions on production rotor hubs. Typically rotor hubs use three independent bearing systems for three fully independent motions. Some production helicopters such as the Agusta A109E use elastomeric bearings that flex to provide the necessary degrees of freedom [42]. Using three independent bearing systems is not possible for this facility, as it would require years of work to design and build such a rotor hub. Scaled, multibearing rotor hubs exist in some scaled-rotor wind tunnel facilities. In fact, the SHARCS rotor was designed to be used with one such hub owned by Agusta Westland, but for whirl tower tests a simpler system is sufficient. Elastomeric systems require substantial testing and experience with the material, so instead an even simpler connection is chosen.

The degrees of freedom will all be provided by a single, spherical, rod-end bearing. This bearing consists of a ball bearing with a bore, enclosed in a circular race, with a threaded rod used for attachment (see Figure 3.16). The bearing selected is from the high-strength, high-precision 'AM' series. The size selected is AM-7, which has a 7/16 in. bore and uses a 7/16-20 mounting thread. It has a rated radial capacity of 10,285 lbf $(45,750 \mathrm{~N})$, which is approximately 4 times the force needed for a SHARCS blade. The complete dimensions and tolerances are given in Table 3.2 below.

The bearing will be installed in the rotor hub with its circular race in the vertical plane. This will allow for unrestricted flapping motion, and up to $14^{\circ}$ of total lead-lag 
and pitch motion range. Thread lock compound and a set screw will be used to install the rod end so as to not have it unthread during operation.

Table 3.2: AuroraBearing AM-7 bearing dimensions (inches) [43], see Figure 3.15.

\begin{tabular}{|c|c|c|c|c|c|c|c|c|c|}
\hline $\mathrm{B}$ & $\mathrm{W}$ & $\mathrm{H}$ & $\mathrm{A}$ & $\mathrm{D}$ & Ball & $\mathrm{C}$ & $\mathrm{a}^{\circ}$ & Load & Weight \\
\hline 0.4375 & 0.562 & 0.437 & 2.125 & 1.125 & 0.812 & 1.375 & 14 & $10,285 \mathrm{lb}$ & $0.16 \mathrm{lb}$ \\
\pm 0.0015 & +0.000 & \pm 0.005 & \pm 0.010 & \pm 0.010 & & +0.062 & & & \\
& -0.005 & & & & & -0.031 & & & \\
\hline
\end{tabular}

FItting Optional
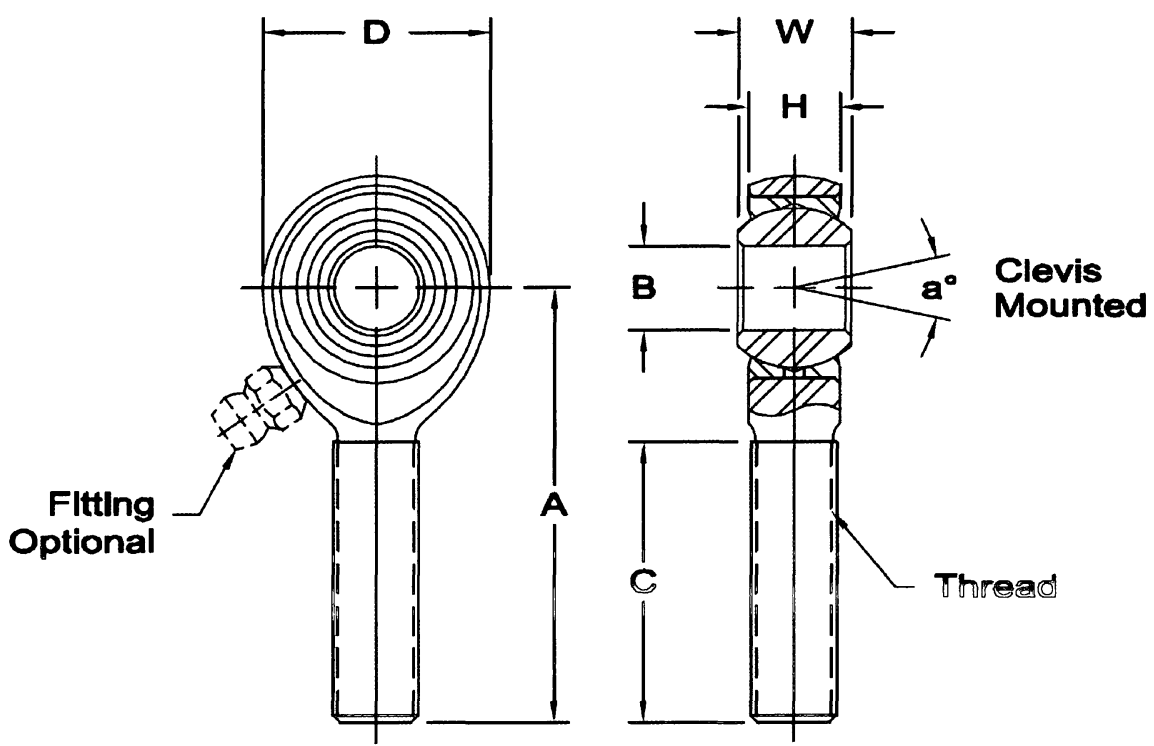

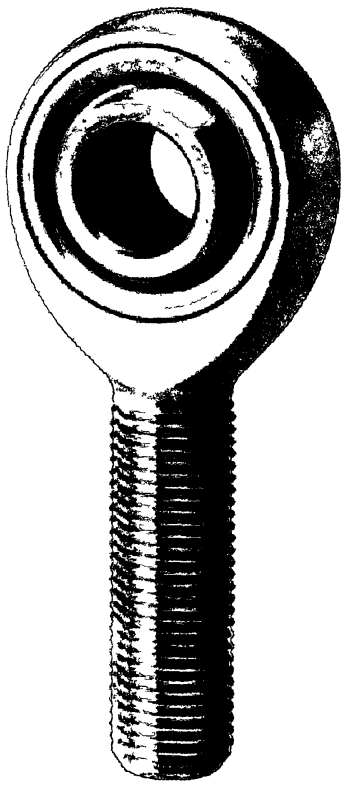

Figure 3.16: AuroraBearing AM series rod end [43].

\subsubsection{Design Work Remaining}

An interface component is required to connect the rotor blade to the rod end, as well as connect the lead-lag and pitch control mechanisms. Only the rod end and rotor blade attachment have currently been defined, with final selection of a lead lag damper, and 
completion of an Active Pitch Link still pending. Due to the number of interfaces this part requires, and that the interfacing mechanisms are each being produced by a different designer, it has not been possible to finalize this component yet. The currently known features are:

- A 7/16 in. clevis mount for the rod end connection

- A droop stop so the rotor does not sag when not in rotation

- A pitch horn of unknown moment arm and position to connect the APL

- An armature and connection point for an as yet unselected lead-lag damper, and

- Two 1/4 in. bolt holes at $126 \mathrm{~mm}$ radial location to attach the rotor blade. The blade thickness for attachment is $1 / 2$ in.

If this design of this component eventually produces a part with sufficient safety factor, and the part can be statically tested for strength, it may be possible to remove the mechanism's predicted centripetal force from the tower's load predictions as it will be possible to eliminate it as a failure point. This will allow the allotted force to be assigned to heavier rotor blades instead.

\subsection{Counterweight System}

In order to operate the whirl tower with a single rotor blade, a variable force counterweight system will be required. DLR uses a threaded rod with a heavy mass and jamb nuts to provide the counterweight needed. This method allows precise placement of the mass, but is time consuming to loosen and tighten the nuts for every adjustment when 
balancing. It also has an inherent risk in its design since, if retightening the nuts is ever forgotten, then the mass could potentially unthread from the rod and become a violent projectile. A system with less risk and greater ease of use was desired, preferably with a tool-less design.

The design developed uses a threaded rod of the same thread used in the rod ends, 7/16 in. -20 . This was done to be able to interchangeably install a rod end for a second blade, or the counterweight system. The threaded rod was end-milled with a very shallow slot of 0.13 in. width. This slot is to be used to catch a spring loaded pin embedded in the counterweight mass. The mass used is a steel round of $2.875 \mathrm{in}$. length and 2.413 in. diameter with a mass of $3.56 \mathrm{lb}(1,615 \mathrm{~g})$. The pin is primarily $1 / 8^{\text {th }}$ in. in diameter, but has a shoulder of $3 / 16^{\text {th }}$ in. The shoulder is used to press against a $3 / 16^{\text {th }}$ in. coiled spring, which is installed in the unit and constrained with a hollow $1 / 4 \mathrm{in}$. bolt. This bolt is threaded into the counterweight mass and allows the pin to protrude from the top so that the operator can pull the pin to disengage it from the channel in the threaded rod. The spring loaded pin is fail safe; no matter what state the counterweight is left in, when the pin passes over the channel in the threaded rod, it will engage and prevent the mass from further unthreading. It also achieves the other design goal of being entirely tool-less in operation. An exploded view of the counterweight system is shown in Figure 3.17, and a cross-section view in Figure 3.18. 


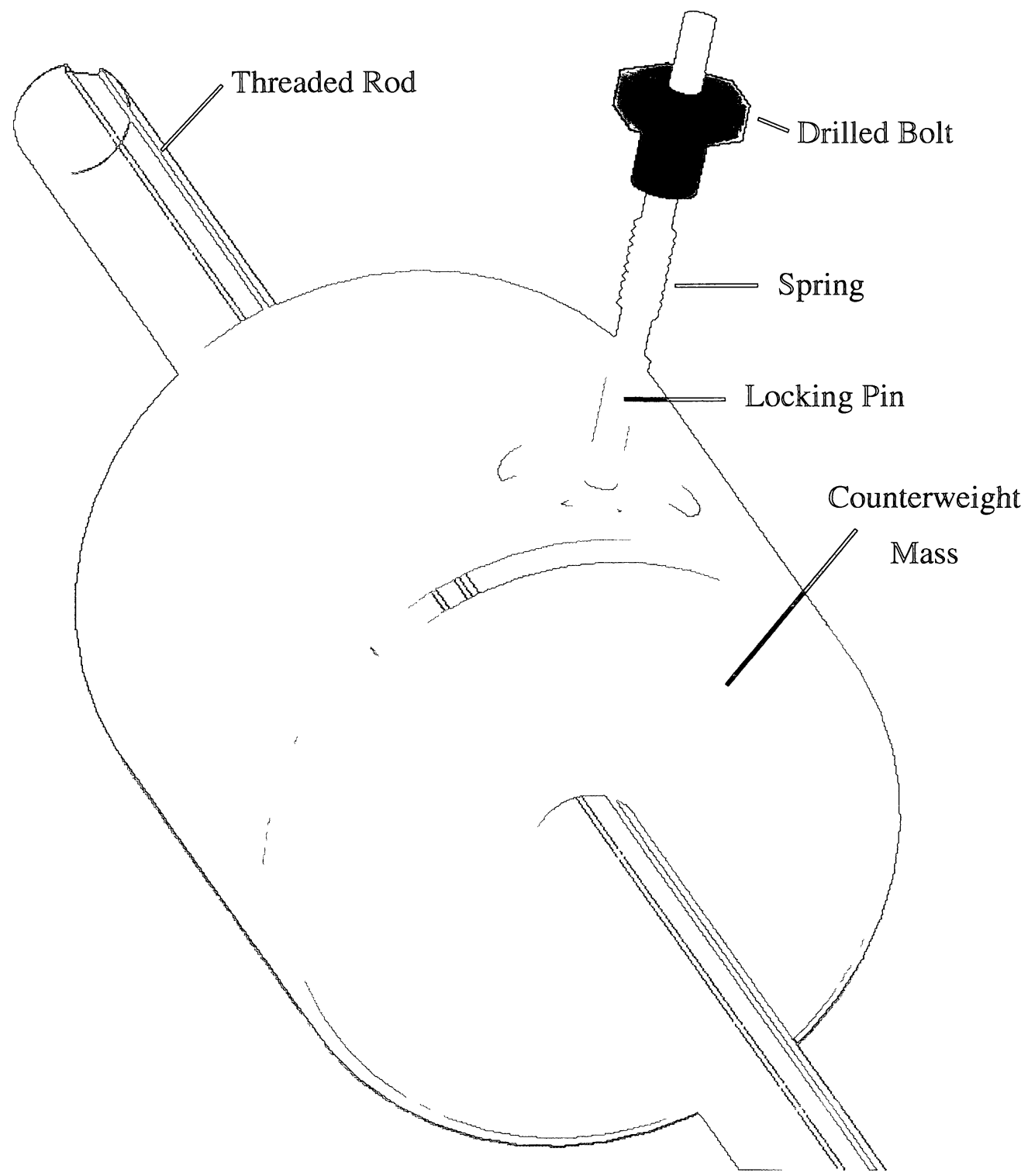

Fignure 3.17: Coumterweight mechæmism expldded view。 


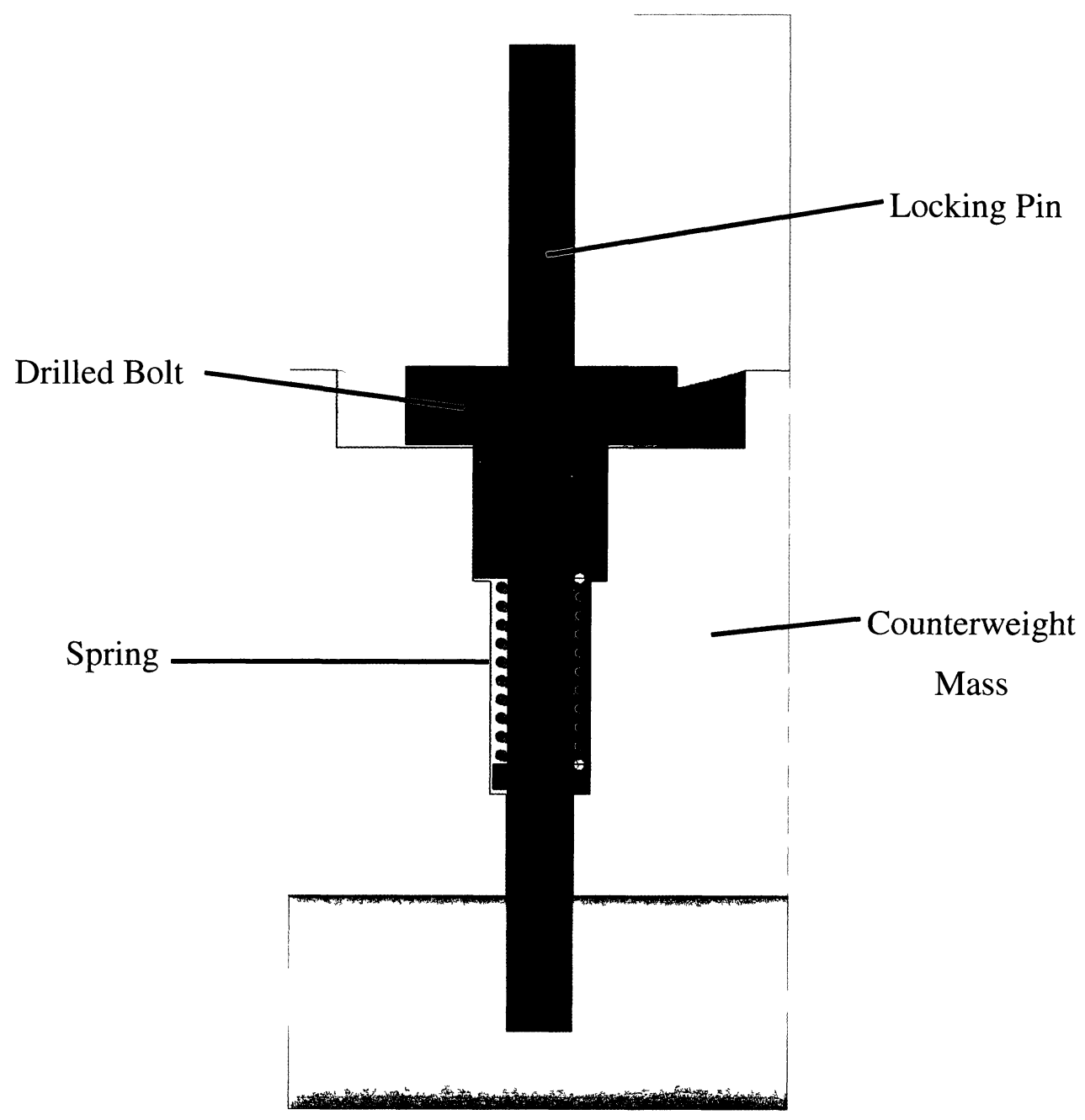

Figure 3.18: Counterweight locking mechanism cross-section view.

The rod used is B7 grade steel, which has an ultimate strength of $125 \mathrm{ksi}$ (862 MPa) [44]. 7-16 in. -20 thread fasteners have a tensile area of $0.1187 \mathrm{in}^{2}$ [31], giving an ultimate strength of $14,800 \mathrm{lbf}(60 \mathrm{kN})$, approximately five times the value expected from the SHARCS blade. The mass of the threaded rod is $0.591 \mathrm{lb}(268 \mathrm{~g})$ and the mass of the counterweight is $3.56 \mathrm{lb}(1,615 \mathrm{~g})$. The counterweight can be moved from a mean radial 
position of approximately 4 in. to $15 \mathrm{in}$. (100 to $380 \mathrm{~mm})$. The equation giving the balancing force of the counterweight system is:

$$
F=0.0590 \mathrm{~kg} \cdot \mathrm{m} * \omega^{2}+1.615 \mathrm{~kg} \cdot \bar{r} \cdot \omega^{2}
$$

For the SHARCS blade configuration, the force required is approximately $11 \mathrm{kN}$ and the angular velocity is 163 radians/s. This gives a mean radial distance for the counterweight of $22 \mathrm{~cm}(8.6$ in.), which happens to be half of the length of the threaded $\operatorname{rod}, 43 \mathrm{~cm}(17$ in.).

One potential failure mode of the threaded rod that is of concern is the bending moment experienced during high angular acceleration. The motor has substantial torque, and the drive system has quite low rotational inertia, so if the motor were to accelerate without a gentle velocity ramp profile, it would cause severe bending stress in the threaded rod. Neglecting the drive shaft and rotor's inertia, the motor by itself has rotational inertia of $0.945 \mathrm{~kg} \cdot \mathrm{m}^{2}$ [20]. With a motor torque of $243 \mathrm{~N} \cdot \mathrm{m}$ this would allow the motor to accelerate from stationary to $1,800 \mathrm{RPM}$ in $0.75 \mathrm{~s}$, a dangerous rate for both the blade and the counterweight system. For this reason, an acceleration profile of no more than $100 \mathrm{RPM} / \mathrm{s}$ is recommended as a safe rate, and will be programmed into the VFT's firmware. This limitation is also necessary due to the rotor blades having a leadlag axis, and rapid acceleration could overload the ability of the lead-lag damper to resist the blades 'lagging' during acceleration. 
The counterweight system is shown installed on the rotor hub in Figure 3.19.

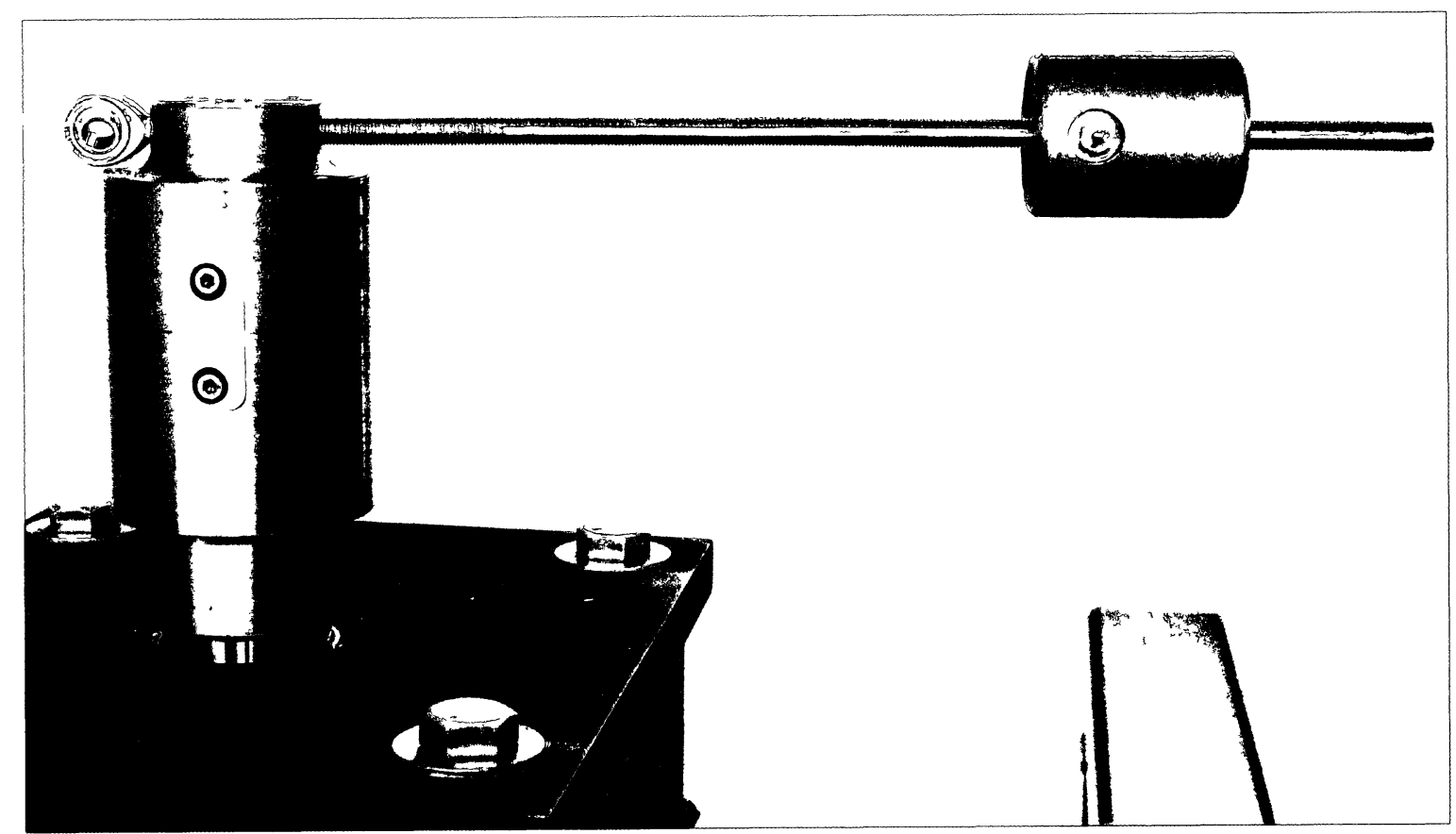

Figure 3.19: Counterweight mechanism installed on rotor hub. 


\section{Chapter 4: Frame Design}

\subsection{Frame History}

The frame of the whirl tower has been by far the most frequently changing component of the whole design process. The frame's role is to support and constrain all components and systems, therefore each time a component selection, dimension, or operational change is made, the frame must be adapted to accommodate it. Describing every individual design change the frame has experienced from day one would not be practical, but before describing the frame in its current version, some of the design decisions that happened along the way that affected the frame will be discussed.

\subsubsection{The First Concept}

The first frame concepts started by looking at configurations similar to that used by DLR (see Figure 1.2). The calculations for sizing the power plant were performed very early, and although the critical parameters were refined over time, the trend of larger rotors requiring more torque and less speed was immediately apparent. Given that the goals when starting the design process included capability for large multi-bladed rotors, the use of a transmission system was considered unavoidable. After the selection of the most appropriate transmission type and arriving at the same conclusion for a synchronous 
belt system as DLR did, the first frame designs looked very similar in layout to that of DLR's facility. The material planned for usage was primarily steel angle sections with bolted connections between them.

One of the early differences was that no concrete block was planned as a base. A lighter support structure was preferred instead, consisting of a steel frame connected to at most a few inches of concrete pad, but more likely a steel pan on which mass could be stacked if needed.

\subsubsection{Direct-Coupling}

When the change to direct-coupling was made, a completely new layout for the tower was needed too. The motor moved into what was referred to as the 'lower frame' consisting of a 4 legged frame with the motor enclosed in the center of it. The lower frame had a 1/4 in. steel sheet on its top side which allowed attachment of an upper frame containing the drive shaft and bearings. The plan was to make the upper frame removable from the lower one for maintenance and adjustment purposes.

\subsubsection{Fastener and Structural Section}

The first frame concepts used steel angle sections and bolts for fastening. The joints were to be overlapped and drilled in a regular method, which would create box-like frames. There were two reasons to start with such concept. They are:

- The strength of bolted connections is easily calculated. By using proper fastener installation, the total strength of the structure would be well characterized. 
- This researcher is inexperienced in welding. Welding is a process where the quality of the results is directly affected by the skill of the fabricator. By avoiding welds, the uncertainty in this author's ability to create them would be avoided as well.

These choices persisted until the time to came calculate the strength required and provided by the frame. The loads being predicted were substantial and it was realized that choosing the strongest structural section and fastening technique possible would be advantageous. This meant transitioning to Hollow Structural Sections (HSS), i.e. square tubes, and using full welds to connect them. The only way this could be done reliably was to hire a certified and skilled welder to make the connections. Glen Grant from the Science and Technology Centre at Carleton University was identified for this job.

\subsubsection{Floor Span}

After freezing the design of the whirl tower and beginning fabrication, a meeting was held with NRC to discuss the details and timeline of its installation. During this meeting, the intention to bolt the tower to the floor was brought up; this was not thought to be a problem as we had visited the facility before and seen another such installations bolted there. However, NRC representatives advised that the floor would not be of sufficient strength, as it is only 3-4 inches thick and lacked rebar reinforcement. They advised that the tower should be bolted to the center of the floor support columns underneath the floor, which have a 58 in. span (see ahead to Figure 7.1 and Section 7.1 for more information on the floor fastening and dimensions). This was a span increase 
from the already frozen 36 in. value and required some significant redesign to make it possible. Large gussets were needed to transfer the forces that far away from the vertical columns. It had a detrimental effect on the strength of the tower, as well as the carefully tuned natural frequency of its vibration. The change was made though, as it was advised by the facility owner, and it was decided that additional anchoring locations could be used if the tower did not have the properties expected.

\subsection{Frame Design}

\subsubsection{Design Process}

The whirl tower design had the same requirement as the drive system: to survive a rotor failure and still be useable. There is a major difference in designing the frame compared to the rotating systems, because the load from an imbalanced rotor is now dynamic rather than static. Due to this, the frame needs to have a natural frequency above the operating range of the rotors to be tested in order to avoid harmonic excitation from any rotating imbalance. Having a natural frequency below operating range can be accommodated by having a 'dead zone' programmed into the VFT to prevent operations at certain speeds. In fact, this was necessary at the DLR whirl tower facility, which has a dead zone between 1,100 and 1,350 RPM, very close to the nominal speed of most scaled rotors). If the modes of the frame can all be kept above the motors speed of 1,800 RPM $(30 \mathrm{~Hz})$ then no dead zones would be required. Ideally, the first mode of the tower should be at least $25 \%$ higher than this value. 
To achieve this, the frame must be a very rigid structure, which is also an advantage for the vibration measurements the frame will be used for. The process by which the frame's frequency was controlled was highly iterative. Modal analysis would be performed on a frame concept and the results of that analysis would lead to attempts to stiffen the modes with the lowest frequencies. The new frame concept would be reanalysed to observe the effect of the changes. This process involved dozens of small incremental changes so that each change could be independently observed for effectiveness. Eventually, the process became more intuitive as familiarity with the frame's response to design changes increased.

In order to achieve the frame's strength objectives, the same process was used as when designing for the modal objectives. An FEM model of the frame concept would be statically analysed, and any unacceptably high stress concentrations would be adjusted by making design changes to alleviate them, either with dimensional changes or by creating new load paths such as gusseting.

\subsubsection{Frame Description}

The final version of the frame is constructed primarily out of steel square tubes. This section type was chosen for its ease of welding and the clean corners and angles it gives. The majority of the tube used is $3 \times 3$ in. with $3 / 16$ in. wall thickness. Some select pieces are 1/4 in. wall thickness for use in strategic locations for increased strength. The steel type used is ASTM A500 Grade C. A500 steel is specifically designed for structural applications and has a better surface quality and tighter tolerances for production of 
finished pieces. It is also easily weldable by all methods [45]. For shaped sections, such as square tube, this steel has a yield strength of $50 \mathrm{ksi}(345 \mathrm{MPa})$ and a tensile strength of $62 \mathrm{ksi}(427 \mathrm{MPa})[46]$.

Figures 4.1 and 4.2 depict the 3D CAD model of the finalized whirl tower frame. The motor is attached to the frame with bolts though 4 drilled holes in horizontal beam sections. Three sides of the tower have beams for stiffening, however the side opposite the motor's mounting location is left open. This is so that the frame can be laid on its side and the motor can be dropped into it using a crane or hoist. Four solid steel rounds were welded to the top of the frame for attaching the top bearing housing. The rounds have been tapped with a 3/4-16 thread for fastening the housing.

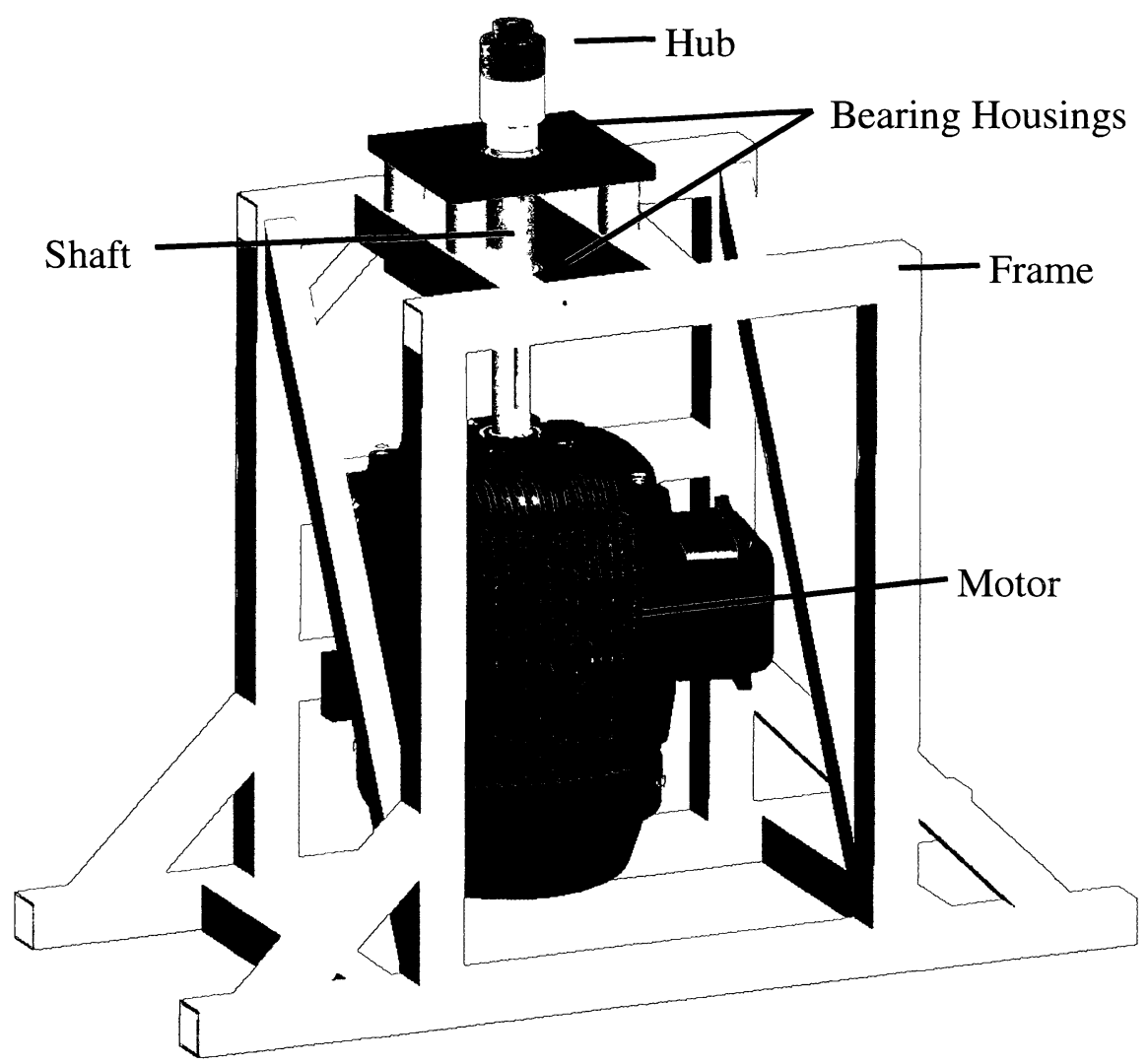

Figure 4.1: CAD model of whirl tower frame. 


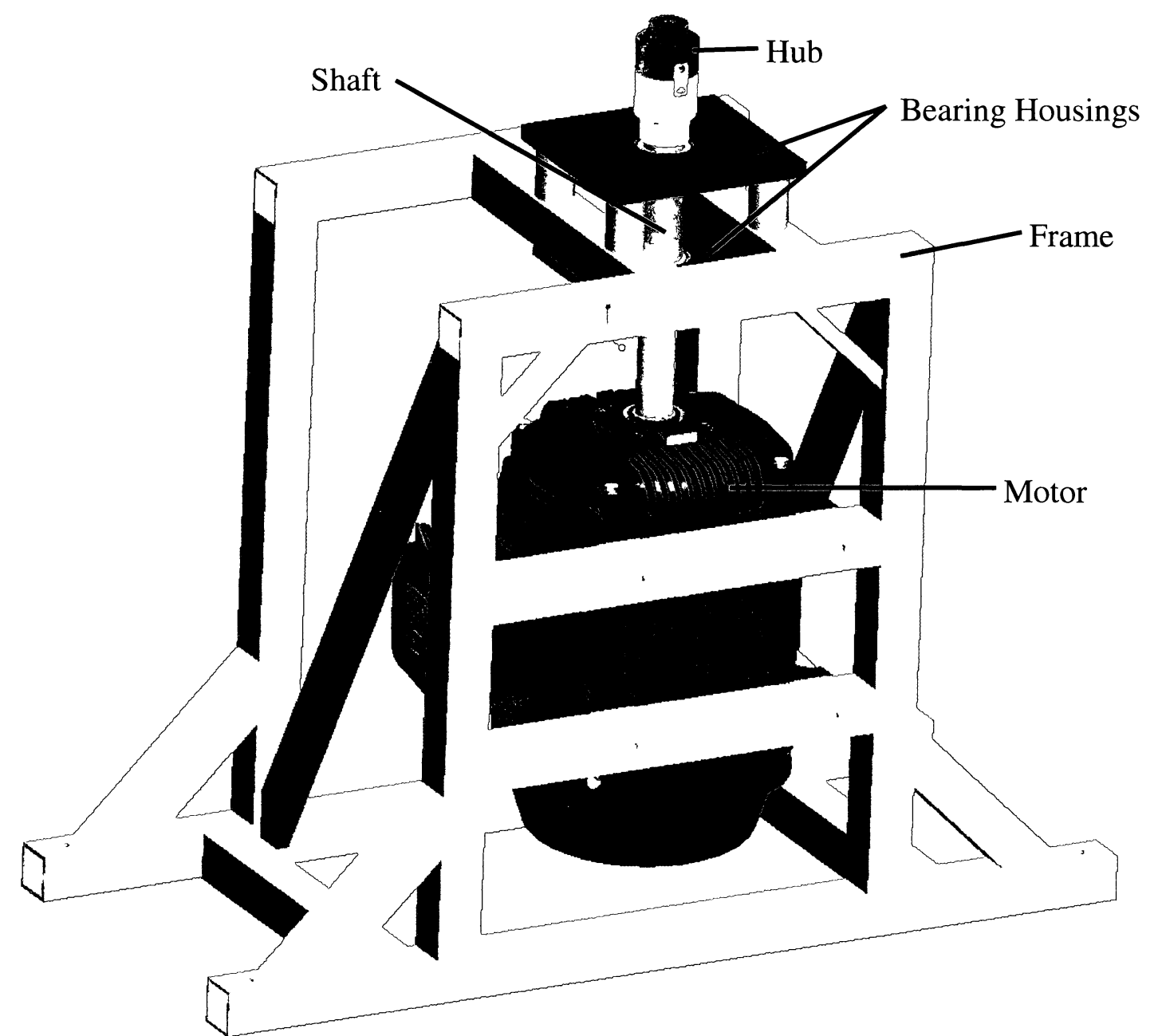

Figure 4.2: CAD model of whirl tower frame, reverse side.

The frame has 4 mounting holes for anchoring to the floor. The holes have crush tubes welded into them with 1.5 in. outer diameter and 25/32 in. inner diameter. The mounting holes were planned to be right next to the vertical columns, but due to a change in tower span, the large gussets were added to transfer loads to the extended mounting locations. Two of the sides have diagonal members added to control modal frequencies and increase strength. 


\subsection{Frame Construction}

\subsubsection{Preparation}

Most of the cuts for the frame were done on a horizontal band saw. In some cases this was found to produce an unacceptable cut due to bending of the blade, producing an unsquare end. These cuts required repair using an end mill, which took more time than using a more accurate cutting process earlier would have. Although much dirtier and noisier to work with, a cold saw will be used in the future. A complete cut list was prepared so that the quantity of material needed, and the most efficient usage of that material, could be planned.

\subsubsection{Welding}

The weld process used for assembly was MIG welding. The wire strength used was $70 \mathrm{ksi}$ (483 MPa), which exceeds the strength of the base material. The bead is approximately $5 \mathrm{~mm}$ wide (approx 3/16 in.), similar to the base material, therefore the welds are not expected to be failure points, unless the base material is insufficiently strong. The welds used were all full welds, with the exception of the diagonal members, which were only welded on 3 sides, leaving out the acute one, and the lower bearing housing which was stitch-welded. The bearing housing has a minimum 2 in. stitch on each side of each corner for a total of $16 \mathrm{in}$. of weld length. With a $5 \mathrm{~mm}$ weld thickness and $70 \mathrm{ksi}$ wire with assumed $58 \%$ shear capacity, this gives an approximate shear strength of 64 tons $(570 \mathrm{kN})$, thus it is not a failure point of concern. 
The welding was performed in 5 steps described in Table 4.1 and Figures 4.3 to 4.7 below. The critical dimensions are given in red and the non-critical dimensions are added for purposes of this report and are given in blue. The non-critical dimensions were not insignificant, they were just pre-cut for welding and thus where not critical to that operation. All dimensions are in inches.

Table 4.1: Welding fabrication steps.

\begin{tabular}{|l|l|}
\hline Step & Operation \\
\hline 1 & $\begin{array}{l}\text { Create two identical sides using 4 pieces of tube each. The welding directions for } \\
\text { this are shown in Figure 4.3. }\end{array}$ \\
\hline 2 & $\begin{array}{l}\text { Weld two horizontal beams into one side of the frame to hold the motor, then } \\
\text { place whole side of the frame onto the large end mill and locate the motor } \\
\text { mounting holes. See Figure 4.4. }\end{array}$ \\
\hline 3 & $\begin{array}{l}\text { Weld in the } 4 \text { horizontal beams that connect the two sides to create the frame box. } \\
\text { See Figure } 4.5 .\end{array}$ \\
\hline 5 & $\begin{array}{l}\text { Mount the motor in the frame and line the shaft up square. Install the top and } \\
\text { bottom bearing housing with the shaft and coupler to locate the appropriate } \\
\text { bearing housing locations. Clamp the housings then weld the top bearing posts } \\
\text { and the bottom bearing housing into place. See Figure 4.7. }\end{array}$ \\
\hline
\end{tabular}




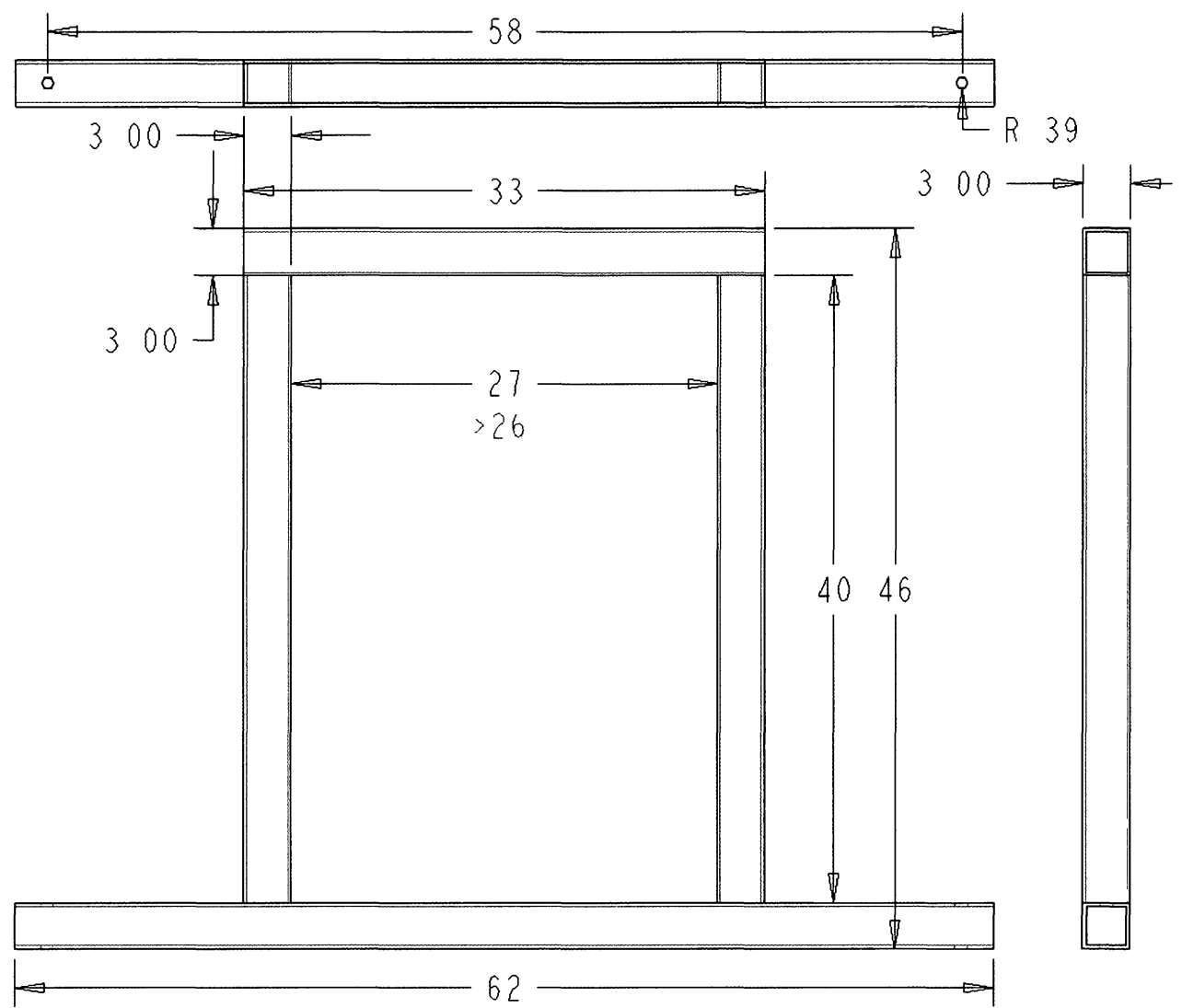

Figure 4.3: First welding step: creating two sides.

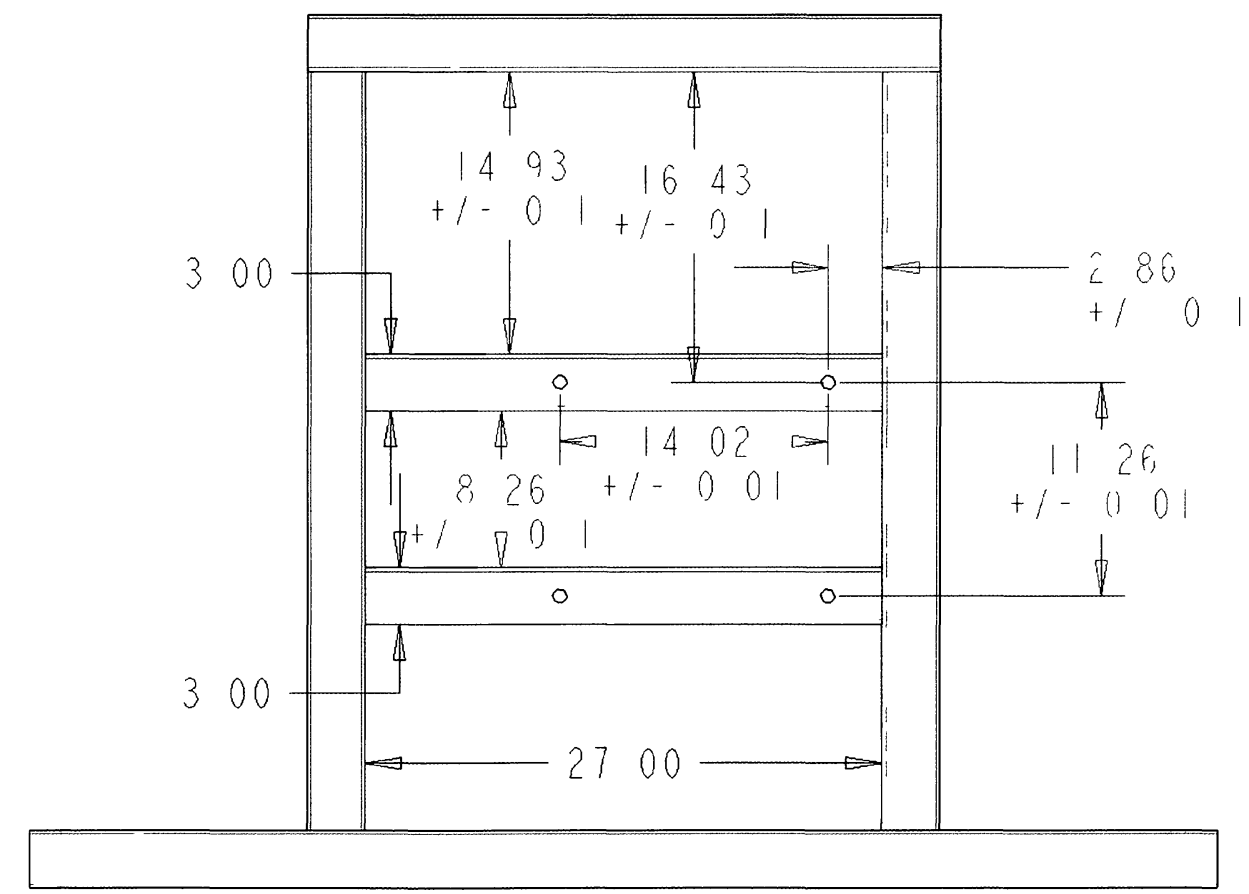

Figure 4.4: Second welding step: creating motor mount. 

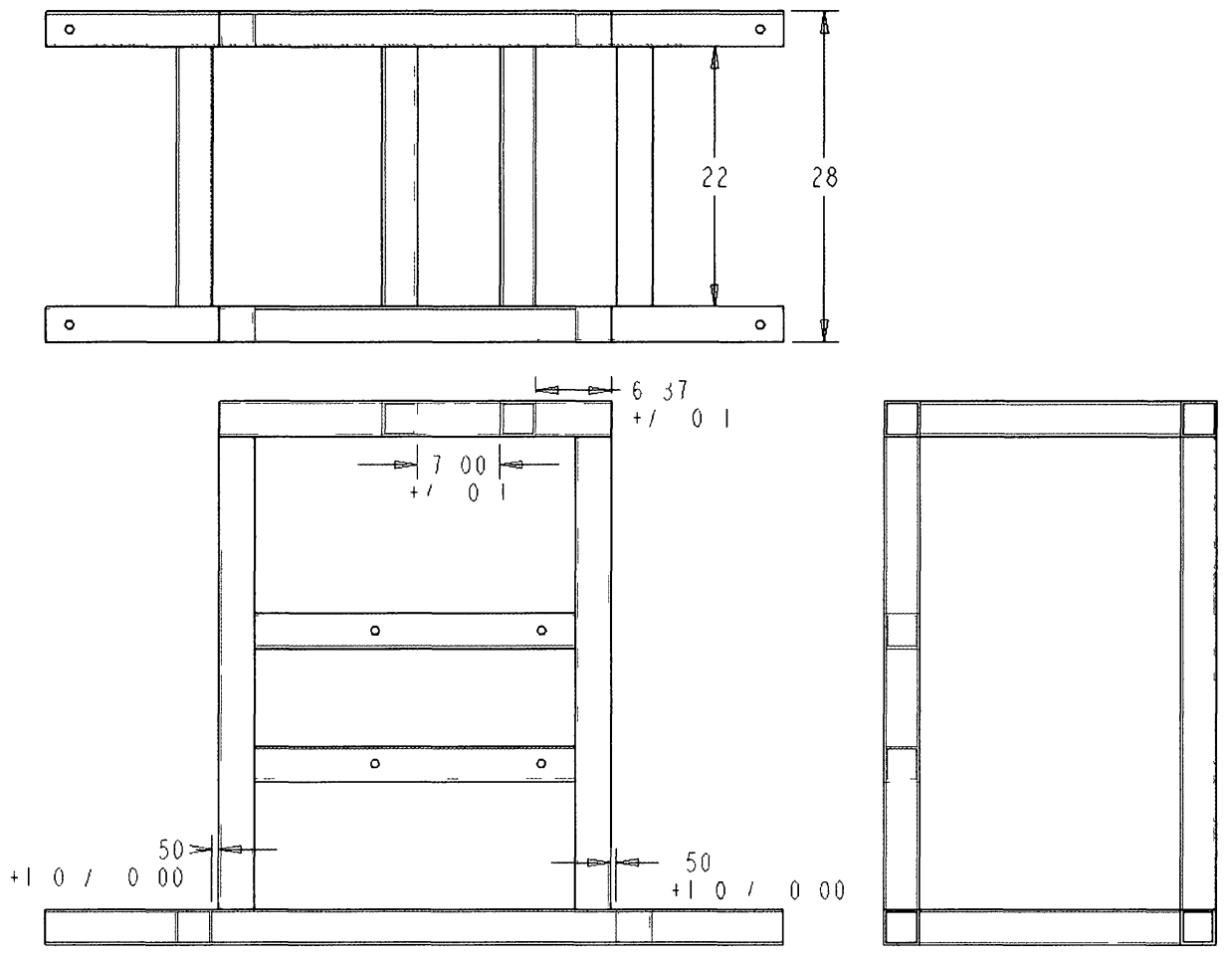

Figure 4.5: Third welding step: complete frame box.

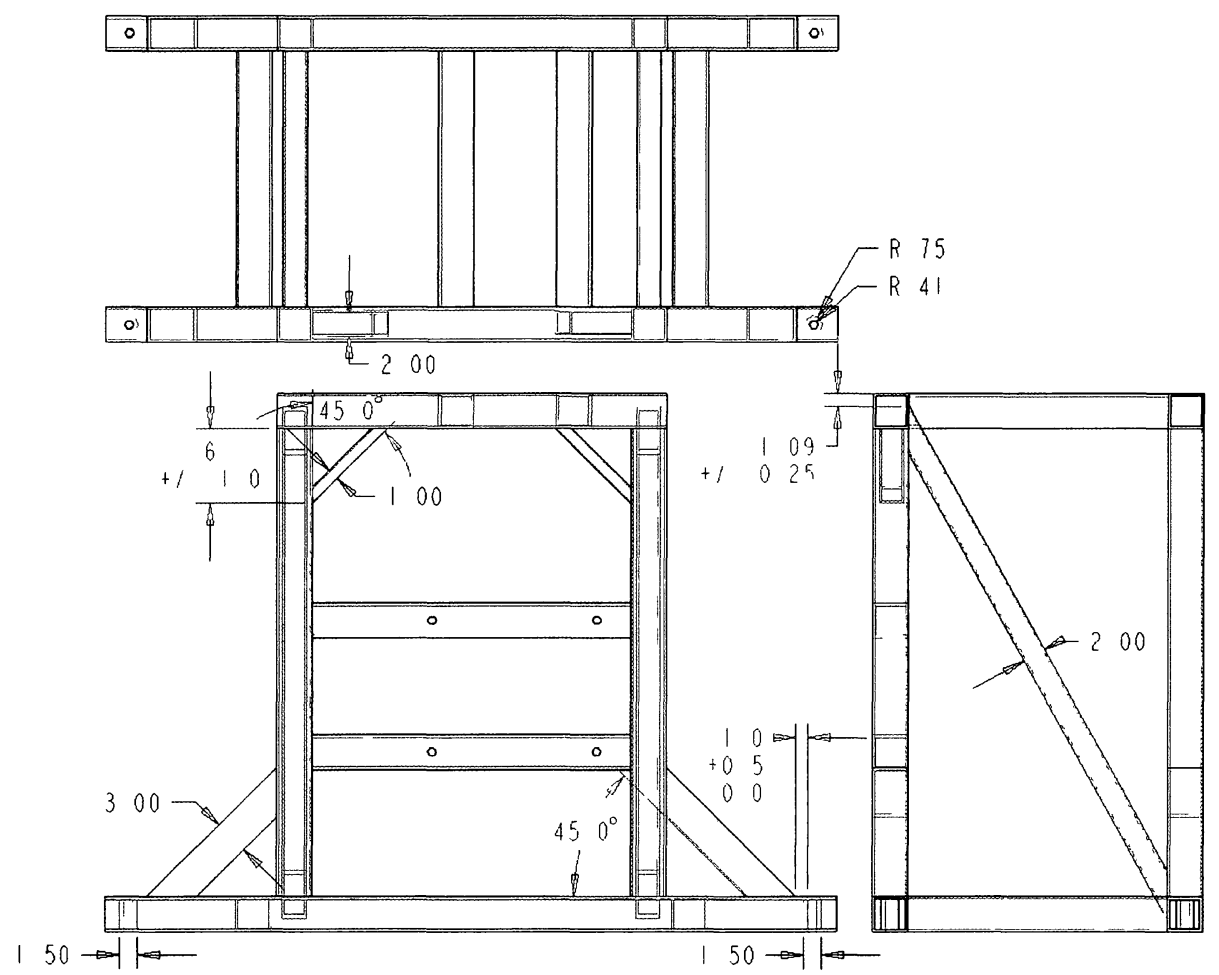

Figure 4.6: Fourth Welding Step: add diagonals, gussets, and crust tube. 


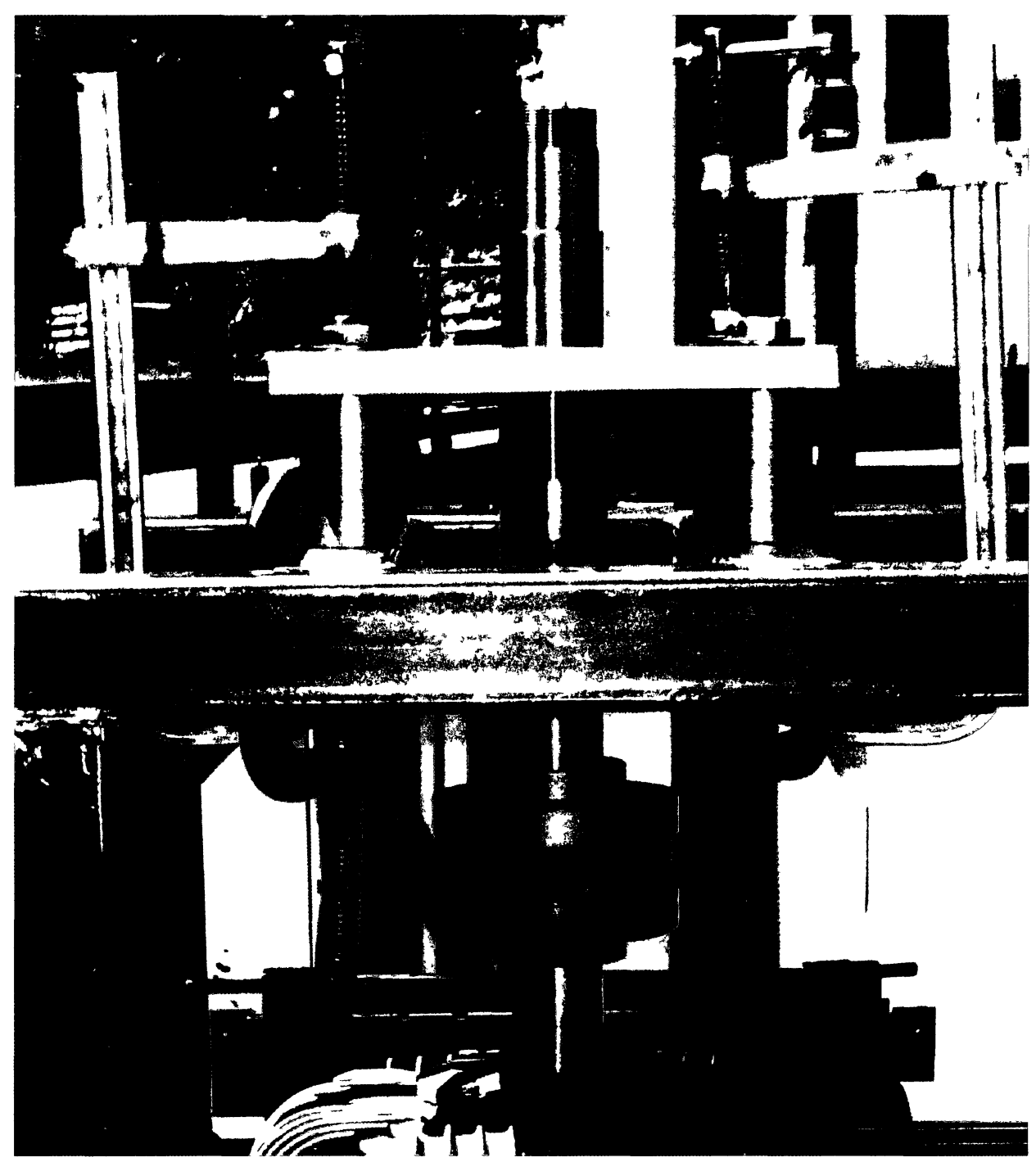

Figure 4.7: Fifth Welding Step: locate then weld the bearing housings and posts.

Note that step five did not have any target dimensions other than lining up the shaft and bearings with the motor. Figure 3.9 depicts the dimension of the top bearing housing, and thus the relative locations of the top bearing posts. The posts are 3.5 in. tall and 2.5 in. diameter. 


\subsubsection{Finishing}

High-level fit and finish was a key requirement for the whirl tower. Thus, the tower requires a clean look, both in fabrication and finish. The welding was done by a very skilled, professional welder and the results are exemplary. Although the directions given had loose tolerances in many places, as loose as an inch at times, these were allowed to give the fabricator choice of placement; however the importance of symmetry in placement was highly stressed. As such, the finished whirl tower is very square and symmetric. The open tubes in the top corners of the tower have plate welded into them, and then ground to provide smooth, rounded, closed ends. One closed end of the frame, as an example of finish quality, is shown in Figure 4.8.

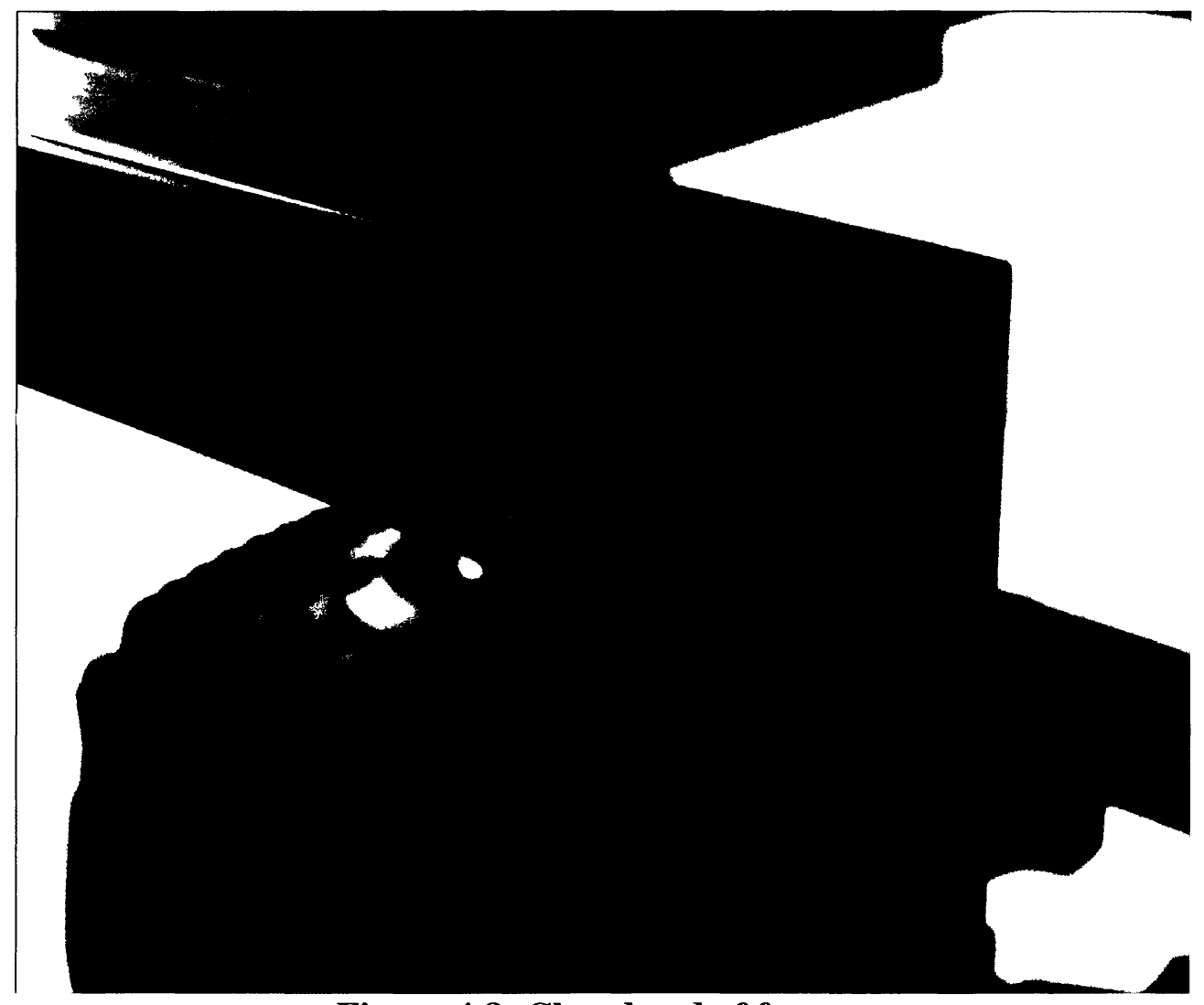

Figure 4.8: Closed end of frame. 
After welding was complete, the frame was sent out for painting. The paint selected is a matte black powder coat. Matte black is the ideal colour of choice for paint that may need matching or touch-up in the future. It is very easy to match and provides a very clean look. The powder coat process uses powdered solid paint and electrostatically attaches it to the frame. The paint is then baked on, which provides one of the most durable paint finishes possible [47]. Prior to painting, the frame was sand-blasted to remove the hot-roll scale and weld slag from the steel, and then primed for better adhesion. The painting was outsourced to R.L.D. Industries who provided pick-up, sandblasting, painting, and delivery of the frame.

\subsection{Frame Analysis}

The analysis done on the whirl tower frame consisted of two types, modal and structural. Due to the complicated geometry of the frame, finite element method (FEM) was the preferred method of evaluating the frame's properties. The software suite used to perform the FEM analysis is Ansys Workbench.

A CAD model was created that was an assembly of each individual cut section of steel tube. This was done so that the automatic mesh generation in Ansys Workbench would give preference to using structured grids. Some geometric simplifications were used, such as replacing the bearings with solid connections, and replacing the motor with a simplified model of similar outer dimensions. Custom material properties were input for the steel used (A500 tubing and 9310 drive shaft), and a fictitious material was used 
for assignment to the motor. The material had all the same properties of mild steel, but a density of $3.364 \mathrm{~g} / \mathrm{cm}^{3}$ to give the solid model of the motor the appropriate mass. Since the exact mass distribution within the motor is unknown, this process allowed the motor to have a homogenous mass distribution over its internal volume. It was necessary to change the density, because the modal analysis results are highly dependent on the mass of the motor. The boundary condition used in both simulations was a fully constrained connection for 4 pucks that were added to the frame where it would be mounted to the floor.

\subsubsection{Modal Analysis}

After loading the CAD model and material properties into Ansys Workbench, a mesh was generated to the perform simulations. Grid generation was handled by the automatic tools provided, with adjustments being made only for the fineness of the mesh. Grid dependence was checked by comparing results from two grids, one with 122,000 nodes and another with 322,000 . Each frequency decreased slightly when moving to the finer grid, but with the change being approximately $2 \%$, the results from either mesh were considered acceptable. The difference in the first 4 modes between the two grids is shown in Table 4.2.

Table 4.2: Grid dependence results.

\begin{tabular}{|l|c|c|c|}
\hline Mode & Coarse Mesh Frequencies (Hz) & Fine Mesh Frequencies (Hz) & \% Difference \\
\hline 1 & 33.87 & 32.92 & -2.87 \\
\hline 2 & 49.17 & 47.71 & -3.06 \\
\hline 3 & 56.11 & 54.94 & -2.13 \\
\hline 4 & 73.90 & 72.73 & -1.60 \\
\hline
\end{tabular}


The first mode of the frame is first bending in the thinner axis of the tower (depth), with a predicted frequency of $33 \mathrm{~Hz}$. The maximum amplitude of the mode is not the sway of the top of the tower, which is constrained due to the diagonal members used, but a plunging motion observed in the motor. This mode is depicted in Figure 4.9. The frequency of the mode is greater than $30 \mathrm{~Hz}$, as required, but does not achieve the $25 \%$ difference desired between frequencies. It is, however, $32 \%$ higher than the SHARCS rotor operational frequency, indicating that those operations should be unaffected by modal concerns. The modes of the tower can be further altered as needed by adding more stiffening. The tower itself has a natural frequency of over $50 \mathrm{~Hz}$ and it is the mass of the motor that causes the tower to vibrate more slowly (see Table 4.3). If needed in the future, any stiffening to be added to the frame should be focused on controlling the motion of the motor within the rest of the frame.

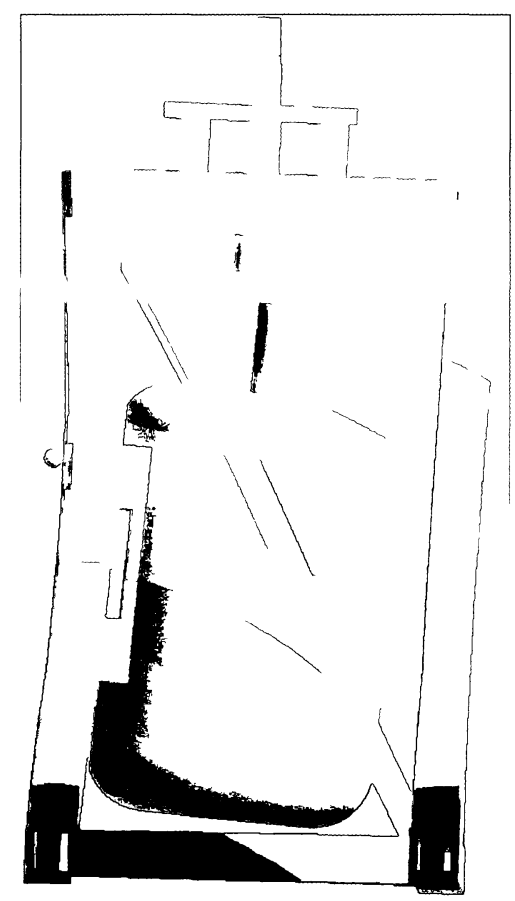

Figure 4.9: First mode of the whirl tower, warmer colours indicate displacement. 
Table 4.3: Modal frequencies with and without the motor.

\begin{tabular}{|c|c|c|}
\hline Mode & Frequency $(\mathbf{H z})$ & Frequency w/o Motor $(\mathbf{H z})$ \\
\hline 1 & 32.92 & 50.77 \\
\hline 2 & 47.71 & 65.51 \\
\hline 3 & 54.94 & 115.8 \\
\hline 4 & 72.73 & 139.2 \\
\hline
\end{tabular}

Prior to increasing the span of the tower, the frequency of the first mode achieved the $25 \%$ overhead goal with a value of $39.73 \mathrm{~Hz}$. This indicates that changes in floor fastening could be used to alter the modal frequencies, if the floor permitted mounting at other locations. The current design is deemed effective, as it will not excite inappropriate modes in the thin floor at NRC, but alterations can be made easily by adjusting the fastening locations. The decision to do this will hinge on how accurately FEM modal analysis was able to predict the modal frequencies. Measurement of the modes is being planned for the immediate future.

\subsubsection{Structural Analysis}

Structural analysis of the frame consisted of performing static stress simulations with various load direction vectors to determine the most likely failure points and their expected strength. The results produced compare the von Mises stress against the material tensile strength and output results in the form of minimum safety factor, i.e. the ratio of ultimate strength over equivalent stress. The results were slightly dependant on the way the boundary condition for fastening to the floor was defined. This was due to 
the frame's weakest point being consistently in the floor fastening location. The forces and bending moment being transferred down the two wide base beams are large, and have substantially increased from when the floor fastening was planned to be directly adjacent to the vertical columns. The stress concentration being experienced in the foot of the frame is shown in Figure 4.10. Concentrated meshes were attempted to better characterize the stress in this location (see Figure 4.11), but ultimately just the way the boundary is defined has significant impact. The results produced generally show a minimum safety factor between 1.9 and 2.3, which are in the range desired. However, minute adjustments to the model were still producing changes in this range of $10-20 \%$, so it is possible that the true strength lies slightly outside of the predicted range.

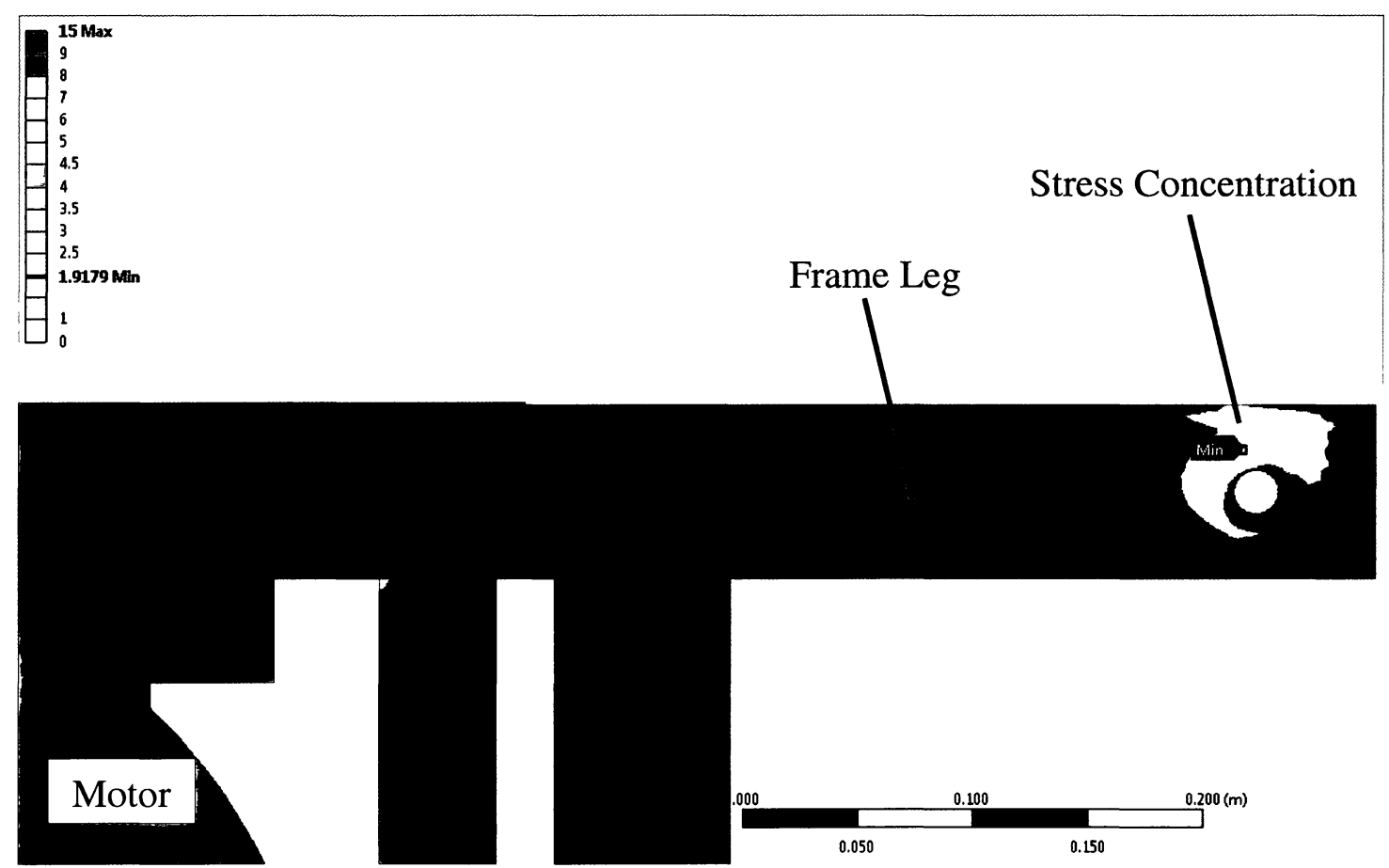

Figure 4.10: Safety factor of frame's base beam near the anchoring location. 


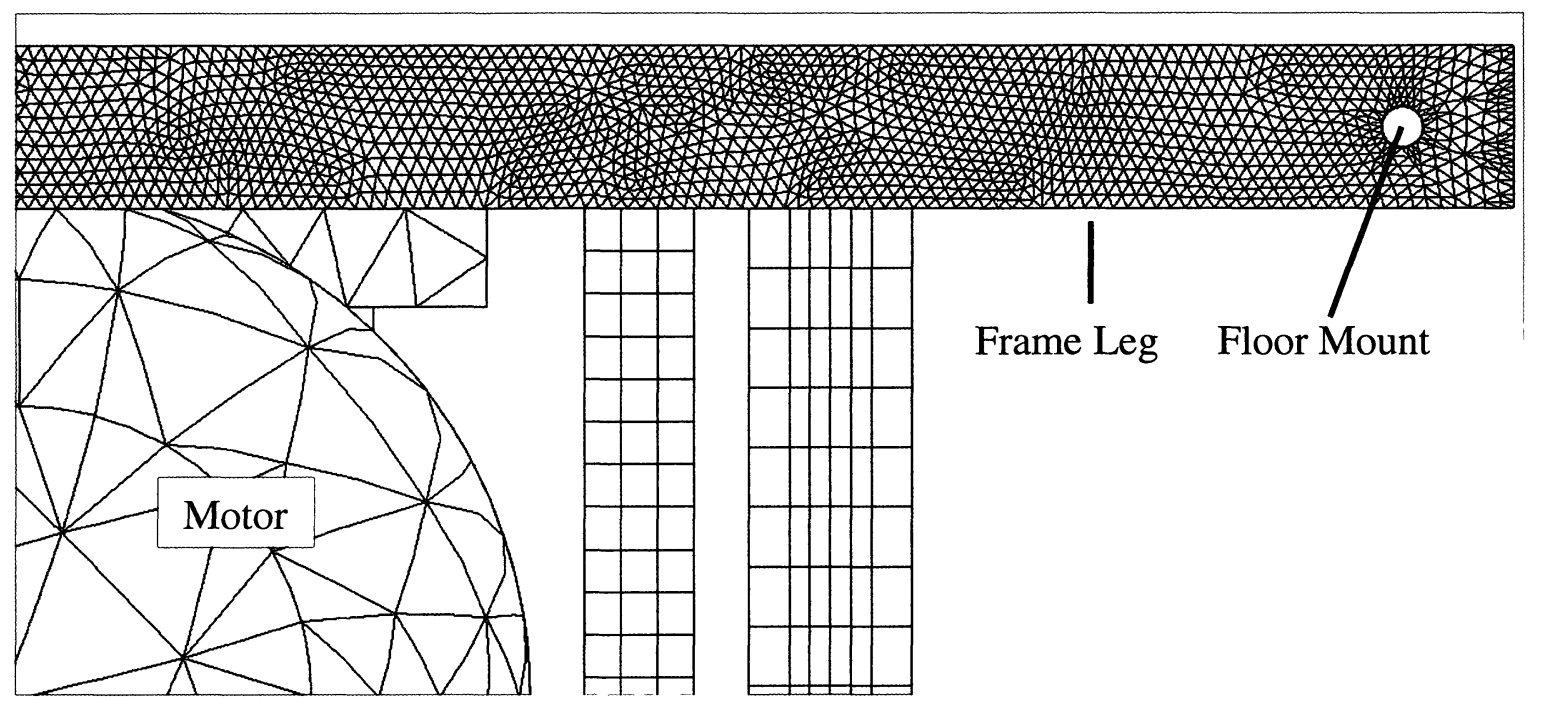

Figure 4.11: Mesh refinement in the vicinity of the predicted failure locations.

Regardless of the specific strength available in the region, the expected failure location has been successfully located. The predicted failure location is in the fastening point of the base, and thus a failure of the frame will likely consist of a bent or fractured base beam, which would then alleviate the stress concentrations in the frame and simply allow it to "rattle" around until the imbalance dies down. If this happens, it could likely be repaired quickly by simply cutting down the span of the tower back to the originally designed span, thus removing the damaged areas. This change is not considered prudent or necessary at the moment as the whirl tower is not expected to fail, since the frame is still very strong, and the likelihood of the worst case rotor failure being used for simulations $(15,500 \mathrm{~N}$ imbalance) actually occurring is admitted as extremely low.

Besides the floor fastening points, the next weakest points on the whirl tower were in the joints of the top gussets. The stress concentrations in these points were on the seam between the beam sections, right where they are welded. These welds are not included in 
the FEM simulations; instead only the base materials were bonded, so the simulation does not properly account for the weld fillet area or the higher strength of the weld material. The stress concentrations in the top gusset are shown in Figure 4.12. The minimum safety factor in this area is 3.23 .

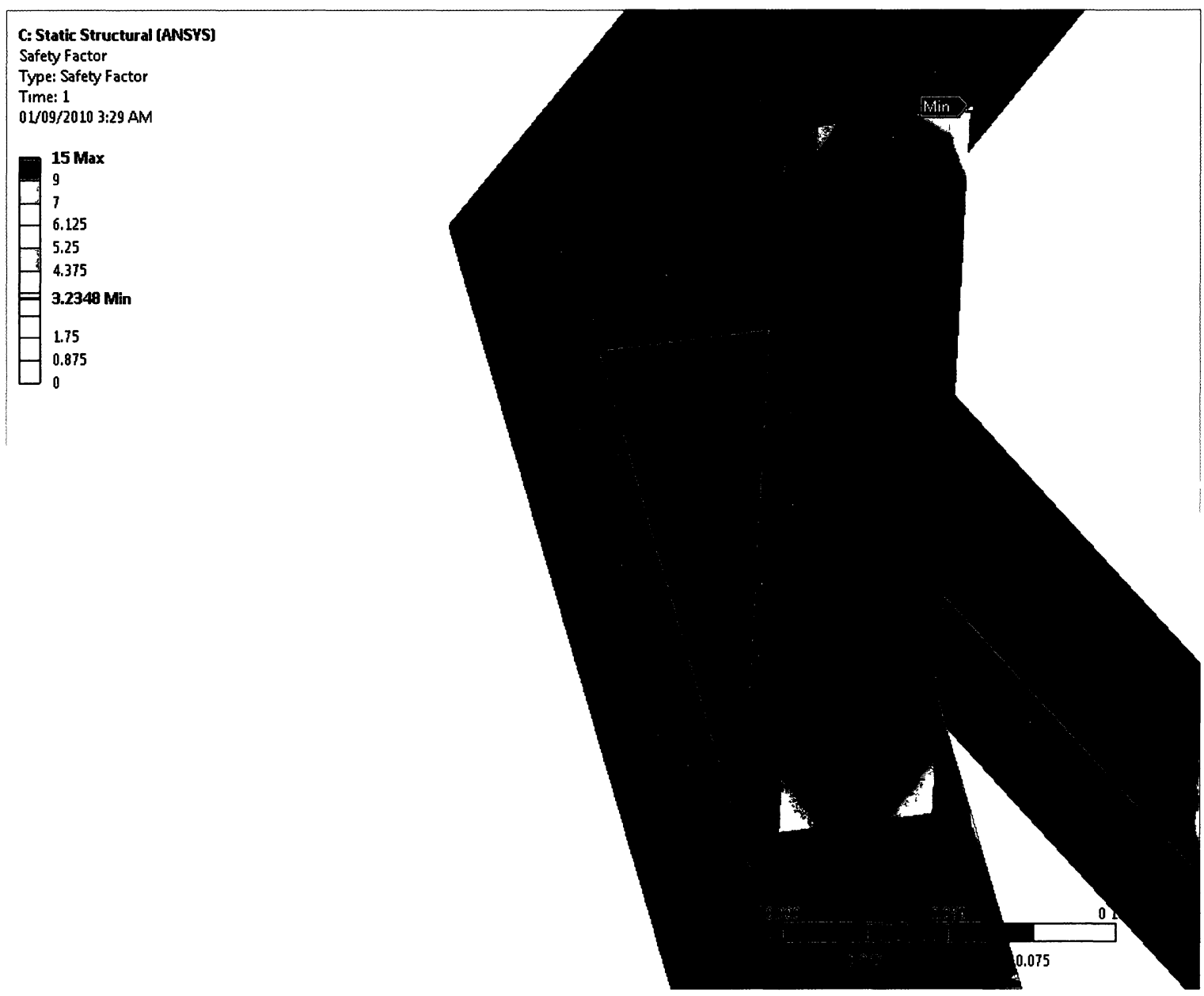

Figure 4.12: Stress concentration in the seams between the frame beam members.

Overall the structural simulations of the frame indicate a very strong assembly. There is some minor concern regarding the frame's strength at the floor fastening points, but even if an unlikely failure in this location did occur, it does not pose a safety risk and 
is not expected to be a tremendous amount of work to repair. The upper sections of the whirl tower, which contain the drive system, are incredibly strong. None of the rotating components, other than the rotor blades, are expected to be damaged in failures and can be reused should the frame ever need replacing.

To put the failure of the frame in context, if a completely new frame of similar or slightly altered design were ever required, it would take approximately three weeks to produce. 


\section{Chapter 5: Signal Interfaces}

\subsection{Communication Requirements}

The SHARCS rotor will be a highly instrumented rotor due to the number of active systems it contains. Communication channels to collect all the data from instrumentation are required, and control / power channels to control the active systems are also needed. The ability to do closed-loop control of some active system entirely within the rotating frame is also a requirement. Currently, the SHARCS rotor blade specifies instrumentation with:

- 8 full bridge strain gauge systems

- 3 Hall sensors

- 2 accelerometers

Discussions with the instrumentation designer lead to the development of a master channels list, which is summarized in Table 5.1.

Although a total of 29 signal channels are specified, it is not necessary to operate the strain gauges and other sensors simultaneously, therefore reducing the minimum number of channels to 18 .

For control channels a total of three independent systems must be controlled. Assuming that shared grounds are not possible, this gives a minimum of six control / 
power channels. The requirements at time of selection were for "low-voltage" $(\sim 0-150$ V) piezoelectric actuator based systems, but the desire for "high-voltage" $(\sim 1,000 \mathrm{~V})$ capability was expressed. The two system candidates for high-voltage requirements were high-voltage piezoelectric actuators, which are much smaller than their low voltage counterparts, and for shape memory alloy based systems.

Table 5.1: Instrumentation channels.

\begin{tabular}{|l|c|}
\hline \multicolumn{1}{|c|}{ Description } & Quantity \\
\hline Master Ground and Excitation for Strain Gauges & 2 \\
\hline Signal Channels for Strain Gauges (2 each) & 16 \\
\hline Master Ground and Excitation for Hall Sensors & 2 \\
\hline Signal for Hall Sensors & 3 \\
\hline Master Ground and Excitation for Accelerometers (piezo-resistive) & 2 \\
\hline Signal Channels for Accelerometers (2 each) & 4 \\
\hline
\end{tabular}

\subsection{Slip Rings}

Slip rings were the first investigated communication system. There are two main types of slip ring installation that are possible.

End-of-shaft slip rings have no bore, and are designed to have the stator wiring access the shaft from one end. It is not possible to install them mid-shaft, or to transmit mechanical power through or around them. The advantage is that they are compact, have much lower brush speeds, and are less expensive due to simpler design and less material. They are also much more likely to offer high-voltage capability due to the offering of 
liquid mercury slip rings in this configuration. Liquid mercury slip rings have a conductive liquid interface between the rotor and stator, and completely seal this interface in insulation, thus allowing for high electrical resistance between channels. It also provides much lower electrical contact resistance, which is a major problem for high-voltage slip rings, and thus allows for high-voltage power transmission. Due to the main shaft having the motor on one side and the rotor on the other, in the present design it is only possible to install end-of-shaft slip rings above the rotor plane and then running the wiring from the ceiling, as well as an armature, or tensile guide wires to keep the stator from rotating. This would be an extremely difficult and unsightly installation and therefore end-of-shaft slip rings are dismissed in preference of the other type, through bore slip rings, for the Carleton whirl tower facility.

Through-bore slip rings have a clearance hole in the middle for a shaft or wiring to pass through. They are much more expensive due to the use of much more material, since the rings are larger in diameter (the best slip rings are frequently coin silver to provide the best signal quality) and higher brush speeds requiring more design consideration. Sourcing a suitable set of slip rings for this application was the most difficult part sourcing of this entire project. After contacting dozens of manufacturers, two basic barriers were found in slip ring designs. High-speed slip rings, which are capable of operation over 1,000 RPM, are very difficult to locate with bores over 1.5 to 2 inches, less than the required shaft diameter. Large bore slip rings, basically those starting with bores over 2 inches, are very difficult to locate with higher than 500 to 1,000 RPM operational speed. The only suitable models found were by a German supplier, 
Schleifring. No supplier could be found that met the physical and high-voltage requirements concurrently.

Schleifring offers one series of various models that meet the requirements for the whirl tower signal systems. The slip rings to be used for power transmission are Series $\mathrm{K}$ Type S, consisting of graphite brushes on solid silver rings. They are stated to have 10,000 RPM maximum speed (although no bore size or radius is defined, so this is rather ambiguous) and 200 million rotation lifespan with 16 A capability at $125 \mathrm{~V}$ (although discussions with Schleifring concluded that $150 \mathrm{~V}$ will not be a problem) [48]. Figure 5.1 depicts a sample of S model type. On the other hand, the model appropriate for signal transmission is Type SIB, which uses a braided silver rope as a brush to provide low contact resistance and large contact area for very low electrical noise, quoted as less than $2 \mathrm{~m} \Omega$. They provide 8 A capability up to $220 \mathrm{~V}$ with $15,000 \mathrm{RPM}$ stated speed and 200 million rotations [48]. Figure 5.2 depicts a sample of the SIB model type.

The Schleifring quotation process did not allow for simply requesting specific models, but instead required full description of the application, as well as any special needs, so that proper selection can be made. Tentatively, an 8 channel $\mathrm{S}$ model for power, and a 24 channel SIB model for signals were selected, both with $70 \mathrm{~mm}$ inner bore. An inquiry was also made into modifying an existing unit for $1000 \mathrm{~V}$ operation. In response, Schleifring quoted us with a modified 24 channel Type $S$ with only each third channel included, thus giving eight channels with large spacing in between them to provide sufficient insulation for high-voltage operations. Also quoted was a 7K242Z424, 
the 24 channel SIB model, which was expected. The itemized quote totalled over $\$ 26,000$, which was deemed too expensive to purchase as is.

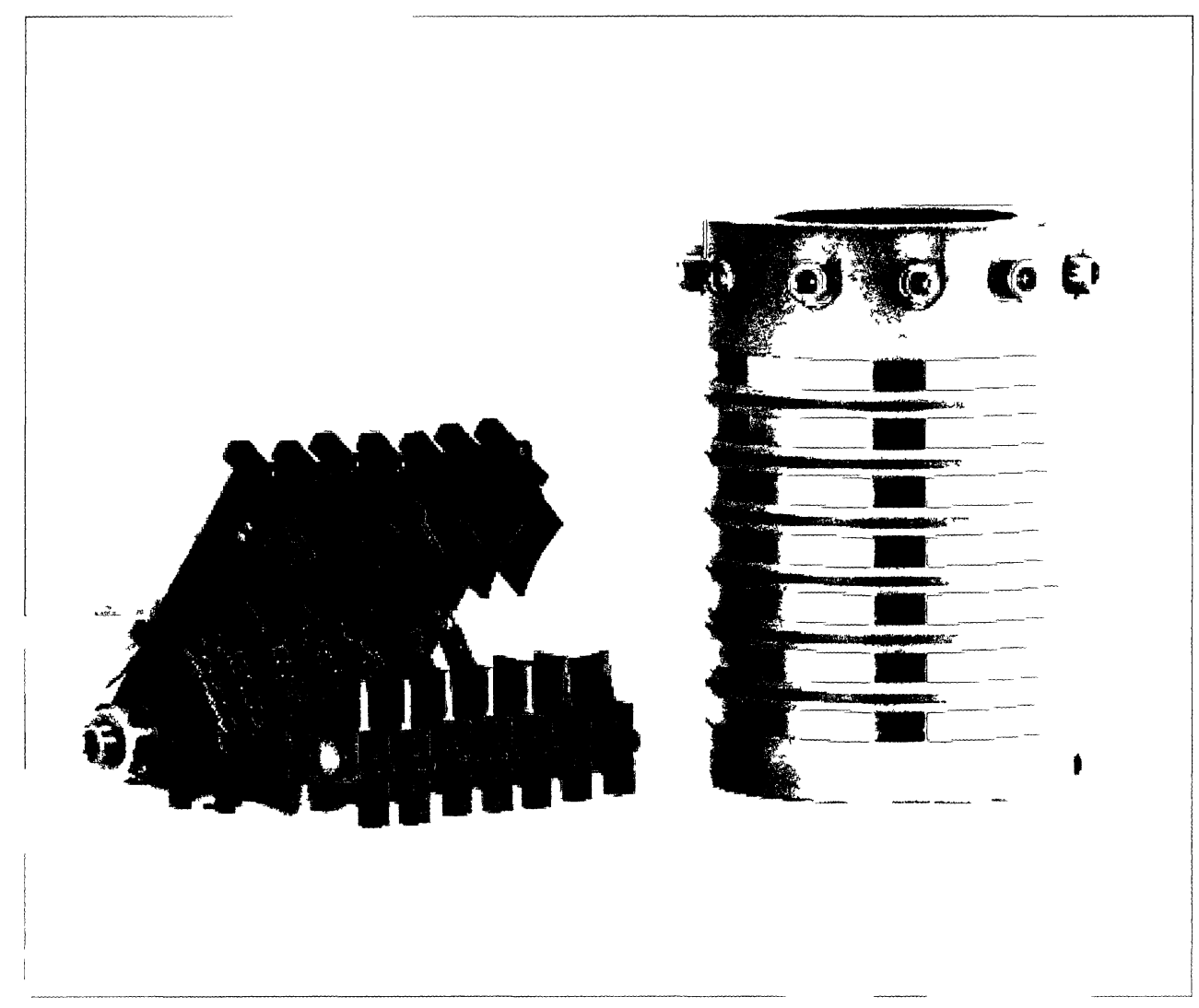

Fingure 5.11: Schleeifriong Series $\mathbb{K}$ Type $\mathbb{S}$ sampple photo [48].

Therefore, alternative methods for collecting data were investigated. Wireless telemetry systems appeared to be suitable for data acquisition and therefore the only slip rings needed were for power transmission channels. It was decided to request the SIB series for this application as they had higher brush speed rating, higher voltage capability, less electrical contact resistance, and still had ample current capability with 8 A. Additionally they could be used for limited data acquisition when needed. An eight 
channel unit from Schleifring, 7K242Z408, was eventually selected and purchased at less than $20 \%$ of the cost of the original quote.

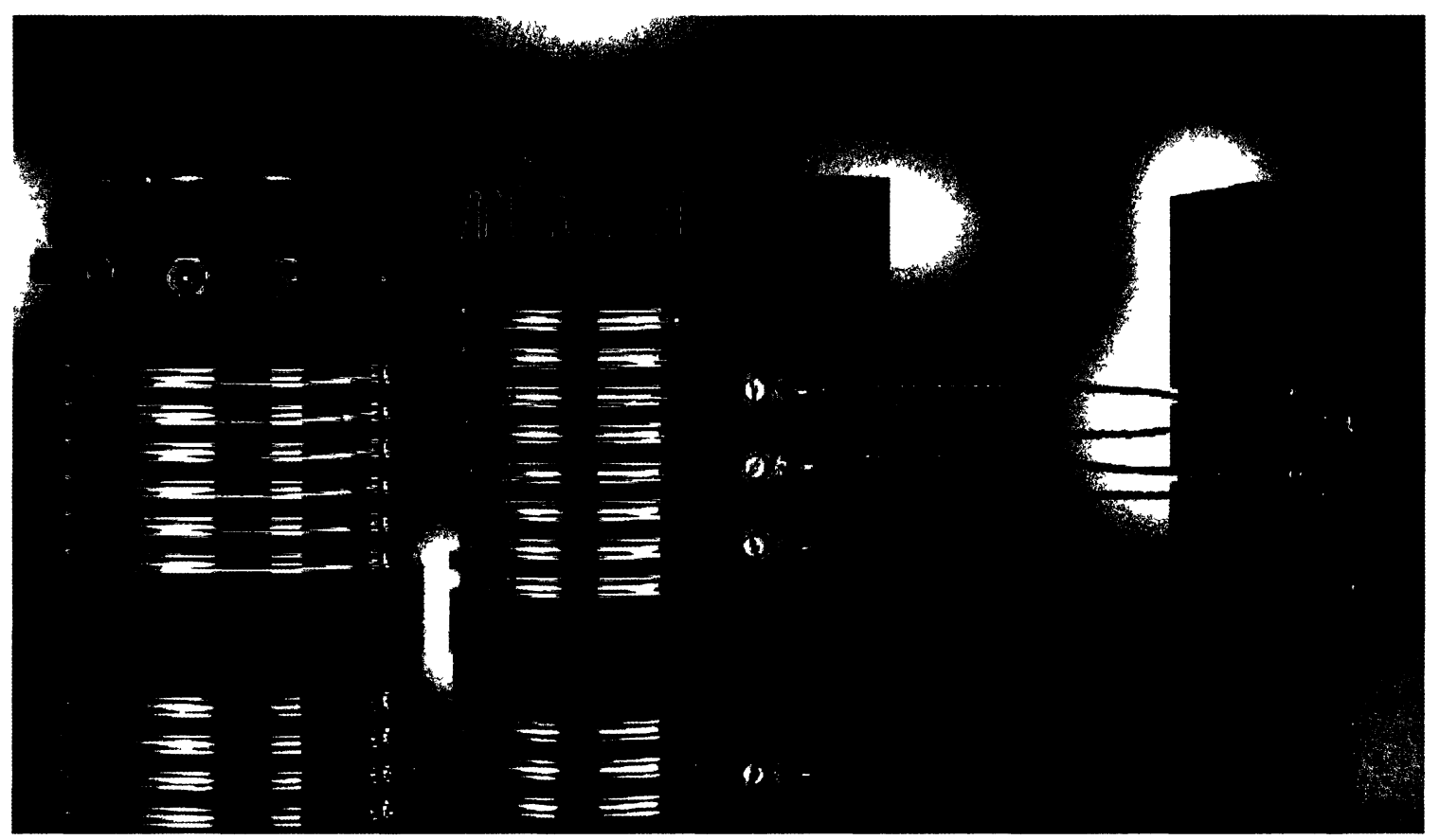

Figure 5.2: Schleifring Series K Type SIB sample photo [48].

The purchased model is $100 \mathrm{~mm}$ in outer diameter, $65 \mathrm{~mm}$ in height, and has a 70 $\mathrm{mm}$ bore. The stator or brush blocks are just simple plastic blocks to hold silver rope brushes which are self tensioning with springs. The electrical connections are all solder points. The rotor is attached to a shaft with set screws and the entire assembly is open to the environment with no cowling.

Wiring for running through the bore of the shaft was needed, with preference that it have as high a heat tolerance, flexibility, and gauge rating (lease size) as possible. Silver plated Teflon coated wire, the same type used for MilSpec cable, is rated to $200^{\circ} \mathrm{C}$ 
operation. Therefore, AWG 22 gauge was selected as it is capable of carrying $13 \mathrm{~A}$, with a de-rating down to $10 \mathrm{~A}$ because it is run in an eight cable bundle [49]. This is higher than the $8 \mathrm{~A}$ the slip rings are rated for, thus making it an ideal choice. The cable purchased is 19 strand, making it very flexible, and less than 0.050 in. in diameter, making it easy to thread through the shaft's cross-hole and bore.

\subsection{Wireless Telemetry}

\subsubsection{Selection}

Selection of a suitable wireless telemetry system was based on Ref. [50], in which a low RPM whirl tower was constructed for helicopter-ship interference studies. This reference used a system called V-Link by Microstrain, which appeared to be a very capable multi-channel digital telemetry device. Alternative systems were located, but were dismissed due to either the extremely expensive custom design involved, or being based on older analog technology, which resulted in comparably larger size and worse electrical noise due to interference with the drive's VFT. Therefore Microstrain's V-Link was selected for the present application.

V-Link is a multi-nodal system, where each node is capable of recording or monitoring seven data channels with 12-bit resolution. The system is exclusively 0-3 V, which means that sensors in this voltage range should be selected for use with this system for best results. The seven channels are divided into two types by default:

- Four channels are provided for full differential measurement, designed for use with strain gauge bridges or piezo-resistive accelerometers. These channels come 
with controllable single conditioning including DC offset and adjustable gain from 210 to 4,884 amplification which allows weak signals to be amplified to take full advantage of the 12 bit resolution.

- Three channels are simple 0-3 V unconditioned inputs, ideal for timing circuits, hall sensors, or any other simple or custom built sensor input.

The nodes have onboard memory so they can store sensor input for later download, up to one million data points. The sampling rate is adjustable from $1 \mathrm{~Hz}$ to $4 \mathrm{kHZ}$ total in streaming mode and $2 \mathrm{kHz}$ per channel in data storage mode. An internal rechargeable lithium battery is installed so no power is necessary for operation. The devices are also very compact at $88 \times 72 \times 26 \mathrm{~mm}$ footprint, with a weight of 97 grams, and are rated for operation in up to $500 \mathrm{~g}$ acceleration environments [51]. A V-Link node with base station is shown in Figure 5.3.

The V-Link System was purchased in a starter kit, which provided two nodes, one base station, and all the necessary software, chargers etc. This also provides for a 30 day evaluation period with full refund. The number of nodes was exactly as needed (two nodes provide eight channels for strain gauge bridges) so the evaluation kit was purchased and simple series of tests were planned to evaluate the system on arrival. 


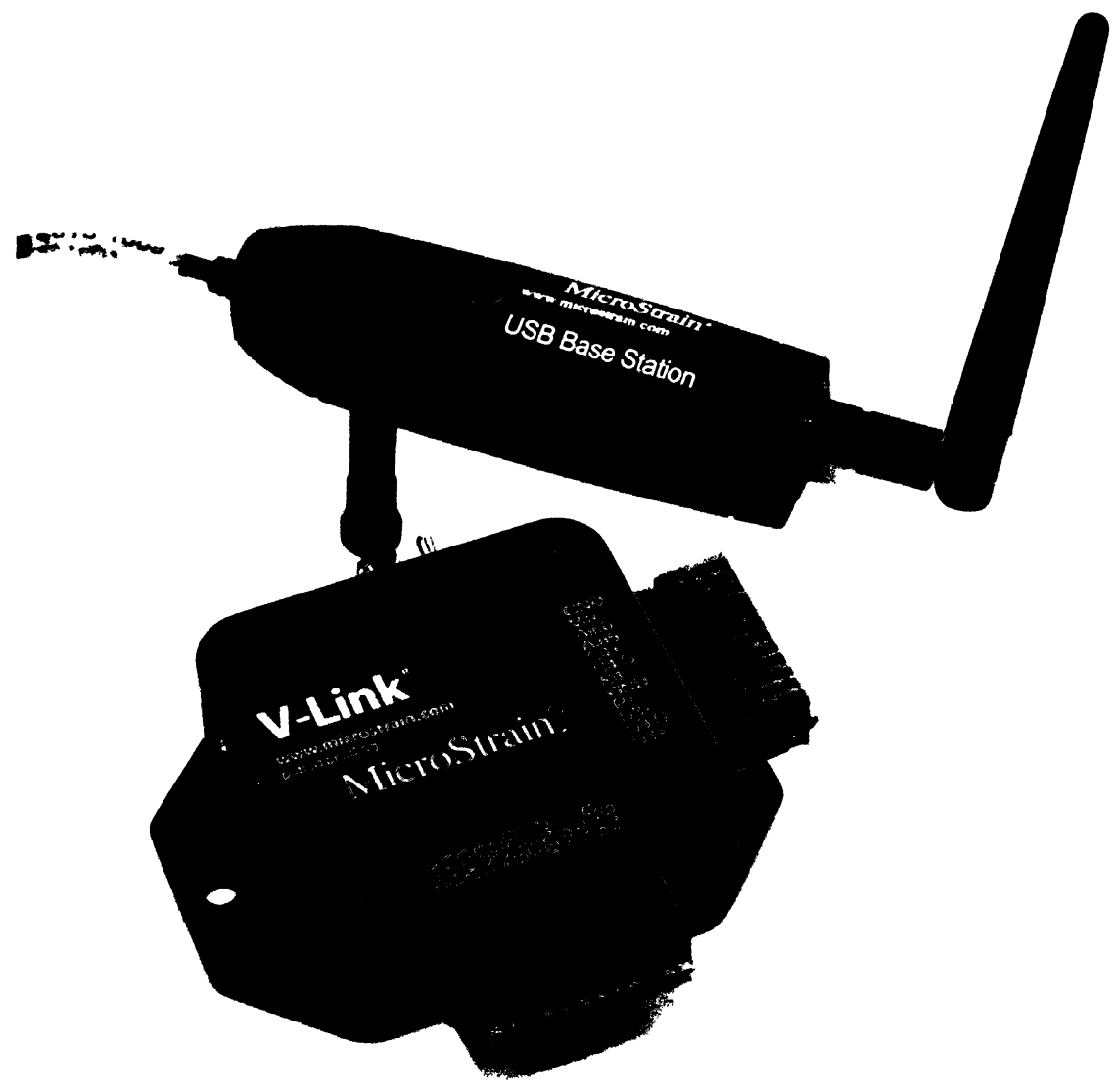

Figure 5.3: V-Link Node and base station.

\subsubsection{Evaluation}

Tests were planned to evaluate how the V-Link system performed with regards to: a, the noise characteristics of the built in V-Link signal conditioning, specifically whether its amplification produces unuseable levels of noise which could drown out small signals; and $b$, the system's ability to transmit cleanly in the presence of electrical noise from the VFT and the motor. Ref. [50] had discovered packet loss occurring in this situation, but had not characterised its severity and effect. The tests planned were: 
- Test 1: perform two measurements with a different gain setting and verify the linear function and expected effect of the gain setting. It is expected that the gain would simply multiply the measured signal and perform linearly.

- Test 2: perform one measurement of a very weak signal using high gain and verify that high gain settings do not interfere with making clean measurements. It is expected that the gain setting be useable over its available range.

- Test 3: measure a predictable signal using wireless transmission in the presence of an operating VFT and determine if any of the data is lost during transmission. Due to discovery of this by Ref. [50], the loss is expected.

\section{Test 1: Effect of gain setting tests}

To evaluate the V-Link measurement quality, a strain gauge based test was performed. A $0.5 \mathrm{in}$. solid aluminum square rod of approximately $1 \mathrm{ft}$. length was obtained and a full bride strain gauge bridge was bonded to its surface near one end. The aluminum rod was clamped to a rigid surface in a cantilevered fashion and a mass was hung from its end to cause bending. The functional equation for a Wheatstone Bridge is:

$$
\frac{U}{U_{E}}=\frac{G F \cdot B F}{4}|\epsilon|
$$

where $U$ and $U_{E}$ are the output and excitation potentials, $G F$ is the strain gauge factor, which for the uses gauges was $2, B F$ is the bridge factor for the bridge configuration, which for this setup was 4 , and $\epsilon$ is strain [52]. The V-Link does not measure voltage directly though; instead it provides its output as a 0 to 4,097 integer by default (which can 
be changed) and thus the equation for measuring strain with V-Link was determined to be:

$$
|\epsilon|=\frac{\Delta s}{2^{12}} * \frac{4}{G F \cdot B F} * \text { Gain }
$$

Where $\Delta \mathrm{s}$ is the change in integer output. The first test was to check the function of the V-Link gain setting. Two measurements were performed; the first with a $4.542 \mathrm{~kg}$ mass suspended $97 / 16$ inches from the strain gauges with a gain of 210 set on the VLink. The second had the same mass at a distance of $95 / 16$ inches with the gain set to 401. These measurements corresponded to 453 and 447 microstrain $\left(\frac{\Delta l}{l} \cdot 10^{-6}\right)$ respectively, which was determined from equation:

$$
\begin{gathered}
\epsilon=\sigma / E \\
\epsilon=\frac{M \cdot y}{I} / E \\
\epsilon=\frac{m \cdot g \cdot l \cdot y}{\frac{1}{12} b h^{3}} / E
\end{gathered}
$$

where:

$y$ - distance from beam neutral axis: $y=0.25 \mathrm{in}$.

$I-$ second moment of area: $I=\frac{1}{12} b h^{3}=\frac{1}{12}(0.5 \text { in })^{4}$

$E$ - Young's modulus $E=69 \mathrm{GPa}$

The results obtained from V-Link had a percent error to the expected value of $0.38 \%$ and $2.1 \%$ respectively. These results were better than the expected measurement error in locating the position of mass and thus confirmed the function of the V-Link system and that its gain settings performed as expected, linearly. 


\section{Test 2: Sensitivity Tests}

To test the usage of V-Link for more sensitive measurements, smaller masses were used and the gain was increased. One measurement was for approximately 22 grams, at a distance of $9 \frac{1 / 4}{4}$ inches. The mass measurement was not very accurate at this scale, but with a gain setting of 2,006, the V-Link was still easily able to detect the bending at 2 microstrains. It produced a measurement error of $22 \%$ compared with the expected result, which was approximately the same accuracy with which the mass was measured. Further smaller measurements down to half of 1 microstrain were successful, but the unit was at maximum amplification and the signals were very small, giving this as an approximate lower limit for the particular test configuration. The output from the 22 gram, 2 microstrain test is shown in Figure 5.4. The smooth line is tuned smoothing, which targets the natural frequency of the beam. The important observation from this test is that the output from V-Link is still quite useable with high amplification, as can be seen in Figure 5.4. The oscillation seen is the natural frequency of the beam, not electrical noise from the system. The $\Delta$ s used in the V-Link equation is the difference in the mean value between the flat regions at the start and end of the graph. 


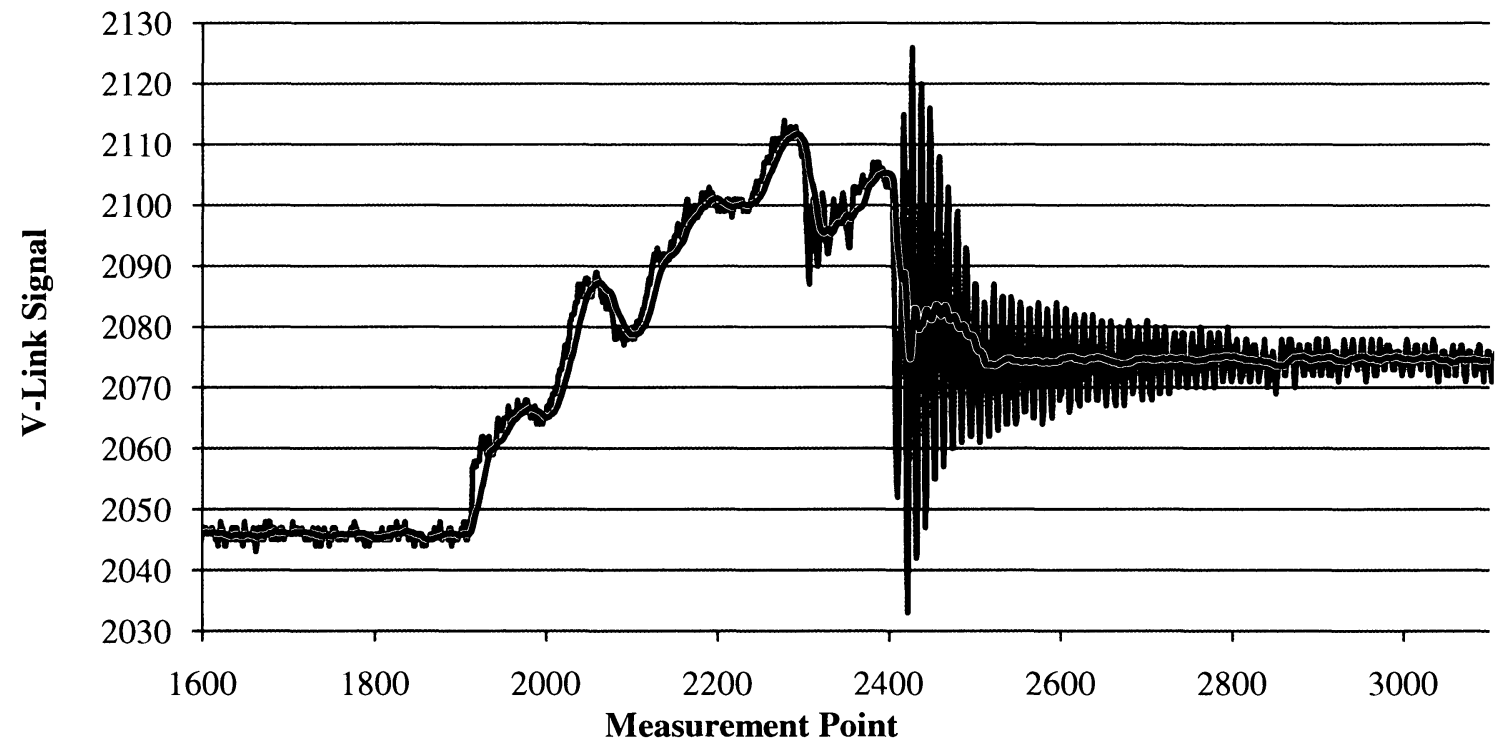

Figure 5.4: Strain from 22 grams placed on $1 / 2$ inch solid aluminum square beam.

\section{Test 3: Interference Tests}

The V-Link was able to satisfactorily complete the tests for measurement quality, now it was time to test its transmission quality. To perform these tests a VFT was required, but the VFT of the whirl tower was not installed at this point. The closed circuit wind tunnel in the Carleton Mackenzie building had approximately the same size (50 HP), although it is of different brand and model, so it was used to perform these tests. The tests consisted of striking the aluminum beam of tests 1 and 2 to vibrate it at its natural frequency, thus producing a predictable signal. Performing this test with and without the VFT (i.e. the wind tunnel) operating would allow comparison against a clean baseline. Note that it is not possible to record and transmit the measurements at the same time and thus compare the transmitted signal against a recorded version of itself. Figure 5.5 depicts the proximity of the V-Link system to the VFT during the tests. 
After performing the tests, the data reduction was attempted. It was not possible to locate any discrepancy or lost information by way of a visual inspection of the data. See Figure 5.6 for vibration data with the VFT in operation, it looks undistinguishable from clean data.

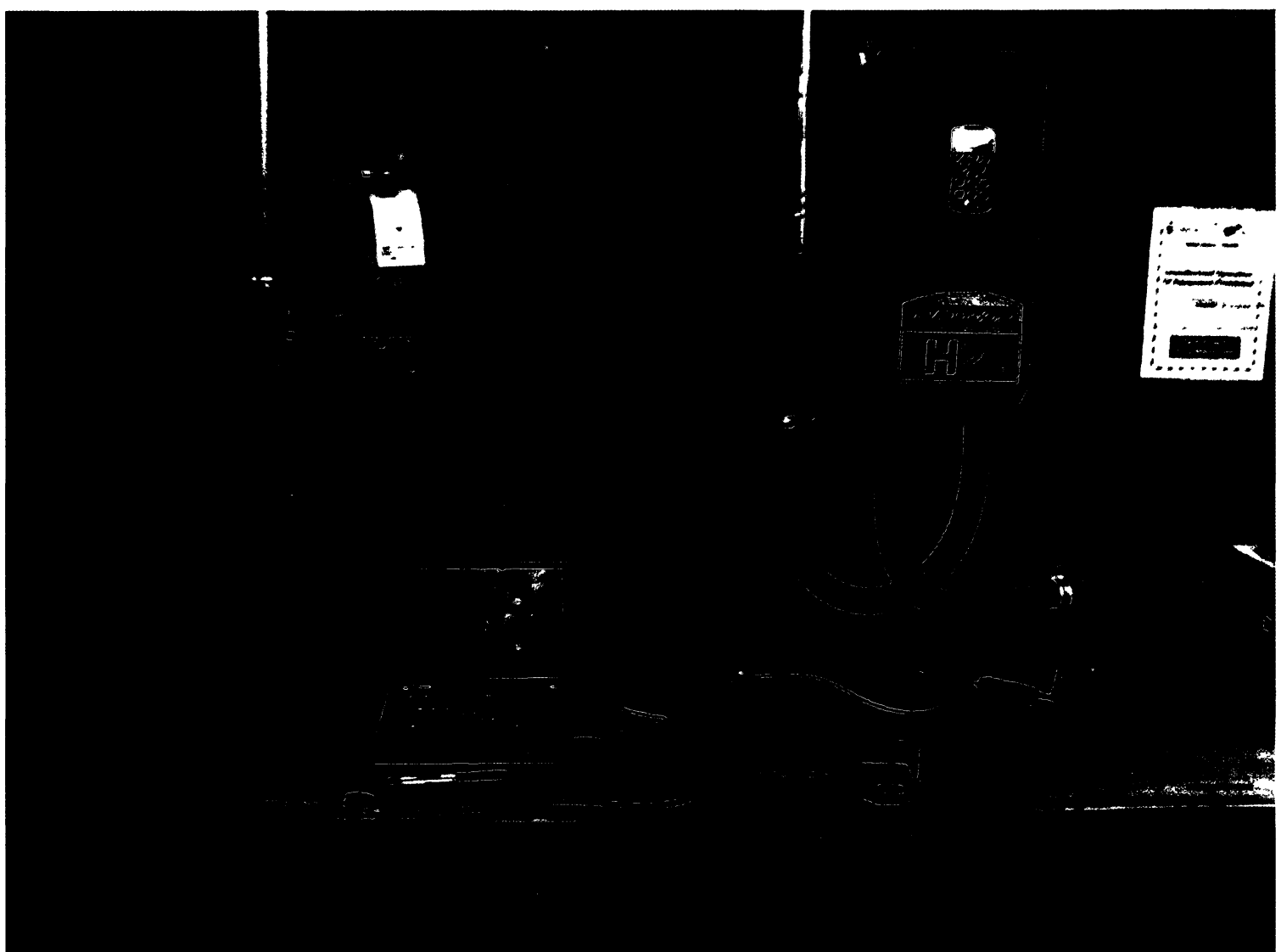

Figure 5.5: V-Link transmission test. 


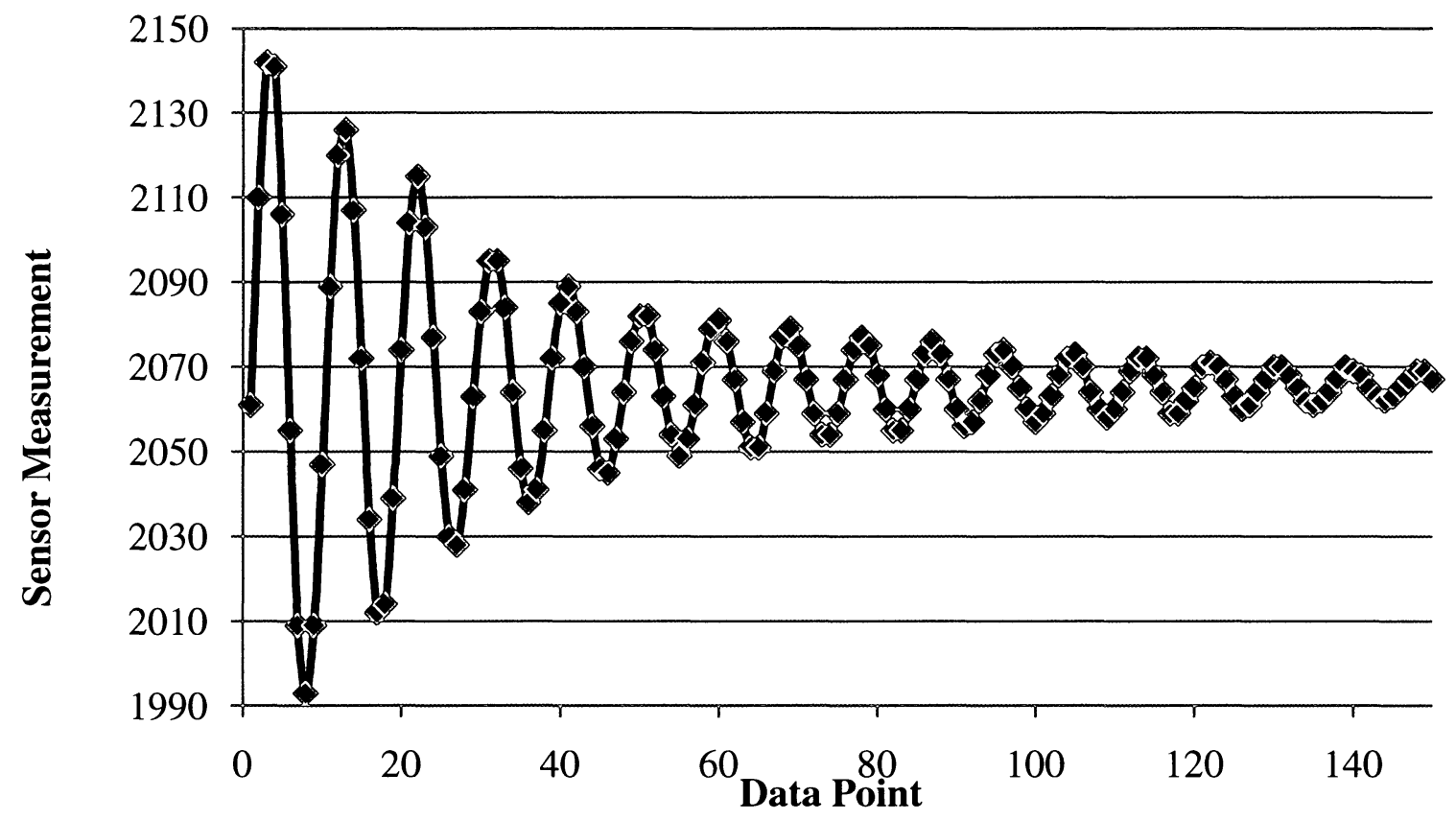

Figure 5.6: V-Link transmission test data.

In an attempt to detect any individual lost packet, the number of data points in between local maxima were counted. This was not successful, as both the reference data and the tested data produced a randomly varying result of $+/-1$ measurement for each cycle. This was due to the sampling rate and the vibration not being perfectly in phase, and the presence of a few bits of measurement error in the data. However, this data reduction method was able to establish that if there was lost data, it was less than $10 \%$ of the total data as no change was detected in the mean vibration period of 10 measurements (at $736 \mathrm{~Hz}$ ).

An attempt at detecting any change with a Fast Fourier Transform (FFT) analysis was not successful either. The FFT process naturally smoothes out any individual missing packet due to performing its data reduction over multiple periods. This was 
verified by creating artificial data and manually contaminating it. This establishes that the data V-Link transmits is clean enough for frequency analysis, even if packets are determined to be missing.

The final method used was able to establish that packets had been lost. For this, plots were created of the derivatives of the recorded data. By taking the derivative, any data that was missing would show as an unusual increase or irregularity in the derivative curve. Figure 5.7 shows such an irregularity, although not very pronounced, and others were found as well. This technique was also confirmed by creating artificial test data; it was possible to determine that any data point lost in the periodic cycle was detectable. With further recordings being analysed, it was eventually possible to estimate a $0.5 \%$ packet loss rate for the experiment performed. This is extremely low and should not discourage the usage of live data telemetry from V-Link. However if necessary, the option to record measurements on the unit and download them after is available. This experiment shall be performed again in the whirl tower lab once it is operational. 


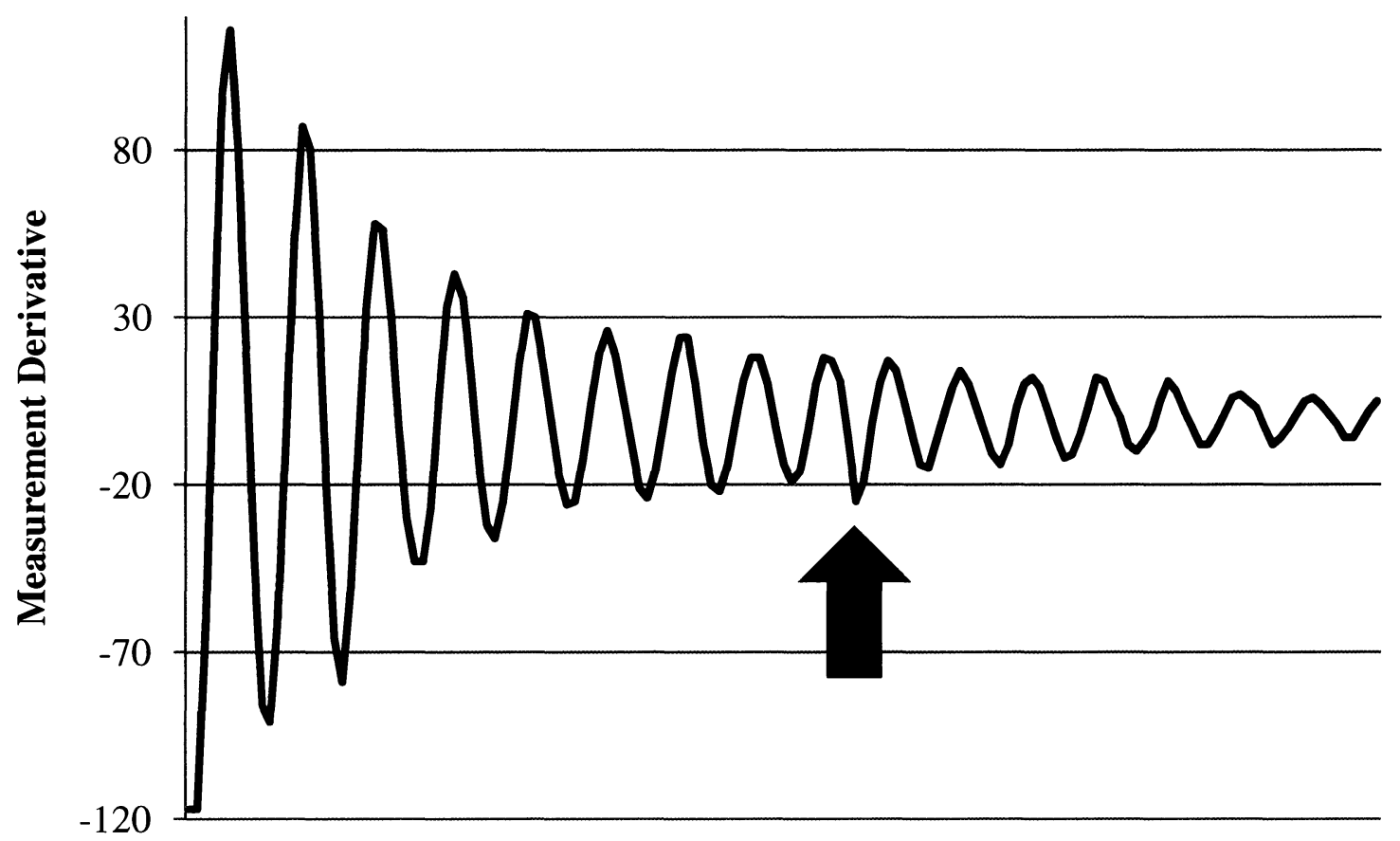

Figure 5.7: V-Link transmission data derivative showing discrepancy.

\section{Test Conclusions}

Table 5.2: V-Link evaluation tests summary

\begin{tabular}{|l|c|c|c|c|}
\hline Test & Expected Result & Actual Result & Error & Assessment \\
\hline $1 \mathrm{a}$ & $453 * 10^{6}$ & $455 * 10^{6}$ & $0.38 \%$ & excellent accuracy \\
\hline $1 \mathrm{~b}$ & $447 * 10^{6}$ & $456 * 10^{6}$ & $2.1 \%$ & confirms gain usage \\
\hline 2 & $2.15 * 10^{6}$ & $2.62 * 10^{6}$ & $22 \%$ & good signal:noise ratio \\
\hline 3 & Data Loss & $0.5 \%$ Data Loss & N/A & data loss is minor \\
\hline
\end{tabular}

After passing the three tests, and providing a generally pleasant usage experience, the decision was made that the V-Link telemetry system will be used as the primary data collection method for the whirl tower. 


\section{Chapter 6: Safety Systems and Considerations}

\subsection{Failure Containment}

\subsubsection{Containment Sizing}

The rotor blade consists of numerous components of varying density and strength, and their placement gives varying likelihood of becoming hazardous projectiles. For various plausible failure scenarios of the SHARCS rotor, the projectile energy is calculated and given in Table 6.1 below. The mass distribution and internal blade design are taken from the 2007 SHARCS blade design, which can be found in Ref. [1]. For this table, rotational kinetic energy is calculated by the integral:

$$
\begin{gathered}
E_{k}=\int_{0}^{m} \frac{1}{2} v^{2} d m \\
E_{k}=\int_{0}^{m} \frac{1}{2}(\omega r)^{2} d m
\end{gathered}
$$

where,

$$
\begin{gathered}
\omega=M_{\text {tip }} * \frac{a}{R} \\
M_{\text {tip }}=0.52 \quad a \cong 340 \frac{\mathrm{m}}{\mathrm{s}} \quad R=1.096 \mathrm{~m}
\end{gathered}
$$




$$
d m=\frac{m}{r_{o}-r_{l}} d r \quad \text { assuming } \quad \frac{d(\rho A)}{d r}=0
$$

Thus,

$$
\begin{aligned}
& E_{k}=13011 s^{-2} \cdot \frac{m}{r_{o}-r_{l}} \int_{r_{o}}^{r_{l}} r^{2} d r \\
& E_{k}=4337 s^{-2} \cdot \frac{m}{r_{o}-r_{l}}\left(r_{o}^{3}-r_{l}^{3}\right)
\end{aligned}
$$

Table 6.1: Energy for various blade components

\begin{tabular}{|l|c|c|c|c|c|}
\hline Description & $\begin{array}{c}\text { Mass } \\
(\mathbf{g})\end{array}$ & $\begin{array}{c}\text { CG Location } \\
(\mathbf{m})\end{array}$ & $\begin{array}{c}\text { Mean Velocity } \\
(\mathbf{m} / \mathbf{s})\end{array}$ & $\begin{array}{c}\text { Momentum } \\
(\mathbf{k g} \cdot \mathbf{m} / \mathbf{s})\end{array}$ & $\begin{array}{c}\text { Energy } \\
(\mathbf{k J})\end{array}$ \\
\hline Outer Ballast & 18.3 & 1.007 & 162 & 2.96 & 0.24 \\
\hline Outer Ballast-1 & 7.26 & 0.966 & 156 & 1.13 & 0.089 \\
\hline $\begin{array}{l}\text { Blade Tip with } \\
\text { Ballast }\end{array}$ & 64 & 1.017 & 164 & 10.5 & 0.90 \\
\hline $\begin{array}{l}\text { Skeleton with } \\
\text { Ballast }\end{array}$ & 170 & 0.836 & 135 & 22.9 & 1.6 \\
\hline Whole Blade & 578 & 0.628 & 101 & & $<3.5 *$ \\
\hline Counterweight** & $1.9 \mathrm{~kg}$ & $<0.36$ & $<66$ & $<123$ & $<4.4$ \\
\hline
\end{tabular}

*higher uncertainty due to $\frac{d(\rho A)}{d r} \neq 0$

**The counterweight calculations are for maximum extension and 1,750 RPM, the absolute upper limit, see Section 3.7 (22.6 kN balance)

The blade ballast consists of tungsten rods with $4 \mathrm{~mm}$ to $5.5 \mathrm{~mm}$ diameter and 30 $\mathrm{mm}$ to $40 \mathrm{~mm}$ length. These tungsten rods are the blade components most closely resembling bullets, of which there are over a dozen in the blade. However, after the 
outermost ballast having a kinetic energy of $240 \mathrm{~J}$, their energy falls off steeply to less than $100 \mathrm{~J}$. These pieces are unlikely to become projectiles unless a significant blade failure occurs as they are located within the main blade structure. It is the outermost one inside the blade tip that would behave as a single projectile, should it be released.

The blade tip weighs 64 grams including the tungsten ballast. This whole system is a very likely candidate for becoming a projectile in a failure. It has a kinetic energy of $900 \mathrm{~J}$ and an approximate profile of $10 \mathrm{~cm} \times 8 \mathrm{~cm} \times 1 \mathrm{~cm}$, making it less bullet like but still relatively compact.

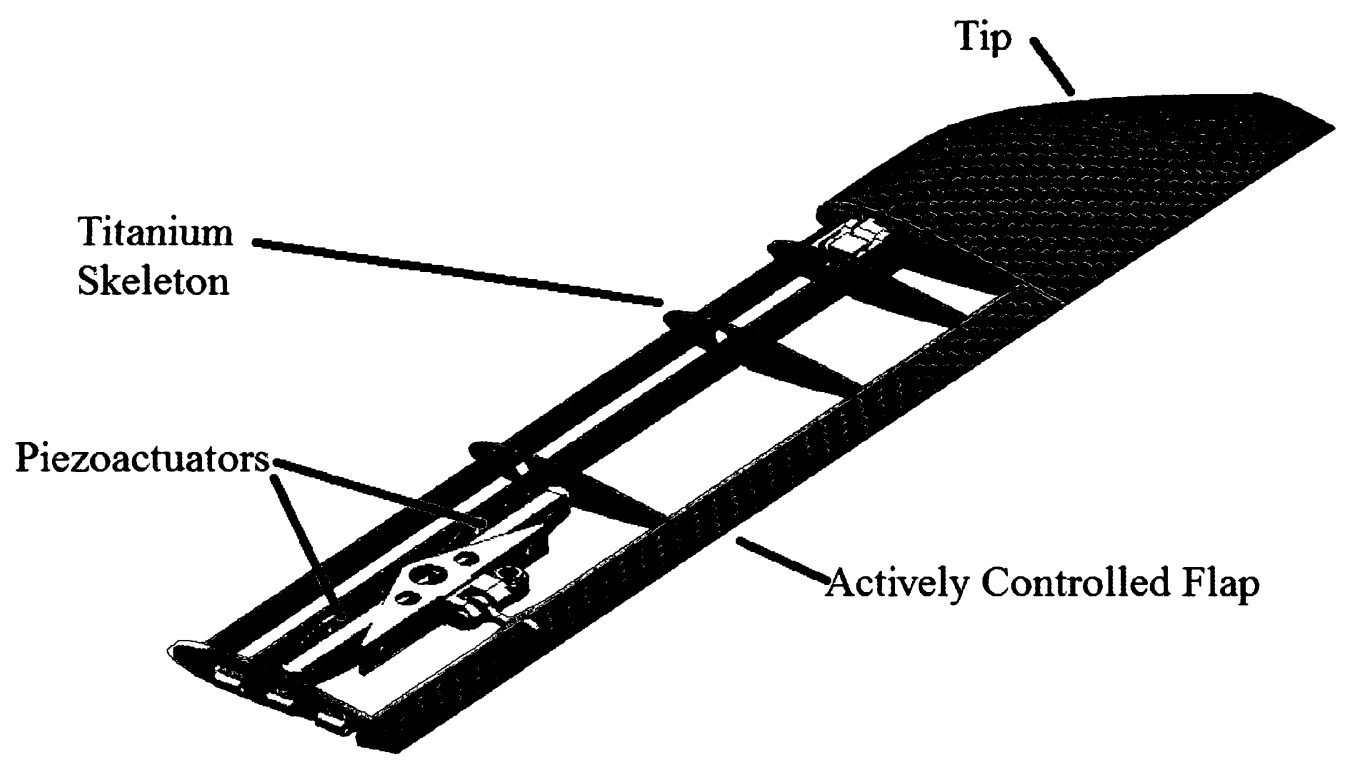

Figure 6.1: 3 SHARCS blade titanium skeleton [1].

The largest likely solid projectile would come from the titanium skeleton exiting the blade. It is a relatively thin, shell-like structure that is unlikely to have much penetrating potential (see Figure 6.1), but it does contain 36 grams of tungsten ballast. 
With the tungsten, it has a kinetic energy of $1.6 \mathrm{~kJ}$, but due to its larger size, thin frame, and distribution of tungsten, it would be more akin to multiple weaker projectiles rather than one high-energy one.

Finally, a full blade has an energy value of approximately $3.5 \mathrm{~kJ}$, and there is the potential for multiple of any event due to it being a four bladed system. This sets the expected upper limit of protection needed for the SHARCS rotor.

It should be noted that if the system is operating with a counterweight rather than with symmetric blades, then a counterweight failure could be more hazardous, as it would be a dense steel projectile. Since rotational energy is proportional to $m \cdot r^{2}$, where centripetal force is proportional to $m \cdot r$, it is possible to balance the rotor with a heavy counterweight with less energy and lower mean velocity. The value shown in Table 5.1 is for the counterweight at full extension on its armature, with the failure including the armature, and rotating at 1,800 RPM. This configuration would have the counterweight balancing a $24 \mathrm{kN}$ rotor blade, higher than the designed safety limits of the counterweight and tower and therefore representing a failure that should never occur. However, it is possible that an improperly operated rotor could be spun in this configuration and therefore it is included as the unlikely upper limit. For normal operations of the counterweight, it should never be in danger of failure due to its safety factor, although a failure could occur due to impact with an obstruction. 


\subsubsection{Containment System}

Waco Composites produces a ballistic protection panel called ArmorCore, with a 1 to 8 rating system for protection from projectiles described in Table 6.2 below. Note that for the first three levels, the panels are rated for a 3-round burst.

Table 6.2: Bullet resistance for ArmorCore protection levels 1 to 8 [53].

\begin{tabular}{|l|c|c|c|c|c|}
\hline Description & $\begin{array}{c}\text { Mass } \\
(\mathbf{g})\end{array}$ & $\begin{array}{c}\text { ArmorCore } \\
\text { Level }\end{array}$ & $\begin{array}{c}\text { Velocity } \\
(\mathbf{m} / \mathbf{s})\end{array}$ & $\begin{array}{c}\text { Momentum } \\
(\mathbf{k g * m} / \mathbf{s})\end{array}$ & $\begin{array}{c}\text { Energy } \\
(\mathbf{k J})\end{array}$ \\
\hline $9 \mathrm{~mm} \times \mathbf{3}$ & 8 & 1 & 394 & 3.2 & 0.620 \\
\hline 0.357 Magnum x 3 & 10.2 & 2 & 419 & 4.3 & 0.896 \\
\hline 0.44 Magnum x 3 & 15.6 & 3 & 452 & 7.1 & 1.594 \\
\hline $0.30-06 \times 1$ & 11.7 & 4 & 851 & 10.0 & 4.241 \\
\hline $7.62 \mathrm{~mm} \times 1$ & 9.7 & 5 & 922 & 8.9 & 4.121 \\
\hline 9 mm x 5 & 8 & 6 & 394 & 3.2 & 0.620 \\
\hline 5.56 mm x 5 & 3.56 & 7 & 1033 & 3.7 & 1.899 \\
\hline 12 Gauge 00 Shot x 12 & 42 & 8 & 403 & 16.9 & 3.404 \\
\hline
\end{tabular}

The panels are manufactured from compressed layers of fiberglass composite. A description of the panels, as well as the intended panel's use, is provided in Tables 6.3 and 6.4. 
Table 6.3: Physical properties for Armorcore protection levels 1 to 8 [54].

\begin{tabular}{|c|c|c|}
\hline ArmorCore Level & Thickness (in.) & Weight $\left(\mathbf{l b} / \mathbf{f t}^{2}\right)$ \\
\hline 1 & $1 / 4$ & 2.6 \\
\hline 2 & $5 / 16$ & 3.6 \\
\hline 3 & $7 / 16$ & 4.9 \\
\hline 4 & $13 / 8$ & 14 \\
\hline 5 & $17 / 16$ & 14.9 \\
\hline 6 & $3 / 8$ & 3.9 \\
\hline 7 & $11 / 8$ & 11.9 \\
\hline 8 & $17 / 16$ & 14.9 \\
\hline
\end{tabular}

Table 6.4: Armorcore protection levels 1 to 8 bullet resistance description [55].

\begin{tabular}{|c|l|}
\hline $\begin{array}{c}\text { ArmorCore } \\
\text { Level }\end{array}$ & \multicolumn{1}{c|}{ Description } \\
\hline 1 & $\begin{array}{l}\text { Protection against hand guns of medium power, such as the 9 mm, Super } \\
38 \text { Automatic, and the like, with muzzle energy of 515-624 J }\end{array}$ \\
\hline 2 & $\begin{array}{l}\text { Protection against hand guns of high power, such as the 0.357 Magnum, } \\
\text { and the like, with muzzle energy of 743-899 J }\end{array}$ \\
\hline 3 & $\begin{array}{l}\text { Protection against hand guns of super power, such as the 0.44 Magnum, } \\
\text { and the like, with muzzle energy of 1,317-1,593 J }\end{array}$ \\
\hline 4 & $\begin{array}{l}\text { Protection against high-power hunting and sporting rifles, such as the 30- } \\
06, \text { and the like, with muzzle energy of 3,498-4,929 J }\end{array}$ \\
\hline 5 & $\begin{array}{l}\text { Protection against military ball full metal copper jacket ammunition fired } \\
\text { from a hunting rifle such as the 308 Winchester or a military rifle with } \\
\text { muzzle energy of 3,416-4,133 J }\end{array}$ \\
\hline 6 & $\begin{array}{l}\text { Protection against multiple shots from a submachine-gun, such as a 9 mm } \\
\text { Uzi, and the like, with muzzle energy of 732-885 J }\end{array}$ \\
\hline 7 & $\begin{array}{l}\text { Protection against multiple shots from a military assault rifle, such as the } \\
\text { M-16, and the like, with muzzle energy of 1,570-1,901 J }\end{array}$ \\
\hline 8 & $\begin{array}{l}\text { Protection against multiple shots from a military assault rifle, such as an } \\
\text { M-14, and the like, with muzzle energy of 3,416-4,133 J }\end{array}$ \\
\hline
\end{tabular}


Panel level 3 is capable of absorbing and retaining a 3-round burst of $1.6 \mathrm{~kJ}$ projectiles with approximately 2-3 inch separation (test burst depicted in Figure 6.2). Since $1.6 \mathrm{~kJ}$ represents the total energy in the titanium skeleton with ballast included, but over an area a minimum of $8 \mathrm{~cm}$ in length (blade chord representing a perpendicular impact, a worst case scenario for this impact), it appears that Level 3 will certainly provide sufficient protection from SHARCS blade failures. A full blade off contains 3.5 $\mathrm{kJ}$, but with such a large distribution of energy that it should not represent more than a 3round burst of $1.6 \mathrm{~kJ}$ projectiles either. A concentrated perpendicular strike is very unlikely from a full blade in rotation, and even so, the blade will likely spread its energy over an area at least an order of magnitude larger than a 0.44 Magnum bullet.
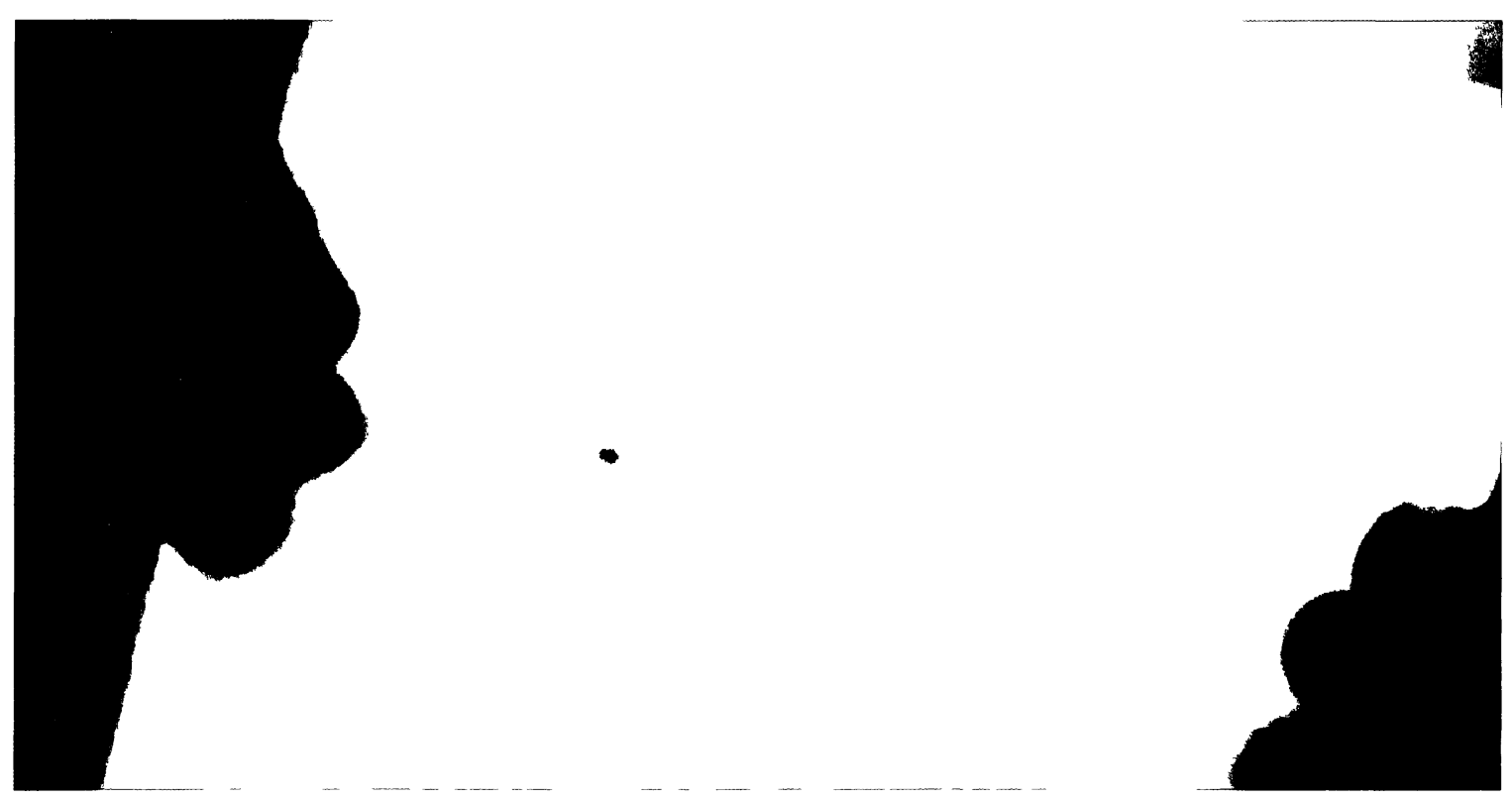

Figure 6.2: 3 Live fire test - 0.44 Magnum on Level 3 [56]. 
The certainty of Level 3 panels to withstand an impact from a large steel counterweight depends on its ability to withstand a strike with high momentum. Besides firearms, Level 3 panels are additionally the recommended type for F5 tornado safe rooms. They have been tested with the impact of two successive 15 pound $2 \times 4$ 's traveling over $100 \mathrm{mph}$, striking in a perpendicular tip impact [57]. These projectiles have a momentum of $305 \mathrm{~kg} \cdot \mathrm{m} / \mathrm{s}$ and $7 \mathrm{~kJ}$ kinetic energy, each indicating that Level 3 protection is certainly adequate for the current counterweight and rotor blades, and for future larger rotors as well. The upper limit of its safe capability will require looking at each rotor's particular composition, and no flat specific values can be given.

The installation of these panels will create a wall from floor level to eight feet high. No roof will be included, therefore to protect against debris exiting the test cell when shattering, as well as any possible breach, a second layer of protection is required for the operator's area. A Level 1 system is selected for that application.

\subsection{Safe Operation Measures}

The safe operating requirements were discussed and decided upon with representatives of the facility owner, NRC. Other than containment for the tower and the operators as discussed in section 6.1 , the following safety requirements were decided upon. Justifications are not given as many were logical precautions or conditions for using the facility. 
- Two operators must be present at all times; no one may operate the facility by him or herself.

- Operations can only happen during normal working hours when NRC is staffed.

- The test room and the operators console must both have a kill switch.

- The door to the test room must have an automatic kill switch.

- The door to the test room must have a self-closing mechanism to ensure it is latched and will not open due to aerodynamic forces.

- The operating station must be on the side of the test room closest to the main exit.

- No one may leave the safety of the operating zone while the tower is rotating

- A gate or rope on each approach to the test room must be present along with warnings.

- The test room will contain cameras to check before start-up and monitor during operation for problems.

- Operating procedures for all standard operations will be written and provided.

These requirements may change or be expanded as needed in the future. 


\section{Chapter 7: Facility Infrastructure}

\subsection{Installation}

The location where the whirl tower is being installed is building M22 of NRC's Montreal Rd. campus in Ottawa. The facility is a retired water-towing trench and was one of a few options presented by NRC. This site was immediately regarded as an excellent choice, as it had the space and isolation desired. The trench box is below ground level and has concrete walls. There are no neighbours to disturb, including above or below. A balcony exists to look down upon what was once the towing pool, but now it serves as a vantage point for lighting or photographic equipment. A crane on rails is available with a two ton capacity. The access is through a large bay door that could fit any needed vehicles. There is also ample electrical power in the building, although not run to the locations needed. Finally, the ceiling is very tall and the trench very long, so no air conditioning will be necessary for the heat being generated. A drawing was given by NRC that depicts the trench cross section; a heavily edited version of it is shown as Figure 7.1. The location did lack lights and electrical sockets, so when ownership was taken in July 2010, substantial time was needed to run lighting and power and bring all the equipment to begin construction of the test cell. 


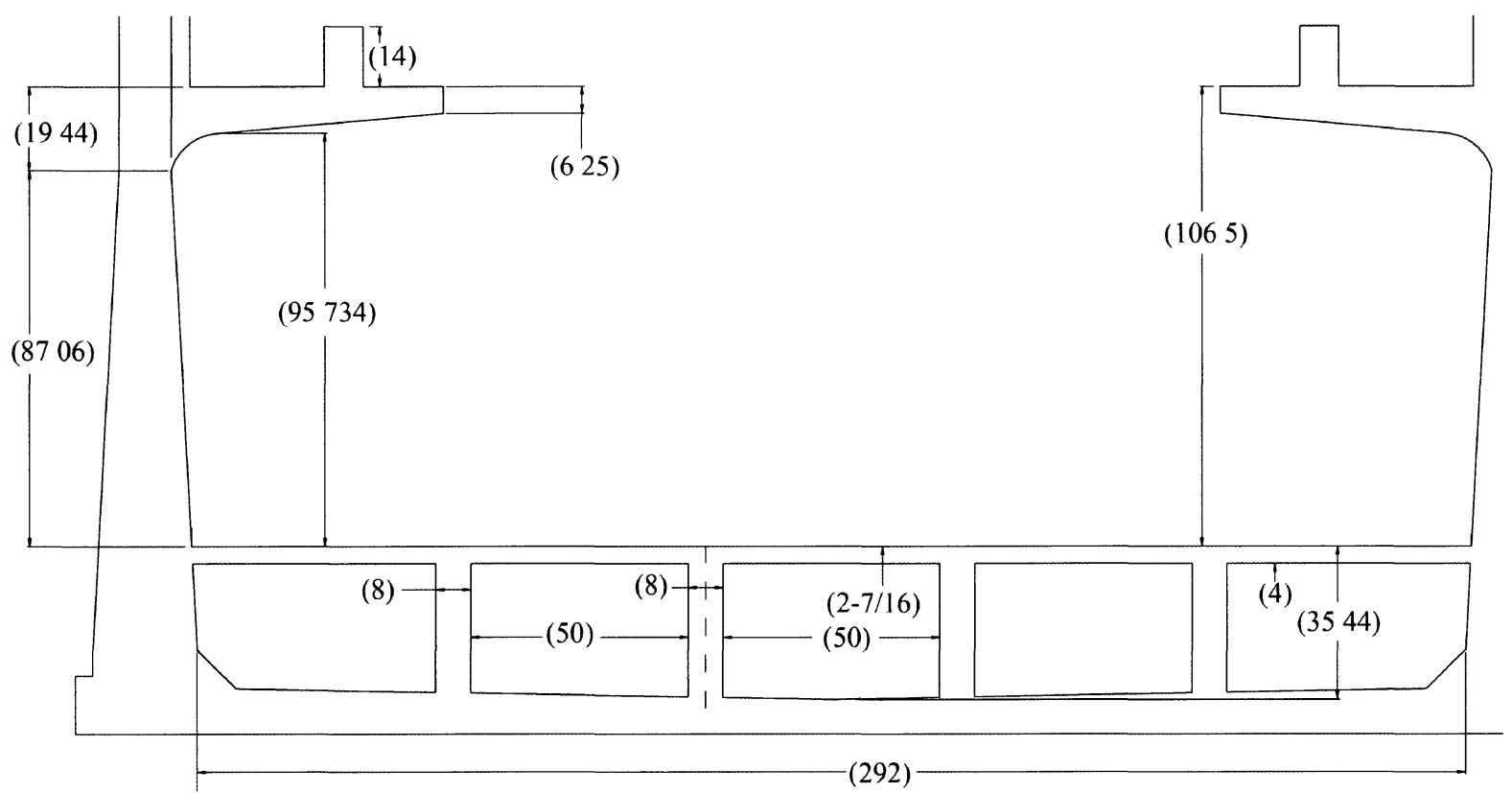

Figure 7.1: M22 trench cross section, dimensions in inches, all concrete.

The floor is only a shallow, poured concrete slab on steel pans; it was not meant for significant loading as the floor had water below it when the pool was flooded. Discussions with NRC also indicated that the floor was not reinforced with rebar, so it should not be considered a secure mounting platform. In light of this, it was decided to change the span of the tower to 58 inches for fastening to the floor in the center of the 8 inch concrete supports beneath the poured slab. The anchors can still be put only into the poured surface, but by putting them in the center of the support columns it will avoid exciting the modes of the floor in a rotor failure. By choosing this span, it is also possible to put the anchors into the support column later if needed, although coring tools would be needed to penetrate the steel pan. The fasteners selected are single-expansion concrete

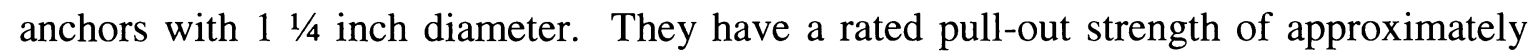
12,500 pounds force, depending on the concrete properties [58]. 
When time came to install the anchors, two fluted concrete bits and a hammer drill were used. The first hole drilled was a pilot hole through the whirl tower frame to locate the larger anchor hole. While drilling this hole, at approximately 1.5 inches below the surface, a rebar was hit and the drill violently stopped. This was not expected and after careful consideration it was decided that the rebar was likely 6 or 12 inches on center and therefore the hole was moved over 3 inches to try again. On this hole the pilot drilling was successful, but upon starting with the larger bit for the anchor diameter, another rebar was struck again in the perpendicular direction. Since four holes needed to be placed in a row, with no rebar being hit on any, it was time to consider other options.

After considering the options available, the decision was made to contract a coring company. This technique uses a coring bit, which is a circular bit similar to a hole saw which grinds though the concrete and any rebar, with the help of water cooling, rather than a fluted bit which chips it out. The equipment was not available to attempt this, so the work needed to be contracted. Since a coring bit cannot be located precisely or use a pilot hole, it was necessary to construct a jig using half-inch ply with pre-located $1 \frac{1 / 4}{4}$ inch holes for the contactors to drill through. This was fastened to the floor with small anchors and the whole process eventually proved successful. The previous unsuccessful holes were filled with epoxy afterwards, and as a benefit to this complication, the poured floor is now considered stronger than originally expected due to it containing rebar, and thus its use for anchoring is satisfactory. 


\subsubsection{On Site Assembly}

After coring and installing the concrete anchors, the tower was prepared to have the motor loaded into it. The first step was to install the bearings and drive shaft. To do this, a custom bearing puller/pusher was used. It consists of a hollow aluminum square tube with three holes drilled in it, two corresponding to the diagonal span of the top bearing plate's mounting holes, and one hole in the center. This is bolted to the tower and then a threaded rod is used with nuts and washers to pull out the aluminum plug that protected the bearing mount during painting. After this, any paint that would interfere with pressing the bearing was sanded, the bearing and mounting holes were both lubricated with light oil, and the bearing was pressed in using the aluminum plug, threaded rod, and aluminum armature in a pusher configuration. Once the lower bearing was installed into the bearing housing, the drive shaft with top bearing assembly and slip rings were lifted onto the tower and dropped into the lower bearing. The bearing housing was bolted to the tower with $200 \mathrm{ft} \cdot \mathrm{lb}$ of torque using a torque wrench as planned.

The tower was then laid on its side on top of two large wooden beams with the motor mounting holes facing downward. The motor was hoisted with the crane over the opening in the tower and lowered into its approximately correct position. The motor bolts were loosely installed and then the motor was lined up relative to the drive shaft. This was done by using a set of parallels (steel bars ground parallel that are used in machining) to check the centering of the two shafts with respect to each other. (See Figure 7.2 for an image of the alignment process.) Adjustments were done by using soft lumber as a lever against the frame. The alignment achieved is within an estimated 0.002 
in., much less than the 0.017 in. coupler tolerance [30]. With this precision, the coupler assembly is able to slide from one shaft onto the other without any resistance being experienced due to misalignment. The coupler was installed at the midpoint between the two shafts and the setscrews were engaged. Once assembly was completed, the tower was hoisted into position above the concrete fasteners and bolted into place. The rubber pucks for final mounting were not available at this point, so wood blocks were used and the floor bolts were not torqued to full pre-load. Figure 7.3 depicts the installed tower at this point.

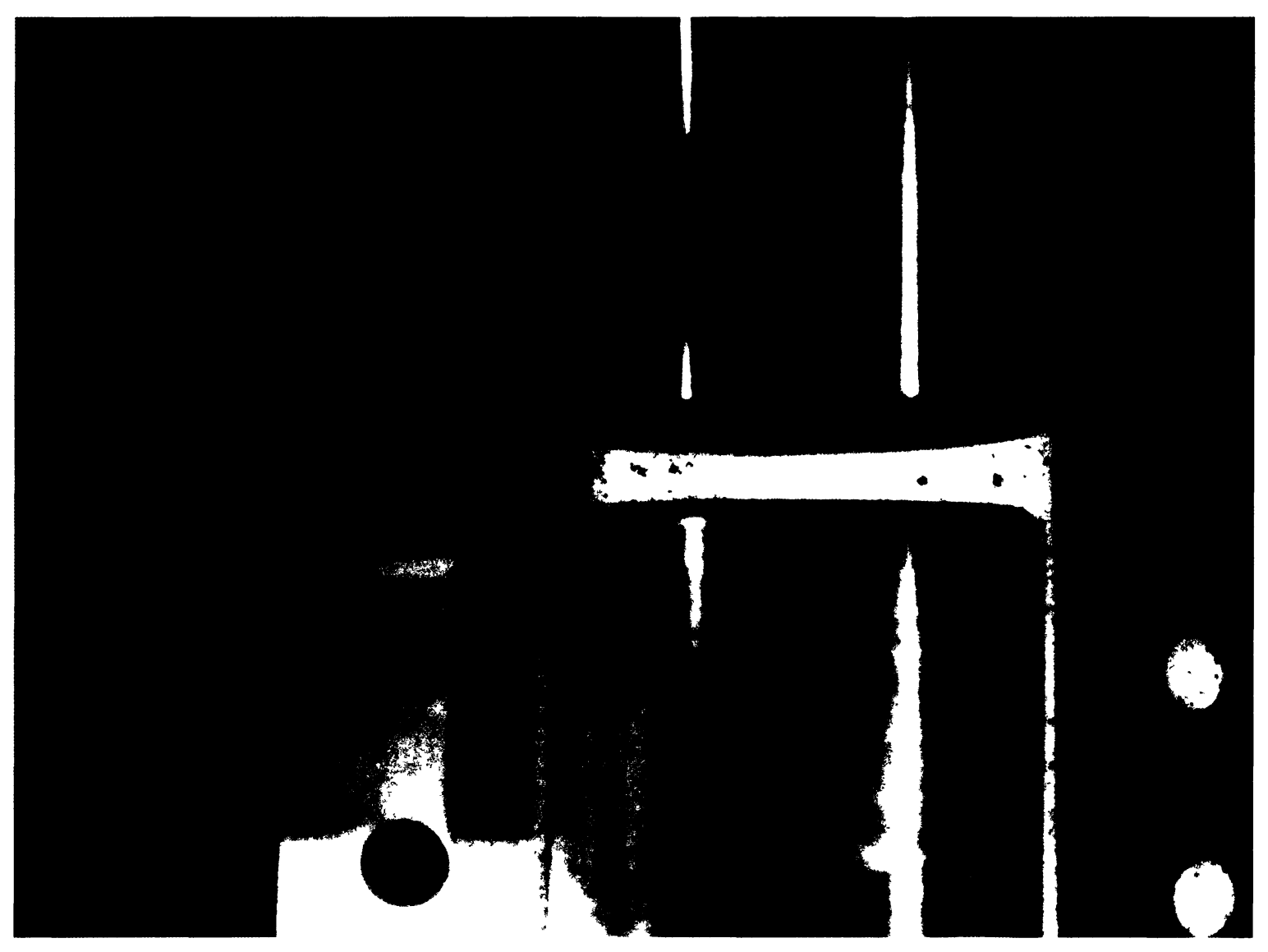

Figure 7.2: Aligning the two shafts using parallels. 


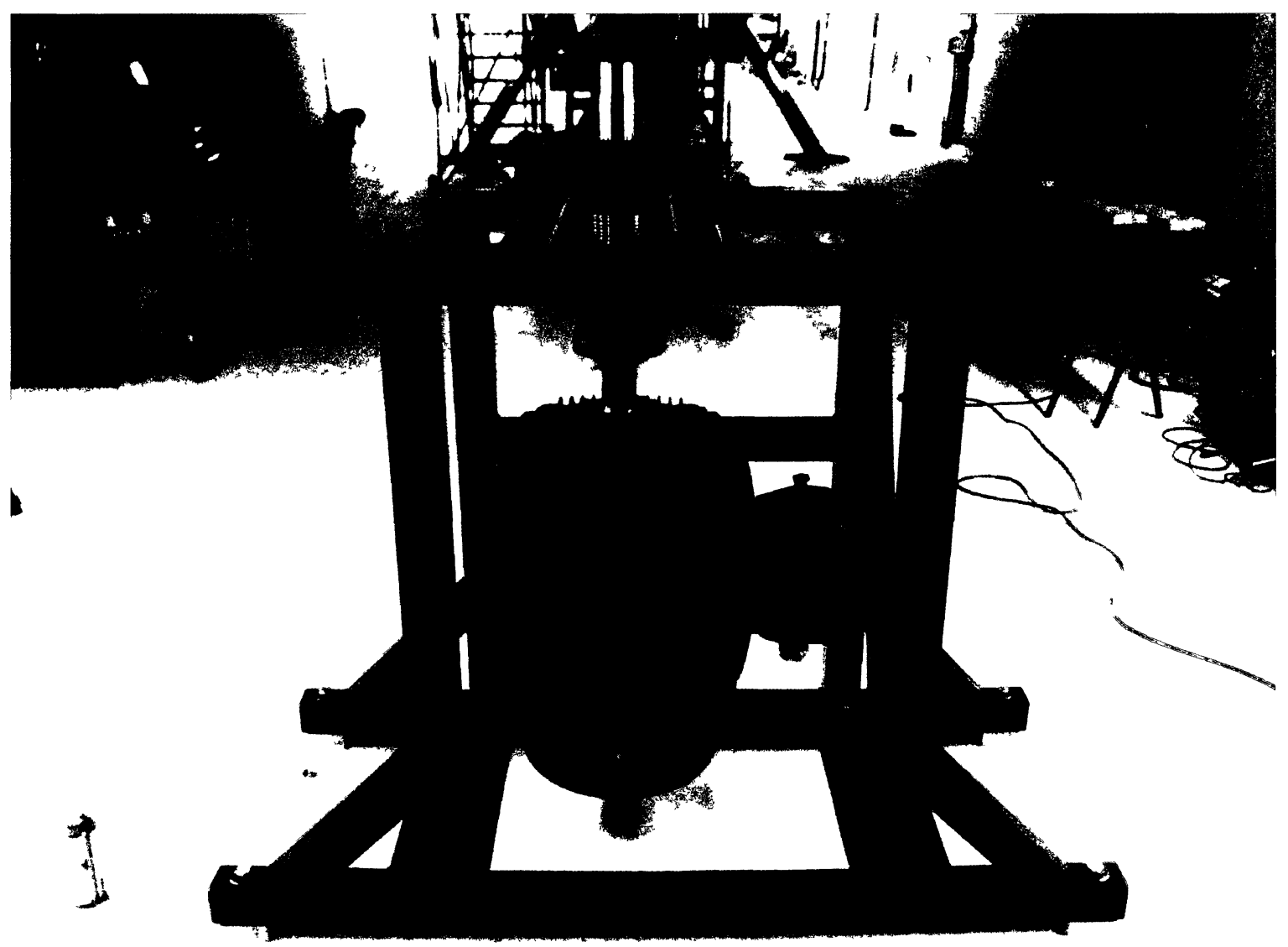

Figure 7.3: Assembled and installed whirl tower.

\subsection{Whirl Tower Room}

The goal for the test room is to have as circular an environment as possible so as not introduce periodic aerodynamics into the testing. Due to the protective panels being very difficult to cut, the room was designed to use 4 by 8 foot ArmorCore panels (see Chapter 6) standing vertically. The dimension constraints that were developed for the room were to:

- fit within the available space of $24 \mathrm{ft}$. and leave room to walk around it,

- provide sufficient tip clearance to the wall to allow circulation, and 
- have a door that opens inwards so the door jamb can resist the door failing if stuck by debris, but to not be at risk of striking the rotor should the door blow open.

The geometry decided upon was a dodecagon ( 12 sided) configuration which resulted in a minimum internal radius of $7.46 \mathrm{ft}(2.27 \mathrm{~m})$, i.e. twice the SHARCS rotor size. By using a regular polygon, the construction could be planned with a repetitive process involving less variety of cuts. The plan developed was to use two top and bottom plates that were staggered and overlapped with the opposing plates on adjacent panels; this would allow adjacent panels to be screwed together by fastening the two top or bottom plates together. Three vertical studs would be used per panel at 16 inches on center, with a fourth vertical stud located on the seam between panels with a 4 inch wide strip of ArmorCore screwed to it. This is to protect against debris exiting the chamber at the seams between panels by doubling up the ballistic paneling in those areas. The cut list for this design consists of 48 identical cuts for the top and bottom plates, and 48 identical cuts for the vertical studs, not accounting for changes needed for a door. Figure 7.4 depicts the planned framing in CAD. 


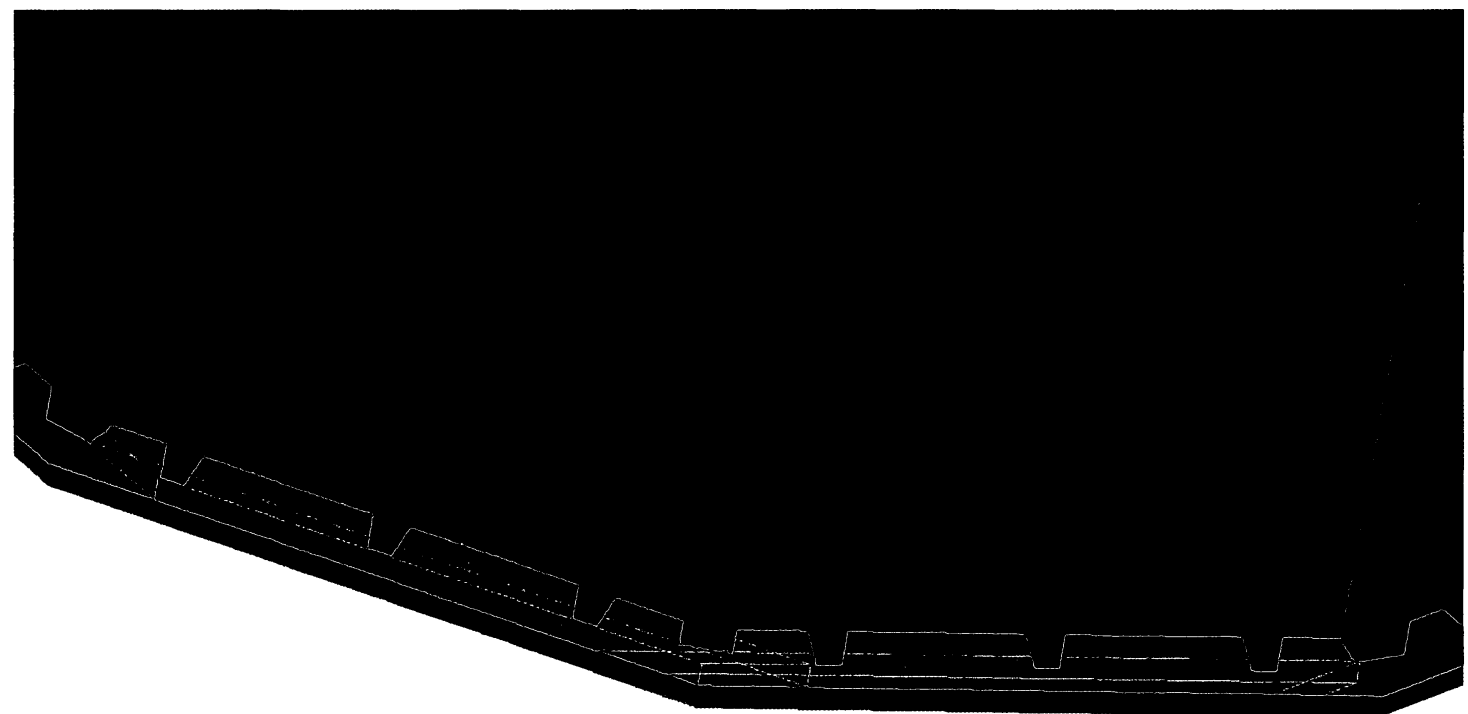

Figure 7.4: 3D CAD model of the test room framing.

When it came time to construct the room, a jig was developed, since the same frame was needed 12 times. The jig was plywood with blocks screwed to it where all the studs and plates could be butted up against to achieve a square and consistent frame (see Figure 7.5). Two frames were constructed first so that the cut dimensions and joints could be verified before proceeding. After constructing each frame, the $160 \mathrm{lb}$ ArmorCore panel was placed on top of it on the ground for screwing to the frame. This was done in advance of standing up the walls, as the panels are too heavy and difficult to work with for hanging. Every drywall screw used needed to be pre-drilled and countersunk through the ArmorCore. ArmorCore is an extremely hard product and causes heavy wear on tooling. Cobalt or carbide tooling is needed to drill or cut the panels and protective gear needs to be worn due to the fiberglass dust created (see Figure 7.6). This includes gloves, eyewear, dust masks, and long sleeves and pants [59]. Once two panels were completed, the crane was used to stand and screw them together. The two standing panels can be seen in Figure 7.7, the frame joints in Figure 7.8, and the room layout in Figure 7.9. 


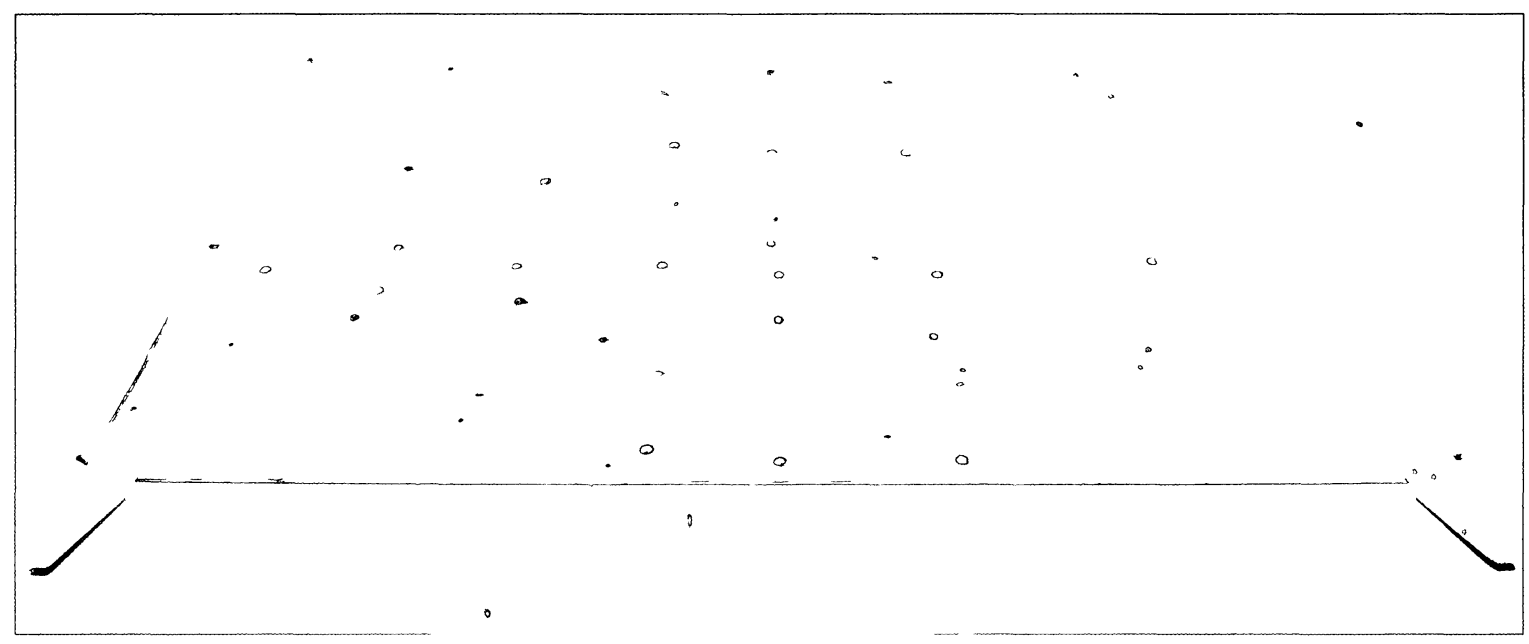

Figure 7.5: Framing jig with frame being fabricated.

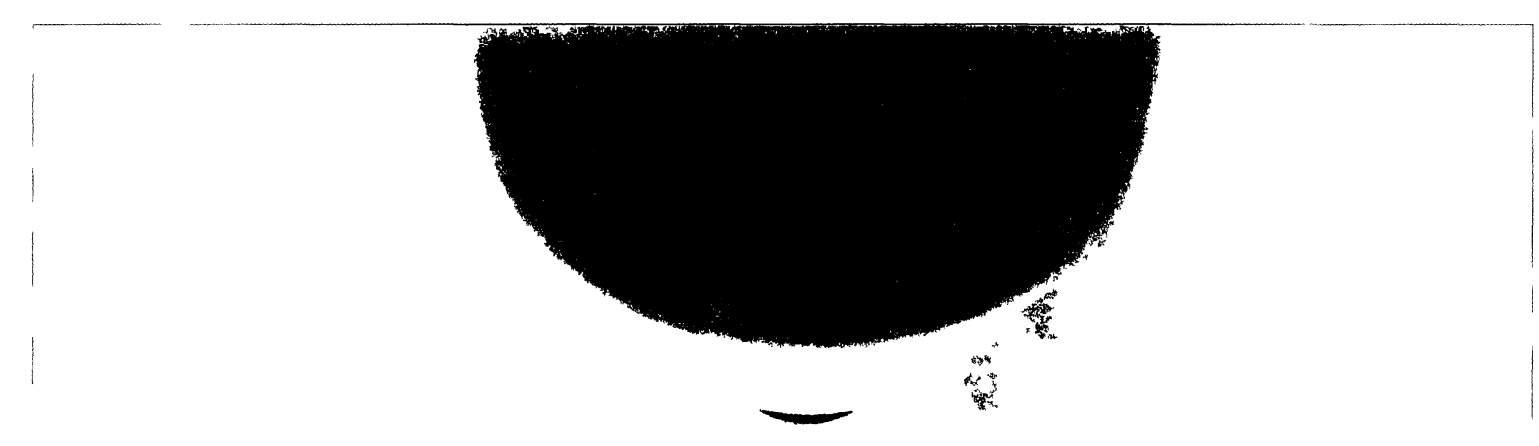

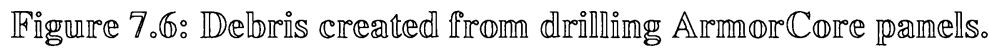




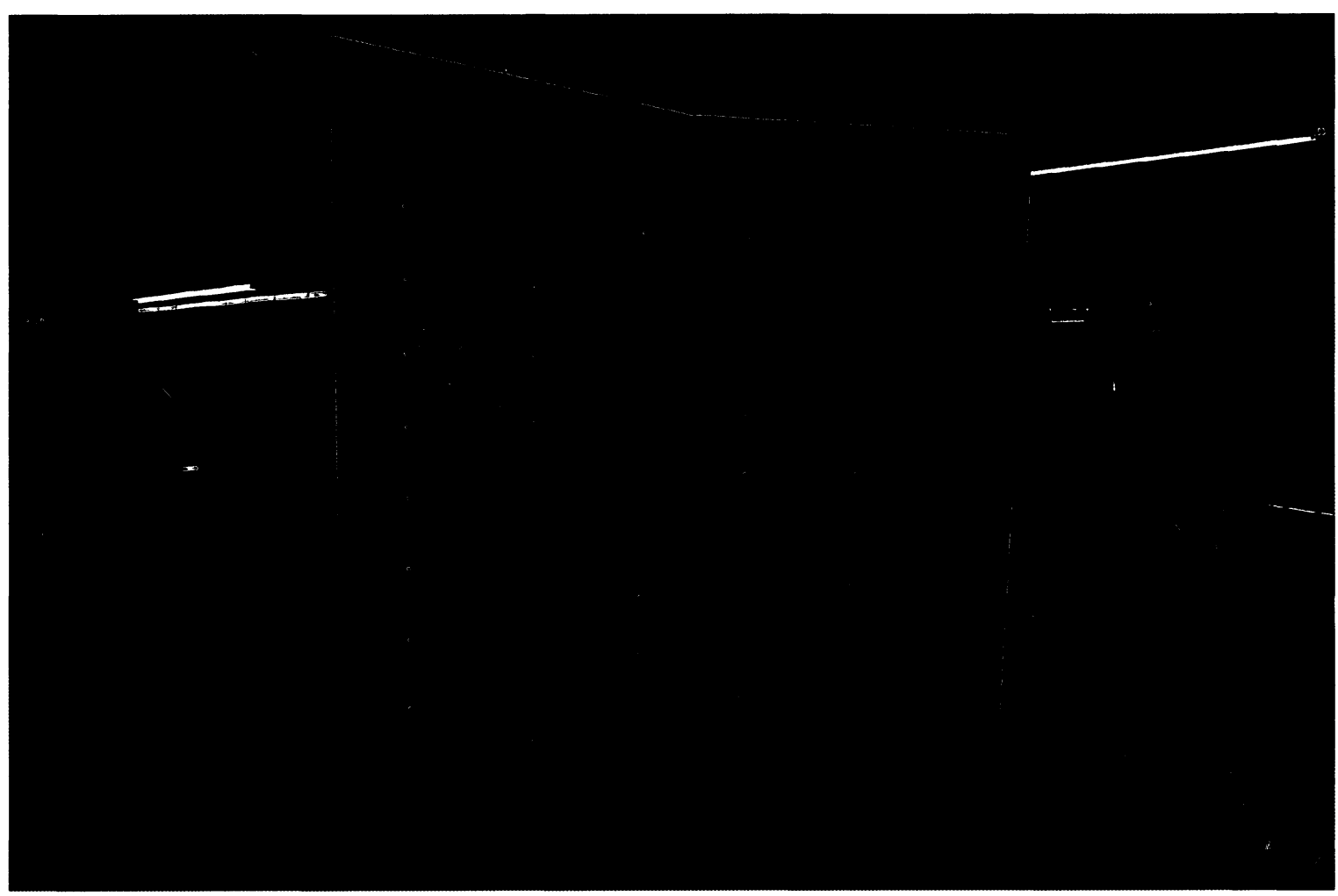

Figure 7.7: Completed pair of safety walls standing together.

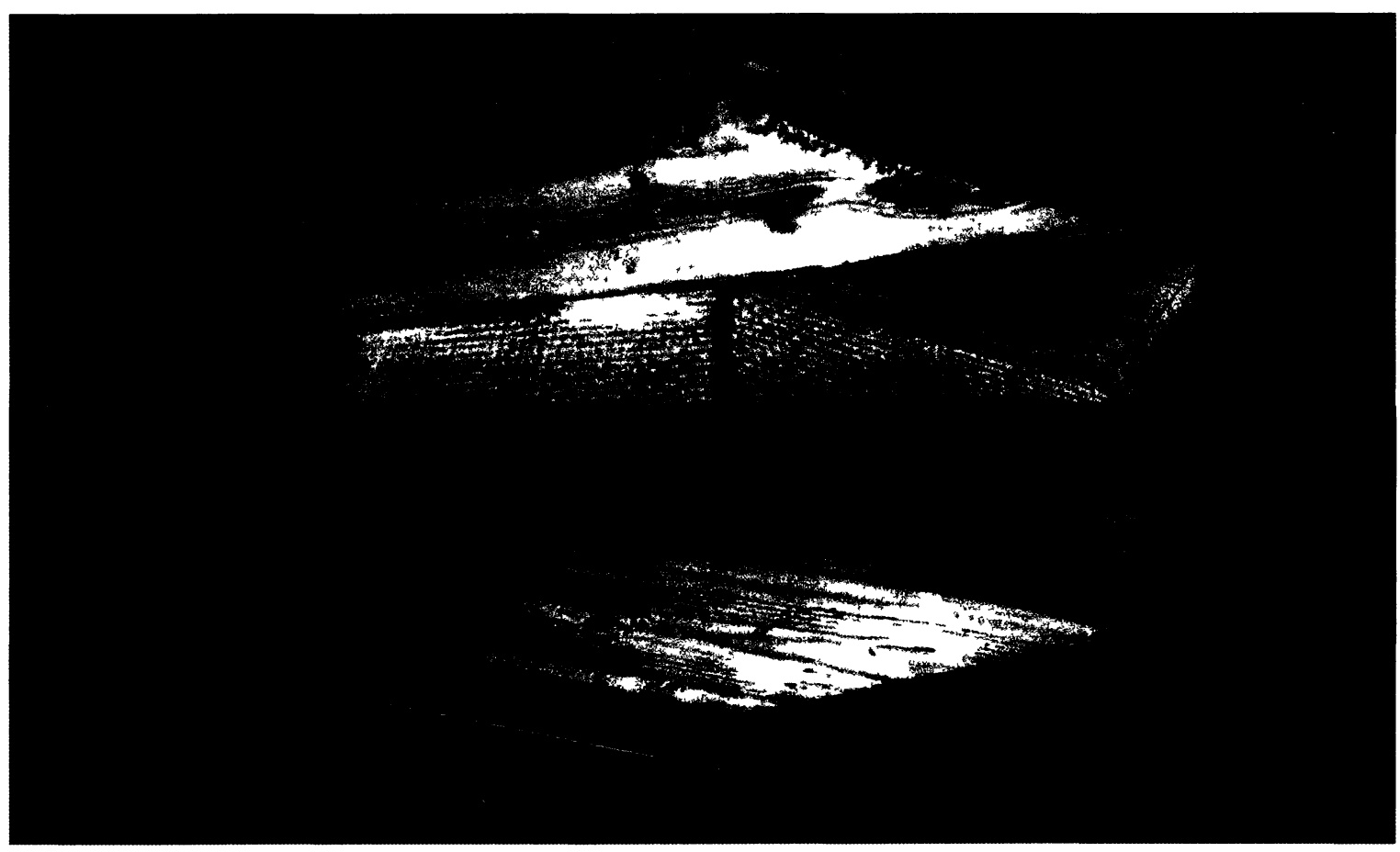

Figure 7.8: Top and bottom joint for wall frame. 


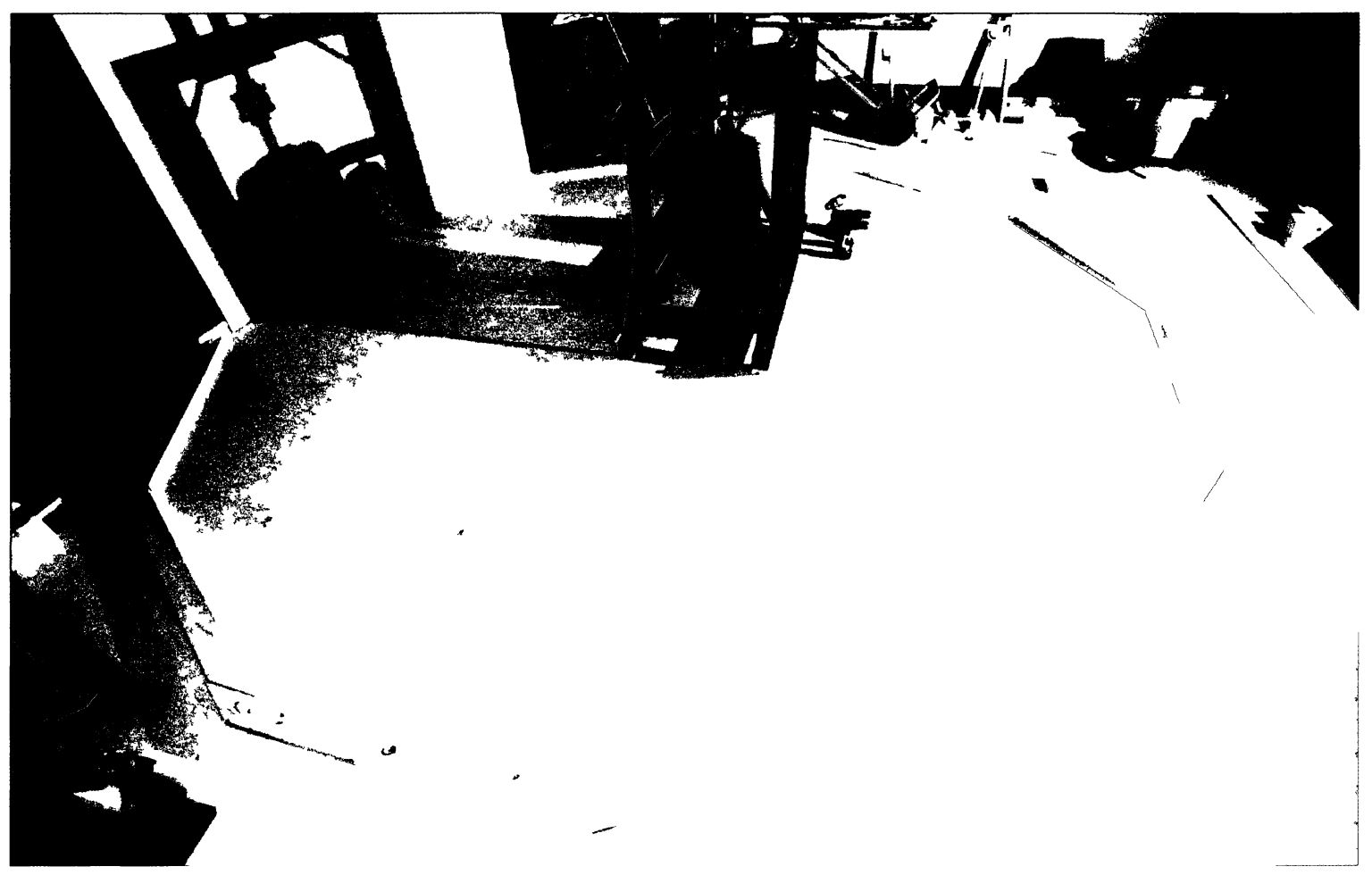

Figure 7.9: Layout of planned whirl tower room.

Once the room frame design had checked out by joining two panels, construction proceeded for the last 10 segments. A substantial amount of tooling was worn out working with the ArmorCore, so in the future spares should be budgeted and kept on hand when working with it. Two panels had changes made to the standard design. The first had a square knocked out at floor level for the motor power cable to enter the test cell. This was also a test of the panel's resistance to cutting. After successfully cutting out the wiring hole, a standard door was planned for installation in the last panel. A solid wood door was used, as it had greater strength to hold the heavy panel and could be directly screwed to (in contrast to a hollow door). The door was cut out with a masonry circular saw; significant dust was created and the tool destroyed, but the cuts were 
successful. After all 12 walls were fabricated and joined, the room was centered on the rotor shaft to within 1 inch consistency.

With the walls standing, the 4 inch strips with stud backing were needed for the panel seams. The stud needed to be thinned out and have two $15^{\circ}$ angle cuts placed on its back side for mounting of an exterior covering. The covering used for the test cell exterior is half-inch plywood. It will give the walls more rigidity against deformation and will provide a second layer of protection from penetration, although not believed to be needed in any situation. It also serves as a cosmetic covering which can later be painted and even have promotional material or logos mounted to it. The preparation and installation of the seam studs is seen in Figures 7.10 and 7.11. The interior of the test cell is shown in Figure 7.12 and the exterior in Figure 7.13.

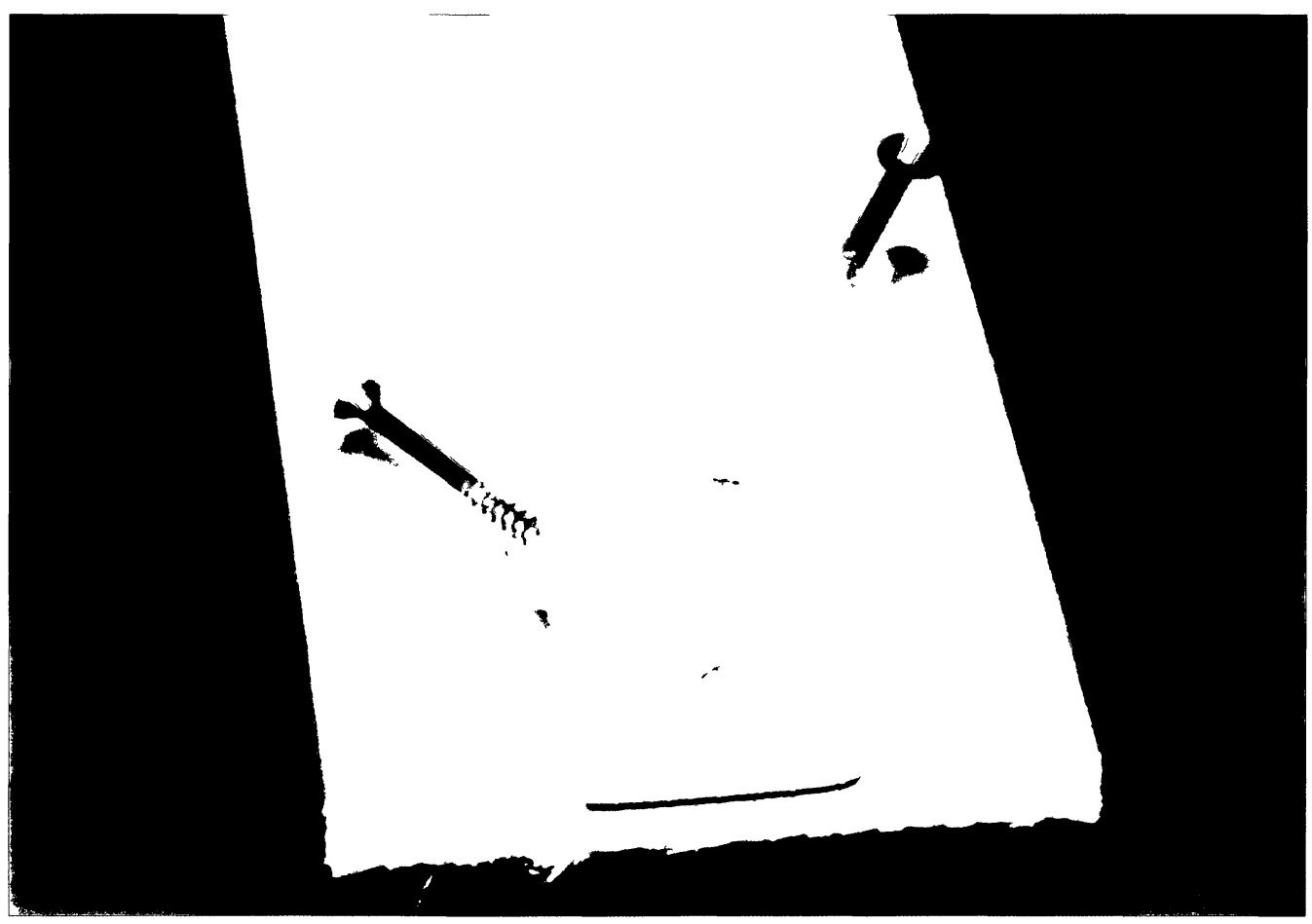

Figure 7.10: Seam stud preparation. 


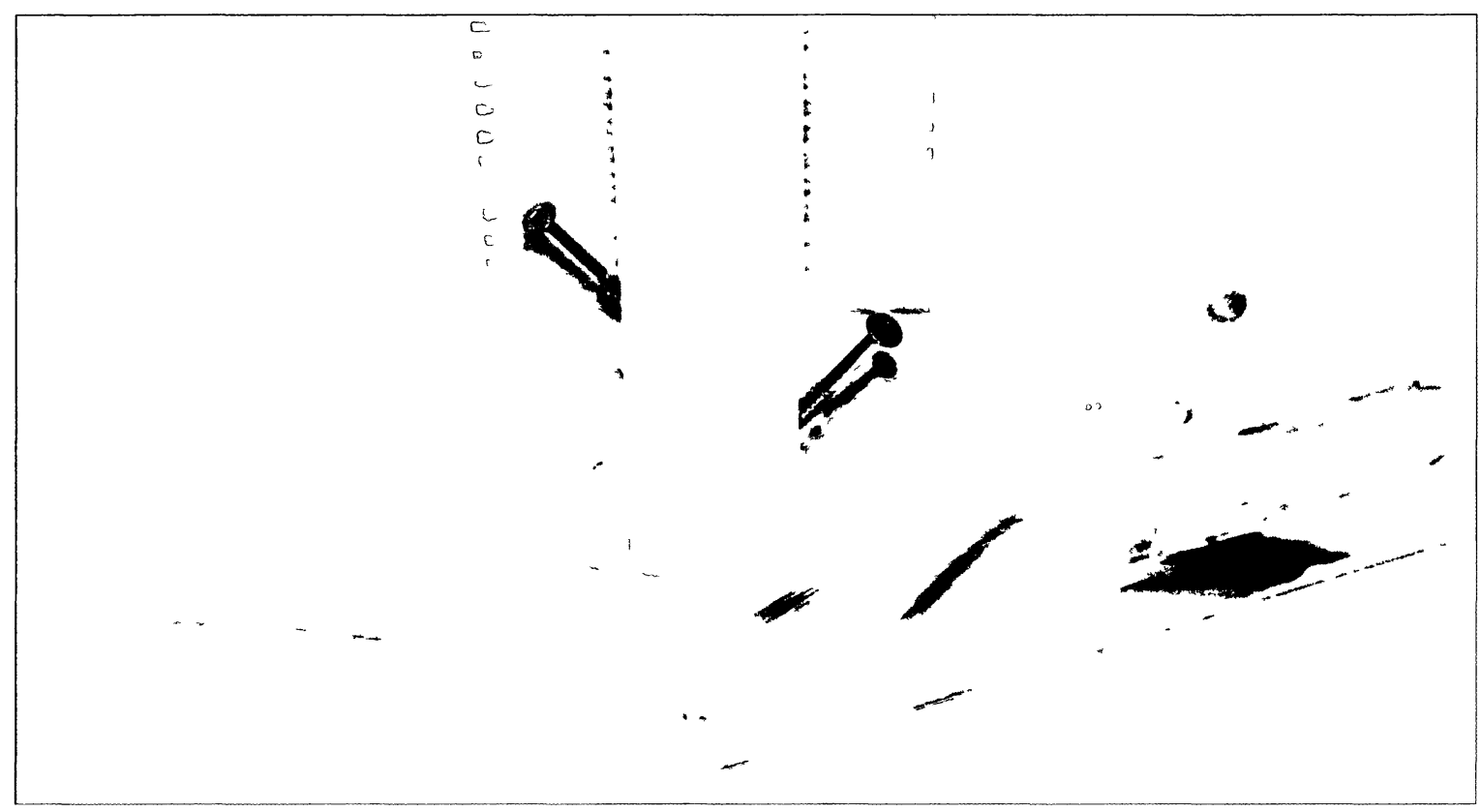

Figure 7.11: Seam stud installation.

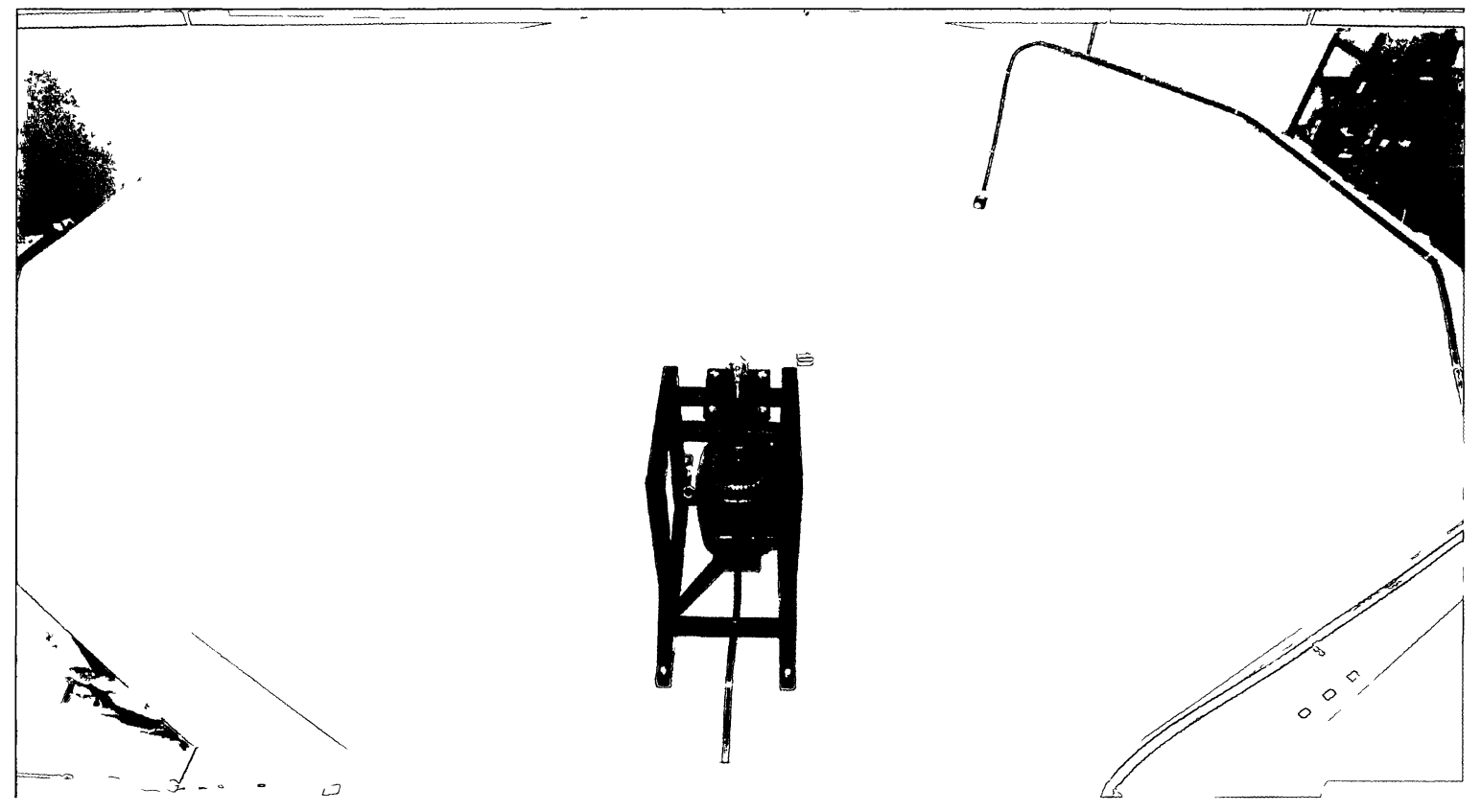

Figure 7.12: Whiñl tower room inmterior. 


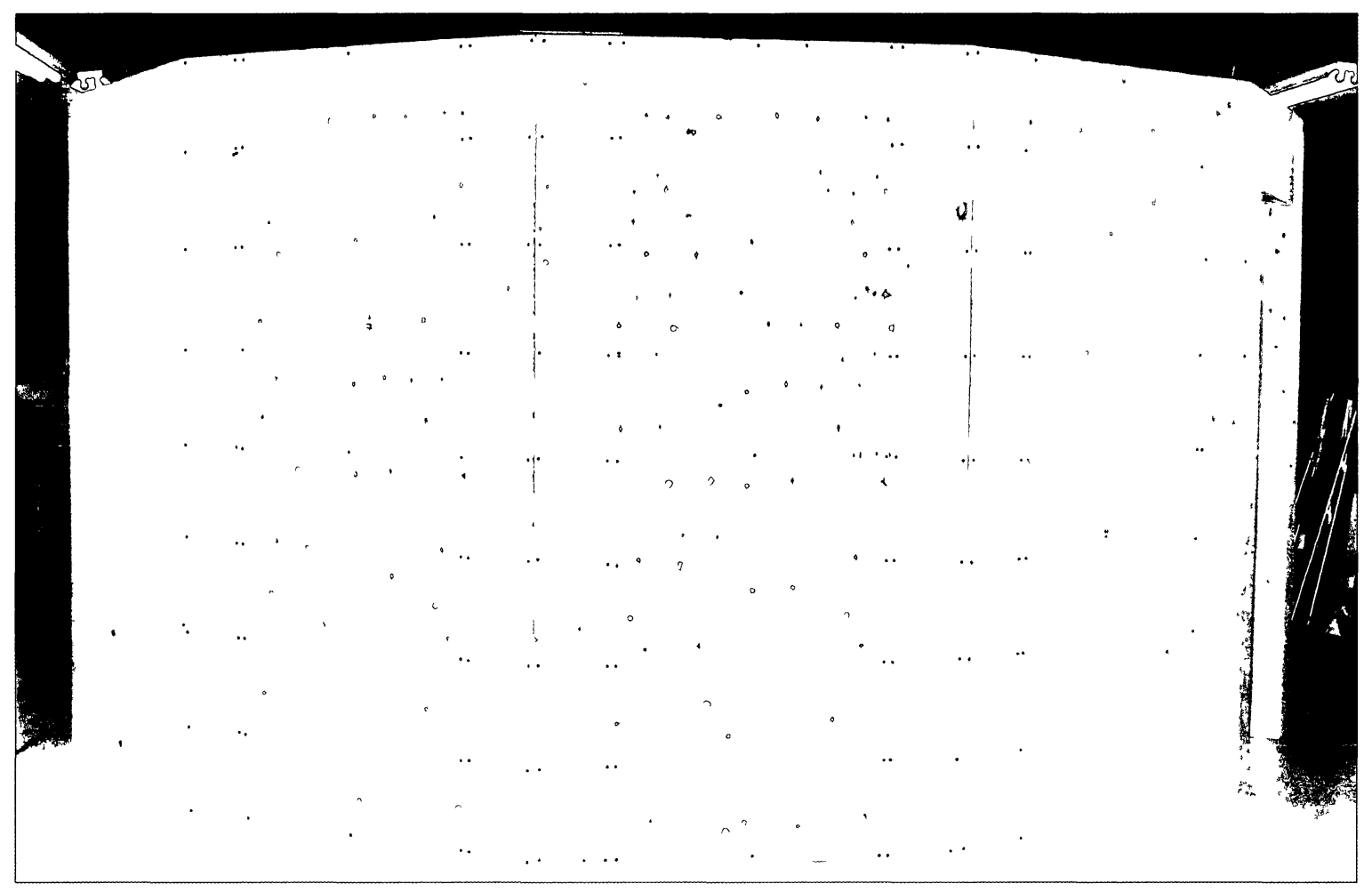

Figure 7.13: Whirl tower room exterior.

At this time, some construction is still needed for the test facility, such as the operator's room. It will be assembled using standard framing and will consist of a straight wall of two ArmorCore panels for the operators to work behind, with any extra coverage provided by plywood covering only. The electrical installation was severely delayed, but is currently underway, and first spin-up is expected in September.

\subsection{New Site Requineements}

The installation at NRC is not permanent and therefore the facility might eventually move. The whirl tower test room was designed to be modular and easy to disassemble. Moving the main containment walls would be one or two days of work with disassembly, loading, unloading and reassembly. The whirl tower should be secured by 
bolting it down to prevent it from moving and to keep it as rigid as possible. A poured concrete pad would suffice if anchoring into existing floor is not possible. The facility requires $100 \mathrm{~A}$ of 3 phase $575 \mathrm{~V}$ service for the drive system. 30 A 3 phase $208 \mathrm{~V}$ service is needed for some of the required equipment such as high-voltage power supplies, and approximately 40 to $50 \mathrm{~A}$ of $115 \mathrm{~V}$ service will be needed for computers, lighting, cameras and other equipment. If operated in a small, closed environment, all of the energy into the drive system will eventually end up as heat and thus ventilation will be required. As a guideline, the ventilation required should be approximately equal to:

$$
\text { Ventilation }\left(\frac{m^{3}}{s}\right)=\frac{\text { Duty Cycle } * \text { Power }}{\Delta T * 1.12 k W /{ }^{\circ} K}
$$

where $\Delta \mathrm{T}$ is the difference in temperature for the exchanged air (approximately $10^{\circ} \mathrm{C}$ for example), and the power is the rated motor power. Using a lower power value will mean reduced duty cycle when at higher loads, which may be acceptable. The duty cycle of the facility will be easier to establish once the current facility is in operation. Assuming a $100 \%$ duty cycle (continuous operation) at $60 \mathrm{HP}$ as the worst-case, the room would stabilize with a $10^{\circ} \mathrm{C}$ temperature rise if $4.0 \mathrm{~m}^{3} / \mathrm{s}$ of air was exchanged. This would be a half meter diameter ventilation conduit with $20 \mathrm{~m} / \mathrm{s}$ flow. The expected duty cycle is closer to $10-20 \%$. 


\section{Chapter 8: Conclusions}

The facility produced, through the work described in this thesis, pushes the envelope in terms of test facility standards for scaled rotor centrifugal testing. It has many design improvements over other similar facilities available.

The power plant of the facility is selected to be capable of driving 4-bladed rotors. This is an improvement over some whirl tower facilities, which are only designed for single bladed testing.

For the drive system two major concepts were considered, a synchronous belt system and a direct drive with elastomeric coupling. Due to the designed usage of the facility being for vibration reduction research, the use of a direct drive system is selected to provide a cleaner measurement environment. Although this will decrease the flexibility of the facility in terms of the rotor sizes and RPM that can be accommodated, it will mean superior capability compared to belt driven facilities in terms of the measurement quality that can be attained.

The large diameter high-strength shaft, two bearing installation, and solid steel rotor hub, provide a durable design that allow this facility to withstand the rotor failures that may occur when testing custom designed experimental blades. This is an improvement over some other known facilities which are not designed to survive these 
failures. It additionally provides the capability to using custom rotor hubs with varying root distance, as required by each rotor tested.

The frame was designed with careful control of its mode shapes and frequencies. The result is a structure with full operational capability from 0 to 1,800 RPM with no 'dead zones'. Some other facilities do have these limitations and are therefore immediately dismissed for ability to test certain rotors.

The data collection and signal transmission systems are designed to be leading edge in terms of capability and quality. This is a standard followed by many experimental research facilities, so it does not set this one apart, but it does ensure that this facility is not behind the curve for this important infrastructure.

The safety system of the whirl tower was designed to provide robust and comprehensive protection, while at the same time being mobile. This system is unique to this facility as whirl towers are not typically designed with relocation in mind, but instead usually depend on concrete structures for containment.

Due to the detailed and innovative design produced, this facility will push forward the local and national capability for research in experimental rotor systems.

The following future work remains before full operation of the facility can begin:

- Validate the modal analysis by performing vibration measurements of the finished whirl tower.

- Complete fabrication of the facility infrastructure (lighting, control room, safety gates). 
- Create a control interface consisting of either a control console or software interface for the VFT.

- Perform shakedown tests, primarily consisting of vibration measurements while in operation and dynamic balancing.

- Install cameras, monitors and sensors needed for the facility.

- Create operations documents to fully describe safe operating procedures for the facility.

- Create maintenance documents describing which components should be checked, what to look for, and how to replace them. 


\section{References}

[1] F.Nitzsche and D.Feszty, "SHARCS: Smart Hybrid Active Rotor Control System, Design Report 004," Ottawa, 2007.

[2] Gregory Oxley, "Smart Spring Control of Vibration on Helicopter Rotor Blades," Journal of Aircraft, vol. 46 no.2, pp. 693-696, 2009.

[3] W. R. Mantay, R. L. Campbell, and P. A. Shidler, "Full-Scale Testing of an Ogee Tip Rotor," in Helicopter Acousticsp., 1978, pp. 277-308.

[4] Henning Mainz, "Auslegung und Entwurf eines Prüfstandes für Schleudertests an einem Rotorblattsegment," Institut für Strukturmechanik, Braunschweig, 2001.

[5] J. Gordon Leishman, Principles of helicopter aerodynamics.: Cambridge University Press, 2006.

[6] Erik Goldhahn, Friedrich Leopold, and Markus Raffel Kolja Kingler, "Recent Developments in Background Oriented Schlieren Methods for Rotor Blade Tip Vortex Measurements," Lisbon, 2006.

[7] Jeffrey L. Johnson and Larry A. Young, "Tilt Rotor Aeroacoustic Model Project," , Rome, 1999.

[8] Jeffrey D. Singleton and William T. Yeager Jr. ", Important Scaling Parameters for Testing Model-Scale Helicopter Rotors. Hampton, VA: NASA Langley Research Center, 1998.

[9] Wieslaw Zenon Stepniewski and C. N. Keys, Rotary-wing Aerodynamics.: Courier Dover Publications, 1984.

[10] Tim McAdams. (2010, Aug.) Speed Limits. [Online]. http://blog.aopa.org/helicopter/?p=96 
[11] D. J. Graham, G. E. Nitzberg, and R. N. Olson, "A Systematic Investigation of Pressure Distributions at High Speeds Over Five Representative NACA Low-Drag and Conventional Airfoil Sections," 1945.

[12] J. P. Shivers and P. J. Carpenter, "Effects of Compressibility on Rotor Hovering Performance and Synthesized Blade-Section Characteristics Derived from Measured Rotor Performace of Blades having NACA 0015 Airfoil Tip Sections," Langley Field, VA, 1958.

[13] U.S. Federal Aviation Administration, Airplane Flying Handbook. Washington D.C.: U.S. Government Printing Office, 2004.

[14] J. P. Shivers and P. J. Carpenter, "Low Top Mach Number Stall Characteristics and High Tip Mach Number Compressibility Effects on a Helicopter Rotor Having an NACA 009 Tip Airfoil Section," Langley, VA, 1958.

[15] J. Seddon and Simon Newman, "Basic Helicopter Aerodynamics, Second Edition," 2002.

[16] (2010, Aug.) NACA 0015 Drag Data. [Online]. http://www.cyberiad.net/library/airfoils/foildata/n0015cd.htm

[17] (2010, Aug.) NACA 0015 Lift Data. [Online]. http://www.cyberiad.net/library/airfoils/foildata/n0015cl.htm

[18] R. E. Sheldahl and P. C. Klimas, "Characteristics of Seven Airfoil Sections Through 180 Degrees Angle of Attack for Use in Aerodynamic Analysis of Vertical Axis Wind Turbines," Albuquerque, NM, 1981.

[19] S. S. Turkel. (2010, Aug.) Understanding Variable Speed Drives. [Online]. http://ecmweb.com/mag/electric_understanding_variable_speed_3/

[20] WEG. (2010, Aug.) Motor Electrical Data. [Online]. http://www.weg.net/files/products/WEG-stock-motor-catalog-electrical-datausa100-brochure-english.pdf

[21] WEG. (2010, Aug.) CFW-09 User's Guide. [Online]. 
http://www.weg.net/files/products/WEG-cfw-09-a-users-guide-0899.5694-4.0xmanual-english.pdf

[22] Efunda. (2010, Aug.) AISI 9310. [Online].

http://www.efunda.com/materials/alloys/alloy_steels/show_alloy.cfm?ID=AISI_93 10\&show_prop=all\&Page_Title=AISI\%209310

[23] EPI Inc. (2010, Aug.) Metallurgy of Rotorway Secondary Shaft. [Online]. http://www.epieng.com/rotorway_helicopter/rotor_drive_system/secondary_shaft_metallurgy.htm

[24] Unknown. (2010, Aug.) Rockwell C Hardness Conversion Chart. [Online]. http://emat.eng.hmc.edu/database/rockwell_conversion.htm

[25] Carbide Depot. (2010, Aug.) Hardness Conversion Chart. [Online]. http://www.carbidedepot.com/formulas-hardness.htm

[26] Aerospace Specification Metals Inc. (2010, Aug.) Steel Alloys. [Online]. http://www.aerospacemetals.com/steelalloys.html

[27] Rich Henry, Ron Sullivan, John Walden and Dave Zdrojewski. (2010, Aug.) Understanding Shaft Alignment: Basics. [Online]. http://www.maintenanceworld.com/Articles/mt-online/Understanding-ShaftAlignment.html

[28] TB Woods. (2010, Aug.) Sure-Flex Elastomeric Couplings. [Online]. http://warnernet.com/litportal/pdfs/FC-Catalog_web\%20AUG2007.pdf

[29] DIY Trade. (2010, Aug.) TB Woods Sure-Flex. [Online]. http://www.diytrade.com/china/2/products/468852/TB_Woods_公司联轴器.html

[30] TB Woods. (2010, Aug.) Flexible Couplings. [Online]. http://warnernet.com/litportal/pdfs/FC-Catalog_web\%20AUG2007.pdf

[31] E. Oberg, F. D. Jones, H. L. Horton, and H. H. Ryffel, Machinery's Handbook, 28th Ed. New York: Industrial Press, 2008.

[32] SKF. (2010, Aug.) Selection of Bearing Size. [Online]. 
http://www.skf.com/portal/skf/home/products?maincatalogue=1\&lang=en\&newlin $\mathrm{k}=1 \_0 \_20$

[33] SKF. (2010, Aug.) Single Row Deep Groove Ball Bearings Product Data. [Online]. http://www.skf.com/portal/skf/home/products?maincatalogue=1\&lang=en\&newlin $\mathrm{k}=1 \_1 \_1$

[34] Tessco. (2010, Aug.) Bolt Grade Markings and Strength. [Online]. http://www.tessco.com/yts/customerservice/techsupport/whitepapers/pdf/bolt_grad e.pdf

[35] Joseph C. Dille. (2010, Aug.) How A Bolt Works. [Online]. http://www.algeo.com/ joe/KIAT/kiat_1.htm

[36] Engineer's Handbook. (2010, Aug.) Reference Tables -- Coefficient of Friction. [Online]. http://www.engineershandbook.com/Tables/frictioncoefficients.htm

[37] Efunda. (2010, Aug.) Torque and Tension in Bolts. [Online]. http://www.efunda.com/designstandards/screws/fasteners_intro.cfm

[38] Rask Cycle. (2010, Aug.) U.S. Bolt Torque Specifications. [Online]. http://www.raskcycle.com/techtip/webdoc14.html

[39] Engineer's Edge. (2010, Aug.) Minimum Thread Engagement Formula and Calculation ISO. [Online]. http://www.engineersedge.com/thread_strength/thread_minimum_length_engagem ent.htm

[40] Metal Suppliers Online. (2010, Aug.) Properties of 12L14. [Online]. http://www.metalsuppliersonline.com/research/property/metals/913.asp

[41] Efunda. (2010, Aug.) AISI 12L14. [Online]. http://www.metalsuppliersonline.com/research/property/metals/913.asp

[42] aerospace-technology.com. (2010, Aug.) AgustaWestland AW109 Power Light Multirole Helicopter. [Online]. http://www.aerospacetechnology.com/projects/agusta/ 
[43] Aurora Bearing Company. (2010, Aug.) Aurora Bearing Company Catalog. [Online]. http://www.aurorabearing.com/Files/articles/Aurora\%20Bearing\%20610\%20Catal og.pdf

[44] National T Bucket Association. (2010, Aug.) ASTM, SAE and ISO Greade Markings and Mechanical Properties for Steel Fasteners. [Online]. http://www.nationaltbucketalliance.com/tech_info/Generalinformation/fasteners/nt ba_bolt_chart.asp

[45] At Last Tube. (2010, Aug.) Comparison of ASTM A500 Round vs. A53 Pipe. [Online]. http://www.atlastube.com/files/comparison.htm

[46] Independence Tube. (2010, Aug.) ASTM A500. [Online]. http://www.independencetube.com/downloads/ASTM_A500.pdf

[47] Mario S Pennisi. (2010, Aug.) Powder Coating. [Online]. http://www.finishing.com/Library/pennisi/powder.html

[48] Schleifring. (2010, Aug.) Schleifring Data Sheet - Series K. [Online]. http://www.schleifring.com/en_pdf/products/standards/Series_K_en.pdf

[49] Wiremax. (2010, Aug.) Current Carrying Capacities for FEP (Teflon) and Silicone Cable. [Online]. http://connectronics.thomasnet.com/Asset/WIREMAX-conductorCURRENT--2-.pdf

[50] Alanna Wall, "A Discrete Approach to Modelling Helicopter Blade Sailing," Ottawa-Carleton Institute for Mechanical and Aerospace Engineering, Ottawa, 2009.

[51] Microstrain. (2010, Aug.) V-Link Technical Product Overview. [Online]. http://www.microstrain.com/product_datasheets/VLink_2.4GHz_Datasheet_Rev_10.00.pdf

[52] K. Hoffmann, "Applying the Wheatstone Bridge Circuit," 1986.

[53] ArmorCore. (2010, Aug.) UL 752 Specifications and Ammunition. [Online]. 
http://armorcore.com/docs/UL_752_Specification.pdf

[54] Waco Composites. (2010, Aug.) Armorcore Products. [Online]. http://armorcore.com/products.html

[55] ArmorCore. (2010, Aug.) UL752 Weapons Definitions. [Online]. http://armorcore.com/htmlspecs/docs/UL752_Paragraphs.pdf

[56] Waco Composites. (2010, Aug.) Level 3 Video Test. [Online]. http://armorcore.com/media/13_test_video.swf

[57] E. W. Kiesling and R. R. Carter, "Investigation of Wind Projectile Resistance of Waco Composites, Inc. Armorcore UL752 Level 3 Panels," Lubbock, TX, 1999.

[58] Confast. (2010, Aug.) Concrete Single Expansion Anchor. [Online]. http://www.confast.com/products/technical-info/single-expansion-fastener.aspx

[59] Waco Composites. (2010, Aug.) Manufacturer's Installation Recomendation for ArmorCore Bullet Resistant Panels. [Online]. http://armorcore.com/docs/Installation.pdf

[60] TB Woods. (2010, Aug.) Synchronous Drives. [Online]. http://warnernet.com/litportal/brands.asp?brandid=9\#cat20 


\section{Appendix A}

\section{Transmission System Sizing and Component Selection}

Sizing and part selection for the synchronous belt system follows the drive selection guide for TB Wood's products [60]. The process and results are outlined below.

Step 1 is to calculate the design horsepower (DHP) of the drive system. This consists of taking the motor horsepower and multiplying it by a service factor depending on its usage and speed ratio. For a NEMA A 1,800 rpm motor of $100 \mathrm{HP}$, that puts the drive into Class I, which is for drives with overload requirement up to $150 \%$ of rated capacity. As a fan system, the base service factor for Class I is 1.4 to 1.6 , with propellers being on the higher end. A modifier of -0.1 is applied due to intermittent and brief usage. No modifier is required due to speed ratio as the drive will be operated as a slow-down, not speed-up drive. The chosen service factor is therefore 1.5 with a resulting design horsepower of $150 \mathrm{HP}$.

Step 2 is to determine the pitch of the teeth in the belt. A table is referred to, which shows the required pitch (either $8 \mathrm{~mm}$ or $14 \mathrm{~mm}$ ) for the drive based on the horsepower of the motor (not DHP) and the rpm of the fastest shaft. This is based on power transmission being a product of torque and rpm, where the torque available is a 
result of the pitch of the belt. The pitch required for a $100 \mathrm{HP}$ motor is $14 \mathrm{~mm}$. Only the pertinent portion of the table is shown in Table A.1 below.

Table A.1: Pertinent section of belt pitch selection table [60].

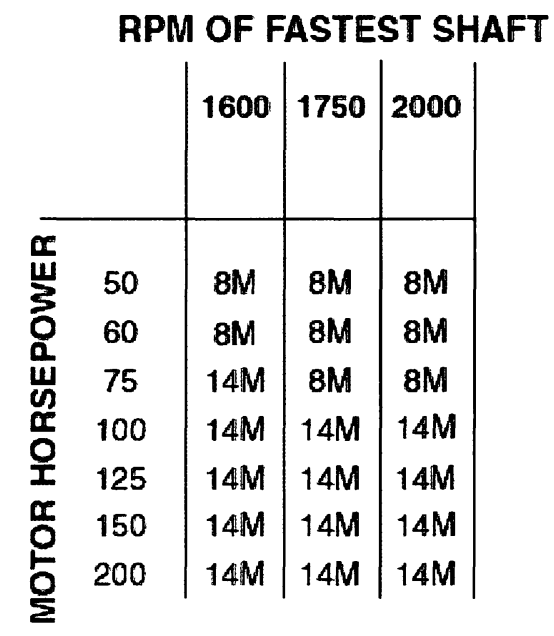

Step 3 is to check the NEMA minimum sprocket pitch diameter for a $100 \mathrm{HP}$ motor operating at 1750 RPM. According to the table provided, the minimum diameter is 7.7 in. This is again a result of the torque requirement for the drive where larger sprockets can transmit more torque between the belt and drive shaft. The drive system for the whirl tower will use the minimum sprocket diameter possible due to space constraints.

Step 4 is to determine the necessary speed ratio of the drive. Other than the 1:1 ratio required, it is necessary to drive rotors with 2 m blades up to Mach 0.65 . For a $2 \mathrm{~m}$ blade running from Mach 0.5 to 0.65 , the necessary rpm is 810 to 1,050 . This gives a necessary speed ratio range from a $1,750 \mathrm{rpm}$ motor of 1.66 to 2.16 , where the lower ratio is preferred since the VFT can lower the motor speed. 
Step 5 is to determine the sprocket combination to achieve the desired speed ratio. The tables are organized first by belt pitch $(14 \mathrm{~mm})$ then by speed ratio (approximately 1.66 is desired), and finally by sprocket diameter (for which the minimum is 7.7 in.). The combination available to fulfill this system is a 44 tooth driver socket having a 7.7 in diameter, with a 72 tooth driven socket with 12.6 in. diameter. This combination provides a speed ratio of 1.64 , very close to the desired value.

Step 6 is to determine a belt service factor to apply to the belt's rated horsepower based on belt pitch, length and sprocket size. Belt length and sprocket size dictate the center distance between sprockets, but since only one belt is desired, both the center distance for $1: 1$ and 1:1.64 operation must be considered. For 1:1 operation, an 1,890 $\mathrm{mm}$ (74.41 in.) belt allows a center distance of $25.08 \mathrm{in}$. and a service multiplier of 0.95 . This same belt for 1:1.64 operation provides a center distance of 21.08 " and 0.95 service factor. This belt length requires a center distance accuracy of $\pm 0.46 \mathrm{in}$. according to the table on $\mathrm{C} 2-7$.

Step 7 is to select the belt and socket width based on the corrected horsepower for the belt and the DHP. For a 1,750 rpm motor with the sprockets selected, a $42 \mathrm{~mm}$ belt can provide $137 \mathrm{HP}$ and a $65 \mathrm{~mm}$ belt can provide $212 \mathrm{HP}$. With a 0.95 service factor applied, the belt capabilities are $130 \mathrm{HP}$ and $201 \mathrm{HP}$ respectively. The necessary belt width for the drive system is therefore $65 \mathrm{~mm}$ due to the DHP being $150 \mathrm{HP}$.

Step 8 is to check the drive system for a dynamic balancing requirement. A line is drawn between each sprocket diameter and the belt width. The intercept between this drawn line and the maximum RPM curve shows what operational speeds are allowable 
without dynamic balancing being required. The intercepts show that the allowable speed is approximately twice the maximum expected operational speed for each sprocket, allowing safe operation without balancing. The results of this check are shown below.

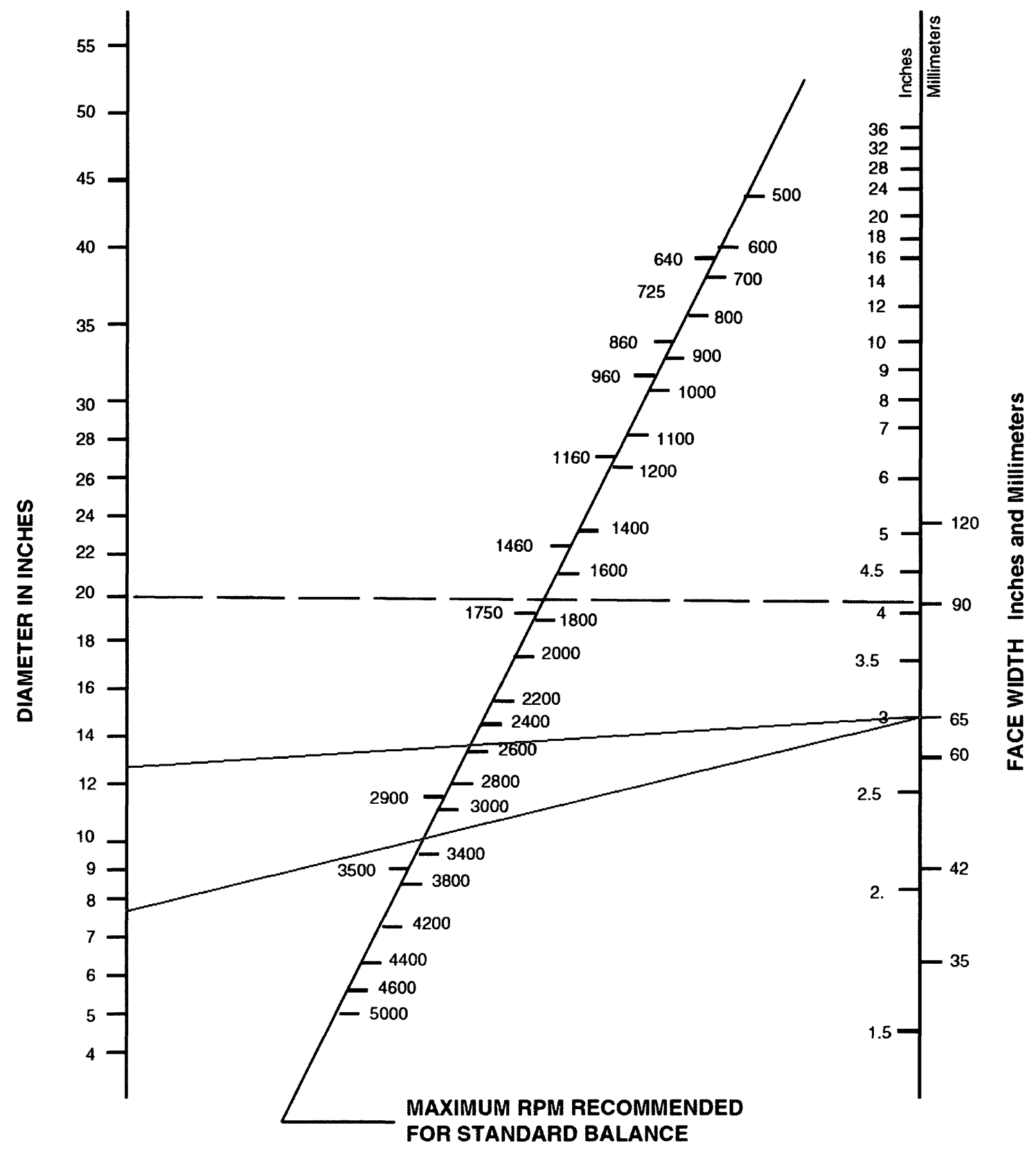

Figure A.1: Dynamic Balancing Requirements [60]. 
Step 9 is to determine the part numbers required for the system via the product tables. The belt table is found on $\mathrm{C} 2-8$ and the sprocket tables on $\mathrm{C} 2-5$. The required parts are shown below in Table A.2.

Table A.2: Parts for Transmission System.

\begin{tabular}{|c|c|c|}
\hline Part Description & Quantity & Part Number \\
\hline 44 Tooth Sprocket & 2 & W4414M65 \\
\hline 72 Tooth Sprocket & 1 & W7214M65 \\
\hline 1890 mm Belt & 1 & $189014 M 65 W$ \\
\hline Bushings & Various & TBD \\
\hline
\end{tabular}

